Computer-Aided Structural Engineering Project

\title{
Theoretical Manual for Pile Foundations
}

Reed L. Mosher and William P. Dawkins

November 2000

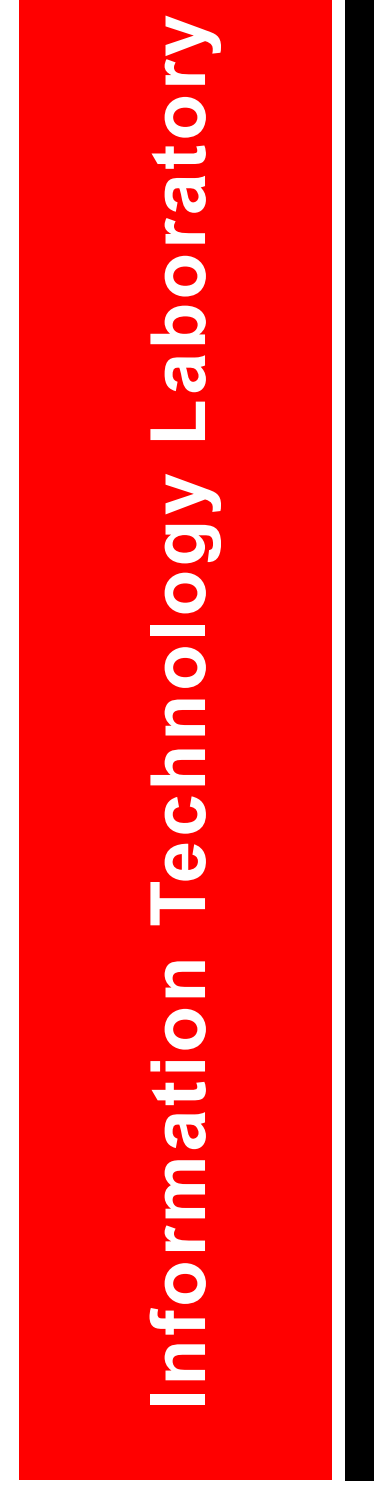

US Army Corps

of Engineers ${ }_{\circledast}$

Engineer Research and

Development Center

Approved for public release; distribution is unlimited. 
The contents of this report are not to be used for advertising, publication, or promotional purposes. Citation of trade names does not constitute an official endorsement or approval of the use of such commercial products.

The findings of this report are not to be construed as an official Department of the Army position, unless so designated by other authorized documents. 


\title{
Theoretical Manual for Pile Foundations
}

\author{
by Reed L. Mosher \\ Geotechnical and Structures Laboratory \\ U.S. Army Engineer Research and Development Center \\ 3909 Halls Ferry Road \\ Vicksburg, MS 39180-6199 \\ William P. Dawkins \\ Oklahoma State University \\ Stillwater, OK 74074
}

Final report

Approved for public release; distribution is unlimited 


\section{Contents}

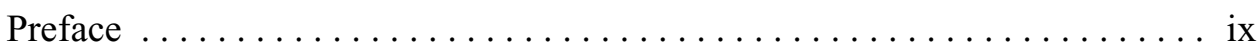

Conversion Factors, Non-SI to SI Units of Measurement $\ldots \ldots \ldots \ldots \ldots \ldots$

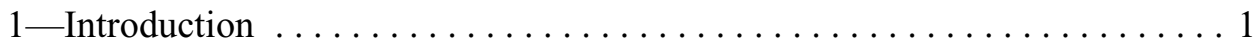

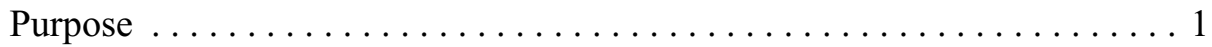

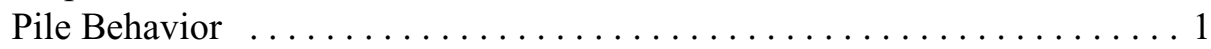

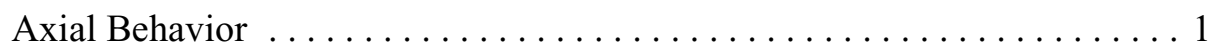

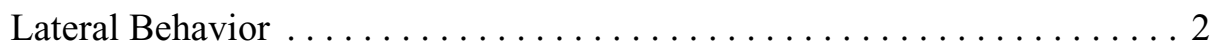

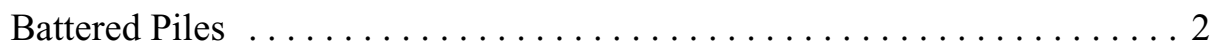

Classical Analysis and/or Design Procedures $\ldots \ldots \ldots \ldots \ldots \ldots \ldots . \ldots . \ldots . \ldots$

State-of-the-Corps-Art Methods for Hydraulic Structures . . . . . . . . . . 3

2 - Single Axially Loaded Pile Analysis . . . . . . . . . . . . . . . 5

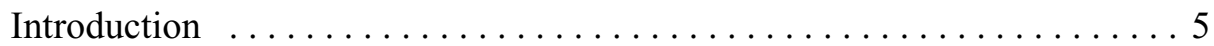

Load-Transfer Mechanism . . . . . . . . . . . . . . . . 5

Synthesis of $f-w$ Curves for Piles in Sand Under Compressive Loading . . 8

Synthesis of $f-w$ Curves for Piles in Clay Under Compressive Loading . . 17

Tip Reactions ................................ 23

Synthesis of $q-w$ Curves for Piles in Sand Under Compressive Loading . . 24

Synthesis of $q-w$ Curves for Piles in Clay Under Compressive Loading . . . 27

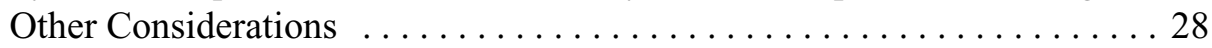

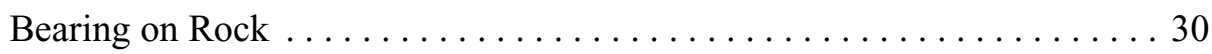

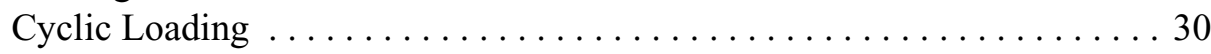

Algorithm for Analysis of Axially Loaded Piles . . . . . . . . . . . . 30

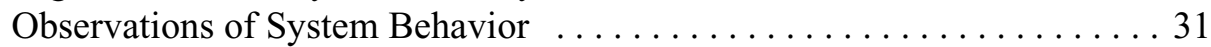

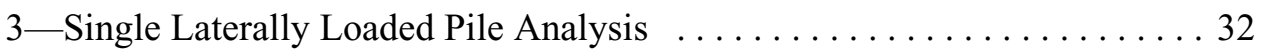

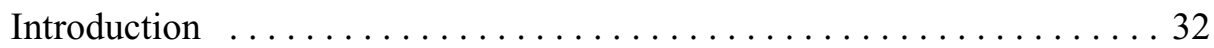

Load Transfer Mechanism for Laterally Loaded Piles . . . . . . . . . . . . 34

Synthesis of $p-u$ Curves for Piles in Sand ................ 34

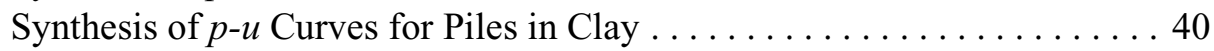

Algorithm for Analysis of Laterally Loaded Piles . . . . . . . . . . 53

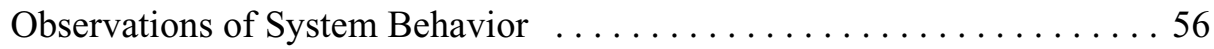

Linearly Elastic Analyses . . . . . . . . . . . . . . . . . 56

Variation of Lateral Resistance Stiffness . . . . . . . . . . . . . . . 58 
Pile Head Stiffness Coefficients for Lateral Loading $\ldots \ldots \ldots \ldots \ldots 60$

Evaluation of Linear Lateral Soil Resistance . . . . . . . . . . . . 61

4-Algorithm for Analysis of Torsionally Loaded Single Piles . . . . . . . . 63

Elastic Analysis . . . . . . . . . . . . . . . . . . . . . . . 64

5-Pile Head Stiffness Matrix . . . . . . . . . . . . . . . . . . . . 67

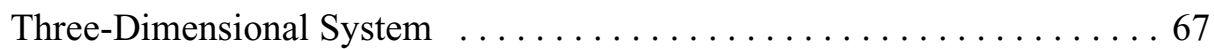

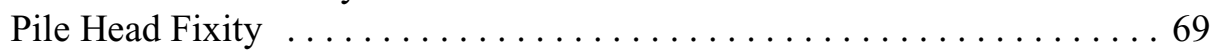

Pinned-Head Pile ........................... 70

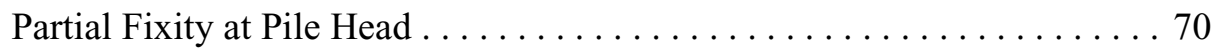

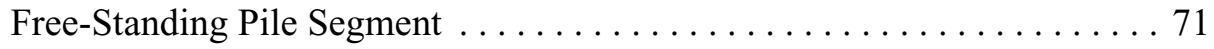

Alternatives for Evaluating Pile Head Stiffnesses $\ldots \ldots \ldots \ldots \ldots \ldots 73$

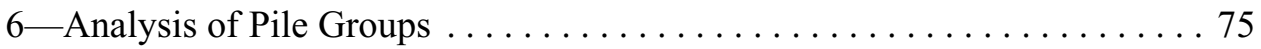

Classical Methods for Pile Group Analysis . . . . . . . . . . . . . . . 75

Moment-of-Inertia (Simplified Elastic Center) Method . . . . . . . . . . 75

Culmann's Method ............................ 76

"Analytical" Method .......................... 76

Stiffness Method of Pile Foundations $\ldots \ldots \ldots \ldots \ldots \ldots \ldots \ldots$

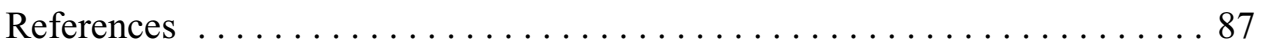

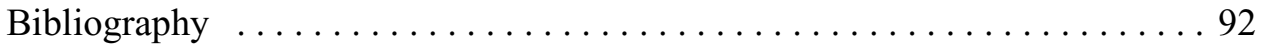

Appendix A: Linear Approximation for Load Deformation of Axial Piles . . A1

Appendix B: Nondimensional Coefficients for Laterally Loaded Piles . . . . B1

SF 298

\section{List of Figures}

Figure 1. Axially loaded pile $\ldots \ldots \ldots \ldots \ldots \ldots \ldots \ldots \ldots \ldots \ldots \ldots \ldots \ldots \ldots$

Figure 2. One-dimensional model of axially loaded pile $\ldots \ldots \ldots \ldots \ldots 7$

Figure 3. $f-w$ curve by Method SSF1 $\ldots \ldots \ldots \ldots \ldots \ldots$

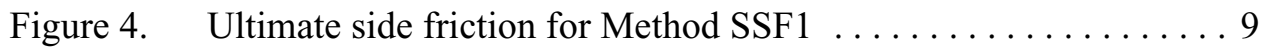

Figure 5. Equivalent radius for noncircular cross sections $\ldots \ldots \ldots \ldots 10$

Figure 6. $f-w$ curve by Method SSF2 $\ldots \ldots \ldots \ldots \ldots \ldots \ldots \ldots \ldots \ldots$

Figure 7. Direct shear test of softening soil $\ldots \ldots \ldots \ldots \ldots \ldots \ldots$

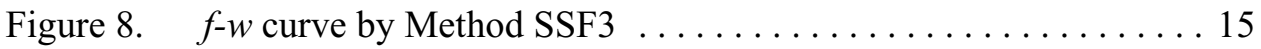

Figure 9. $f-w$ curves by Method SSF $4 \ldots \ldots \ldots \ldots \ldots \ldots \ldots \ldots \ldots \ldots \ldots$

Figure 10. $f-w$ curve by Method SSF5 $\ldots \ldots \ldots \ldots \ldots \ldots \ldots \ldots \ldots$

Figure 11. $f-w$ curves by Method CSF1 . . . . . . . . . . . . 19 
Figure 12. Side friction - soil strength relation for Method CSF1 . . . . . 19

Figure 13. $f-w$ curve by Method CSF2 .................. 20

Figure 14. Strength reduction coefficients $\ldots \ldots \ldots \ldots \ldots \ldots \ldots \ldots \ldots$

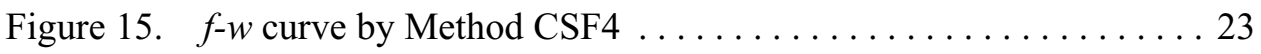

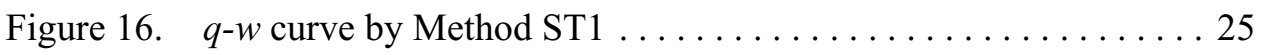

Figure 17. Ultimate tip resistance for Method SF1 $\ldots \ldots \ldots \ldots \ldots \ldots$

Figure 18. $q-w$ curve by Method SF4 $\ldots \ldots \ldots \ldots \ldots \ldots \ldots \ldots \ldots \ldots \ldots \ldots \ldots$

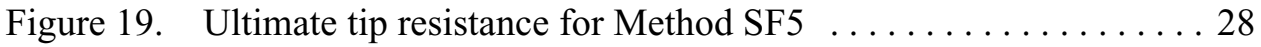

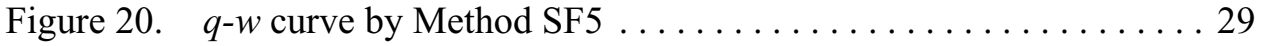

Figure 21. Assessment of degradation due to static loading . . . . . . . 30

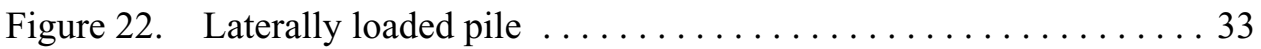

Figure 23. $p$ - $u$ curve by Method SLAT1 $\ldots \ldots \ldots \ldots \ldots \ldots \ldots \ldots \ldots \ldots \ldots \ldots \ldots \ldots$

Figure 24. Factors for calculation of ultimate soil resistance for

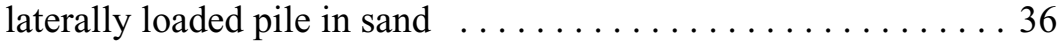

Figure 25. Resistance reduction coefficient - A for Method SLAT1 . . . . . 37

Figure 26. Resistance reduction corefficient - B for Method SLAT1 . . . . 38

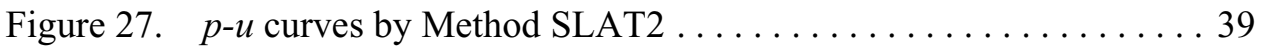

Figure 28. $p$ - $u$ curves by Method CLAT1 $\ldots \ldots \ldots \ldots \ldots \ldots \ldots \ldots$

Figure 29. $\quad p-u$ curves by Method CLAT2 for static loads $\ldots \ldots \ldots \ldots \ldots 42$

Figure 30. Displacement parameter - A for Method CLAT2 . . . . . . . 44

Figure 31. $p$ - $u$ curve by Method CLAT2 for cyclic loads $\ldots \ldots \ldots \ldots 45$

Figure 32. $p-u$ curve by Method CLAT3 for static loads $\ldots \ldots \ldots \ldots \ldots 6$

Figure 33. $p$ - $u$ curve by Method CLAT3 for cyclic loads $\ldots \ldots \ldots \ldots \ldots 47$

Figure 34. $p-u$ curve by Method CLAT4 for static loading $\ldots \ldots \ldots \ldots 48$

Figure 35. $p-u$ curve by Method CLAT4 for cyclic loading $\ldots \ldots \ldots \ldots 51$

Figure 36. $p-u$ curve by Method CLAT5 for static loading $\ldots \ldots \ldots \ldots . \ldots 5$

Figure 37. $\quad p-u$ curve by Method CLAT5 for cyclic loading $\ldots \ldots \ldots \ldots 54$

Figure $38 . \quad$ Model of laterally loaded pile $\ldots \ldots \ldots \ldots \ldots \ldots \ldots \ldots \ldots$

Figure 39. Proposed torsional shear - rotation curve $\ldots \ldots \ldots \ldots 6$

Figure 40 . Notation for pile head effects $\ldots \ldots \ldots \ldots \ldots \ldots \ldots \ldots \ldots$

Figure 41. Linearly elastic pile/soil system with free-standing segment . . . 71

Figure 42. Pile cap loads, displacements, and coordinates . . . . . . . 77

Figure 43. Head forces, displacements, and coordinates for $\mathrm{i}_{\mathrm{TH}}$ pile $\ldots \ldots 78$ 
Figure 44. Relationship between global and local coordinates . . . . . . . 79

Figure 45. Geometric definitions for computation of added displacement . .83

Figure 46. Modification of unit load transfer relationship for

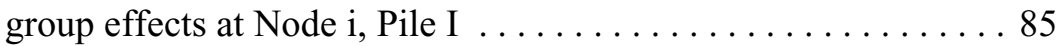

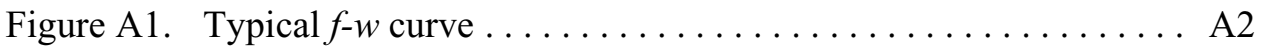

Figure A2. Axial stiffness coefficient for constant soil stiffness $\ldots \ldots \ldots$ A4

Figure A3. Axial stiffness coefficient for soil stiffness varying linearly with depth $\ldots \ldots \ldots \ldots \ldots \ldots \ldots \ldots \ldots \ldots \ldots \ldots \ldots \ldots$

Figure A4. Axial stiffness coefficient for soil stiffness varying as square root of depth $\ldots \ldots \ldots \ldots \ldots \ldots \ldots \ldots$

Figure B1. Deflection coefficient for unit head shear for soil stiffness constant with depth . . . . . . . . . . . . . B4

Figure B2. Slope coefficient for unit head shear for soil stiffness constant with depth $\ldots \ldots \ldots \ldots \ldots \ldots \ldots \ldots \ldots$ B5

Figure B3. Bending moment coefficient for unit head shear for soil stiffness constant with depth $\ldots \ldots \ldots \ldots \ldots \ldots \ldots$ B6

Figure B4. Shear coefficient for unit head shear for soil stiffness constant with depth $\ldots \ldots \ldots \ldots \ldots \ldots \ldots \ldots \ldots \ldots \ldots \ldots \ldots$

Figure B5. Deflection coefficient for unit head shear for soil stiffness varying linearly with depth $\ldots \ldots \ldots \ldots \ldots \ldots \ldots$ B10

Figure B6. Slope coefficient for unit head shear for soil stiffness varying linearly with depth $\ldots \ldots \ldots \ldots \ldots \ldots \ldots$ B1

Figure B7. Bending moment coefficient for unit head shear for soil stiffness varying linearly with depth $\ldots \ldots \ldots \ldots \ldots$ B14

Figure B8. Shear coefficient for unit head shear for soil stiffness varying linearly with depth $\ldots \ldots \ldots \ldots \ldots \ldots \ldots \ldots \ldots$

Figure B9. Deflection coefficient for unit head shear for soil stiffness varying linearly with depth . . . . . . . . . B16

Figure B10. Slope coefficient for unit head shear for soil stiffness varying parabolically with depth . . . . . . . . . . . . . . B19

Figure B11. Bending moment coefficient for unit head shear for soil stiffness varying parabolically with depth $\ldots \ldots \ldots$ B20

Figure B12. Shear coefficient for unit head shear for soil stiffness varying parabolically with depth $\ldots \ldots \ldots \ldots \ldots$ B21

Figure B13. Deflection coefficient for unit head moment for soil stiffness constant with depth $\ldots \ldots \ldots \ldots \ldots \ldots \ldots$ B24

Figure B14. Slope coefficient for unit head moment for soil stiffness constant with depth 
Figure B15. Bending moment coefficient for unit head moment for soil stiffness constant with depth $\ldots \ldots \ldots \ldots \ldots \ldots$ B26

Figure B16. Shear coefficient for unit head moment for soil stiffness constant with depth $\ldots \ldots \ldots \ldots \ldots \ldots \ldots \ldots \ldots \ldots \ldots \ldots$

Figure B17. Deflection coefficient for unit head moment for soil stiffness constant with depth . . . . . . . . . . . . . . B30

Figure B18. Slope coefficient for unit head moment for soil stiffness constant with depth $\ldots \ldots \ldots \ldots \ldots \ldots$ B31

Figure B19. Bending moment coefficient for unit head moment for soil stiffness varying linearly with depth $\ldots \ldots \ldots \ldots$ B32

Figure B20. Shear coefficient for unit head moment for soil stiffness varying linearly with depth $\ldots \ldots \ldots \ldots \ldots \ldots$ B33

Figure B21. Deflection coefficient for unit head moment for soil stiffness varying parabolically with depth

Figure B22. Slope coefficient for unit head moment for soil stiffness varying parabolically with depth $\ldots \ldots \ldots \ldots$ B35

Figure B23. Bending moment coefficient for unit head moment for soil stiffness varying parabolically with depth ......... B36

Figure B24. Shear coefficient for unit head moment for soil stiffness varying parabolically with depth $\ldots \ldots \ldots \ldots \ldots$ B37

Figure B25. Pile head deflection coefficients for unit head shear ...... B38

Figure B26. Pile head slope coefficients for unit head shear . . . . . . . B39

Figure B27. Pile head deflection coefficients for unit head moment .... . B40

Figure B28. Pile head slope coefficients for unit head moment . . . . . . . B41

\section{List of Tables}

Table 1. $\quad k_{f}$ (psf/in.) as Function of Angle of Internal Friction of Sand for Method SSF1 .................... 9

Table 2. Representative Values of $k$ for Method SLAT1 . . . . . . . 35

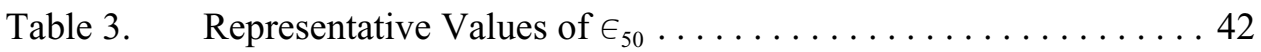

Table 4. Representative Values of Lateral Soil Stiffness $k$ for Piles in Clay for Method CLAT2 .............. 43

Table 5. Curve Parameters for Method CLAT4 . . . . . . . . . . . 50

Table 6. Representative Values of $k$ for Method CLAT4 . . . . . . . . . 50

Table 7. Soil Modulus for Method CLAT5 $\ldots \ldots \ldots \ldots \ldots \ldots$

Table $8 . \quad$ Soil Degradability Factors $\ldots \ldots \ldots \ldots \ldots \ldots \ldots \ldots \ldots \ldots \ldots$ 
Table 9. Values of $E_{s}$ for 1-ft-Wide Piles in Precompressed Clay . . . . 58

Table 10. Values of Constant of Horizontal Subgrade Reaction $n_{h}$ for a 1 -ft-Wide Pile in Sand . . . . . . . . . . . . . . 58

Table A1. Adjustment in $G$ for Various Loading Conditions (Adjustment factor $=G($ operational $/ G($ in situ $))$ )

Table B1. Nondimensional Coefficients for Laterally Loaded Pile for Soil Modulus Constant with Depth (Head Shear $V_{o}=1$, Head Moment $\left.M_{o}=0\right)$. .

Table B2. Nondimensional Coefficients for Laterally Loaded Pile for Soil Modulus Constant with Depth (Head Shear $V_{o}=0$, Head Moment $\left.M_{o}=1\right) \ldots \ldots \ldots \ldots \ldots \ldots \ldots$

Table B3. Nondimensional Coefficients for Laterally Loaded Pile for Soil Modulus Varying Linearly with Depth (Head Shear $V_{o}=1$, Head Moment $\left.M_{o}=0\right) \ldots \ldots \ldots \ldots \ldots \ldots \ldots \ldots \ldots \ldots \ldots$

Table B4. Nondimensional Coefficients for Laterally Loaded Pile for Soil Modulus Varying Linearly with Depth (Head Shear $V_{o}=0$, Head Moment $\left.M_{o}=1\right) \ldots \ldots \ldots \ldots \ldots \ldots$

Table B5. Nondimensional Coefficients for Laterally Loaded Pile for Soil Modulus Varying Parabolically with Depth (Head Shear $V_{o}=1$, Head Moment $M_{o}=0$ ) $\ldots \ldots \ldots \ldots$ B22

Table B6. Nondimensional Coefficients for Laterally Loaded Pile for Soil Modulus Varying Parabolically with Depth (Head Shear $V_{o}=0$, Head Moment $M_{o}=1$ ) 


\section{Preface}

This theoretical manual for pile foundations describes the background and research and the applied methodologies used in the analysis of pile foundations. This research was developed through the U.S. Army Engineer Research and Development Center (ERDC) by the Computer-Aided Structural Engineering (CASE) Project. The main body of the report was written by Dr. Reed L. Mosher, Chief, Geosciences and Structures Division, Geotechnical and Structures Laboratory, ERDC (formerly with the Information Technology Laboratory (ITL)), and Dr. William P. Dawkins, Oklahoma State University. Additional sections were written by Mr. Robert C. Patev, formerly of the Computer-Aided Engineering Division (CAED), ITL, ERDC, and Messrs. Edward Demsky and Thomas Ruf, U.S. Army Engineer District, St. Louis.

Members of the CASE Task Group on Piles and Pile Substructures who assisted in the technical review of this report are as follows:

$$
\begin{aligned}
& \text { Mr. Edward Demsky } \\
& \text { Ms. Anjana Chudgar } \\
& \text { Mr. Terry Sullivan } \\
& \text { Mr. Timothy Grundhoffer }
\end{aligned}
$$

\author{
St. Louis District \\ Louisville District \\ Louisville District \\ St. Paul District
}

Technical coordination and monitoring of this manual were performed by Mr. Patev. Mr. H. Wayne Jones, Chief, CAED, is the Project Manager for the CASE Project. Mr. Timothy D. Ables is the Acting Director, ITL.

At the time of publication of this report, Director of ERDC was Dr. James R. Houston. Commander was COL James S. Weller, EN.

The contents of this report are not to be used for advertising, publication, or promotional purposes. Citation of trade names does not constitute an official endorsement or approval of the use of such commercial products. 


\section{Conversion Factors, Non-SI to SI Units of Measurement}

Non-SI units of measurement used in this report can be converted to SI units as follows:

\begin{tabular}{||l|c|l||}
\hline Multiply & By & To Obtain \\
\hline \hline degrees (angle) & 0.01745329 & radians \\
\hline feet & 0.3048 & meters \\
\hline inches & 0.0254 & meters \\
\hline pounds (force) & 4.448222 & newtons \\
\hline pounds (mass) per cubic inch & $27,679.9$ & kilograms per cubic centimeter \\
\hline pounds (mass) per square foot & 4.882428 & kilograms per square meter \\
\hline pounds (force) per square inch & 0.006894757 & megapascals \\
\hline tons (force) per cubic foot & 32036.9 & kilograms per cubic meter \\
\hline tons (force) per square foot & 95.76052 & kilopascals \\
\hline \hline
\end{tabular}




\section{Introduction}

\section{Purpose}

The purpose of this manual is to provide a detailed discussion of techniques used for the design/analysis of pile foundations. Several of the procedures have been implemented in the CASE Committee computer programs CAXPILE (Dawkins 1984, Mosher et al. 1997), CPGA (Hartman, Jaeger, Jobst, and Martin 1989) and COM624 (Reese 1980). Theoretical development of these engineering procedures and discussions of the limitations of each method are presented.

\section{Pile Behavior}

The purpose of a pile foundation is to transmit the loads of a superstructure to the underlying soil while preventing excessive structural deformations. The capacity of the pile foundation is dependent on the material and geometry of each individual pile, the pile spacing (pile group effect), the strength and type of the surrounding soil, the method of pile installation, and the direction of applied loading (axial tension or compression, lateral shear and moment, or combinations). Except in unusual conditions, the effects of axial and lateral loads may be treated independently.

\section{Axial Behavior}

A compressive load applied to the head (top) of the pile is transferred to the surrounding soil by a combination of skin friction along the embedded length and end bearing at the tip (bottom) of the pile. For relatively short piles, only the end bearing effect is significant. For relatively long piles in soil (excluding tip bearing piles on rock), the predominant load transfer is due to skin friction. Unless special mechanical provisions are present (e.g., an underreamed tip), axial tension load is resisted only by skin friction. 


\section{Lateral Behavior}

Piles are often required to support loads applied perpendicular to their longitudinal axes (lateral loads). As stated previously, lateral load resistance is largely independent of axial effects. However, a high axial compression may interact with lateral displacements (the beam-column effect) to increase lateral displacements, bending moments, and shears.

\section{Battered Piles}

If the horizontal loads imparted to the pile foundation are large, a foundation consisting solely of vertical piles may not possess sufficient lateral resistance. In such circumstances, battered (inclined) piles are installed to permit the horizontal foundation load to be supported by a component of the axial pile/soil resistance in addition to the lateral resistance.

\section{Classical Analysis and/or Design Procedures}

\section{Single piles}

Prior to the development of reliable computer programs, the design of a single pile was based primarily on the ultimate load capacity of the pile as determined from a load test or from semi-empirical equations. The allowable or working load to which the pile could be subjected was taken as some fraction of the ultimate. Little, if any, emphasis was placed on the load-displacement behavior of the pile. Design methodology used in the Corps of Engineers is documented in Engineer Manual 1110-2-2906 (U.S. Army Corps of Engineers (USACE) 1995).

\section{Pile groups}

Classical methods (e.g., Culmann's method, the Common Analytical Method, the Elastic Center Method, the Moment-of-Inertia Method, etc.) of analysis for pile groups were based on numerous simplifying assumptions to allow the numerical calculations to be performed by hand. Common to these methods are the assumptions that only the axial resistance of the piles is significant and that the pile cap is rigid. Force and moment equilibrium equations are used to allot the foundation loads to the individual piles. No attempt is made in these methods to consider force-displacement compatibility (the soil-structure interaction effect). It has been shown that these classical methods frequently result in unconservative designs. 


\section{State-of-the-Corps-Art Methods for Hydraulic Structures}

\section{System modelling}

Rational designs must be based on solutions in which equilibrium and forcedisplacement compatibility are simultaneously satisfied. Ongoing research has resulted in the development of mathematical models for the pile/soil system which permit analysis of the entire range of load-displacement response for single piles subjected to axial and/or lateral loads. Methods have been developed for the design of pile groups in which the soil-structure interaction characteristics of single piles have been incorporated. These methods and the considerations leading to their development are described in detail in Chapters 2-4. A synopsis is provided in the following paragraphs.

\section{Axially loaded piles}

For analysis of a pile subjected to axial loads, the soil surrounding the embedded length of the pile is modelled as a distribution of springs which resist longitudinal displacements of the pile. The resistance of the soil springs is representative of the skin friction of the soil on the pile. The effect of tip resistance is represented by a concentrated spring. The characteristics of these springs are provided in the form of resistance-displacement (load-transfer) curves representing the skin friction effects (Seed and Reese (1957), and other references) and a force-displacement curve representing the tip reaction.

The load-transfer curves and tip reaction curves have been obtained from field tests of instrumented piles subjected to axial compression. Research is continuing to permit evaluation of load-transfer curves for piles in tension. The underlying principles on which the load-transfer curves and tip reaction curve are based and the modelling of the pile/soil system are presented in Chapter 2 .

\section{Laterally loaded piles}

The soil which resists displacements of a laterally loaded pile is also replaced by distributed springs. The force-displacement characteristics of the springs are presented as curves which have been extracted from field tests of laterally loaded piles. Techniques for lateral load analysis are discussed in Chapter 3.

\section{Pile head stiffnesses}

Computer programs (e.g. CAXPILE, CPGS, COM624G) are available which permit the analysis of load-displacement response of a pile/soil system up to an ultimate or failure condition. The relationship between load and displacement 
tends to be essentially linear through the range of loads usually allowed (the working loads) in design. The relationship becomes highly nonlinear as an ultimate condition is neared. For design purposes, the linearly elastic relationship between head loads and head displacements is usually presented as a matrix of stiffness coefficients. These coefficients may be extracted from the full range analyses for axially or laterally loaded piles cited above. In addition, the stiffness coefficients may be estimated using linearized solutions. These processes are discussed in Chapters 2 and 3.

\section{Pile groups}

Pile group behavior is analyzed by the procedure suggested by Saul (1968). The method considers both equilibriun and force-displacement compatibility in distributing the loads on the foundation among the individual piles. The process requires an evaluation of the linearized pile head stiffness matrix for each pile in the group. The pile head stiffness matrix may be evaluated by the single pile analysis procedures alluded to above. However, the evaluation must account for the effects of the proximity of adjacent piles.

Although the group analysis method was originally developed for linear systems with rigid pile caps, it has been extended to allow for flexible caps and, by iterative solutions, can account for nonlinear behavior (e.g. CPGA). The method is described in detail in Chapter 4. 


\section{Single Axially Loaded Pile Analysis}

\section{Introduction}

A schematic of an axially loaded pile is shown in Figure 1. In the discussions which follow, the pile is assumed to be in contact with the surrounding soil over its entire length. Consequently, the embedded length and the total length of the pile are the same. The effect of a free-standing portion of the pile will be discussed later.

The pile is assumed to have a straight centroidal axis (the z-axis, positive downward) and is subjected to a centric load at the head (top of the pile) $P_{\mathrm{o}}$. Displacements parallel to the axis of the pile are denoted $w$ and are positive in the positive $z$-direction. The pile material is assumed to be linearly elastic for all levels of applied loads. "Ultimate" conditions referred to subsequently indicate that a limit has been reached in which any additional head load would cause excessive displacements.

The major research efforts devoted toward investigation of axially loaded piles have been performed for homogeneous soil media. Only in limited cases has the effect of nonhomogeneity been considered. In most cases the effects of layering in the soil profile and/or lateral variations in soil characteristics can only be approximated.

\section{Load-Transfer Mechanism}

The head load $P_{\mathrm{o}}$ is transferred to the surrounding soil by shear stresses (skin friction) along the lateral pile/soil interface and by end-bearing at the pile tip (bottom of the pile). The rate at which the head load is transferred to the soil along the pile and the overall deformation of the system are dependent on numerous factors. Among these are: (a) the cross section geometry, material, length, and, to a lesser extent, the surface roughness of the pile; (b) the type of soil (sand or clay) and its stress-strain characteristics; (c) the presence or absence 


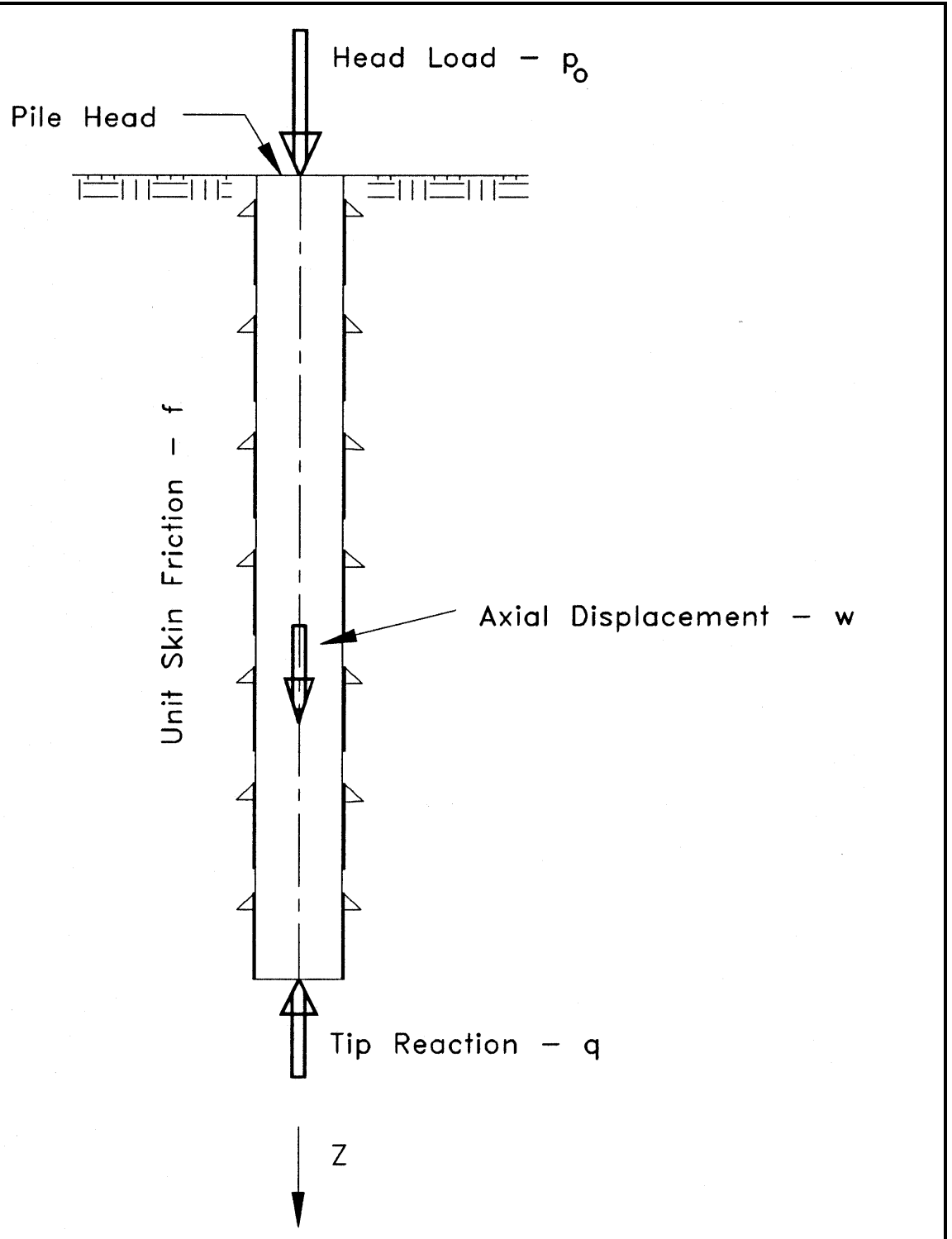

Figure 1. Axially loaded pile

of groundwater; (d) the method of installation of the pile; and, (e) the presence or absence of residual stresses as a result of installation.

A heuristic approach has been followed to reduce the complex three- dimensional problem to a quasi one-dimensional model (illustrated in Figure 2) which is practicable for use in a design environment. In the one-dimensional model, the soil surrounding the pile is replaced by a distribution of springs along the length of the pile and by a concentrated spring at the pile tip which resist axial displacements of the pile. The characteristics of these springs are presented in the form of curves which provide the magnitude of unit skin friction ( $f$ - $w$ curves) or unit tip reaction ( $q-w$ curve) as a function of pile displacement. The nomenclature used to define axial curves is based on unit skin friction $f$, unit tip reaction $q$, and $w=$ displacement in the $z$-direction for axial loads. 


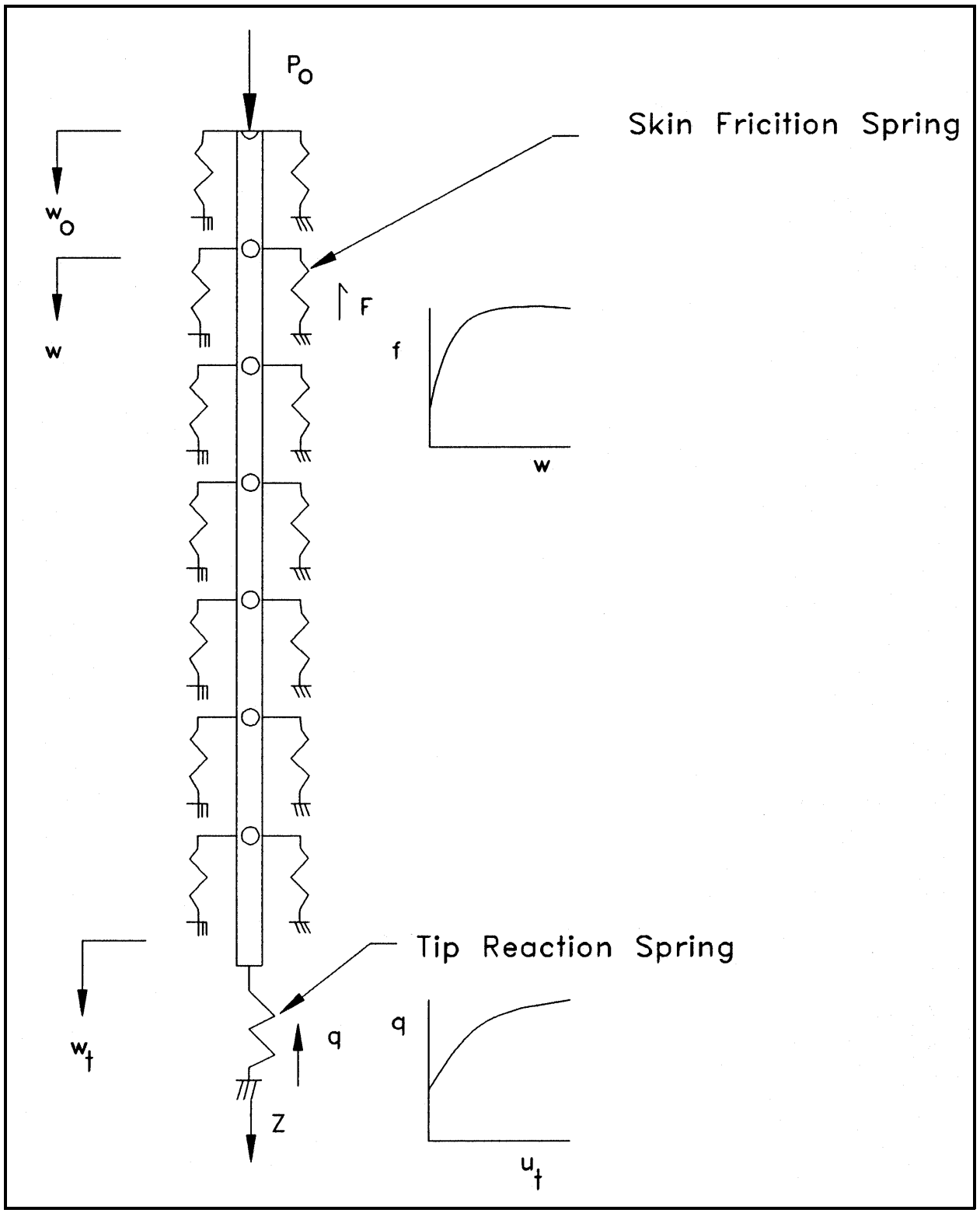

Figure 2. One-dimensional model of axially loaded pile

The $f-w$ and $q-w$ curves have been developed using the principles of continuum and soil mechanics and/or from correlations with the results of field tests on instrumented axially loaded piles. Several different criteria are presented below for development of $f-w$ and $q-w$ curves. The reliability of any method in predicting the behavior of a particular pile depends on the similarity of the system under investigation with the database used to establish the method. Most of the methods account explicitly or implicitly for the three factors cited on page $5(\mathrm{a}, \mathrm{b}$, and $\mathrm{c})$. In all cases the pile is assumed to be driven into the soil or to be a cast-in-place pier. Only one of the procedures attempts to account for the effects of residual stresses; the remaining methods exclude these effects. 


\section{Synthesis of $f-w$ Curves for Piles in Sand Under Compressive Loading}

\section{Mosher (1984)}

Mosher (1984) utilized the results of load tests of prismatic pipe piles driven in sand and the work of Coyle and Castello (1981) to arrive at the hyperbolic representation of the $f$ - $w$ curve (see Figure 3 ).

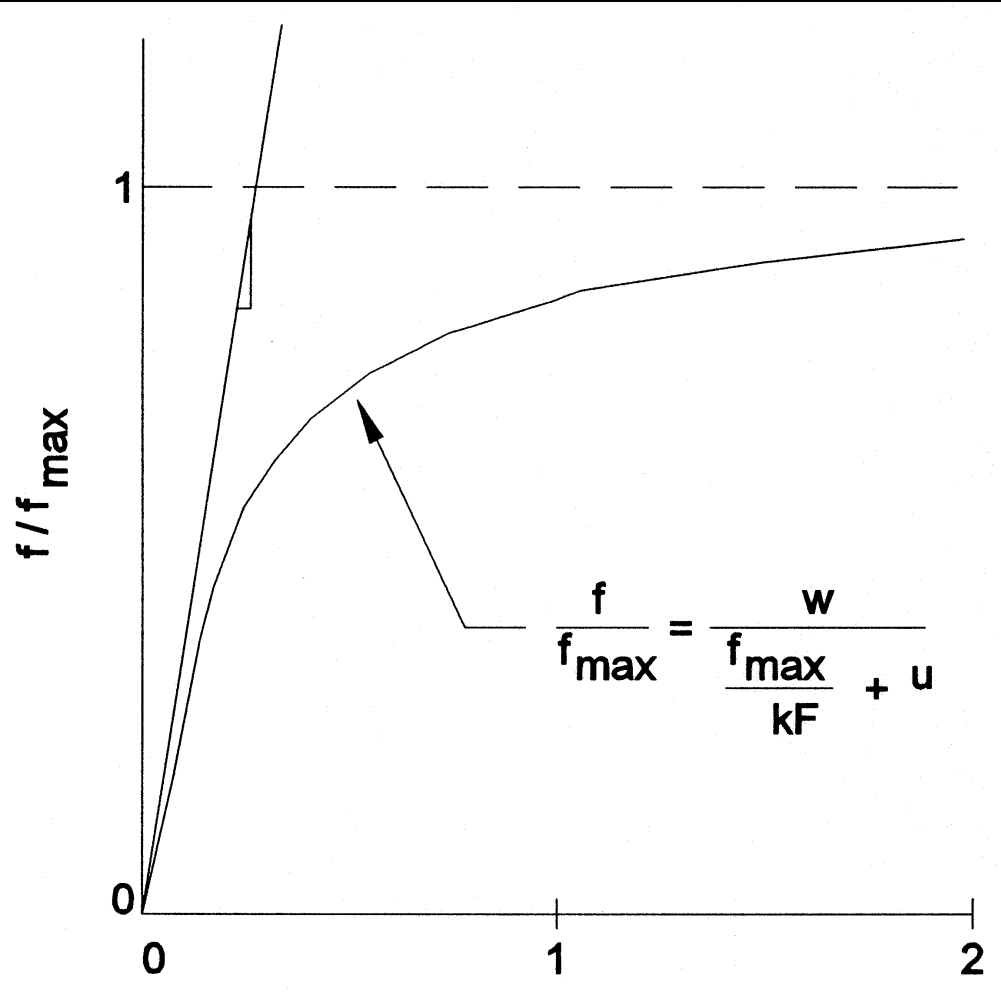

w (in.)

Figure 3. $f-w$ curve by Method SSF1

$$
f=\frac{w}{\frac{1}{k_{f}}+\frac{w}{f_{\max }}}
$$

The initial slope $k_{f}$ of the curve is given in Table 1 as a function of the angle of internal friction and the ultimate side friction $f_{\max }$ is given in Figure 4 as a function of relative depth (depth $z$ below ground surface divided by the diameter of the pile $2 R$ ). 


\begin{tabular}{|c|c|}
\hline \multicolumn{2}{|c|}{$\begin{array}{l}\text { Table } 1 \\
k_{f}(p s f / i n .) \text { as Function of Angle of Internal Friction of Sand for } \\
\text { Method SSF1 }\end{array}$} \\
\hline Angle of Internal Friction (degrees) ${ }^{1}$ & $k_{f}$ (psf/in.) \\
\hline $28-31$ & $6,000-10,000$ \\
\hline $32-34$ & $10,000-14,000$ \\
\hline $35-38$ & $14,000-18,000$ \\
\hline
\end{tabular}

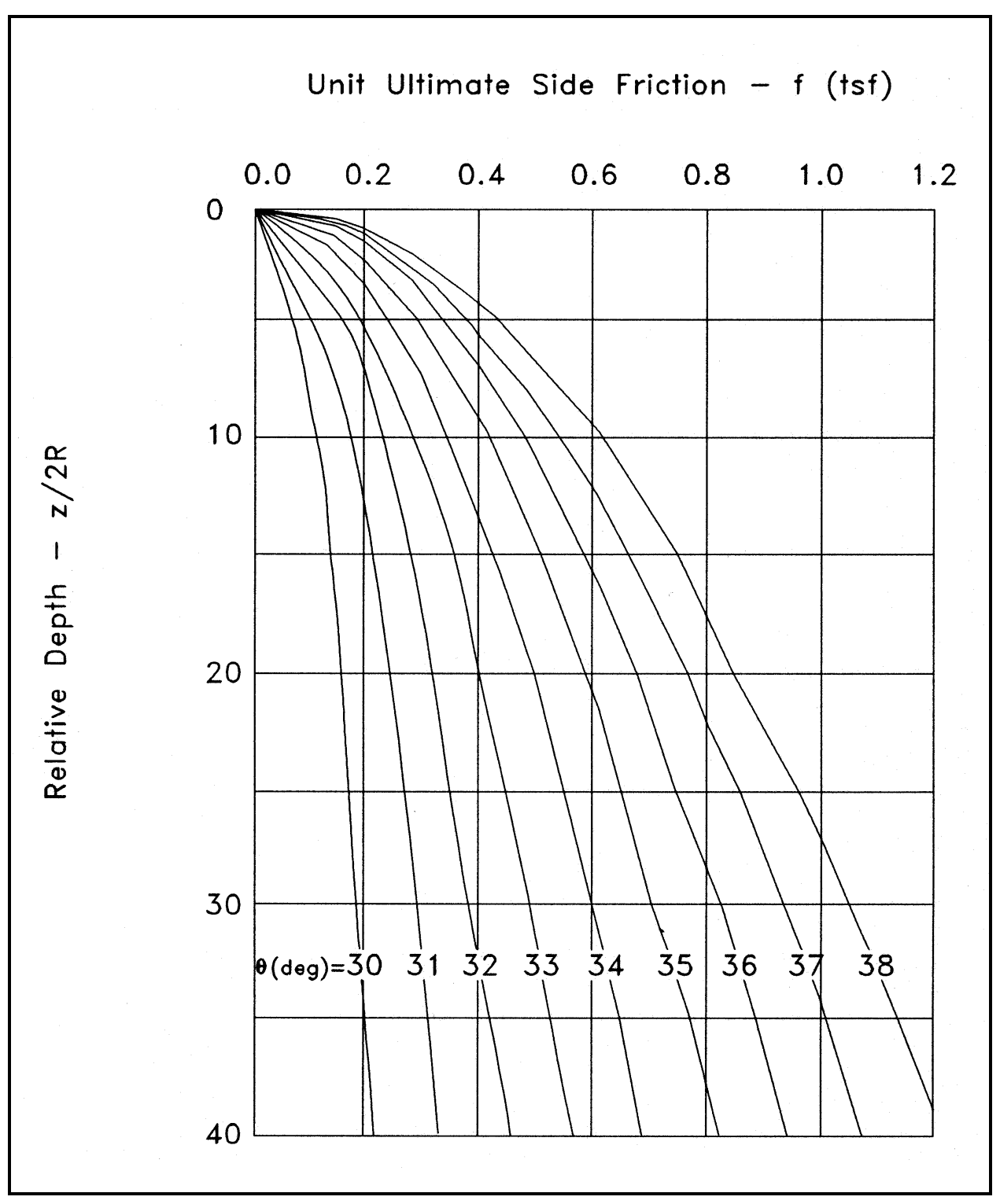

Figure 4. Ultimate side friction for Method SSF1 
The effects of groundwater, layering, and variable pile diameter may be accounted for approximately by adjusting the relative depth at each point as follows. The effective depth $z^{\prime}$ below ground surface is obtained by dividing the effective vertical soil pressure at a point by the effective unit weight at that point; the relative depth is obtained by dividing the effective depth by the pile diameter at that point. This approximation will result in unrealistic discontinuities in the distribution of $f-w$ curves at soil layer boundaries, at the location of a subsurface groundwater level, and at changes in pile diameter.

The method may also be extended to approximate the behavior of noncircular cross sections using the equivalent radius of the pile as indicated in Figure 5.

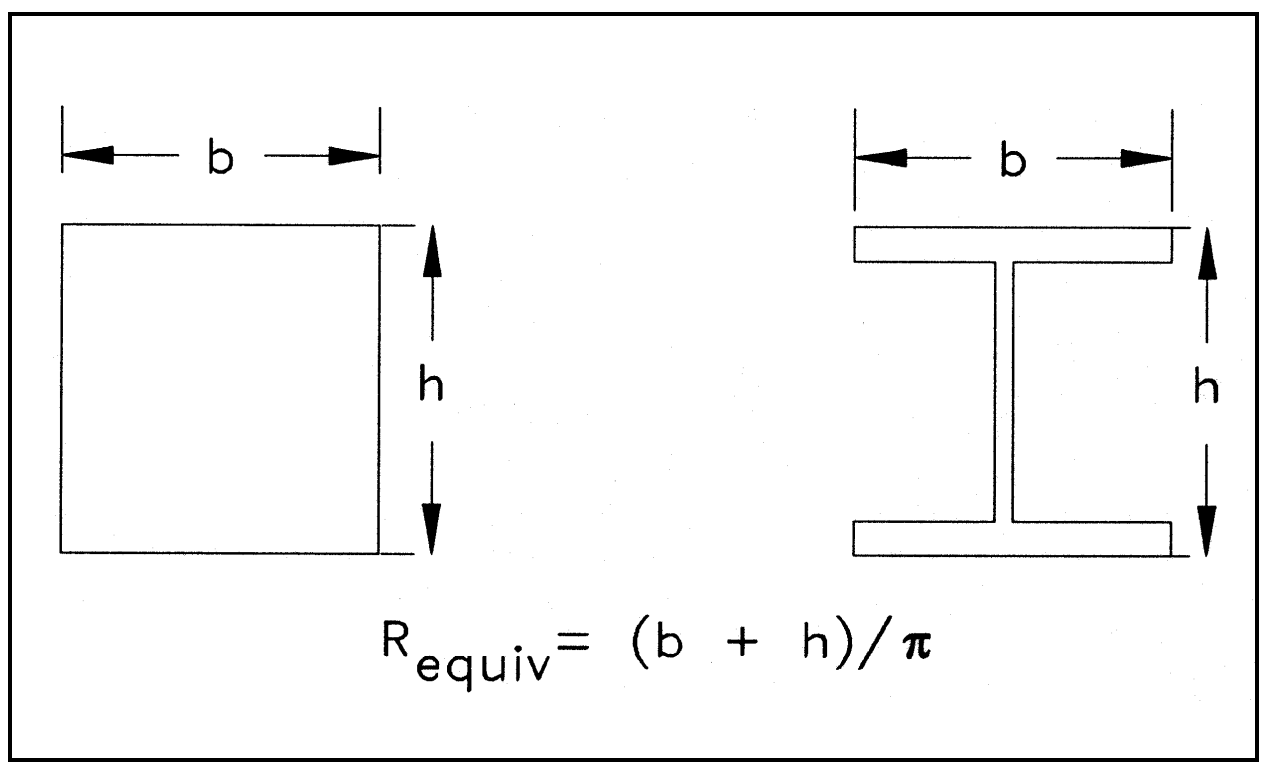

Figure 5. Equivalent radius for noncircular cross sections

\section{Kraft, Ray, and Kagawa (1981)}

Numerous analyses (Randolph and Wroth 1978; Vesic 1977; Kraft, Ray, and Kagawa 1981; Poulos and Davis 1980) have been performed in which the pile/soil system is assumed to be radially symmetric and the soil is assumed to be a vertically and radially homogeneous, elastic medium. The principles of continuum mechanics as well as finite element methods have been used to arrive at the relationship between side friction and axial pile displacement. The process due to Kraft, Ray, and Kagawa (1981) is outlined below.

Shear stresses are assumed to decay radially in the soil according to

$$
\tau=f R / r
$$


where

$\tau=$ shear stress in the soil

$f=$ side friction at pile/soil interface

$R=$ pile radius

$r=$ radial distance from the pile centerline

If radial deformations of the soil are ignored, the shear strain at any point in the soil may be expressed as

$$
\gamma=\frac{d w}{d r}=\frac{\tau}{G}=\frac{f R}{G r}
$$

where $G$ is the soil shear modulus of elasticity.

The axial displacement at the interface is obtained by integrating Equation 3 to obtain

$$
w=\frac{f R}{G} \int_{R}^{r_{m}} \frac{d r}{r}=\frac{f R}{G} \ln \left(\frac{r_{m}}{R}\right)
$$

where

$w=$ axial displacement of the pile

$r_{m}=$ a limiting radial distance beyond which deformations of the soil mass are negligible

Randolph and Wroth suggested

$$
r_{m}=2 L \rho(1-v)
$$

where

$$
\begin{aligned}
& L=\text { embedded length of the pile } \\
& \rho=\text { a factor to account for vertical nonhomogeneity of the soil medium to be } \\
& \quad \text { discussed later } \\
& v=\text { Poisson's ratio for the soil }
\end{aligned}
$$

Combination of Equations 4 and 5 yields a linear relationship between pile displacements and side friction as 


$$
w=\frac{f R}{G} \ln \left[\frac{2 L \rho(1-v)}{R}\right]
$$

The side friction-displacement relationship expressed in Equation 6 is appropriate only for very small displacements. To account for deviations from linearity, a hyperbolic variation in side friction-displacements proposed by Kraft, Ray, and Kagawa (1981) is

$$
w=\frac{f R}{G} \ln \left[\frac{\frac{2 L \rho(1-v)}{R}-\frac{f R_{f}}{f_{\max }}}{1-\frac{f R_{f}}{f_{\max }}}\right]
$$

where $R_{f}$ is a curve fitting parameter (Kraft, Ray, and Kagawa 1981) which may be taken as 0.9 for most conditions. The value of $f_{\max }$ may be obtained from the curves due to Mosher (Figure 4) or may be estimated as suggested under method SSF3 which follows.

After $f_{\max }$ has been reached, the $f-w$ curve becomes a horizontal line at $f_{\max }$. The $f$ - $w$ curve produced by this method is illustrated in Figure 6 by the solid curve $0-1-2$.

Some soils exhibit a degradation in strength after a maximum resistance has been reached. The results of a direct shear test for a softening soil illustrated in Figure 7 are used to construct the descending branch of the $f-w$ curve for softening soils shown by the dashed line in Figure 6 as follows. The displacement beyond the maximum $f_{\max }$ required to reduce the side friction to its residual value is obtained by adjusting the direct shear displacement to account for elastic rebound of the pile due to the reduction in side friction. This adjustment is given by

$$
w=\frac{f_{\max } R}{G}\left\{\ln \left[\frac{\frac{2 L \rho(1-v)}{R}-R_{f}}{1-R_{f}}\right]-\ln \left[\frac{\frac{2 L \rho(1-v)}{R}-\frac{f_{\text {resid }} R_{f}}{f_{\max }}}{1-\frac{f_{\text {resid }} R_{f}}{f_{\max }}}\right]\right\}
$$

The softening portion of the $f$ - $w$ curve is obtained by scaling the normalized direct shear curve to the $f$-w curve (dashed line 1-3 in Figure 6).

Because the shear strength of sands increases with depth (i.e. confining pressure), the shear modulus $G$ is not constant along the length of the pile. Finite element analyses have indicated, for a linear increase in $G$ with depth, the value of $\rho$ to be 


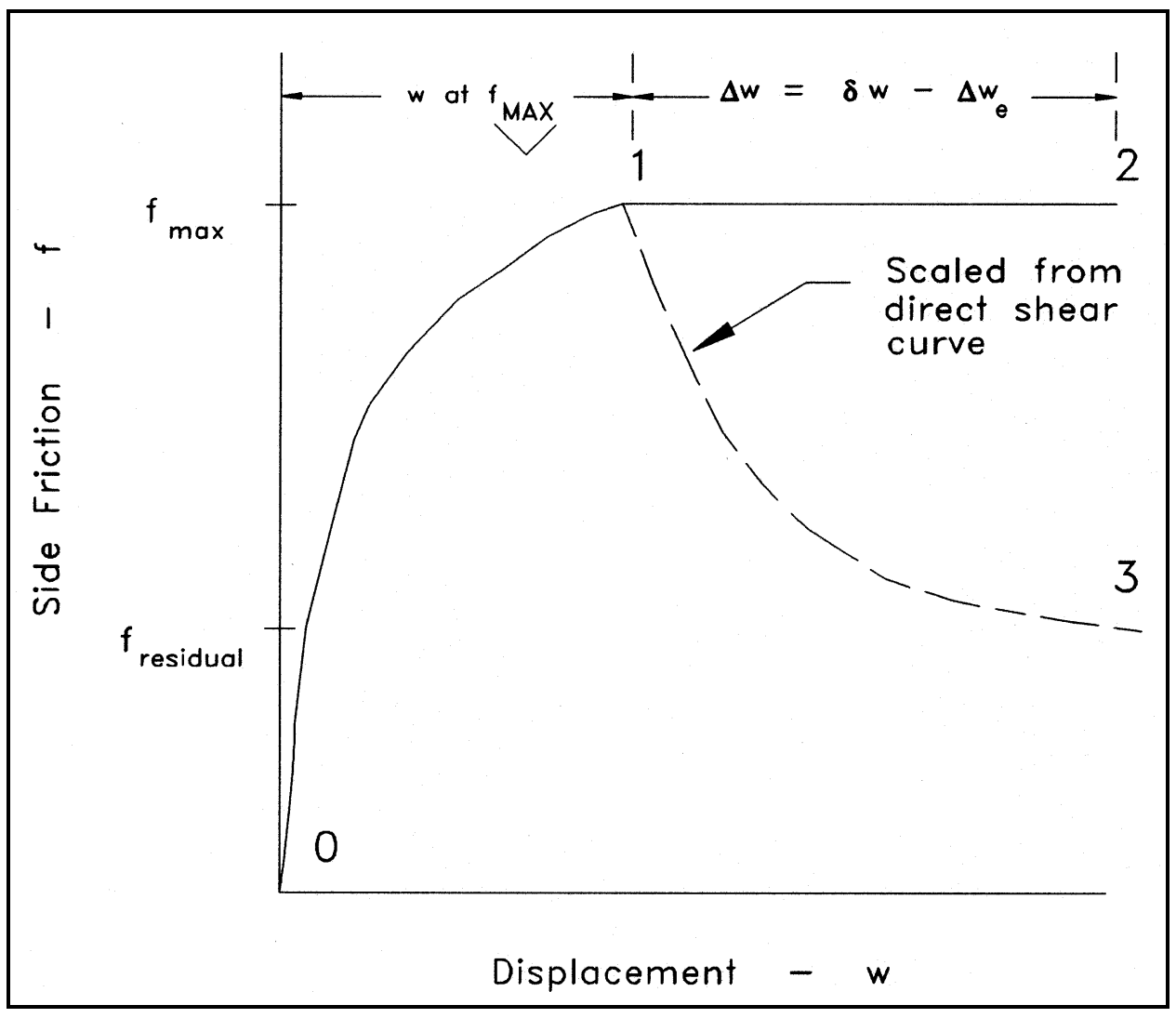

Figure 6. $f$-w curve by Method SSF2

$$
\rho=\frac{G_{m}}{G_{t}}
$$

where

$$
\begin{aligned}
G_{m} & =\text { soil shear modulus at mid-depth of the pile } \\
G_{t} & =\text { shear modulus at the pile tip }
\end{aligned}
$$

The preceding equations also assume that the soil modulus $G$ is unaffected by the pile installation. Randolph and Wroth (1978) performed finite element analyses for two hypothetical variations of shear modulus radially away from the pile. These variations and the effective shear modulus were:

a. $G=G \infty / 4$ for $1 \leq r / R \leq 1.25 ; G=G \infty$ for $r / R>1.25$ which produced

$$
G_{\text {eff }}=\frac{G^{\infty}}{3 \ln 1.25+\ln \left[\frac{2 L \rho(1-v)}{R}\right]}
$$




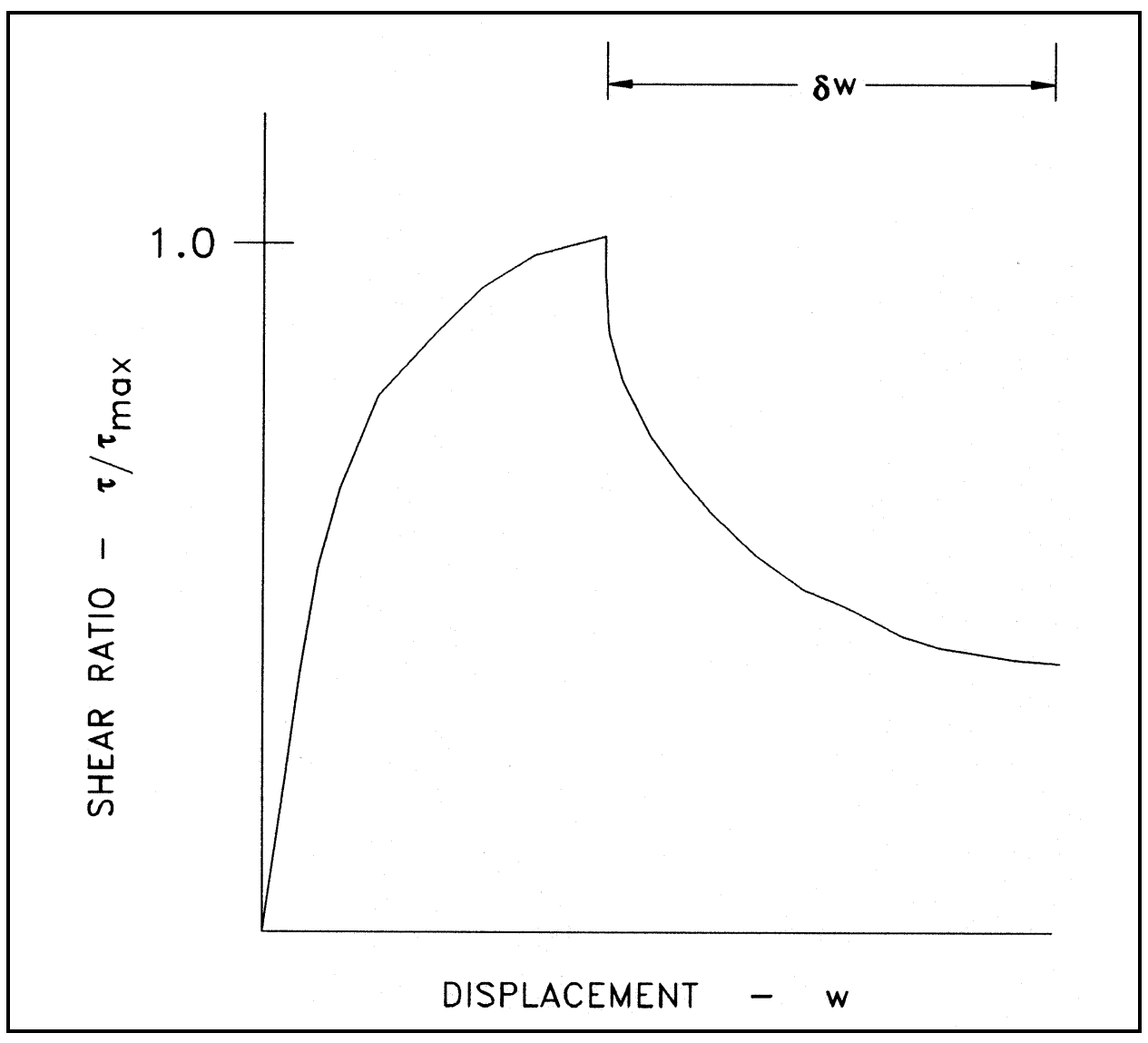

Figure 7. Direct shear test of softening soil

b. $G=G \infty / 4$ for $1 \leq r / R \leq 1.25 ; G=G^{\infty}$ for $r / R .2 ; G$ varied linearly between $1.25 \leq r / R \leq 2$ which produced

$$
G_{e f f}=\frac{G^{\infty}}{5 \ln 1.25+\ln \left[\frac{2 L \rho(1-v)}{R}\right]}
$$

where

$G_{\text {eff }}=$ reduced effective shear modulus

$G^{\infty}=$ shear modulus of the undisturbed soil

The shear modulus $G$ in the preceding equations should be evaluated at a low strain value such as in the range of values obtained from seismic velocity tests conducted in situ or from resonant column tests. As an alternative, the following expression may be used

$$
G=83 \kappa \sqrt{\sigma_{o}^{\prime}}
$$


where

$\kappa=\mathrm{a}$ function of relative density, varying from 50 at a relative density of 60 percent to 70 at a relative density of 90 percent

$\sigma_{o}^{\prime}=$ mean effective stress in the soil (vertical stress plus two times horizontal stress); with $G$ and $\sigma_{o}^{\prime}$ in psi

\section{Vijayvergiya (1977)}

Vijayvergiya (1977) proposed a relationship between side friction and pile displacement of the form

$$
\frac{f}{f_{\max }}=2 \sqrt{\frac{w}{w_{c}}}-\frac{w}{w_{c}}
$$

where $w_{\mathrm{c}}$ is the displacement required to develop $f_{\max }$. For $w$ greater than $w_{c}, f$ remains constant at $f_{\max }$. Vijayvergiya gives limiting values of $f_{\max }$ as 1 tsf for clean medium dense sand, 0.85 tsf for silty sand, 0.7 tsf for sandy silt, and 0.5 tsf for silts. The suggested values of $w_{c}$ range from 0.2 to 0.3 in. for nominal sized piles. A typical $f-w$ curve by this method is shown as the solid curve in Figure 8.

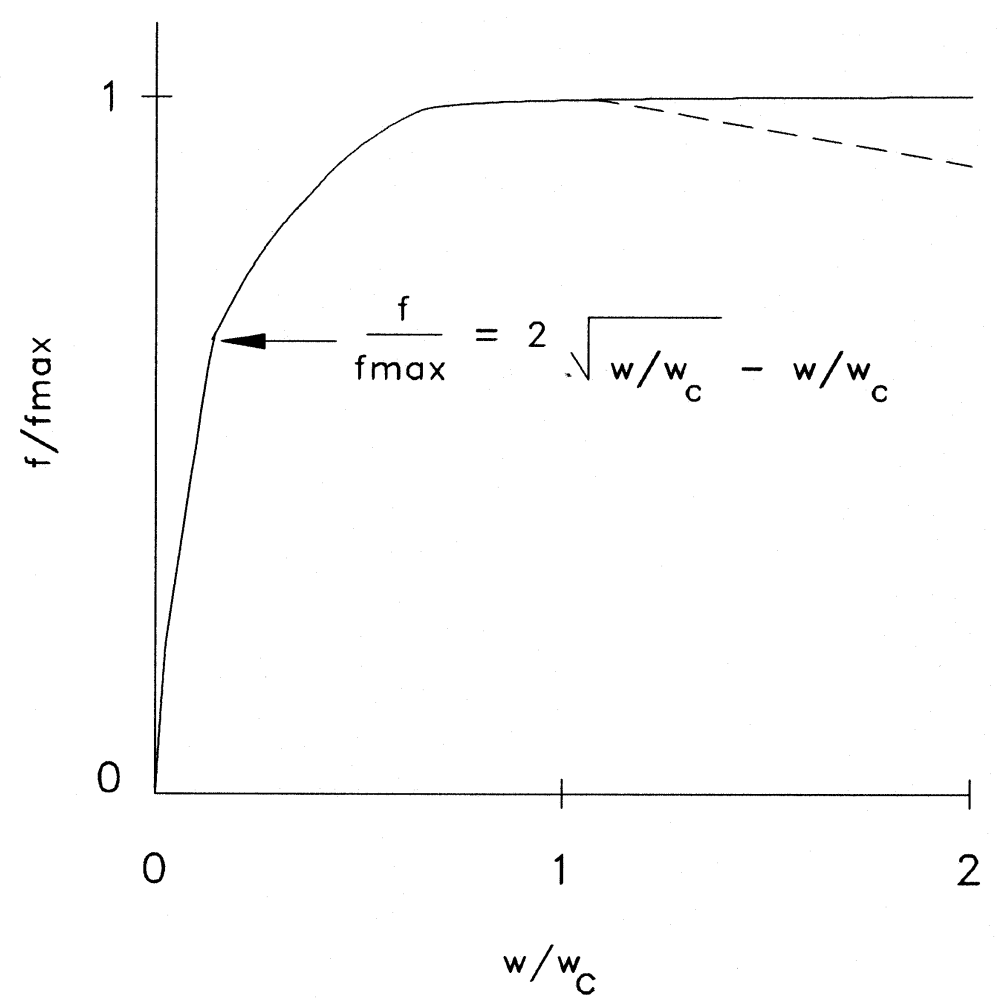

Figure 8. $f$-w curve by Method SSF3 


\section{Coyle and Sulaiman (1967)}

Coyle and Sulaiman (1967) performed tests on miniature piles in sand and correlated the laboratory results with data from field tests of instrumented piles in sand. They concluded that skin friction increases with pile deflection up to pile displacements of 0.1 to $0.2 \mathrm{in}$. They further concluded that the ratio of skin friction to soil shear strength is high (greater than one) near the ground surface and decreases to a limiting value of 0.5 with increasing depth. Two curves, as shown in Figure 9, were proposed for the analysis of axially loaded piles in sand. Curve A was proposed for use at depths less than $20 \mathrm{ft}$ below the surface and Curve B for depths greater than $20 \mathrm{ft}$.

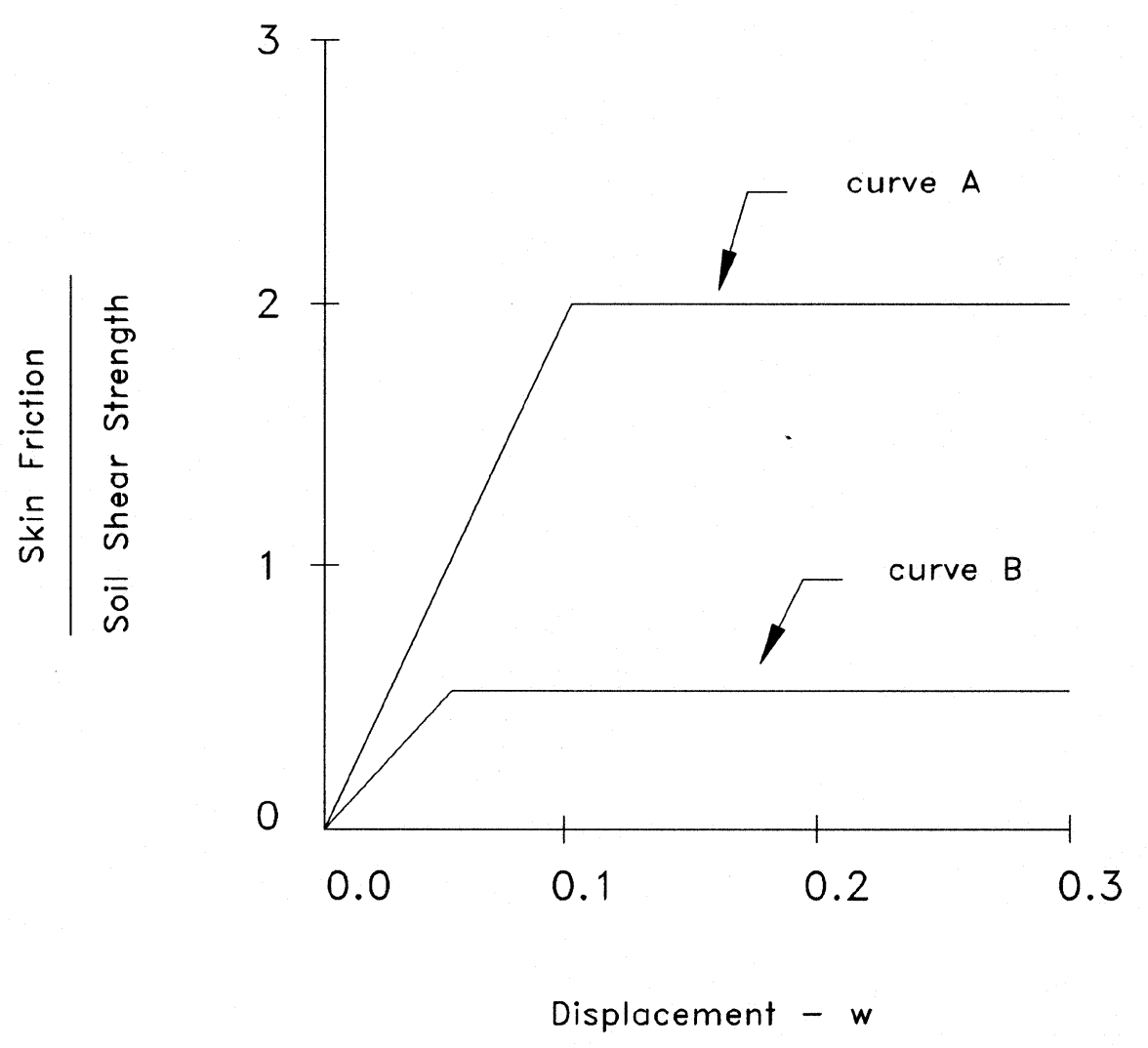

Figure 9. $f$-w curves by Method SSF4

\section{Briaud and Tucker (1984)}

Analyses using the $f-w$ curves discussed above do not consider the presence of residual stresses in the pile/soil system which result from the installation process. Field tests of instrumented piles indicate that significant residual stresses may be encountered in long, flexible piles driven in sand or gravel (see, for instance, Mosher (1984)). If the $f-w$ curves and tip reaction representation (see later) are both based on ignoring residual stresses, the predicted pile head 
displacement at any load will be essentially unaffected. However, the distribution of axial load and the predicted tip reaction may be in error. Briaud and Tucker (1984) extracted the residual stresses from field tests of piles in sand. A hyperbolic representation of the $f$ - $w$ curve (Figure 10) was proposed for inclusion of the effects of residual stresses as

$$
f=\frac{W}{\frac{1}{k_{f}}+\frac{w}{f_{\max }-f_{r}}}-f_{v}
$$

with

$$
\begin{aligned}
& k_{f}=5.01\left(N_{s}\right)^{0.27} \\
& f_{\max }=0.224\left(N_{s}\right)^{0.29} \\
& \Omega=k_{f} \frac{C}{A E} \\
& f_{r}=5.57 L \Omega \frac{A_{t}}{A_{s}}<f_{\max }
\end{aligned}
$$

where

$N_{s}=$ number of blows per foot in a standard penetration test

$C=2 \Pi R=$ pile circumference

$A=$ pile cross section area

$E=$ pile modulus of elasticity

$L=$ length of pile

$A_{t}=$ tip reaction area

$A_{s}=C L=$ area of pile-soil interface; with $k_{f}$ in tsf/in.; and $f_{\max }$ and $f_{r}$ in tsf

\section{Synthesis of $f$ - $w$ Curves for Piles in Clay Under Compressive Loading}

\section{Coyle and Reese (1966)}

The results of load tests of instrumented piles in clay as well as the results of laboratory tests of model pile/soil systems were used by Coyle and Reese (1966) 


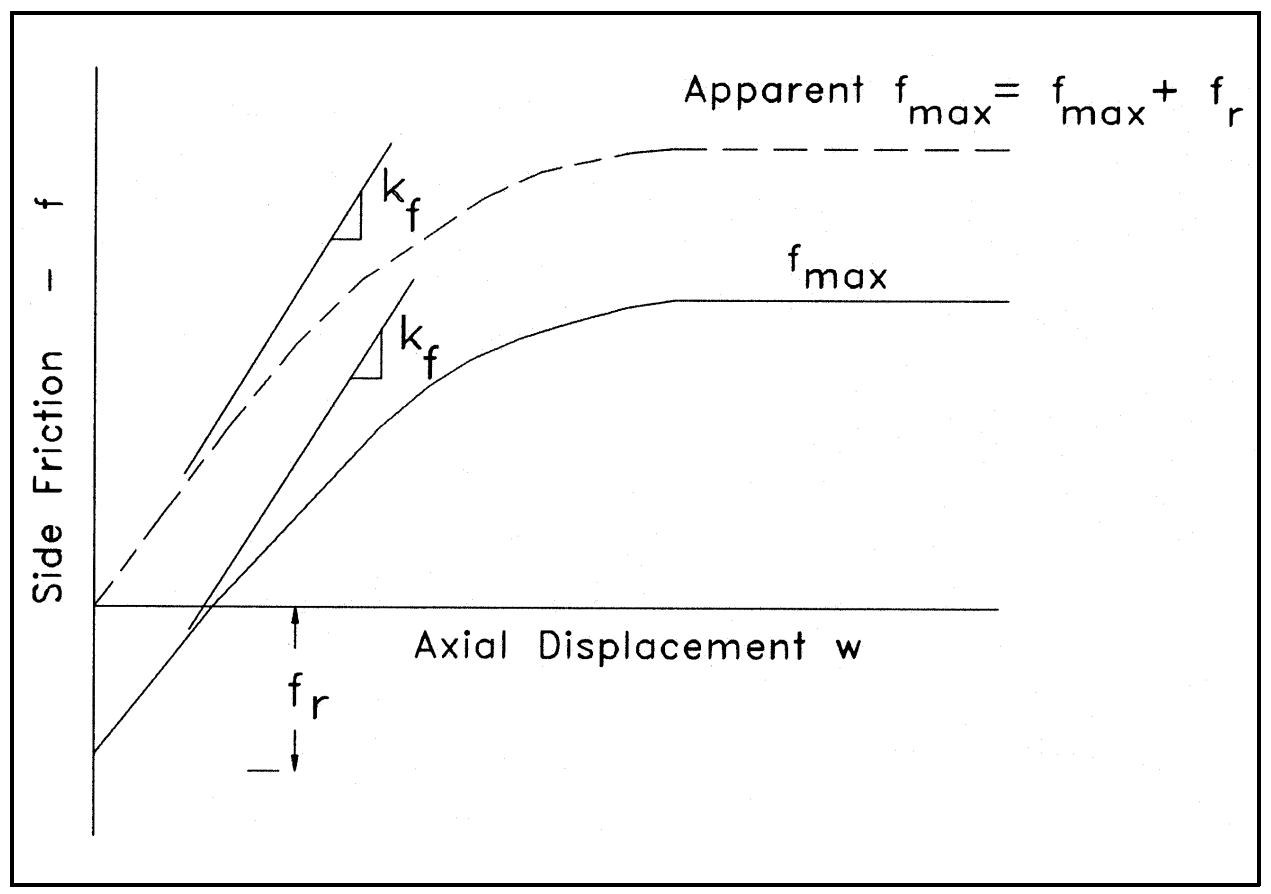

Figure 10. $f$-w curve by Method SSF5

to establish the three load transfer curves shown in Figure 11. Curve A is applicable for points along the pile from the ground surface to a depth of $10 \mathrm{ft}$, curve $\mathrm{B}$ applies for depths from $10 \mathrm{ft}$ to $20 \mathrm{ft}$, and curve $\mathrm{C}$ is applicable for all depths below $20 \mathrm{ft}$.

The relationship between maximum side friction and soil shear strength provided by Coyle and Reese is shown in Figure 12.

\section{Aschenbrener and Olson (1984)}

Data obtained from a large number of field load tests of piles in clay were examined by Aschenbrener and Olson (1984) with the intent to devise load transfer relationships which provided the best fit to the diverse pile and soil properties represented by the database. The simple bilinear relationship shown in Figure 13 was selected as a result of their study.

Aschenbrener and Olson expressed the relationship between $f_{\max }$ and soil shear strength as

$$
f_{\max }=\alpha s_{u}
$$




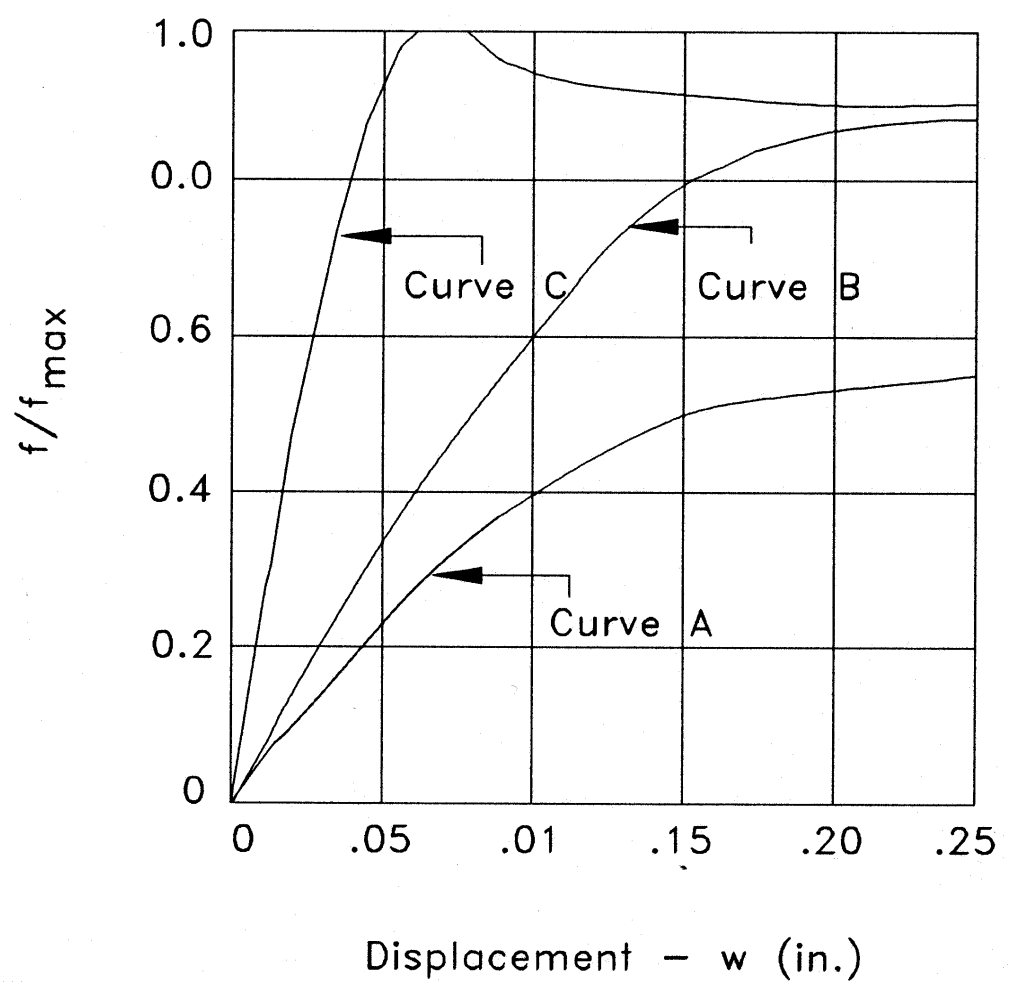

Figure 11. $f$-w curves by Method CSF1

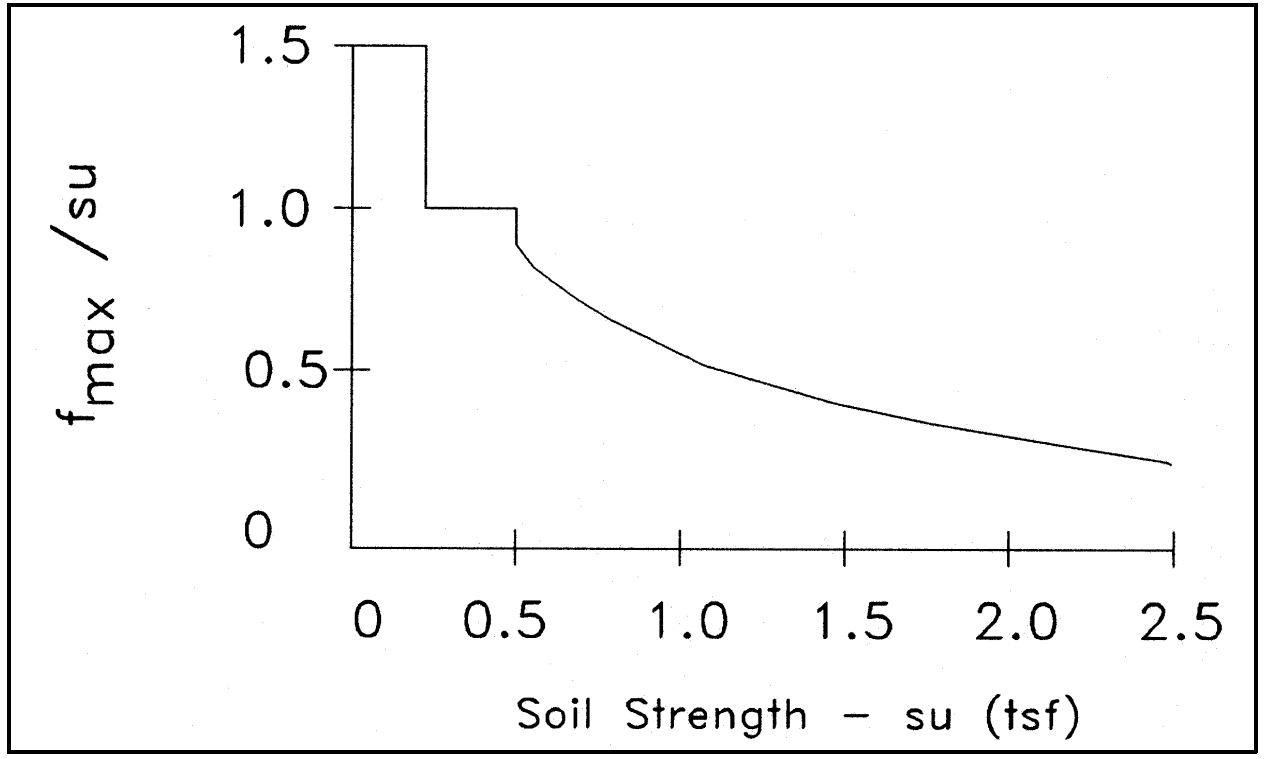

Figure 12. Side friction - soil strength relation for Method CSF1 


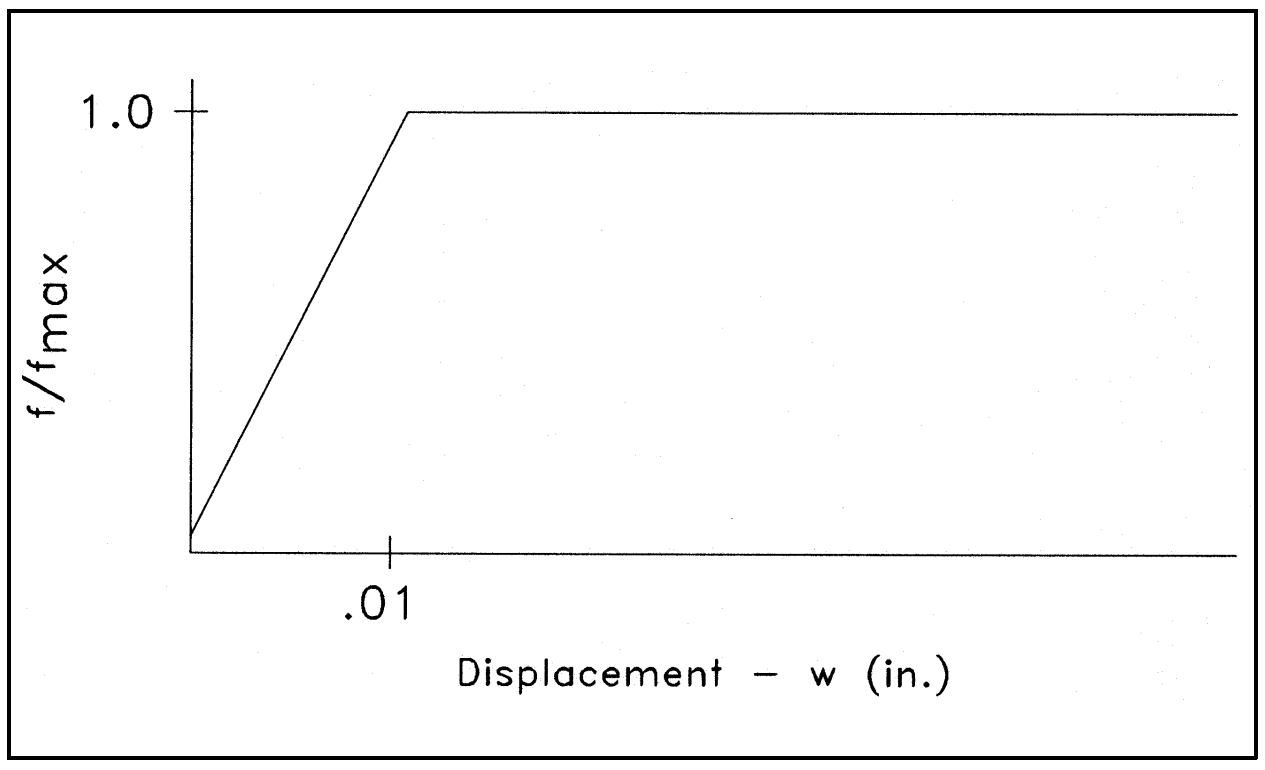

Figure 13. $f$-w curve by Method CSF2

where

$$
\begin{gathered}
\alpha=\text { a proportionality factor } \\
s_{u}=\text { undrained shear strength }
\end{gathered}
$$

Aschenbrener and Olson were able to evaluate $\alpha$ from the field test data as

$$
\alpha=\frac{\left(P_{o u}-P_{t u}\right)}{s_{u} A_{s}}
$$

where

$$
\begin{aligned}
& P_{o u}=\text { pile head load at failure } \\
& P_{t u}=\text { tip load at failure } \\
& S_{u}=\text { undrained shear strength } \\
& A_{s}=\text { area of pile-soil interface }
\end{aligned}
$$

In a design situation, the ultimate head and tip loads will not be known. For design, the value of $\alpha$ may be obtained from the curves provided by Semple and Rigden (1984) shown in Figure 14 as

$$
\alpha=a_{p} a_{l}
$$


where

$$
\begin{aligned}
& a_{p}=\text { peak strength reduction factor from Figure } 14 \mathrm{a} \\
& a_{l}=\text { length factor from Figure } 14 \mathrm{~b}
\end{aligned}
$$

In Figure 14, $s_{u}$ is the undrained shear strength; $\sigma_{v}$ is the effective overburden pressure; $L$ is the length of pile; and, $R$ is the pile radius.

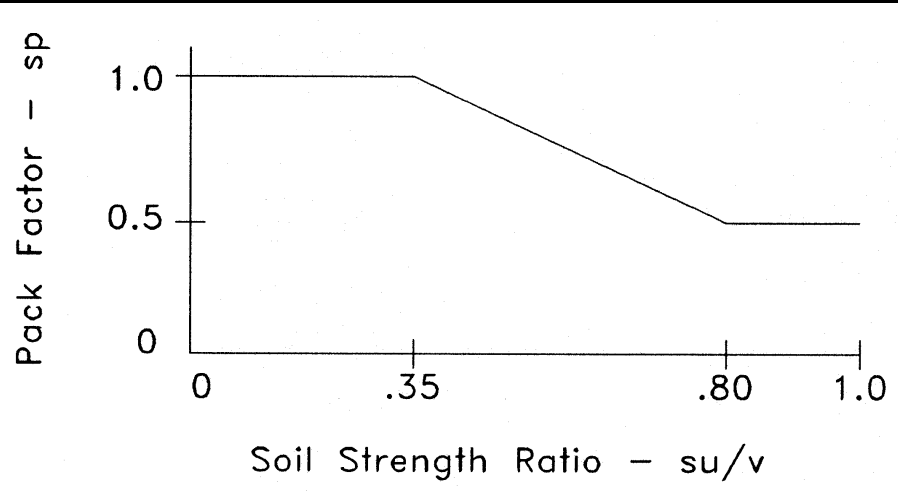

(a)

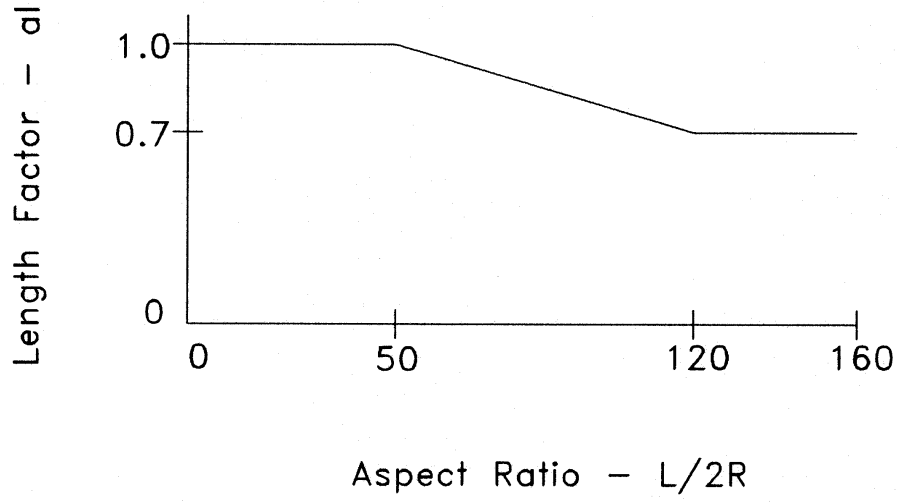

(b)

Figure 14. Strength reduction coefficients

\section{Kraft, Ray, and Kagawa (1981)}

The procedure of Method SSF2 due to Kraft, Ray, and Kagawa (1981) described previously for sand side friction, may be applied to piles in clay. For clays, the shear modulus may again be evaluated from seismic tests, from resonant column tests, approximated as 400 to 500 times $s_{u}$, or evaluated from the modulus of elasticity as $E / 3$ for undrained conditions and $E / 2.75$ for drained conditions. 


\section{Heydinger and O’Neill (1986)}

Finite element and finite difference analyses were performed by Heydinger and O'Neill (1986) to develop $f$ - $w$ curves for piles in clay. An axisymmetric model including interface elements to account for slippage of the pile-soil system was used in the finite element analyses. An unconsolidated-undrained condition was assumed to exist in the soil and the initial mean effective stresses were computed from radial consolidation theory in which the pile installation process was represented by an expanding cylindrical cavity. A general equation for the $f$ - $w$ curves (illustrated in Figure 15) was selected as

$$
\frac{f}{f_{\max }}=\frac{\frac{E_{f}}{f_{\max }} \frac{w}{2 R}}{\left[1+\left(\frac{E_{f}}{f_{\max }} \frac{w}{2 R}\right)^{m}\right]^{1 / m}}
$$

where the parameters $E_{\mathrm{f}}$ and $m$ were determined by statistical correlations with the analytical results as

$$
E_{f}=E / \exp \left(0.36+0.38 \ln \frac{L}{2 R}\right)
$$

and

$$
m=\exp \left(0.12+0.54 \ln \frac{E_{\text {avg }}}{p_{a}}-0.42 \ln \frac{L}{2 R}\right)
$$

where

$$
\begin{aligned}
E= & \text { initial undrained modulus of elasticity of the soil at the depth of interest } \\
E_{\text {avg }}= & \text { the average initial undrained modulus of elasticity over the entire length } \\
& \text { of the pile } \\
p_{a}= & \text { atmospheric pressure in the same units as } E_{\text {avg }}
\end{aligned}
$$

The value of $E$ should be measured at very low strains. An approximation for $E$ is cited as 1,200 to 1,500 times $s_{u}$.

\section{Vijayvergiya (1977)}

Vijayvergiya (1977) indicated that Equation 13 for $f$ - $w$ curves in sand, Method SSF3, is applicable for piles in clay. As for piles in sand, Vijayvergiya suggests values of the critical pile displacement $w c$ of 0.2 to 0.3 in. Although a 


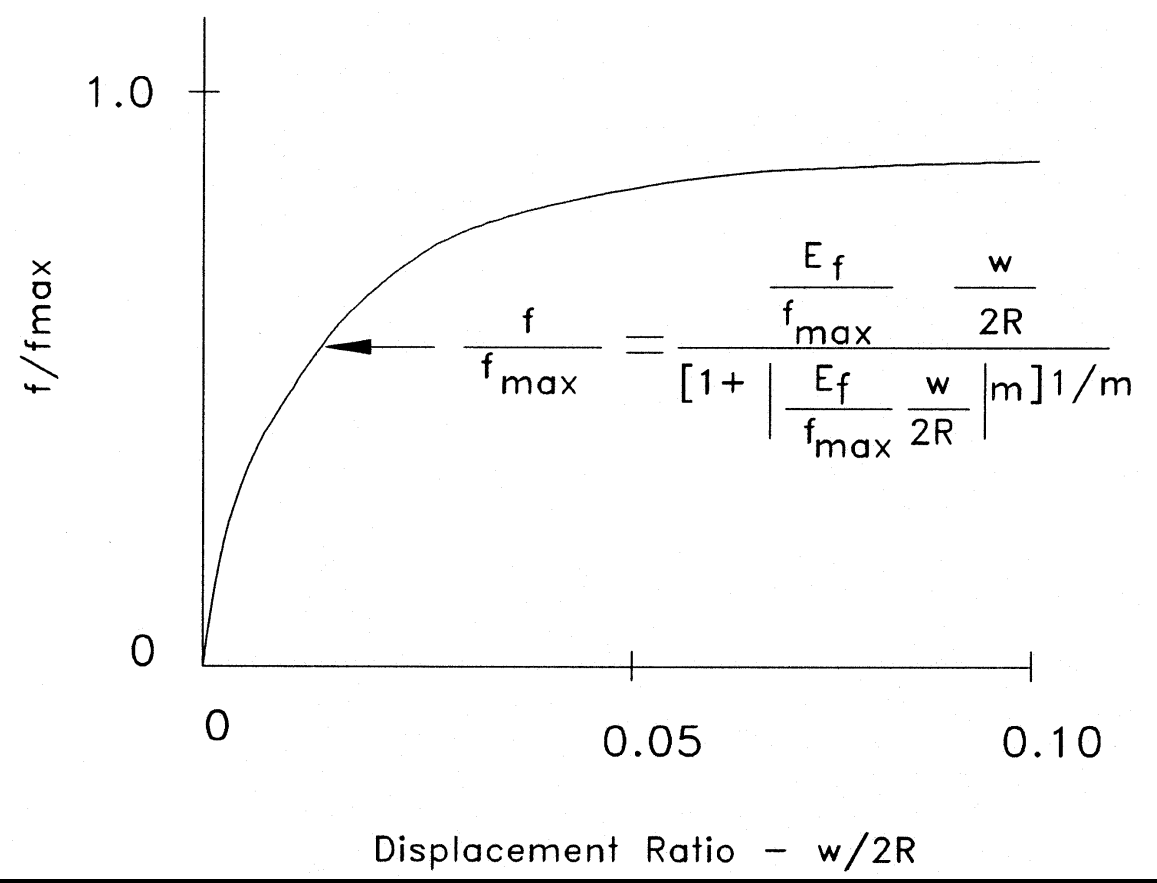

Figure 15. $f$-w curve by Method CSF4

method for evaluating $f_{\max }$ is presented by Vijayvergiya, he suggests that other less complex methods are equally suitable, e.g., the process of Method CSF2 discussed previously.

\section{Tip Reactions}

The influence of the tip reaction on the axial load-displacement behavior depends on the relative stiffness of the pile as well as side friction stiffness of the soil. In the following paragraphs several curves are presented for assessing the tip reaction as a function of the tip displacement. In general these curves have been developed primarily from a consideration of the properties of the soil at the tip elevation. However, numerous theoretical studies (see, for instance, Randolph and Wroth (1978)) have indicated that the tip reaction depends on the characteristics of the soil both above and below the tip elevation. Some of the methods for developing $q-w$ curves for the tip reaction account for the profile in the vicinity of the tip by using average soil properties. Other methods, derived from test results where the soil at the test site was relatively homogeneous, are dependent on the properties of the soil at the tip.

The curves presented below are for unit tip reaction (i.e. force per unit of tip area). To evaluate the total tip reaction, this unit force must be multiplied by the area of the pile tip actually bearing on the soil. For solid or closed-end piles the tip bearing area is reasonably taken as being equal to the gross cross section area. For open-end piles (e.g. pipes) or H-piles the effective tip area may be as little as the material area of the pile or may be as much as the gross section area. 


\section{Synthesis of q-w Curves for Piles in Sand Under Compressive Loading}

Mosher (1984)

Mosher (1984) expanded the work of Coyle and Castello (1981) to determine the $q-w$ relationship for piles in sand. Mosher proposed the exponential $q-w$ curve shown in Figure 16. Values of ultimate unit tip reaction $q_{\max }$ are given as a function of relative depth $(L / 2 R)$ in Figure 17.

\section{Kraft, Ray, and Kagawa (1981)}

Kraft, Ray, and Kagawa (1981) did not attempt to produce a $q$ - $w$ curve corresponding to their analytical $f$ - $w$ curve, but approximated the $q$ - $w$ relationship by the elastic solution for a rigid punch according to

$$
w=\frac{2 R q\left(1-v^{2}\right)}{E} I_{t}
$$

where

$$
\begin{aligned}
w= & \text { tip displacement } \\
R= & \text { radius of pile tip reaction area } \\
q= & \text { tip pressure } \\
v= & \text { Poisson's ratio for the soil at the tip } \\
E= & \text { secant modulus of elasticity of the soil appropriate to the level of soil } \\
& \text { stress associated with } q \\
I_{t}= & \text { influence coefficient ranging from } 0.5 \text { for long piles to } 0.78 \text { for very short } \\
& \text { piles }
\end{aligned}
$$

\section{Vijayvergiya (1977)}

Vijayvergiya (1977) proposed an exponential representation for the $q-w$ curve for a pile in sand similar to those in Method ST1. For $w<w_{c}$ 


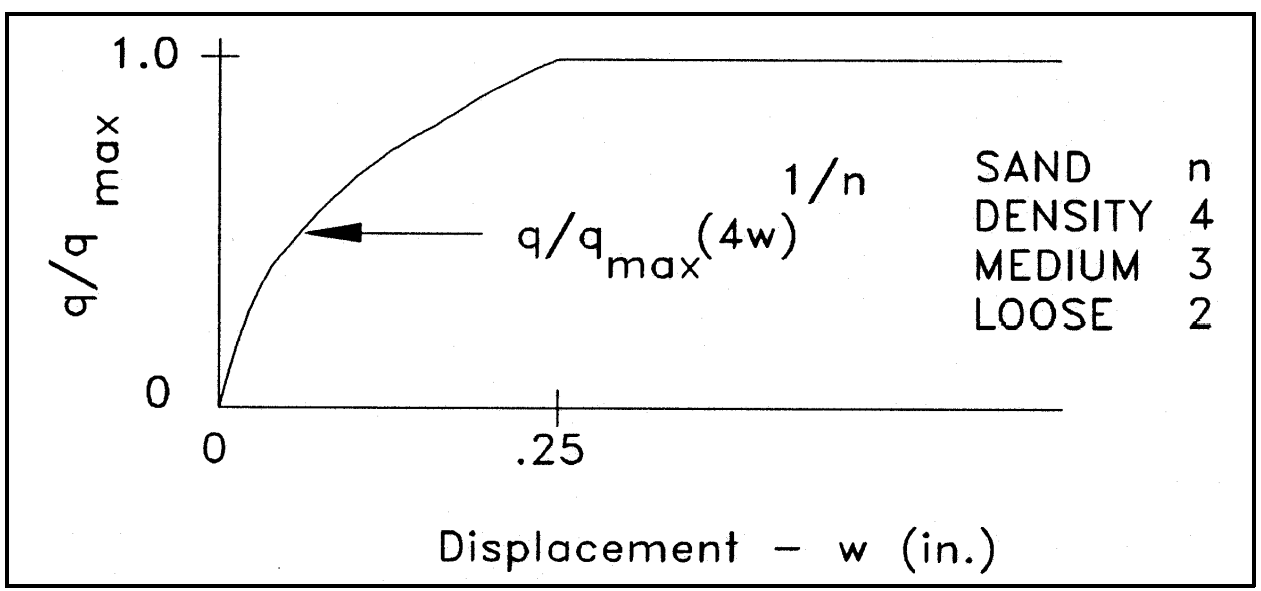

Figure 16. $q-w$ curve by Method ST1

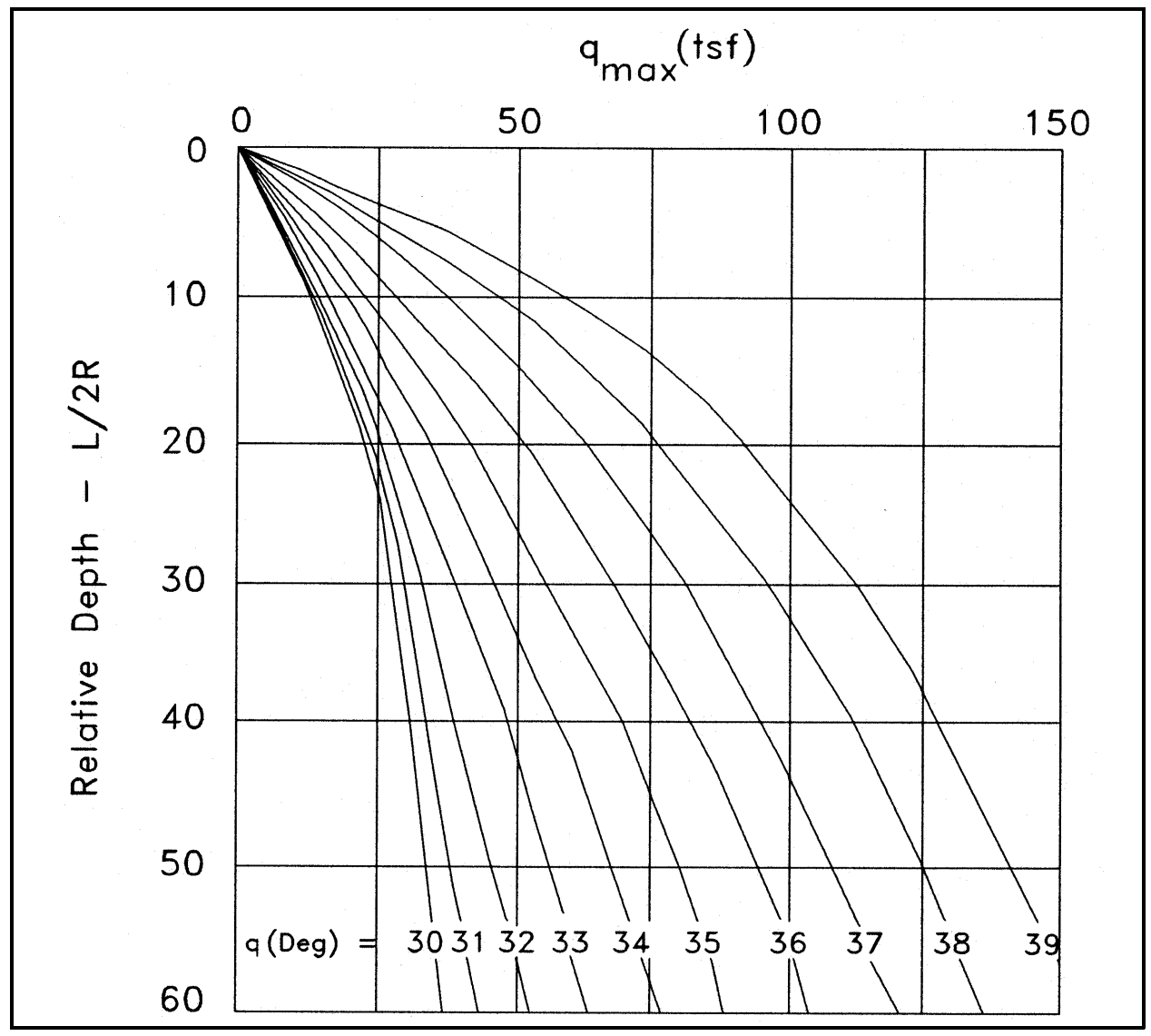

Figure 17. Ultimate tip resistance for Method SF1

$$
\frac{q}{q_{\max }}=\left(\frac{w}{w_{c}}\right)^{1 / 3}
$$


where $w_{c}$ is the critical tip displacement given by Vijayvergiya as ranging from 3 to 9 percent of the diameter of the tip reaction area. For $w>w_{c}, q=q_{\max }$. Vijayvergiya did not suggest adjusting the exponent to account for density.

\section{Briaud and Tucker (1984)}

Briaud and Tucker (1984) offer a means of accounting for the presence of residual stresses due to pile installation on the tip reaction. The hyperbolic relationship between unit tip reaction and tip displacement shown in Figure 18 is given by

$$
\begin{aligned}
& q=\frac{w}{\frac{1}{k_{q}}+\frac{w}{q_{\max }-q_{r}}}+q_{r} \\
& q_{\max }=19.75(N)^{0.36} \\
& q_{r}=5.57 L \Omega \\
& K_{q}=467.1(N)^{0.0065}
\end{aligned}
$$

where

$N=$ uncorrected average blow count of a standard penetration test over a distance of four diameters on either side of the tip

$k_{q}=$ initial slope of the $q-w$ curve in tsf/in.

$q_{\max }, q_{r}=$ ultimate and residual unit tip resistances, respectively, in tsf. Other terms are defined on page 6

\section{Coyle and Castello (1981)}

Coyle and Castello (1981) provided ultimate tip reactions based on correlations for instrumented piles in sand as shown in Figure 19. Coyle ${ }^{1}$ recommended the tip reaction curve shown in Figure 20.

1 Unpublished Class Notes, 1977, H. M. Coyle, "Marine Foundation Engineering," Texas A\&M University, College Station, TX. 


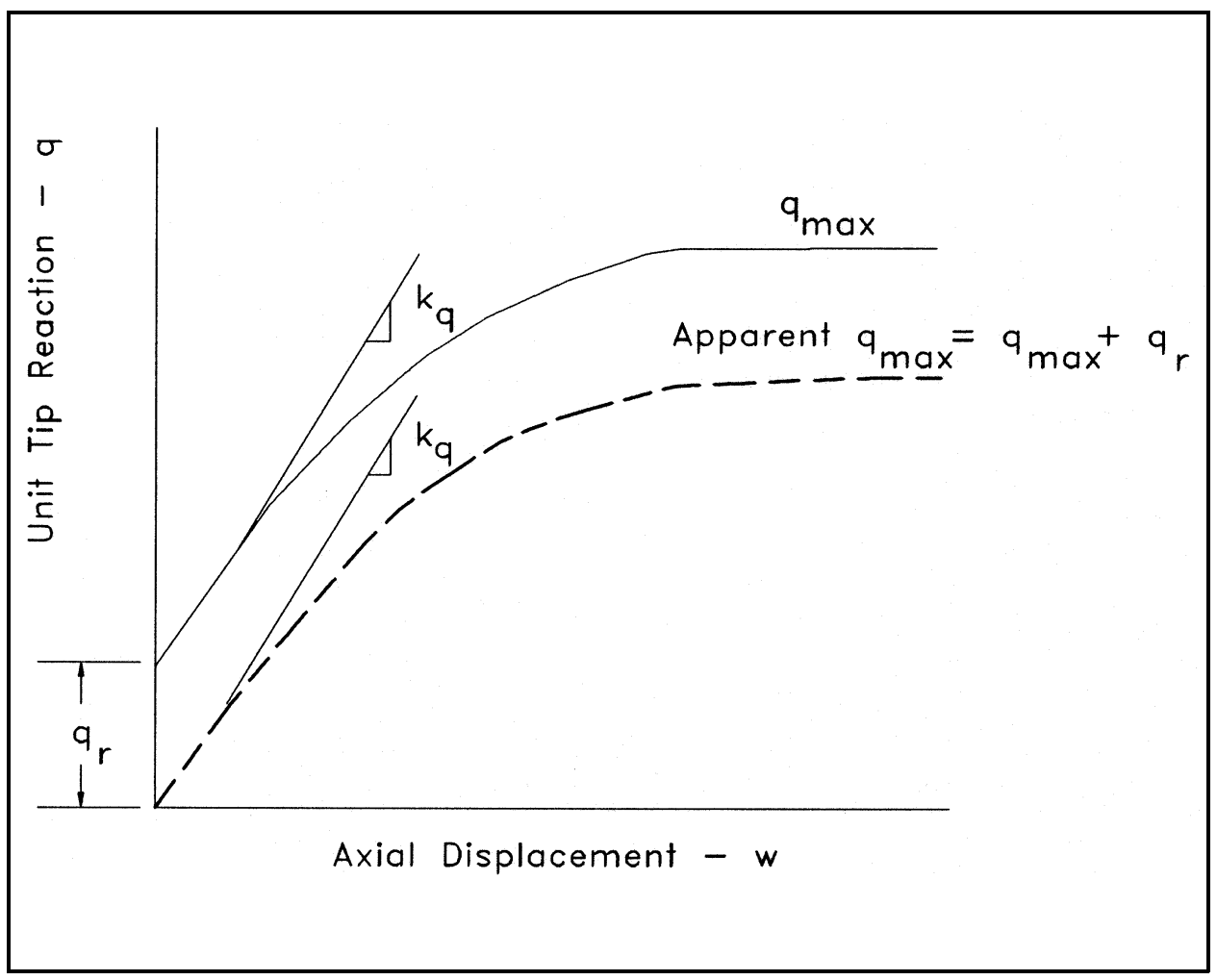

Figure 18. $q$-w curve by Method SF4

\section{Synthesis of $q-w$ Curves for Piles in Clay Under Compressive Loading}

\section{Aschenbrener and Olson (1984)}

Data for tip load and tip settlement were not recorded in sufficient detail in the database considered by Aschenbrener and Olson (1984) to allow establishing a nonlinear $q-w$ relationship. It was concluded that the sparsity and scatter of field data warranted nothing more complex than a simple elasto-plastic relationship. In their representation, $q$ varies linearly with $w$ reaching $q_{\max }$ at a displacement equal to 1 percent of the tip diameter and remains constant at $q_{\max }$ for larger displacements. Ultimate tip reaction was evaluated according to

$$
q_{\max }=s_{u} N_{c}
$$

where

$$
\begin{gathered}
s_{u}=\text { undrained shear strength } \\
N_{c}=\text { bearing capacity factor }
\end{gathered}
$$




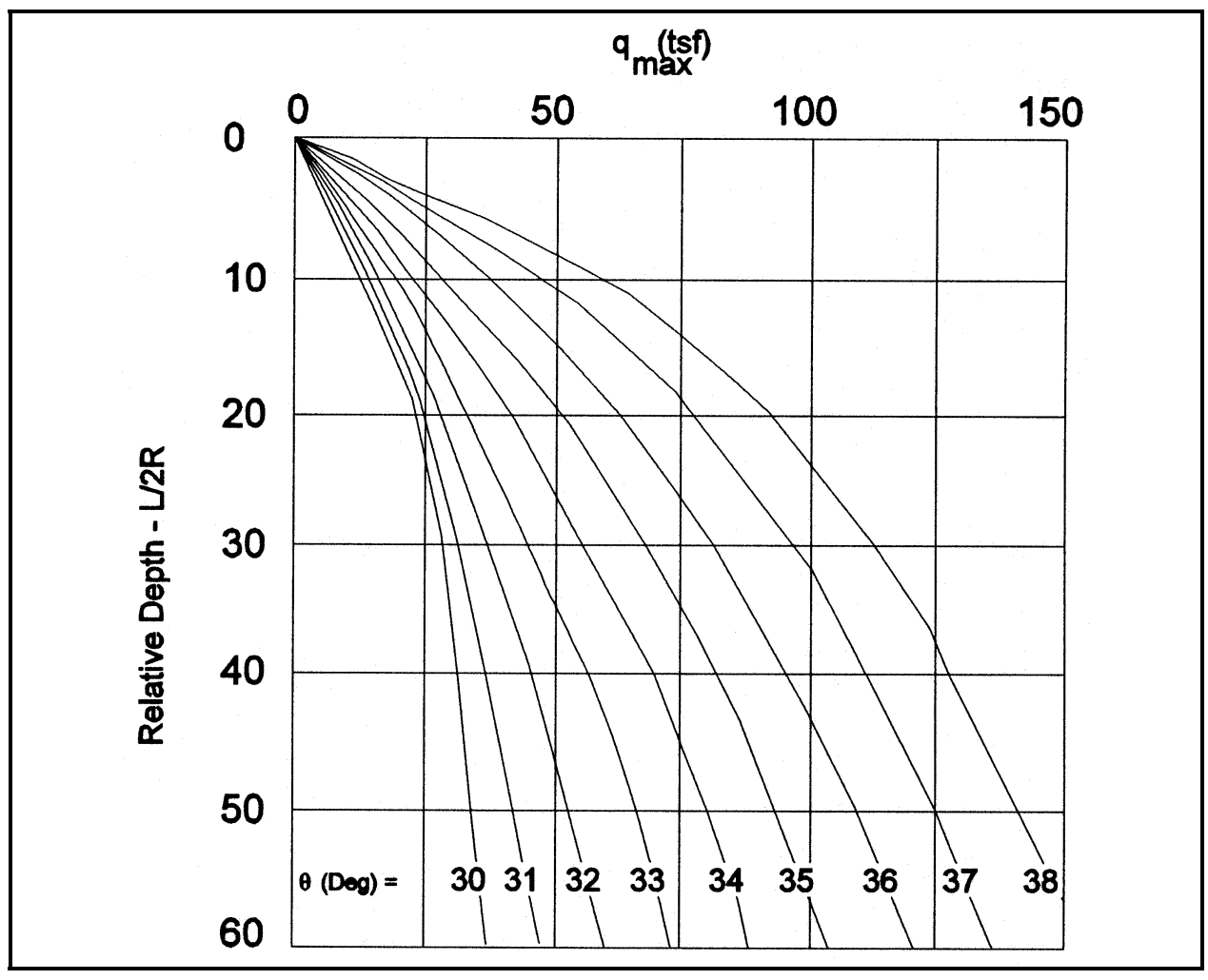

Figure 19. Ultimate tip resistance for Method ST5

Test data indicated that $N_{c}$ varied from 0 to 20 and had little correlation with shear strength. When ultimate tip reaction was not available from recorded data, Aschenbrener and Olson used a conventional value for $N_{c}$ equal to 9.

\section{Vijayvergiya (1977)}

Vijayvergiya (1977) recommends that the exponential $q$ - $w$ curve for sand as discussed on pages 24-26 is applicable for piles in clay. He indicates that $q_{\max }$ can be calculated from Equation 31 above but provides no guidance for the selection of $N_{c}$.

\section{Other Considerations}

\section{Uplift loading}

For some design cases it may be necessary to evaluate the behavior of an axially loaded pile for uplift (tension) loading. Considerably less is known about uplift loading than about compression loading. However, it is believed to be sufficiently accurate to analyze prismatic piles in clay under uplift using the same 


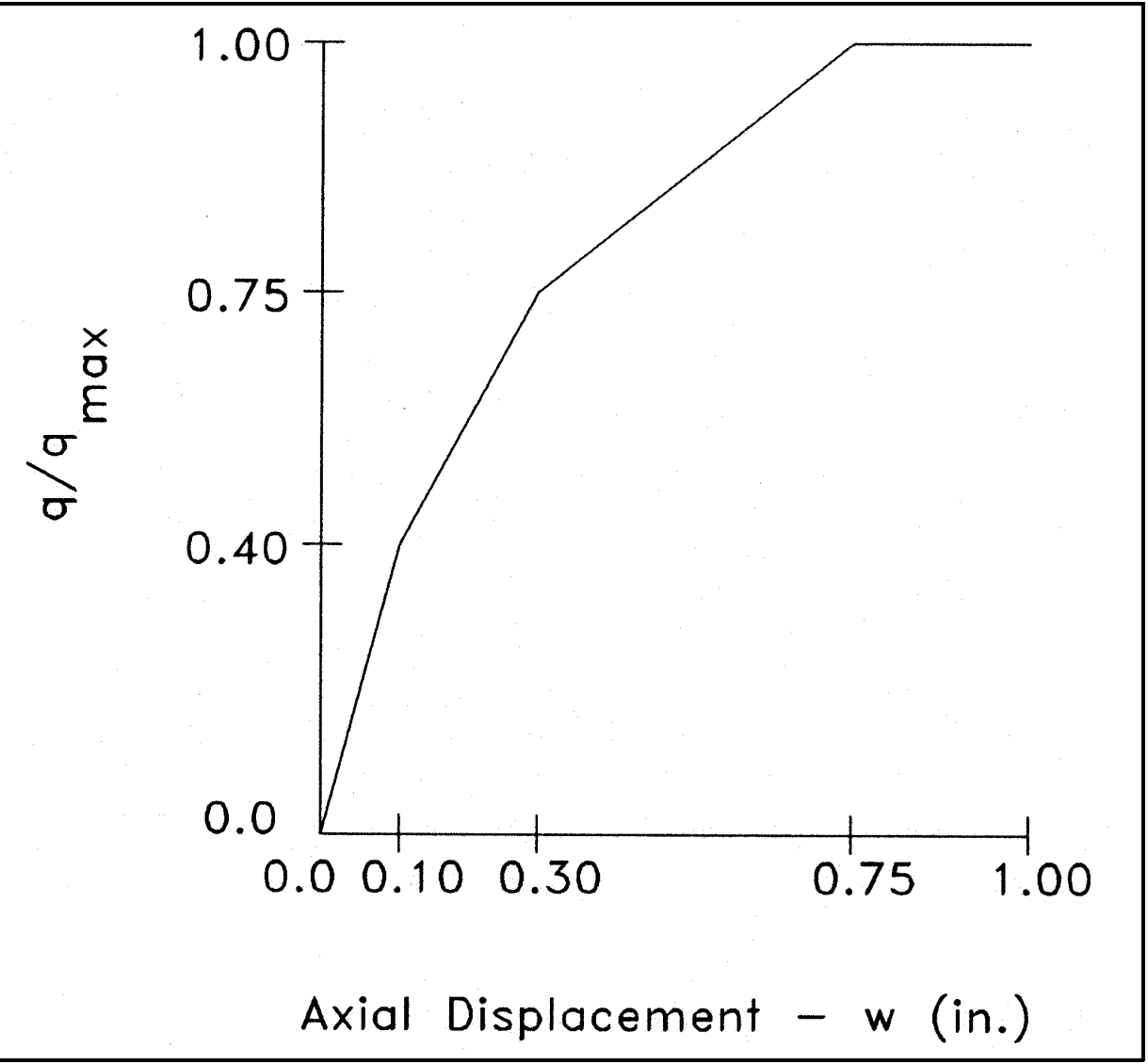

Figure 20. $q$-w curve by Method SF5

procedures used for compression loading, except that the tip reaction should be omitted unless it is explicitly accounted for as discussed below. In sands, use of the same procedures employed in compression loading is recommended, with the exception that $f_{\max }$ should be reduced to 70 percent of the maximum compression value.

For the methods that explicitly include residual driving stress effects in nonlinear $f-w$ and $q-w$ curves (pages 16-17 and 26), it is recommended that the appropriate curves for uplift loading be generated by extending the solid curves in Figures 10 and 18 in the negative $w$ direction with the same initial slopes as exist in the positive $w$ direction and assuring that the $q$ - $w$ curve terminates at $q=$ 0 . That is

$$
f=\frac{w}{\frac{1}{k_{f}}-\frac{w}{0.7 f_{\max }+f_{r}}}-f_{r}
$$

where $w$ is negative and $f_{\max }, f_{r}$, and $k_{f}$ are positive. And

$$
q=\frac{w}{\frac{1}{k_{q}}-\frac{w}{q_{r}}}+q_{r}
$$


where $w$ is negative and $q_{r}$ and $k_{q}$ are positive. All parameters appearing in Equations 32 and 33 are evaluated as for compressive loading.

\section{Bearing on Rock}

The tip reaction-tip displacement relationship for a pile driven to bearing on rock may be assumed to be linear. The tip reaction stiffness given by Equation 25 may be used where the modulus of elasticity and Poisson's ratio should reflect the characteristics of the surficial zone of the rock. The influence coefficient $I_{t}$ in Equation 25 may be taken as 0.78 for very sound rock but should be reduced to account for such effects as fracturing of the rock surface due to driving.

\section{Cyclic Loading}

Studies have shown (Poulos 1983) that the principal concern associated with cyclic axial loading is the tendency for $f_{\max }$ to reduce as the ratio of the cyclic component of axial load $P_{o c}$ to the ultimate static capacity $P_{\text {ous }}$ increases beyond some critical value. As long as the ratio remains below the failure envelope shown in Figure 21, no significant degradation of the pile capacity or forcedisplacement behavior is likely to occur.

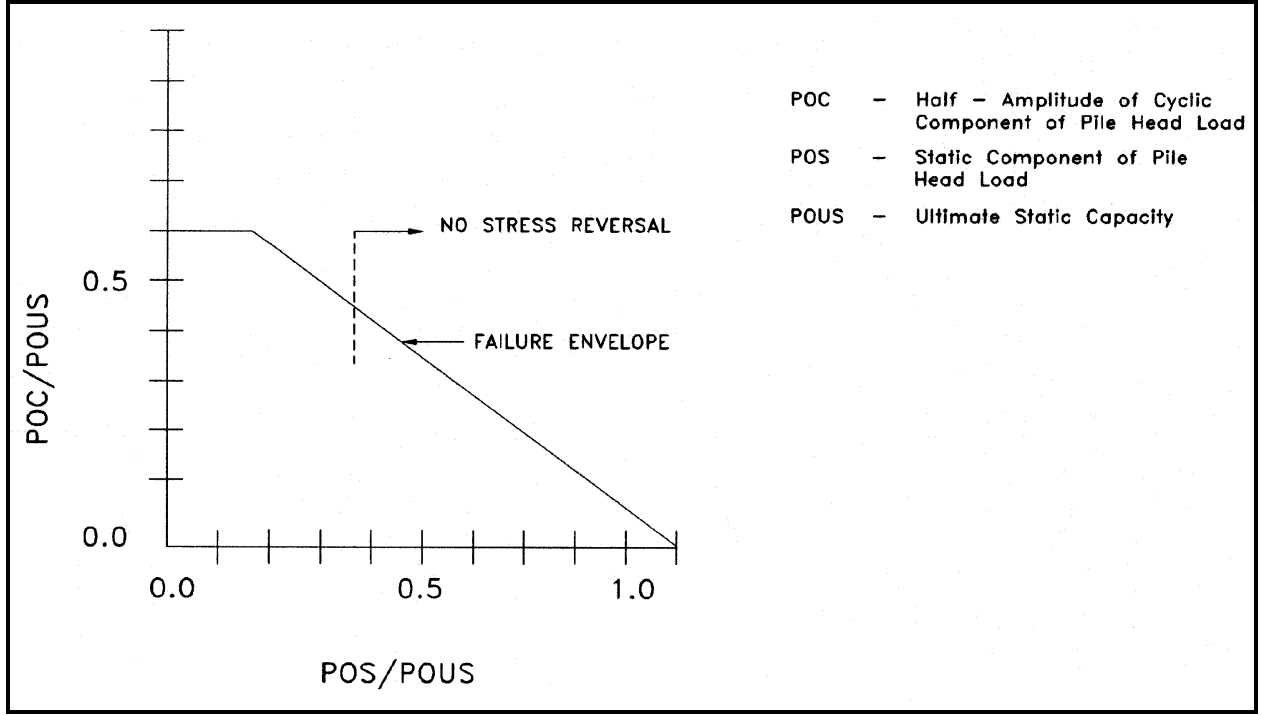

Figure 21. Assessment of degradation due to static loading 


\section{Algorithm for Analysis of Axially Loaded Piles}

The derivation of the $f-w$ and $q-w$ curves from theoretical considerations or from experimental data described in the preceding sections was in all cases based on the assumption that the side friction $f$ or tip reaction $q$ at any point is a function only of the pile displacement at that point (i.e. the well known Winkler assumption). For this assumption and the one-dimensional model of the pile-soil system shown in Figure 2, the governing differential equation for a prismatic, linearly elastic pile is

$E A \frac{d^{2} w}{d z^{2}}-2 \pi R f(z, w)=0$

where

$E=$ modulus of elasticity of the pile material

$A=$ pile material cross section area

$w=$ axial displacement

$R=$ effective radius of pile soil interface; and $f(z, w)$ is the unit side friction, which is a function of both position on the pile as well as pile displacement

Because the displacements must be known before the side friction $f(z, w)$ can be determined, numerical iterative solutions of Equation 34 are required. The most common approach to the solution is to replace the continuous pile-soil system with a discretized model (Coyle and Reese 1966, Dawkins 1982, Dawkins 1984) defined by a finite number of nodes along the pile at which displacements and forces are evaluated. The solution proceeds by a succession of trial and correction solutions until compatibility of forces and displacements is attained at every node.

\section{Observations of System Behavior}

An expedient device in obtaining the numerical solutions described above is to replace the nonlinear $f-w$ and $q-w$ curves by equivalent linearly elastic springs during each iteration. The stiffnesses of these linear springs are evaluated as the secant to the $f-w$ or $q-w$ curve for the displacement calculated during the preceding iteration. It is to be noticed that ultimate side friction increases with depth while pile displacements decrease with depth. Hence it can be concluded that the stiffness of the load transfer mechanism for side friction increases with depth. If the distribution of the side friction for any given head load can be determined then a solution may be obtained from a linearly elastic solution without the need for iterations. 


\section{Single Laterally Loaded Pile Analysis}

\section{Introduction}

Although the usual application of a pile foundation results primarily in axial loading, there exist numerous situations in which components of load at the pile head produce significant lateral displacements as well as bending moments and shears. Unlike axial loads, which only produce displacements parallel to the axis of the pile (a one-dimensional system), lateral loads may produce displacements in any direction. Unless the pile cross section is circular, the laterally loaded pile/soil system represents a three-dimensional problem. Most of the research on the behavior of laterally loaded piles has been performed on piles of circular cross section in order to reduce the three-dimensional problem to two

dimensions. Little work has been done to investigate the behavior of noncircular cross section piles under generalized loading. In many applications, battering of the piles in the foundation produces combined axial and lateral loads. However, the majority of the research on lateral load behavior has been restricted to vertical piles subjected to loads which produce displacements perpendicular to the axis of the pile. In the discussions which follow, it is assumed that the pile has a straight centroidal vertical axis. If the pile is nonprismatic and has a noncircular cross section, it is assumed that the principal axes of all cross sections along the pile fall in two mutually perpendicular planes and that the loads applied to the pile produce displacements in only one of the principal planes.

A schematic of a laterally loaded pile is shown in Figure 22. The $\mathrm{x}-\mathrm{z}$ plane is assumed to be a principal plane of the pile cross section. Due to the applied head shear $V_{\mathrm{o}}$ and head moment $M_{\mathrm{o}}$, each point on the pile undergoes a translation $\mathrm{u}$ in the $\mathrm{x}$-direction and a rotation $\theta$ about the $\mathrm{y}$-axis. Displacements and forces are positive if their senses are in a positive coordinate direction. The surrounding soil develops pressures, denoted $p$ in Figure 22, which resist the lateral displacements of the pile.

The principles of continuum mechanics and correlations with the results of tests of instrumented laterally loaded piles have been used to relate the soil 


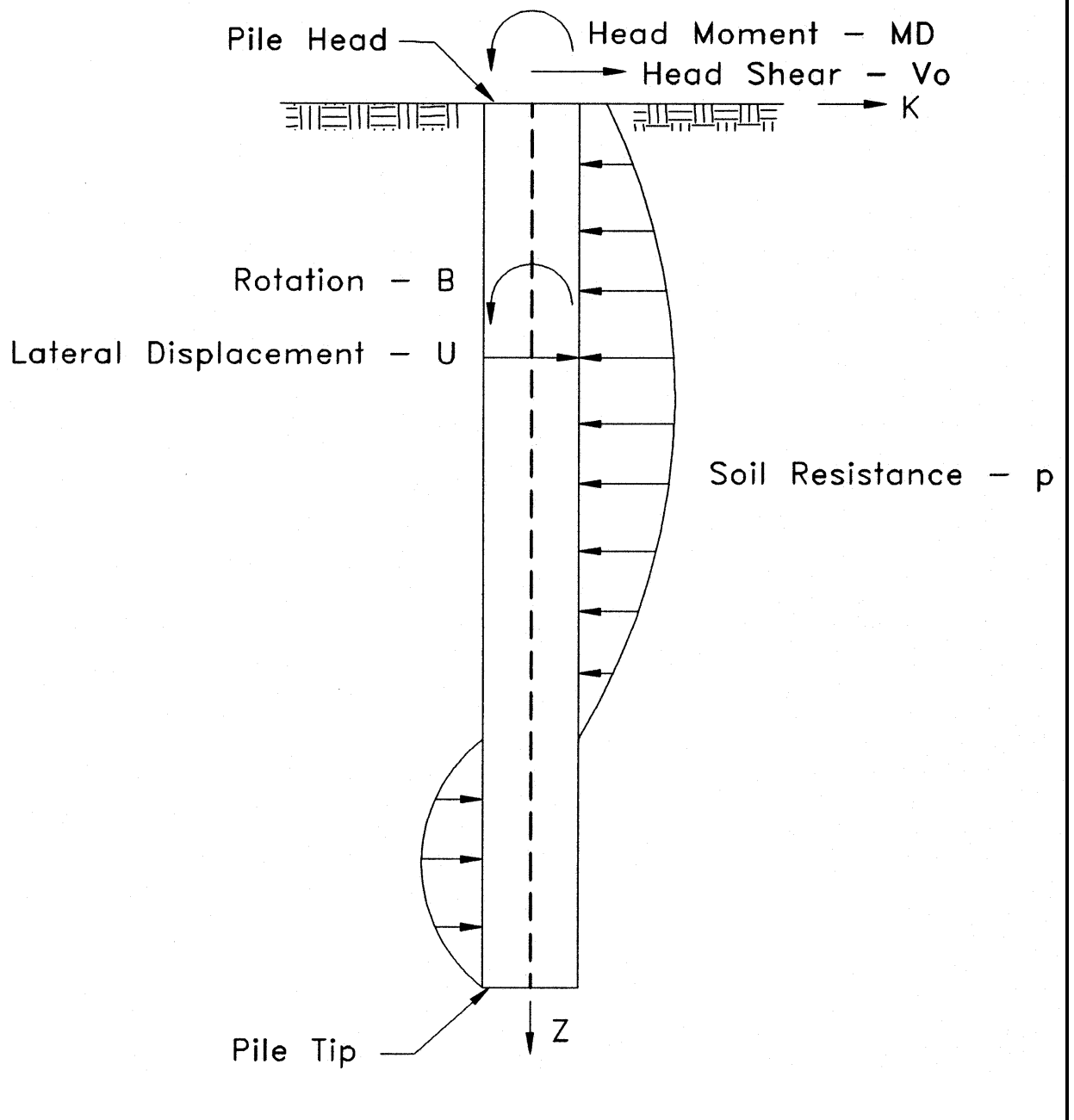

Figure 22. Laterally loaded pile

lateral resistance $p$ at each point on the pile to the lateral displacement $u$ at that point (i.e. the Winkler assumption). The relationship between soil resistance and

lateral displacement is presented as a nonlinear curve - the $p$ - $u$ curve. Several methods are summarized in the following paragraphs for development of $p-u$ curves for laterally loaded piles in both sands and clays. In all of the methods, the primary $p-u$ curve is developed for monotonically increasing static loads. The static curve is then altered to account for the degradation effects produced by cyclic loads such as might be produced by ocean waves on offshore structures. Methods designated SLAT1 and CLAT1 through CLAT4 have been incorporated into the CASE Project Computer program CPGS. 


\section{Load Transfer Mechanism for Laterally Loaded Piles}

The load transfer mechanism for laterally loaded piles is much more complex than that for axially loaded piles. In an axially loaded pile the axial displacements and side friction resistances are unidirectional (i.e., a compressive axial head load produces downward displacements and upward side friction resistance at all points along the pile). Similarly, the ultimate side friction at the pile-soil interface depends primarily on the soil shear strength at each point along the pile. Because the laterally loaded pile is at least two-dimensional, the ultimate lateral resistance of the soil is dependent not only on the soil shear strength but on a geometric failure mechanism. At points near the ground surface an ultimate condition is produced by a wedge type failure, while at lower positions failure is associated with plastic flow of the soil around the pile as displacements increase. In each of the methods described below, two alternative evaluations are made for the ultimate lateral resistances at each point on the pile, for wedge type failure and for plastic flow failure, and the smaller of the two is taken as the ultimate resistance.

\section{Synthesis of p-u Curves for Piles in Sand}

\section{Reese, Cox, and Koop (1974)}

A series of static and cyclic lateral load tests were performed on pipe piles driven in submerged sands (Cox, Reese, and Grubbs 1974; Reese, Cox, and Koop 1974; Reese and Sullivan 1980). Although the tests were conducted in submerged sands, Reese et al. (1980) have provided adjustments by which the $p-u$ curve can be developed for either submerged sand or sand above the water table. The $p-u$ curve for a point a distance $z$ below the pile head extracted from the experimental results is shown schematically in Figure 23. The curve consists of a linear segment from 0 to $a$, an exponential variation of $p$ with $u$ from $a$ to $b$, a second linear range from $b$ to $c$, and a constant resistance for displacements beyond $c$.

Steps for constructing the $p-u$ curve at a depth $z$ below the ground surface are as follows:

a. Determine the slope of the initial linear portion of the curve from

$$
k_{p}=k z
$$

where $k$ is obtained from Table 2 for either submerged sand or sand above the water table. 


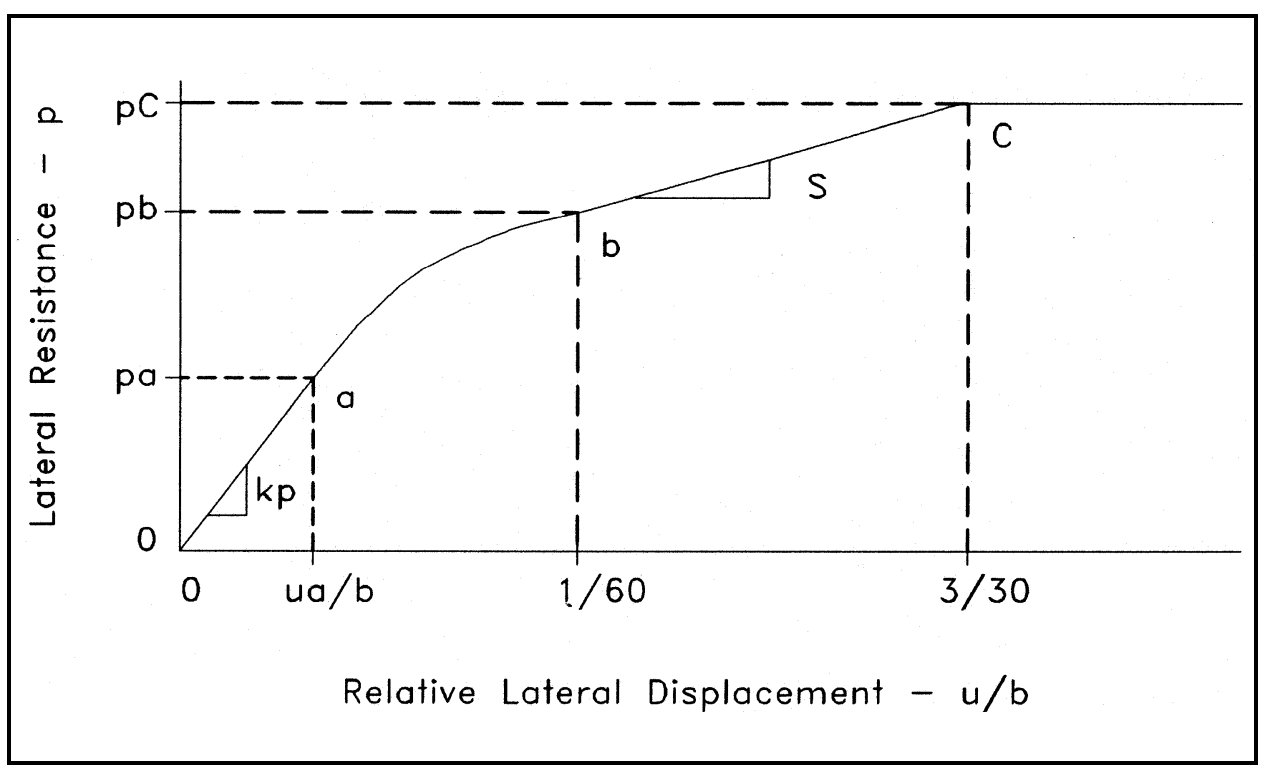

Figure 23. $p$-u curve by Method SLAT1

\begin{tabular}{|c|c|c|c|}
\hline \multicolumn{4}{|c|}{$\begin{array}{l}\text { Table } 2 \\
\text { Representative Values of } k \text { for Method SLAT1 }\end{array}$} \\
\hline \multirow[b]{2}{*}{ Sand } & \multicolumn{3}{|c|}{ Relative Density } \\
\hline & Loose & Medium & Dense \\
\hline Submerged (pci) & 20 & 60 & 125 \\
\hline Above water table (pci) & 25 & 90 & 225 \\
\hline
\end{tabular}

b. Compute the ultimate lateral resistance as the smaller of

$$
p_{s}=(C 1 z+C 2 b) \gamma^{\prime} z
$$

for a wedge failure near the ground surface; or

$$
p_{s}=C 3 b \gamma^{\prime} z
$$

for a flow failure at depth; with

$$
\begin{aligned}
C 1 & =\frac{K \tan \phi \sin \beta}{\tan (\beta-\phi) \cos \phi / 2}+\frac{\tan ^{2} \beta \tan \phi / 2}{\tan (\beta-\phi)} \\
& +K \tan \beta(\tan \phi \sin \beta-\tan \phi / 2) \\
C 2 & =\frac{\tan \beta}{\tan (\beta-\phi)}-\tan ^{2}(45-\phi / 2)
\end{aligned}
$$




$$
C 3=K \tan \phi \tan ^{4} \beta+\tan ^{2}(45-\phi / 2)\left(\tan ^{8} \beta-1\right)
$$

where

$$
\begin{aligned}
& \gamma=\text { effective unit weight of the sand } \\
& z=\text { depth below ground surface }
\end{aligned}
$$

$K=$ horizontal earth pressure coefficient chosen as 0.4 to reflect the fact that the surfaces of the assumed failure model are not planar

$\phi=$ angle of internal friction

$$
\beta=45+\phi / 2
$$

$b=$ width of the pile perpendicular to the direction of loading

Values of $C 1, C 2, C 3$, and the depth $z_{c r}$ at which the transition from wedge failure (Equation 36) to flow failure (Equation 37) occurs are shown in Figure 24.

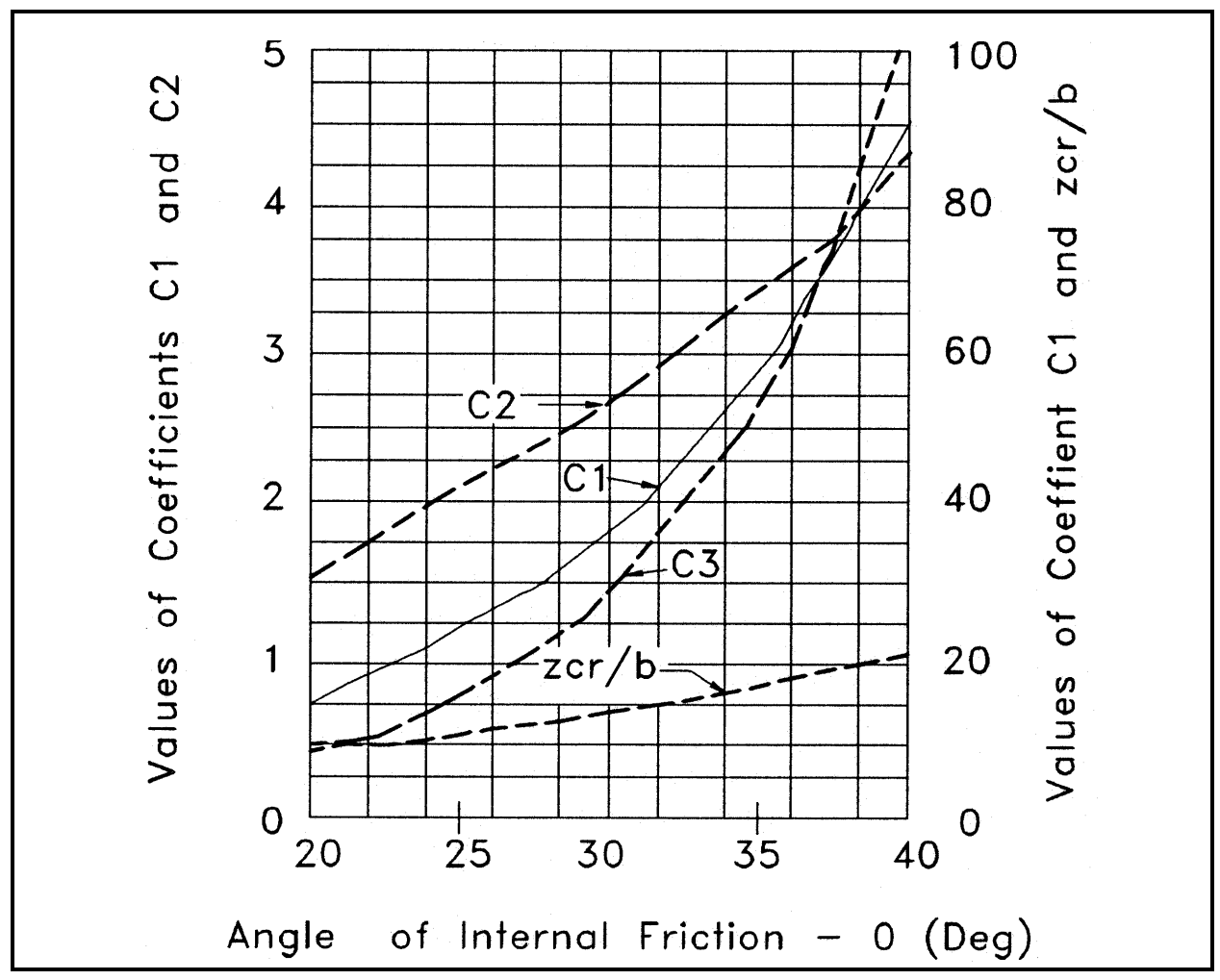

Figure 24. Factors for calculation of ultimate soil resistance for laterally loaded pile in sand 
c. Compute the lateral resistance for the transition points $c$ and $b$ on the curve (Figure 23) from

$$
\begin{aligned}
& p_{c}=A p s \\
& p_{b}=B p s
\end{aligned}
$$

where $A$ and $B$ are reduction coefficients from Figures 25 and 26, respectively, for the appropriate static or cyclic loading condition. The second straight line segment of the curve, from $b$ to $c$, is established by the resistances $p_{b}$ and $p_{c}$ and the prescribed displacements of $u=b / 60$ and $u=3 b / 80$ as shown in Figure 27. The slope of this segment is given by

$$
s=\frac{40\left(p_{c}-p_{b}\right)}{b}
$$

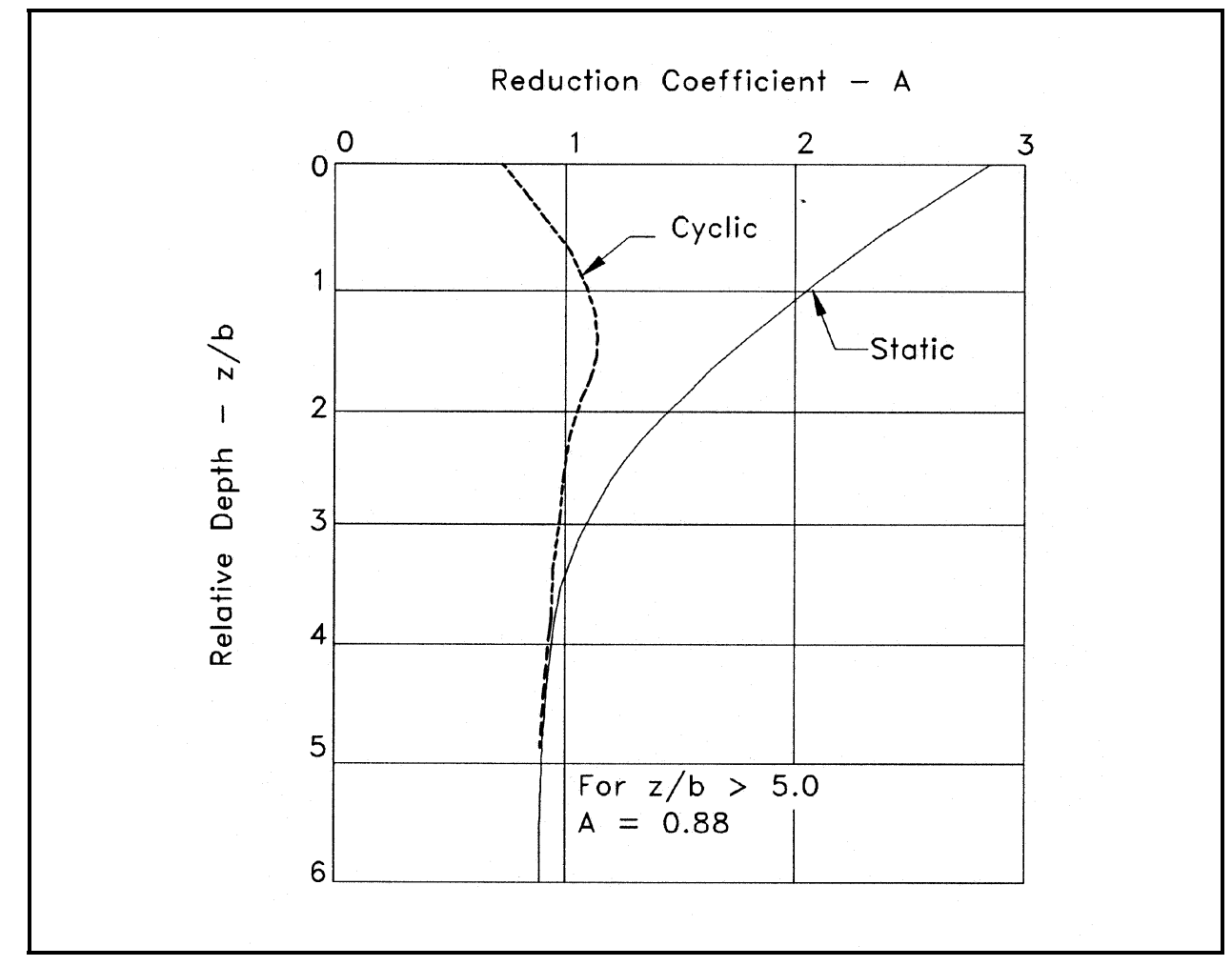

Figure 25. Resistance reduction coefficient - A for Method SLAT1

d. The exponential section of the curve, from $a$ to $b$, is of the form

$$
p=C u^{1 / n}
$$




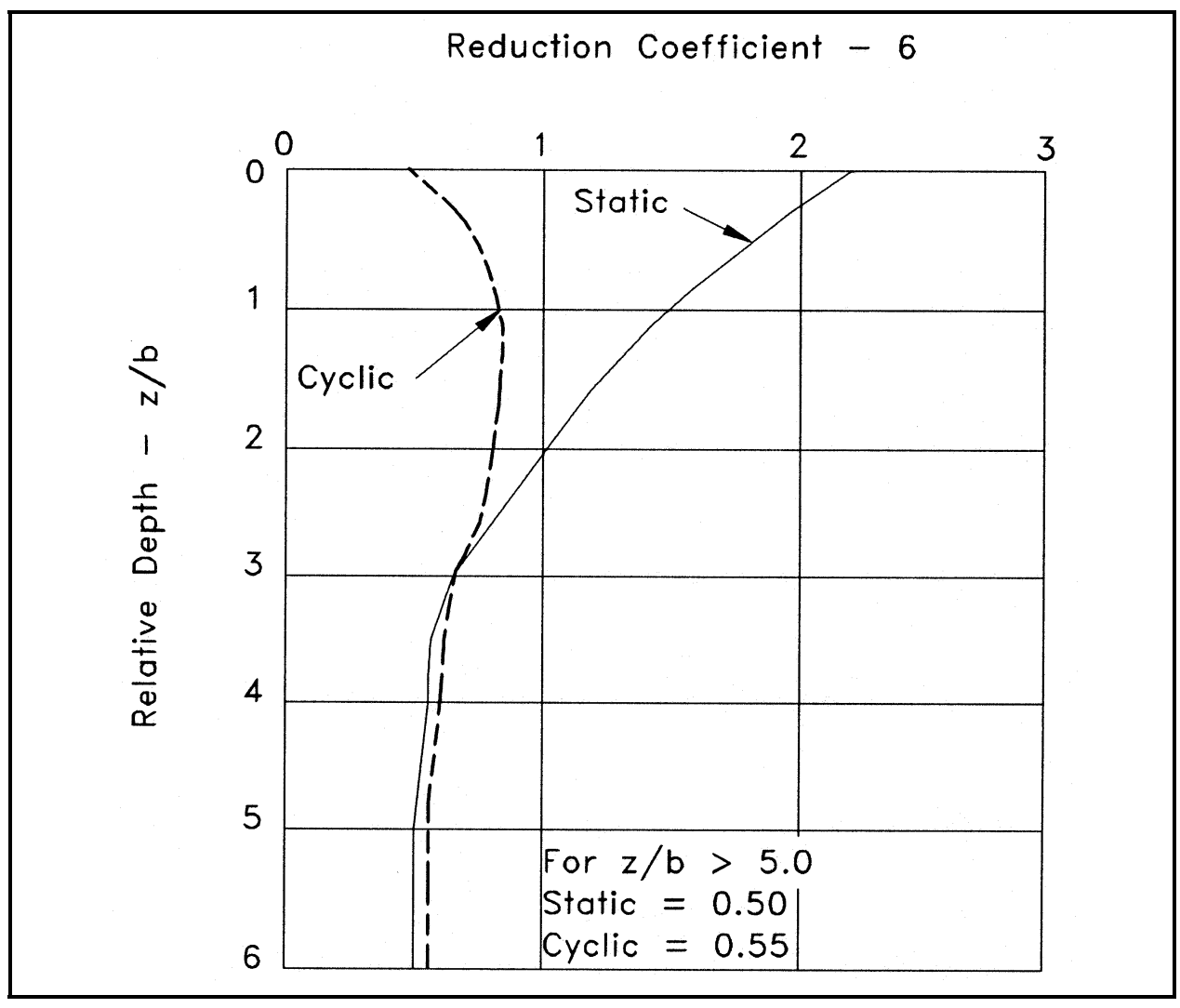

Figure 26. Resistance reduction coefficient - B for Method SLAT1

where the parameters $C, n$, and the terminus of the initial linear portion $p_{a}$ and $u_{a}$ are obtained by forcing the exponential function in Equation 44 to pass through $p_{b}$ and $u_{b}$ with the same slope $s$ as segment $b c$ and to have the slope $k_{p}$ at the terminus of the initial straight line segment at $a$. This results in

$$
\begin{aligned}
& n=\frac{p_{b}}{s u_{b}} \\
& C=\frac{p_{b}}{u_{b}^{1 / n}} \\
& u_{a}=\left(\frac{C}{k_{p}}\right)^{n /(n-1)} \\
& p_{a}=k_{p} u_{a}
\end{aligned}
$$

(Note: In some situations Equations 45 through 48 may result in unrealistic values for $u_{a}$ and/or $p_{a}$. If this occurs, the exponential portion is omitted and the initial linear segment is extended to its intersection with the straight line 


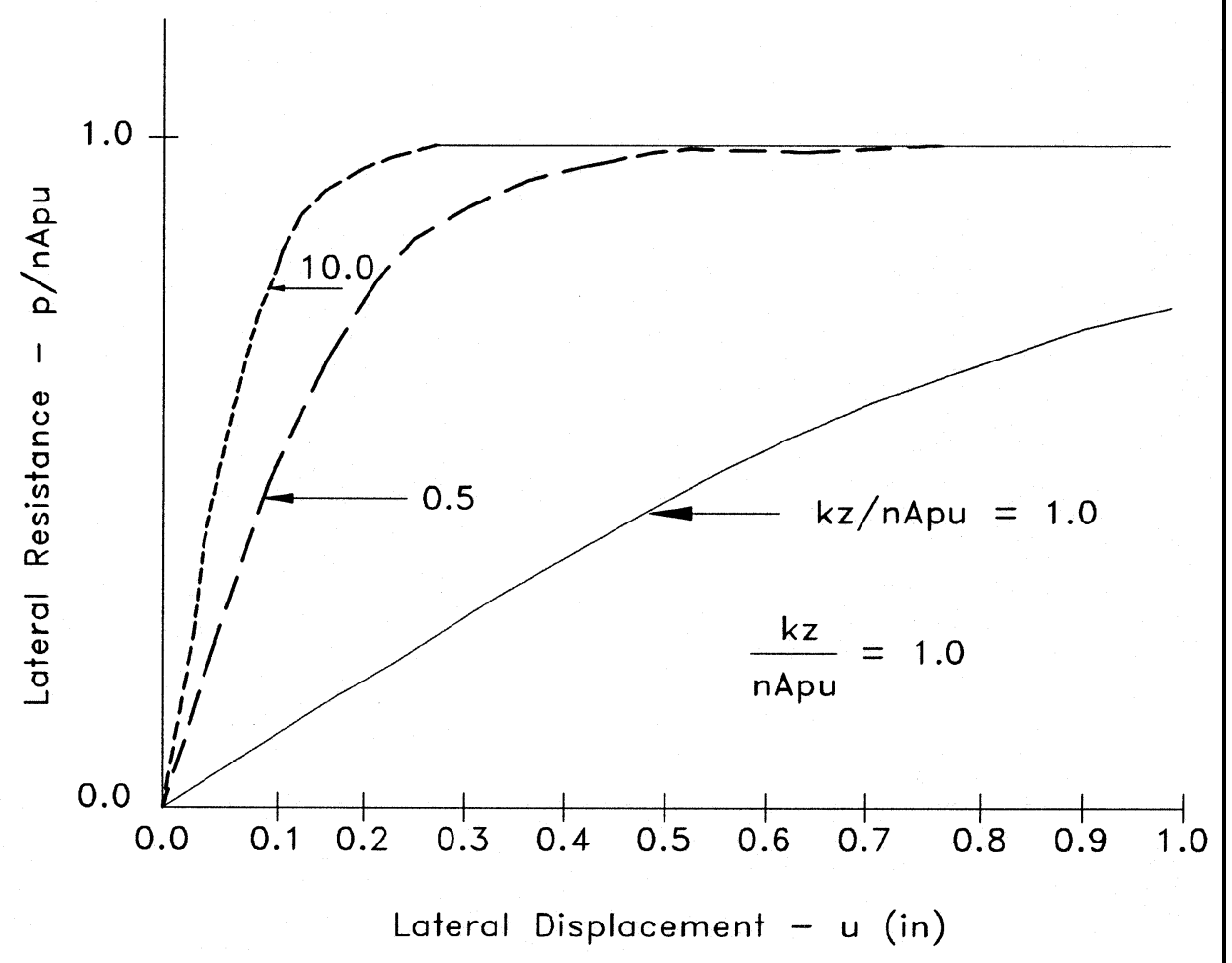

Figure 27. $p$-u curves by Method SLAT2

section $b c$ or until the maximum resistance $p_{c}$ is reached whichever comes first. If segments $O a$ and $b c$ do not intersect at realistic values of $p_{a}$ and $u_{a}$, segment $b c$ is omitted.)

\section{Murchison and O'Neill (1984)}

Murchison and O'Neill (1984) simplified the process of Method SLAT1 by replacing the three-part $p$ - $u$ curve with a single analytical expression as follows.

$$
\frac{p}{p_{u}}=n A \tan h\left(\frac{k z u}{n A p_{u}}\right)
$$

where

$$
\begin{aligned}
& p_{u}=\text { ultimate lateral soil resistance from either Equation } 36 \text { for } z<z_{c r} \text { or } \\
& \quad \text { Equation } 37 \text { for } z>z_{c r} \\
& n=\text { geometry factor }=1.5 \text { for tapered piles or } 1.0 \text { for prismatic piles }
\end{aligned}
$$


$A=3-0.8(z / b) \geq 0.9$ for static loads or $=0.9$ for cyclic loading

$k=$ soil stiffness from Table 2

$z=$ depth at which the $p-u$ curve applies

Several illustrative curves for this method are shown in Figure 27.

\section{Synthesis of $p-u$ Curves for Piles in Clay}

\section{Matlock (1970)}

A series of lateral load tests on instrumented piles in clay (Matlock 1970) were used to produce the $p-u$ relationship for piles in soft to medium clays subjected to static lateral loads in the form

$$
\frac{p}{p_{u}}=0.5\left(\frac{u}{u_{c}}\right)^{1 / 3}
$$

with $p_{u}$, the ultimate lateral resistance, given by the smaller of

$$
p_{u}=\left(3+\frac{\gamma^{\prime}}{s_{u}} z+\frac{J}{b} z\right) s_{u} b
$$

for a wedge failure near the ground surface, or

$$
p_{u}=9 s_{u} b
$$

for flow failure at depth; and $u_{c}$, the lateral displacement at one-half of the ultimate resistance, given by

$$
u_{c}=2.5 \epsilon_{50} b
$$

where

$$
\begin{aligned}
& \gamma^{\prime}=\text { effective unit weight of the soil } \\
& S_{u}=\text { shear strength of the soil } \\
& J=0.5 \text { for a soft clay or } 0.25 \text { for a medium clay } \\
& \epsilon_{50}=\begin{array}{l}
\text { strain at } 50 \text { percent of the ultimate strength from a laboratory stress- } \\
\text { strain curve }
\end{array}
\end{aligned}
$$


Typical values of $\epsilon_{50}$ are given in Table 3. The depth at which failure transitions from wedge (Equation 51) to flow (Equation 52) is

$$
z_{c r}=\frac{6 s_{u} b}{\left(\gamma^{\prime} b+J s_{u}\right)}
$$

The static $p-u$ curve is illustrated in Figure 28a.

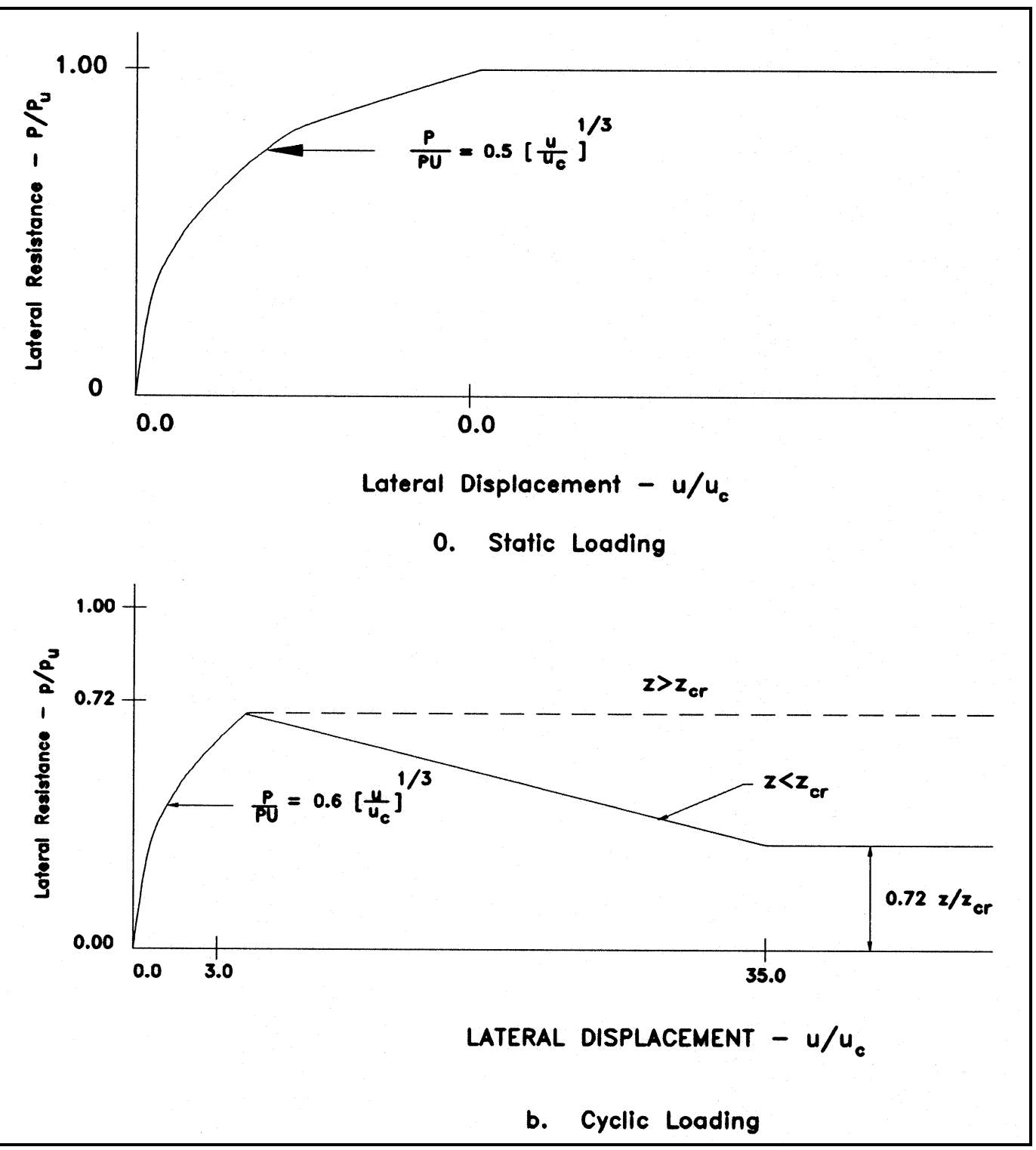

Figure 28. $p$-u curves by Method CLAT1

For cyclic loads, the basic $p$ - $u$ curve for static loads is altered as shown in Figure 28b. The exponential curve of Equation 50 is terminated at a relative displacement $u / u_{c}=3.0$ at which the resistance diminishes with increasing displacement for $z<z_{c r}$ or remains constant for $z>z_{c r}$. 


\begin{tabular}{|c|c|}
\hline \multicolumn{2}{|c|}{$\begin{array}{l}\text { Table } 3 \\
\text { Representative Values of } \epsilon_{50}\end{array}$} \\
\hline Shear Strength (psf) & Percent \\
\hline $250-500$ & 0.02 \\
\hline $500-1,000$ & 0.01 \\
\hline $1,000-2,000$ & 0.007 \\
\hline $2,000-4,000$ & 0.005 \\
\hline $4,000-8,000$ & 0.004 \\
\hline
\end{tabular}

\section{Reese, Cox, and Koop (1975)}

Reese, Cox, and Koop (1975) performed lateral load tests of instrumented piles to develop $p-u$ curves for piles in stiff clay below the water table. The $p-u$ curve for static loading, Figure 29, consists of five segments determined as follows.

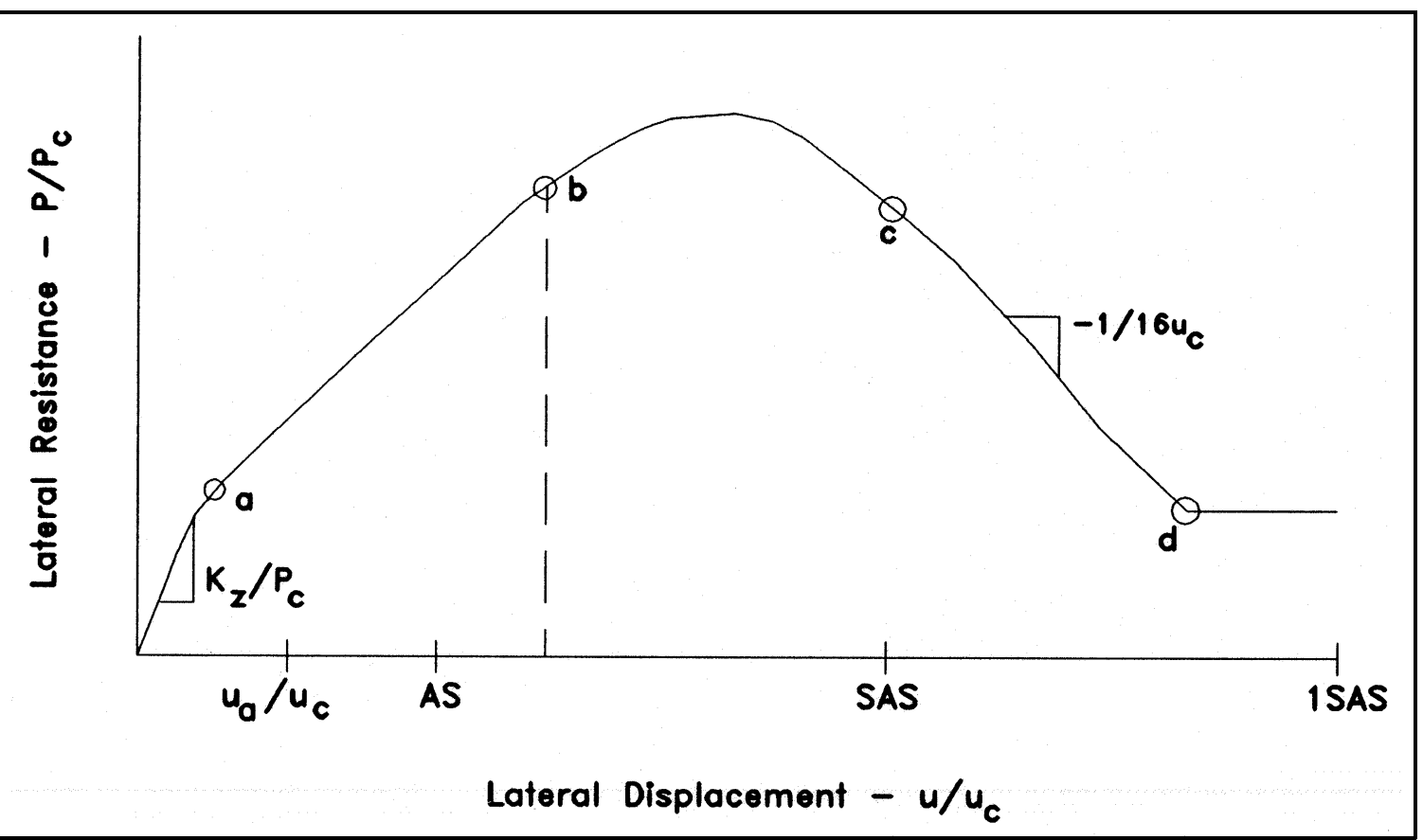

Figure 29. $p$-u curves by Method CLAT2 for static loads

a. The initial linear $p-u$ relationship $0 \mathrm{a}$ has a slope equal to the product of soil stiffness $k$ (see Table 4) and the depth $z$ to the location at which the curve applies. 


\begin{tabular}{|c|c|c|c|}
\hline \multicolumn{4}{|c|}{$\begin{array}{l}\text { Table } 4 \\
\text { Representative Values of Lateral Soil Stiffness } k \text { for Piles in Clay } \\
\text { for Method CLAT2 }\end{array}$} \\
\hline \multirow[b]{2}{*}{ Loading Type } & \multicolumn{3}{|c|}{ Average Undrained Shear Strength (tsf) ${ }^{1}$} \\
\hline & $0.5-1$ & $1-2$ & $2-4$ \\
\hline Static loading $-k_{s}(\mathrm{pci})$ & 500 & 1,000 & 2,000 \\
\hline Cyclic loading $-k_{c}(\mathrm{pci})$ & 200 & 400 & 800 \\
\hline
\end{tabular}

$b$. The second segment of the curve is parabolic of the form

$$
\frac{p}{p_{c}}=\frac{1}{2}\left(\frac{u}{u_{c}}\right)^{1 / 2}
$$

with $p_{c}$ taken as the smaller of

$$
p_{c}=\left(2+\frac{\gamma^{\prime}}{s_{u}} z+2.83 \frac{z}{b}\right) s_{u} b
$$

for wedge failure near the ground surface, or

$$
p_{c}=11 s_{u} b
$$

and

$$
u_{c}=\epsilon_{50} b
$$

where $\epsilon_{50}=$ strain at 50 percent of ultimate strength from a laboratory stressstrain curve; and the parameter $A$ for defining pertinent displacements in Figure 29 is obtained from the curve shown in Figure 30.

c. Points $a$ and $b$, Figure 29, are joined by a parabolic curve of the form

$$
\frac{p}{p_{c}}=\frac{1}{2}\left(\frac{u}{u_{c}}\right)^{1 / 2}
$$

where $p_{c}$ is the smaller of

$$
p_{c}=\left(2+\frac{\gamma^{\prime}}{s_{u}} z+2.83 \frac{z}{s_{u}}\right) s_{u} b
$$




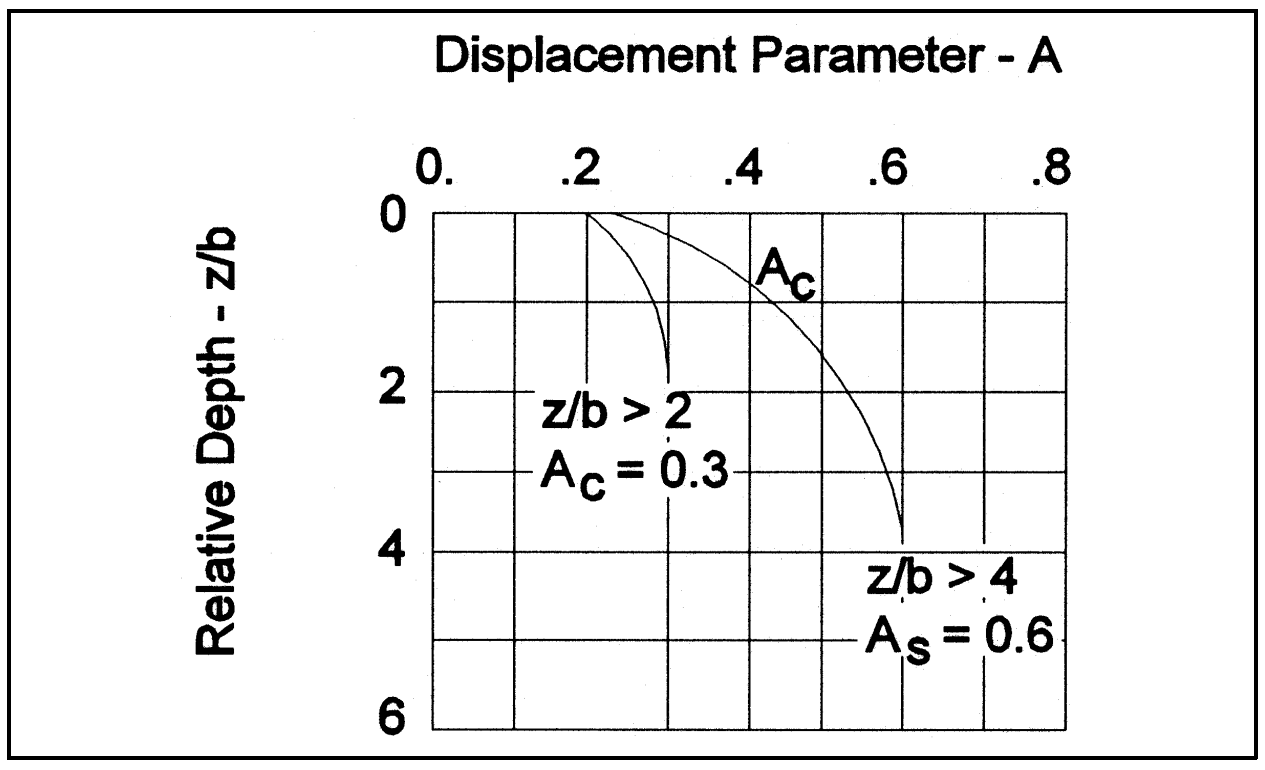

Figure 30. Displacement parameter - A for Method CLAT2

for a wedge failure near the ground surface, or

$$
p_{c}=11 s_{u} b
$$

for a flow failure at depth; and

$$
u_{c}=\epsilon_{50} b
$$

where

$$
\begin{aligned}
\gamma^{\prime} & =\text { effective unit weight of the soil } \\
S_{u}= & \text { undrained shear of the soil } \\
\epsilon_{50}= & \text { strain at } 50 \text { percent of ultimate strength from a laboratory stress-strain } \\
& \text { curve (see Table } 3 \text { ) }
\end{aligned}
$$

The parameter $A_{\mathrm{s}}$ in Figure 29 is obtained from Figure 30.

d. Segment $c d$ of the $p$ - $u$ curve in Figure 29 is of the form

$$
\frac{p}{p_{c}}=\frac{1}{2}\left(\frac{u}{u_{c}}\right)^{1 / 2}-0.055\left(\frac{u}{A_{s} u_{c}}-1\right)^{1.25}
$$

e. A second linear segment joins points $c$ and $d$ at the slope indicated in Figure 29 and the lateral resistance remains constant for lateral displacements greater than $u=18 A_{s} u_{c}$. 
The $p-u$ curve for cyclic loading provided by Reese, Cox, and Koop (1975) is illustrated in Figure 31. The curve is constructed as follows

a. The initial linear $p-u$ relationship 0 a has a slope equal to the product of soil stiffness $k$ (see Table 4 ) and the depth $z$ to the location at which the curve applies.

$b$. The second segment, joining points $a$ and $b$ (Figure 31) is an exponential relationship of the form

$$
\frac{p}{A_{c} p_{c}}=1-\left[\operatorname{abs}\left(\frac{u}{0.45 u_{p}}-1\right)\right]^{2.5}
$$

where

$A_{c}=$ pressure reduction coefficient from Figure 30

$p_{c}=$ ultimate soil resistance from Equation 56 or 57 (whichever is less)

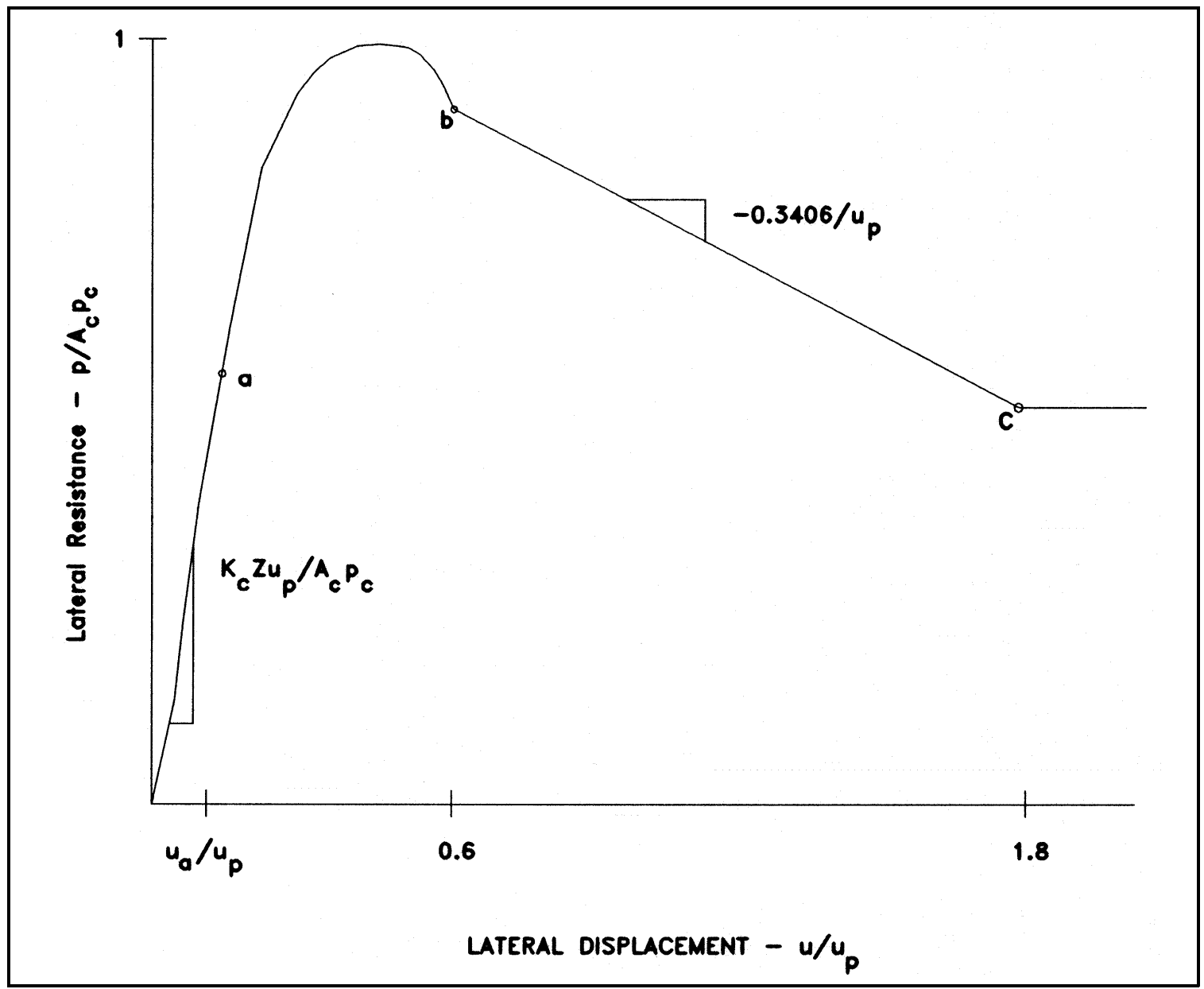

Figure 31. $p$-u curve by Method CLAT2 for cyclic loads 
and

$$
u_{p}=4.1 A_{c} u_{c}
$$

where $u_{c}$ is given by Equation 62 .

c. A second linear p-u relationship joins points $b$ and $c$ with the slope shown in Figure 31. For displacements greater than $u=1.8 u_{p}$, the lateral resistance remains constant.

\section{Reese and Welch (1975)}

Reese and Welch (1975) performed a lateral load test on an instrumented drilled shaft in stiff clay above the water table. The $p$ - $u$ curve obtained from the experimental results for static loads is shown in Figure 32. The curve consists of an exponential relationship between lateral resistance and displacement to an ultimate resistance, after which the resistance remains constant for further displacement. The requisite exponential relationship is

$$
\frac{p}{p_{u}}=\frac{1}{2}\left(\frac{u}{u_{c}}\right)^{1 / 4}
$$

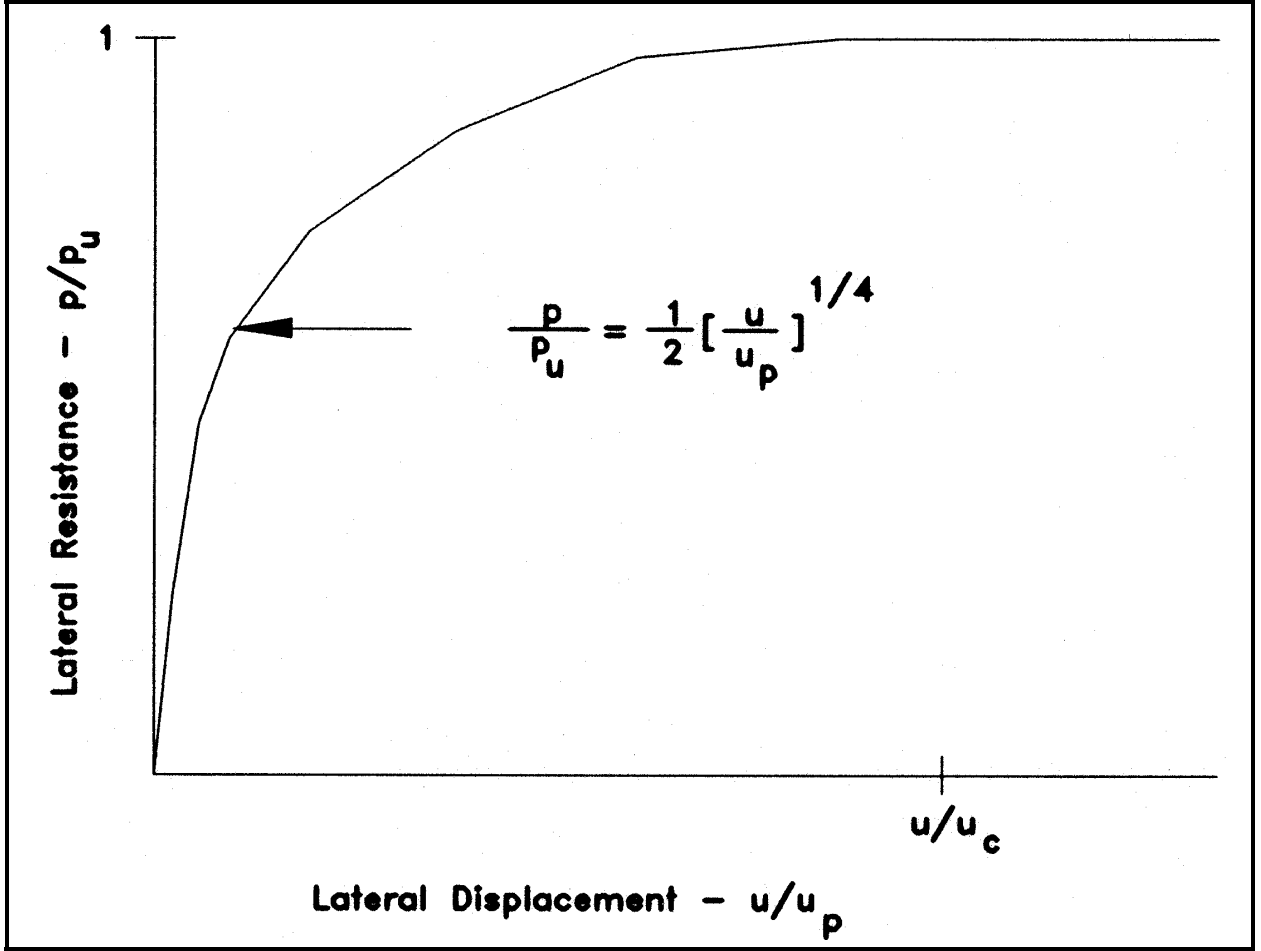

Figure 32. $p$ - $u$ curve by Method CLAT3 for static loads 
where

$p_{u}=$ ultimate resistance obtained as the smaller from Equation 51 with $J=0.5$ or from Equation 52

$u_{c}=$ critical lateral displacement obtained from Equation 88

The $p-u$ curve for cyclic loading, shown in Figure 33, is constructed as follows:

a. Values of $p / p_{u}$ for various values of static displacement $u_{s} / u_{c}$ are computed from Equation 66.

$b$. The displacement for cyclic loading for each value of $p / p_{u}$ is obtained from

$$
\frac{u}{u_{c}}=\frac{u_{s}}{u_{c}}+9.6\left(\frac{p}{p_{u}}\right)^{4} \log (N)
$$

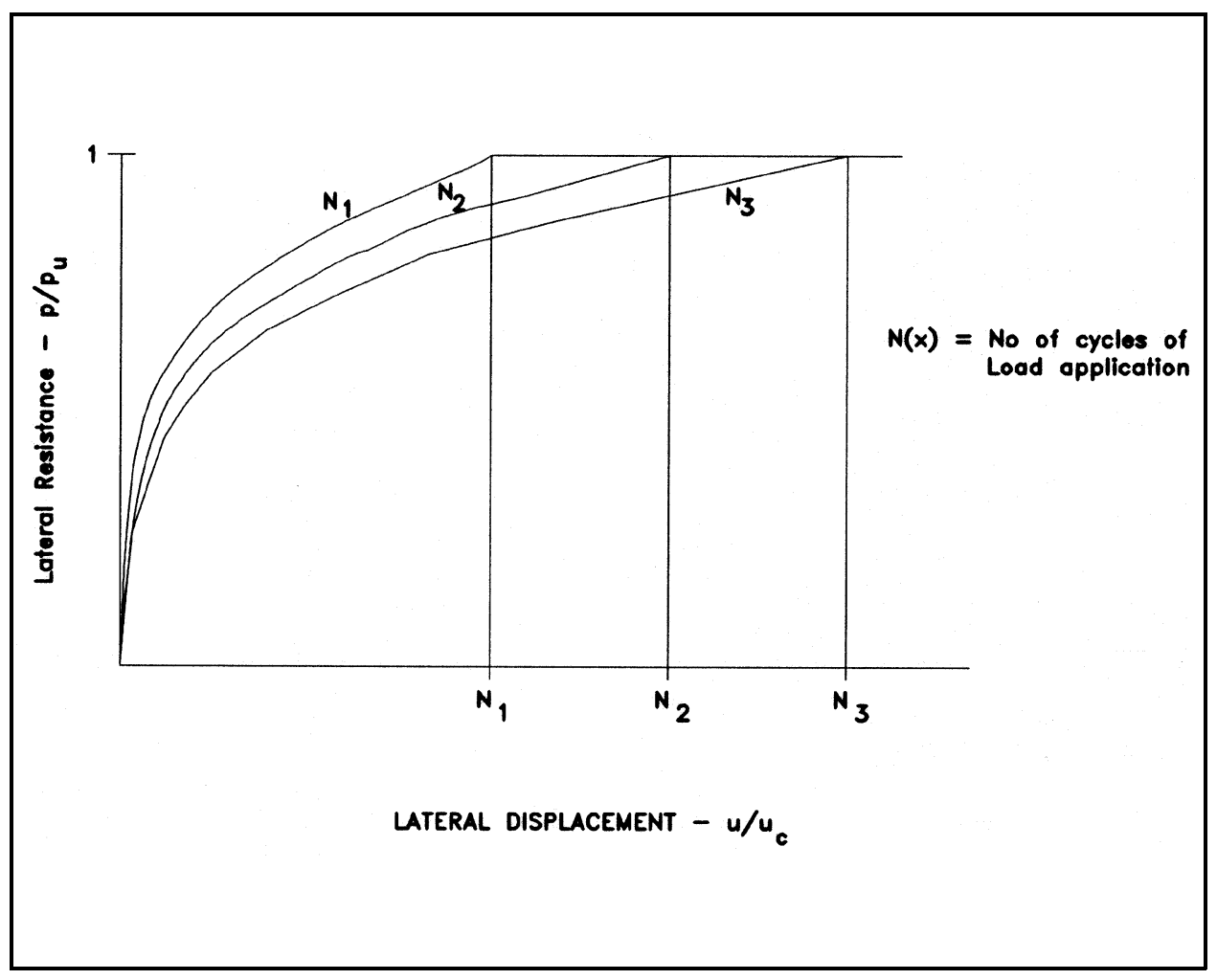

Figure 33. $p$ - $u$ curve by Method CLAT3 for cyclic loads 
where

$$
\begin{aligned}
& u_{\mathrm{s}}=\text { static displacement corresponding to } p / p_{u} \\
& N=\text { number of cycles of load application }
\end{aligned}
$$

\section{Reese and Sullivan (1980)}

Each method for $p-u$ curves for piles in clay described above was developed for a single soil profile; hence there were no recommendations provided for transitioning from "soft" clay criteria to "stiff" clay criteria. Sullivan (1977) and Sullivan, Reese, and Fenske (1979) reexamined the data for soft clays (Matlock 1970) and stiff clays (Reese, Cox, and Koop 1975) and developed a unified criterion (Reese and Sullivan 1980), which yields computed behaviors that are in reasonable agreement with both soft and stiff conditions. However, some judgement on the part of the user is required in selecting appropriate parameters for use in the prediction equations.

The $p$ - $u$ curve by the unified criteria for static loading, illustrated in Figure 34, consists of an initial linear segment $0 \mathrm{a}$, an exponential segment $a b$, a second linear segment $b c$ and a constant lateral resistance for large displacements. The curve for static loading at a particular depth $z$ is constructed as follows:

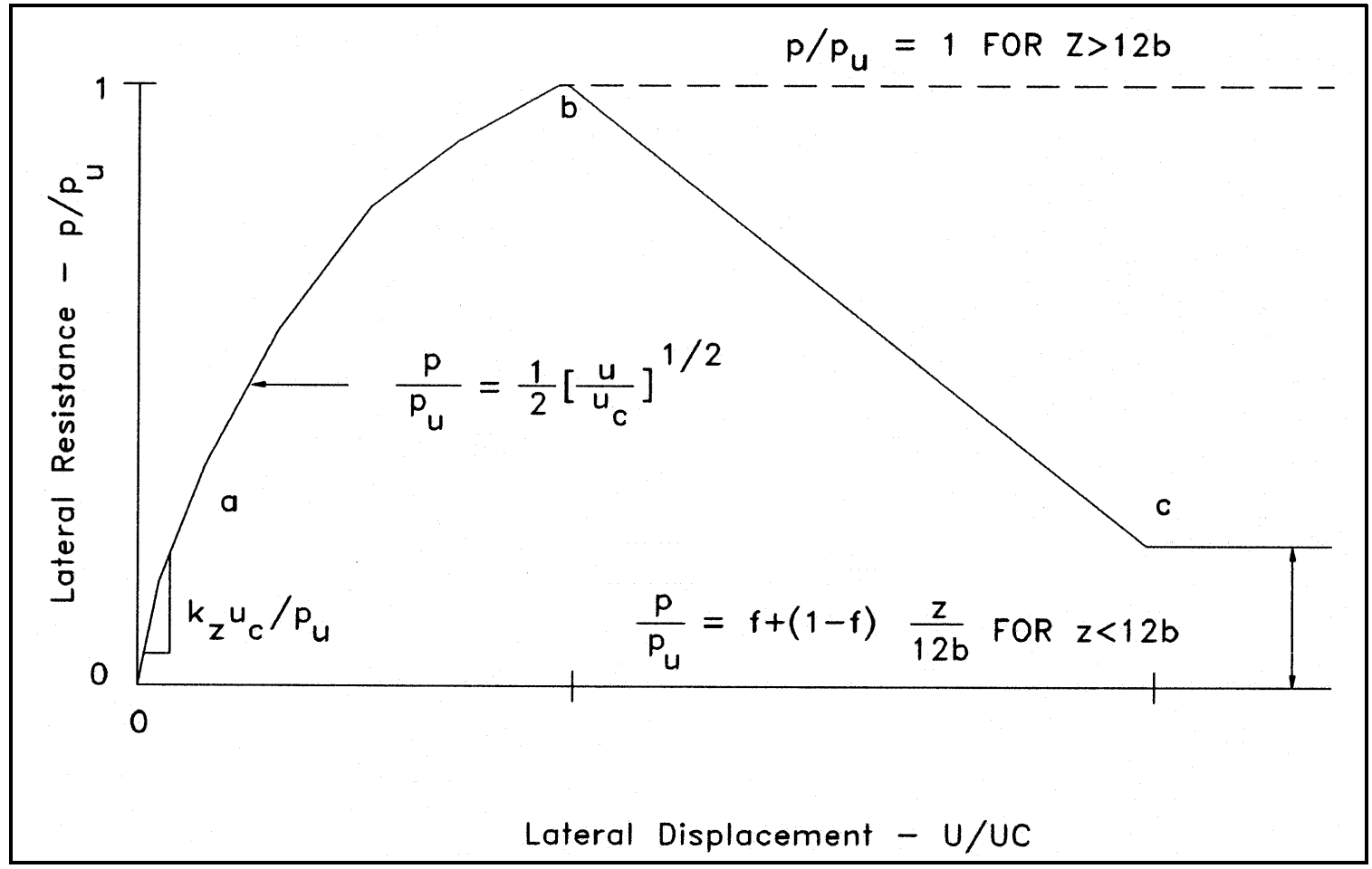

Figure 34. $p$-u curve by Method CLAT4 for static loading 
a. The ultimate lateral resistance is

(1) For $z<12 b$, the ultimate resistance is the smaller of

$$
\begin{aligned}
& p_{u}=\left(2+\frac{\bar{\sigma}_{v}}{c_{a}}+0.833 \frac{z}{b}\right) c_{a} b \\
& p_{u}=\left(3+0.5 \frac{z}{b}\right) c b
\end{aligned}
$$

where

$$
\begin{aligned}
& \bar{\sigma}_{\mathrm{v}}=\text { average effective vertical stress over the depth } z \\
& c_{a}=\text { average cohesion over the depth } z \\
& c=\text { cohesion at depth } z \\
& b=\text { pile diameter }
\end{aligned}
$$

(2) For $z>12 b$, the ultimate resistance is

$$
p_{u}=12 c b
$$

$b$. Compare the properties of the soil profile under analysis with those listed in Table 5 and select the values of parameters $A$ and $F$ to be used in the following calculations.

$c$. The $p-u$ relationship for the initial linear segment is

$$
\frac{p}{p_{u}}=k z
$$

where $k$ is a stiffness parameter from Table 6 (see also Table 4).

d. The exponential segment $a b$ is obtained from

$$
\frac{p}{p_{u}}=0.5\left(\frac{u}{u_{c}}\right)^{1 / 2}
$$

with

$$
u_{c}=A \epsilon_{50} b
$$




\begin{tabular}{|c|c|c|c|}
\hline \multicolumn{4}{|c|}{$\begin{array}{l}\text { Table } 5 \\
\text { Curve Parameters for Method CLAT4 }\end{array}$} \\
\hline \multirow[b]{2}{*}{ Clay Description } & & \multicolumn{2}{|c|}{ Curve Parameters } \\
\hline & & A & $\mathbf{F}$ \\
\hline \multicolumn{2}{|l|}{ Soft, inorganic, intact } & & \\
\hline Cohesion & $\begin{array}{l}=300 \mathrm{psf} \\
=0.7 \%\end{array}$ & & \\
\hline Overconsolidation ratio & $=1$ & & \\
\hline Sensitivity & $=2$ & 2.5 & 1.0 \\
\hline Liquid limit & $=92$ & & \\
\hline Plasticity index & $=68$ & & \\
\hline Liquidity index & $=1$ & & \\
\hline \multicolumn{2}{|c|}{ Stiff, inorganic, very fissured } & & \\
\hline Cohesion & $\begin{array}{l}=2,400 \mathrm{psf} \\
=0.5 \%\end{array}$ & & \\
\hline Overconsolidation ration & $>10$ & & \\
\hline Sensitivity & $=1$ & 0.35 & 0.5 \\
\hline Liquid limit & $=77$ & & \\
\hline Plasticity index & $=60$ & & \\
\hline Liquidity index & $=0.2$ & & \\
\hline
\end{tabular}

\section{Table 6}

Representative Values of $\boldsymbol{k}$ for Method CLAT4

\begin{tabular}{||l|l||}
\hline \hline Cohesion (psf) & $\boldsymbol{k}$ (pci) \\
\hline \hline $200-500$ & 30 \\
\hline $500-1,000$ & 100 \\
\hline $1,000-2,000$ & 300 \\
\hline $2,000-4,000$ & 1,000 \\
\hline $4,000-8,000$ & 3,000 \\
\hline
\end{tabular}

e. The second linear portion extends from a displacement $u=8 u_{\mathrm{c}}$ to a displacement $u=30 u_{\mathrm{c}}$ where the lateral resistance is 


$$
\frac{p}{p_{u}}=F+(1-F) \frac{z}{12 b}
$$

for $z<12 b$. For $z>12 b, p / p_{u}=1$.

The $p-u$ curve by the unified method for cyclic loading, Figure 35, also consists of an initial linear segment, followed by an exponential variation of $p$ with $u$, a second linear segment, and a constant resistance for large displacements. Construction of the curve for cyclic loading follows the same steps as for the static curve, with the exceptions that the exponential segment terminates at a resistance equal to one half of $p_{\mathrm{u}}$, the second linear segment terminates at a displacement $u=20 u_{\mathrm{c}}$, and the constant resistance for $u>20 u_{\mathrm{c}}$ is given by

$$
\frac{p}{p_{u}}=0.5\left(\frac{z}{12 b}\right)
$$

for $z<12 b$. For $z>12 b, p / p_{u}=1$.

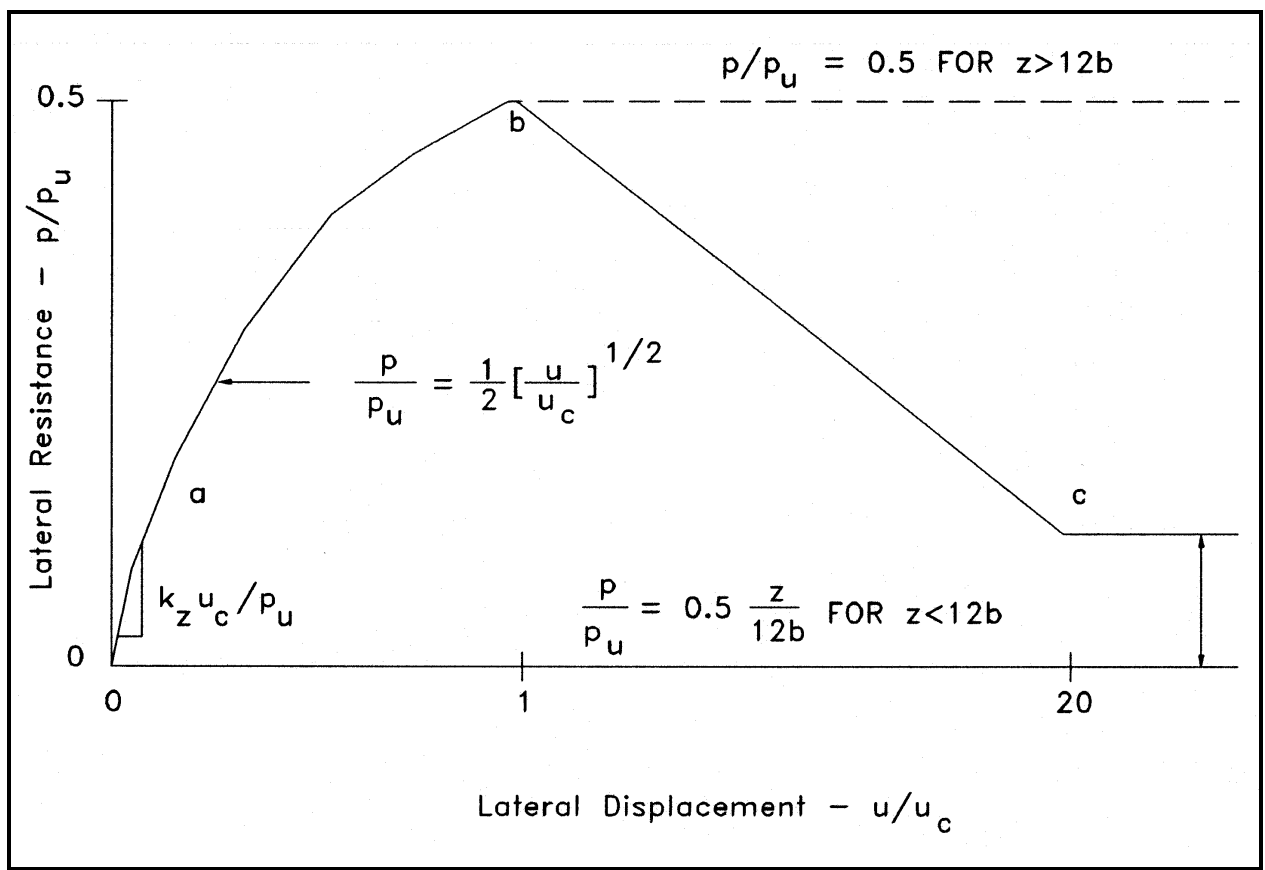

Figure 35. $p$-u curve by Method CLAT4 for cyclic loading

\section{O’Neill and Gazioglu (1984)}

Although the procedure presented as Method CLAT4 attempted to provide a unified criterion for all clays, the procedure requires the user to select parameters a priori which essentially convert the method to a soft-clay-like method or to a stiff-clay-like method (O'Neill and Gazioglu 1984). O’Neill and Gazioglu 
reexamined the data utilized in developing the previous methods as well as the results of other tests of instrumented laterally loaded piles in clay to produce an integrated procedure for $p-u$ curves for piles in clay. The method attempts to incorporate continuum effects and relative pile/soil stiffness characteristics which were not explicitly accounted for in the previous procedures.

O'Neill and Gazioglu, as well as other researchers, reasoned that there exists a critical length of pile such that longer piles no longer influence the pile head behavior. This critical length is presented as

$$
L_{c}=3\left(\frac{E I}{E_{s} b^{1 / 2}}\right)^{0.286}
$$

where $E I=$ flexural stiffness of the pile; and $E_{s}=$ "perhaps a secant Young's modulus at a deviator stress level of one-half of the deviator stress at failure in undrained triaxial compression," with all length units in inches. $E_{s}$ is evaluated for the average UU triaxial shear strength between the ground surface and the depth $L_{c}$. Hence the determination of $L_{c}$ is an iterative process. Representative values of $E_{s}$ are given in Table 7.

\begin{tabular}{|c|c|}
\hline \multicolumn{2}{|c|}{$\begin{array}{l}\text { Table } 7 \\
\text { Soil Modulus for Method CLAT5 }\end{array}$} \\
\hline Undrained Shear Strength $c$ (psf) & Soil Modulus $E_{s}(\mathrm{psi})$ \\
\hline$<500$ & 50 \\
\hline $500-1,000$ & $50-150$ \\
\hline $1,000-2,000$ & $150-450$ \\
\hline $2,000-4,000$ & $450-1,500$ \\
\hline $4,000-8,000$ & $1,500-5,000$ \\
\hline$>8,000$ & 5,000 \\
\hline
\end{tabular}

The reference lateral displacement $u_{c}$ (see Equations 53, 58, 62, and 73) is obtained from

$$
u_{c}=A^{\prime} \epsilon_{50} b^{1 / 2}\left(\frac{E I}{E_{s}}\right)^{1 / 8}
$$

where $A^{\prime}=$ constant taken as 0.8 by O'Neill and Gazioglu; $E_{s}=$ soil modulus from Table 7 for the depth of interest; and all length units are in inches.

The ultimate soil resistance is expressed as

$$
p_{u}=F N_{p} c b
$$


where $F=$ reduction factor from Table 8 for the appropriate loading condition; and $N_{\mathrm{p}}$ is given by

$$
N_{p}=3+6 \frac{z}{z_{c r}} \leq 9
$$

\begin{tabular}{||l|l|l|l|l||}
\hline \multicolumn{2}{|l|}{$\begin{array}{l}\text { Table } 8 \\
\text { Soil Degradability Factors }\end{array}$} \\
\hline \hline \multirow{2}{*}{ Factor } & Loading Condition & \multicolumn{3}{|c|}{ UU Triaxial Compression Failure Strain } \\
\cline { 3 - 5 } & & $<.02$ & $\mathbf{0 . 0 2 - 0 . 0 6}$ & $>0.06$ \\
\hline \hline$F_{s}$ & Static & 0.50 & 0.75 & 1.00 \\
\hline$F_{c}$ & Cyclic & 0.33 & 0.67 & 1.00 \\
\hline
\end{tabular}

where $z_{c r}=L_{c} / 4$, indicating a transition from wedge type failure to flow failure at a depth equal to one fourth the critical length which, unlike the previous methods, reflects the relative pile/soil stiffness.

The $p$ - $u$ curves for static load (Figure 36) and cyclic loads (Figure 37) have an initial exponential relationship between lateral resistance and displacement given by

$$
\frac{p}{p_{u}}=0.5\left(\frac{u}{u_{c}}\right)^{0.387}
$$

with the static curve terminating at $p / p_{u}=1$ and the cyclic curve at $p / p_{u}=0.5$. The second linear section of the curves terminates at

$$
\frac{p}{p_{u}}=F_{s}+\left(1-F_{s}\right) \frac{z}{z_{c r}}
$$

and the cyclic curve at

$$
\frac{p}{p_{u}}=0.5 F_{c} \frac{z}{z_{c r}}
$$

where $F_{s}$ and $F_{c}$ are given in Table 8.

\section{Algorithm for Analysis of Laterally Loaded Piles}

The $p-u$ curves described in the preceding paragraphs were derived on the assumption that the lateral resistance $p$ at any point on the pile is a function only of the lateral displacement $u$ at that point (i.e., the Winkler assumption). For this assumption and the one-dimensional model of the pile-soil system shown in 


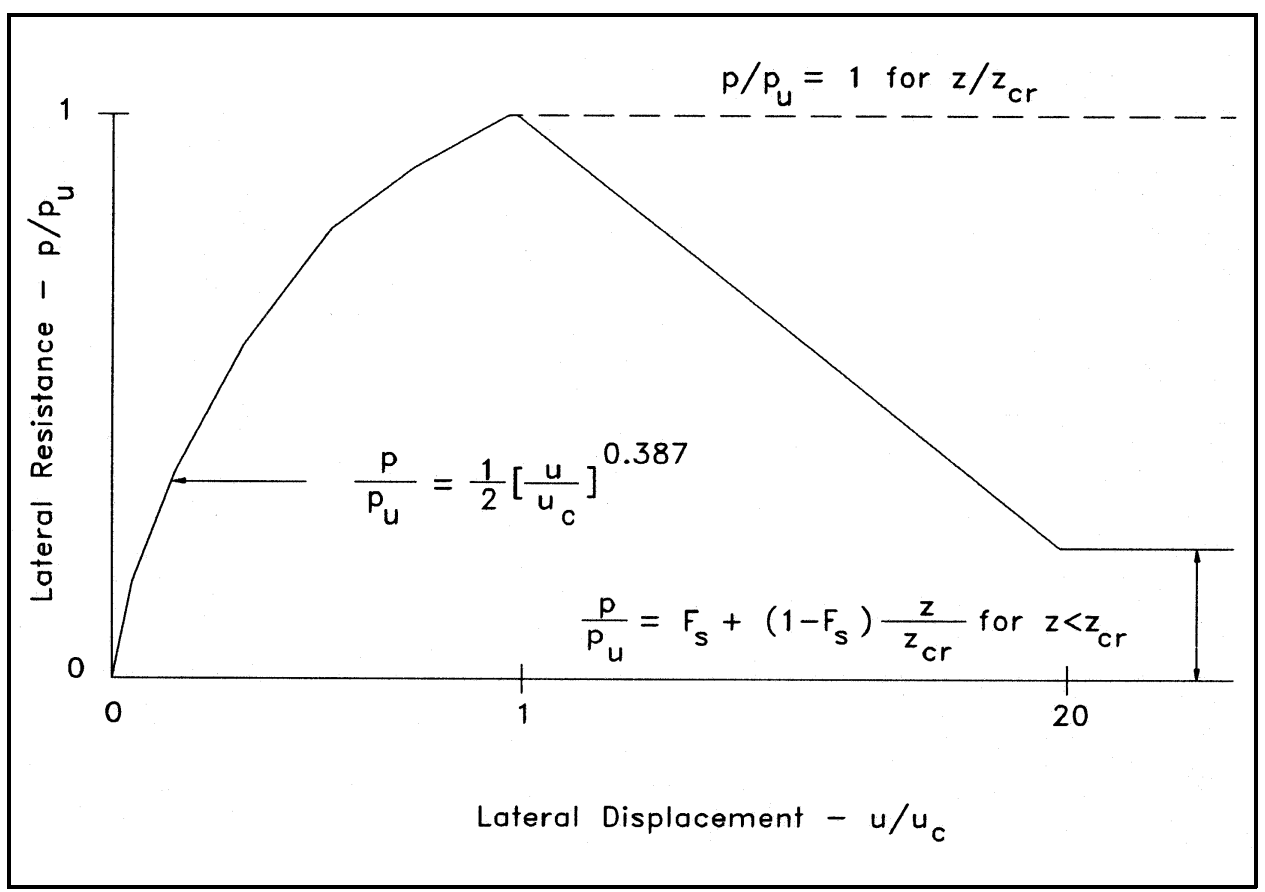

Figure 36. $p-u$ curve by Method CLAT5 for static loading

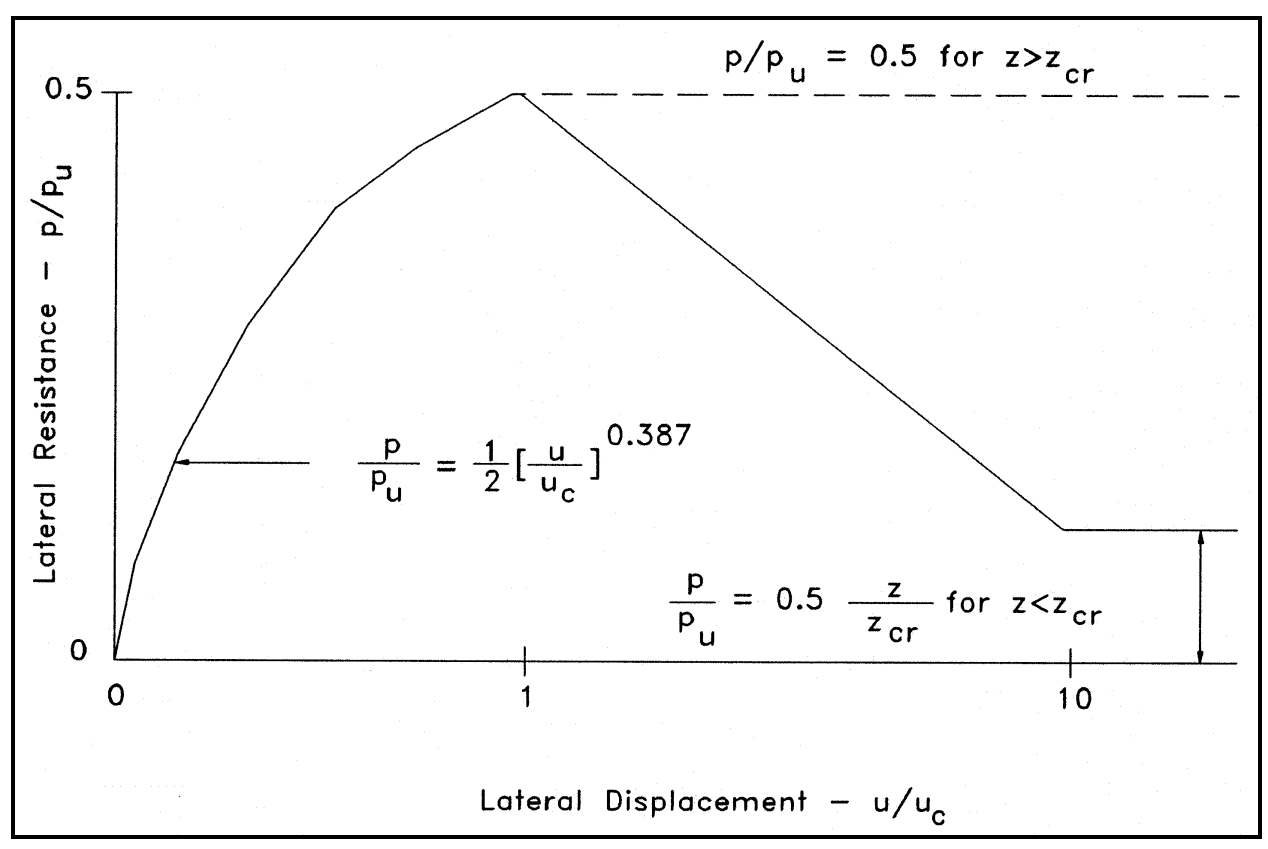

Figure 37. $p-u$ curve by Method CLAT5 for cyclic loading

Figure 38, the governing differential equation for bending in the $x-z$ plane of a prismatic, linearly elastic pile is 


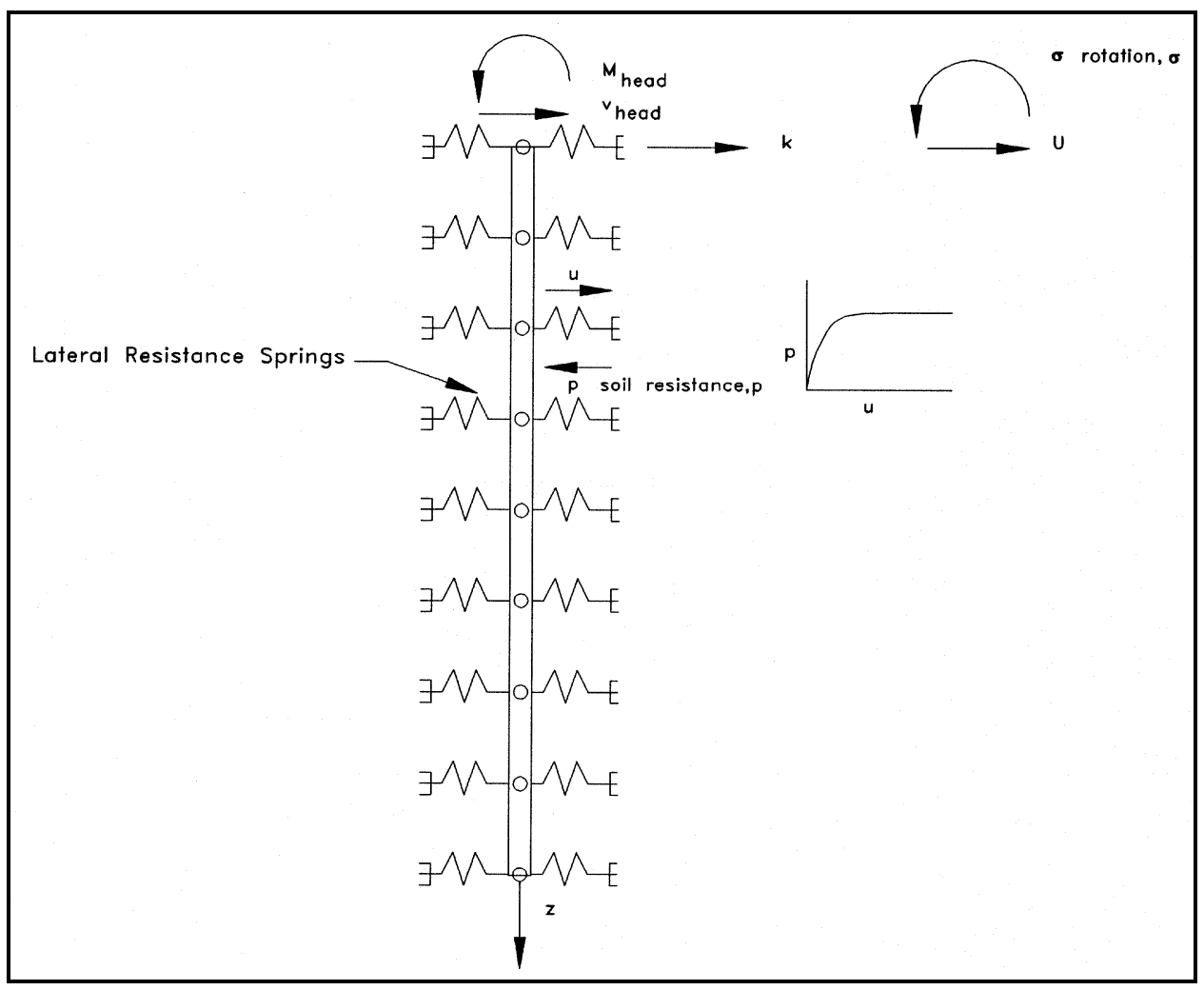

Figure 38. Model of laterally loaded pile

$$
\frac{d^{2}}{d z^{2}}\left(E I \frac{d^{2} u}{d z^{2}}\right)+\frac{d}{d z}\left[P(z) \frac{d u}{d z}\right]-p(z, u)=0
$$

where

$$
\begin{aligned}
E= & \text { modulus of elasticity of the pile material } \\
I= & \text { moment of inertia of pile cross section about an axis perpendicular to } \\
& \text { the } \mathrm{x}-\mathrm{z} \text { plane } \\
P(z)= & \text { axial compressive force in the pile at } z \\
p(z, u)= & \text { lateral resistance which is a function of both position } z \text { on the pile and } \\
& \text { the lateral displacement } u \text { at } z
\end{aligned}
$$


Because the displacement $u$ must be known before the lateral resistance $p$ can be evaluated, numerical iterative solutions of Equation 83 are required. The most common approach is to represent the pile-soil system by a discretized model such as illustrated in Figure 38 where the displacements and forces are evaluated at a finite number of points (Matlock and Reese 1962, Dawkins 1982). The solution proceeds as a succession of trials and corrections until forces and displacements are compatible at every node.

\section{Observations of System Behavior}

Obtaining the numerical solutions described above is expedited by replacing the nonlinear $p-u$ curve by equivalent linearly elastic springs during each iteration. The stiffnesses of these linear springs are evaluated as the secant to $p-u$ curve for the displacements calculated during the preceding iteration. It is to be noted that the ultimate lateral resistance tends to increase with depth, while the pile displacements decrease as $z$ increases. Hence it can be concluded that the secant stiffness of the lateral resistance increases with depth below the pile head. Consequently if the distribution of soil stiffnesses along the pile can be determined, the behavior may be evaluated for working loads without the need for iterative solutions.

The second term in Equation 83 represents the interaction of the axial load in the pile with the lateral displacement to increase the bending moments in the pile (the "beam-column" effect). Distribution of the axial load is not influenced significantly by lateral loading; hence, the distribution may be determined using the axial load analysis techniques described in Chapter 2 before a lateral load analysis is performed. In usual pile-soil systems, the beam-column effect is small and conservative estimates of its influence may be obtained by taking the axial force in the pile equal to the applied head load $P_{o}$.

\section{Linearly Elastic Analyses}

A linear relationship between lateral resistance and lateral displacement is expressed by

$$
p(z, u)=-E_{z}(z) u
$$

where $E(z)=$ secant stiffness of the lateral resistance and the minus sign indicates that the resistance is opposite in direction to the displacement. For a prismatic pile with constant axial force and a linear resistance function, Equation 83 becomes

$$
E I \frac{d^{4} u}{d z^{4}}+P_{o} \frac{d^{2} u}{d z^{2}}+E_{z}(z) u=0
$$


Even with the simplifications inherent in Equation 85, explicit closed form solutions are not possible unless the lateral resistance stiffness is constant with depth. Although the lateral resistance is not constant, insight into the lateral load behavior can be gained from the solution for constant $E_{z}$. In this case the differential equation becomes

$$
E I \frac{d^{4} u}{d z^{4}}+P_{o} \frac{d^{2} u}{d z^{2}}+E_{z} u=0
$$

The solution of Equation 86 (Hetenyi 1946) is

$$
u=e^{-a z / T}\left(C_{1} \cos \frac{b z}{T}+C_{2} \sin \frac{b z}{T}\right)+e^{a z / T}\left(C_{3} \cos \frac{b z}{T}+C_{4} \sin \frac{b z}{T}\right)
$$

where $C_{1}, C_{2}, C_{3}$, and $C$ are constants to be determined from conditions at the pile head and tip; and

$$
\begin{aligned}
T^{4} & =\frac{4 E I}{E_{z}} \\
a^{2} & =1-\lambda^{2} \\
b^{2} & =1+\lambda^{2} \\
\lambda^{2} & =\left(\frac{P_{o} T^{2}}{4 E I}\right)<1
\end{aligned}
$$

For a sufficiently long pile (see Page 51) conditions at the pile tip have no effect on the response at the pile head. In this case the relationship between loads $\left(M_{o}, V_{o}\right)$ and displacements $\left(u_{o}, \rho_{o}\right)$ at the pile head may be expressed as

$$
\left\{\begin{array}{l}
M_{o} \\
V_{o}
\end{array}\right\}=\frac{E I}{T}\left[\begin{array}{cc}
\frac{2}{T^{2}} \sqrt{\left(1-\lambda^{2}\right)} & \frac{1}{T} \\
\frac{1}{T} & \sqrt{\left(1-\lambda^{2}\right)}
\end{array}\right]\left\{\begin{array}{l}
u_{o} \\
\rho_{o}
\end{array}\right\}
$$

For a value of $\lambda^{2}=1 / 2$, the determinant of the coefficient matrix in Equation 92 is zero, indicating that an axial head load

$$
P_{o}=\left(E_{s} E I\right)^{1 / 2}
$$

is the buckling load for the long pile. Hetenyi (1946) gives the buckling load for a finite length pile with both ends fixed against displacement as less than or equal to 


$$
P_{o}=4 \pi^{2} \frac{E I}{L^{2}}+2\left(E_{z} E I\right)^{1 / 2}
$$

For usual pile-soil systems the axial head load must be significantly less than the value given by Equation 93 in order to prevent overstress of the pile material at the head. Hence $\lambda^{2}$ is always considerably less than 1 , so that the beam-column effect may be neglected and the second term of Equations 83, 85, and 86 may be omitted. Consequently, the governing differential equation for elastic analyses becomes

$$
E I \frac{d^{4} u}{d z^{4}}+E_{s}(z) u=0
$$

\section{Variation of Lateral Resistance Stiffness}

In order to utilize Equation 95 for analysis of laterally loaded piles the variation and magnitude of the lateral resistance stiffness must be known. Terzaghi (1955) provides "coefficients of horizontal subgrade reaction" for constant $E_{z}$ for clay (Table 9) and for $E_{s}$ varying linearly with depth $\left(E_{s}(z)=n_{h} z\right)$ for sand (Table 10). The work of Skempton (1951) has been extended to piles in homogeneous soft clays to evaluate $E_{s}$ as

$$
E_{s}=\frac{c_{u}}{5 \epsilon_{50} b}
$$

\section{Table 9}

Values of $E_{s}$ for 1-ft-Wide Piles in Precompressed Clay

\begin{tabular}{||l|l|l|l||}
\hline \hline Consistency of Clay & Stiff & Very Stiff & Hard \\
\hline \hline Values of $c_{u}$ (tsf) & $1-2$ & $2-4$ & $>4$ \\
\hline Range of $E_{s}$ (tcf) & $33-67$ & $67-133$ & $>133$ \\
\hline Proposed value of $E_{s}$ (tcf) & 50 & 100 & 200 \\
\hline
\end{tabular}

\section{Table 10}

Values of Constant of Horizontal Subgrade Reaction $n_{h}$ for a 1-ftWide Pile in Sand

\begin{tabular}{||l|l|l|l||}
\hline \hline Relative Density & Loose & Medium & Dense \\
\hline \hline$n_{h}$ (tcf) for dry or moist sand & 7 & 21 & 56 \\
\hline$n_{h}$ (tcf) for submerged sand & 4 & 14 & 34 \\
\hline
\end{tabular}


The $p-u$ curves discussed previously provide an indication of the variation of $E_{\mathrm{s}}$ with depth. For both clays and sands, the ultimate resistance used for constructing the $p-u$ curves increases with depth near the ground surface. At some depth, the ultimate resistance for clays reaches a limiting value. Considering that the lateral displacements of the pile decrease exponentially with depth (see Equation 87), it seems probable that the secant stiffness of the lateral reaction for both sands and clays increases as some exponential function with depth of the form (Matlock and Reese 1962).

$$
E_{z}(z)=K_{o}+K z^{n}
$$

The stiffness of sand at the ground surface will be zero; hence, $K_{o}$ will be zero. Although the $p-u$ curves for clays suggest that $K_{o}$ will not be zero, it is conservative to take $K_{o}$ as zero for these materials. Therefore, the elastic solutions presented in the following paragraphs will take $K_{o}$ to be zero in all cases.

Although explicit solutions of Equation 95 exist for $E_{\mathrm{s}}$ constant with depth ( $n=0, E_{s}=K$ in Equation 97), all solutions are presented in graphical form. Following the procedures of Matlock and Reese (1962) the following nondimensional parameters are defined

$$
\begin{aligned}
& T^{n+4}=\frac{E I}{K} \\
& Z=\frac{z}{T} \\
& Z_{\max }=\frac{L}{T} \\
& u=\frac{V_{o} T^{3}}{E I} A_{u}(Z)+\frac{M_{o} T^{2}}{E I} B_{u}(Z)
\end{aligned}
$$

where $V_{o}$ and $M_{o}$ are the applied head shear and moment, respectively; and $A_{u}(\mathrm{Z})$ and $B_{u}(\mathrm{Z})$ are nondimensional functions of the nondimensional depth $Z$.

Substitution of Equations 97 through 101 into Equation 95 yields

$$
\frac{d^{4} A_{u}(Z)}{d Z^{4}}+Z^{n} A_{u}(Z)=0
$$

and

$$
\frac{d^{4} B_{u}(Z)}{d Z^{4}}+Z^{n} B_{u}(Z)=0
$$


With solutions of Equations 102 and 103 available, the displacement at any point on the pile is obtained from Equation 136 and the slopes of the pile, the bending moments, and shears are evaluated from the derivatives of $u$ as

$$
\begin{aligned}
& \rho=\frac{d u}{d z}=\frac{V_{o} T^{2}}{E I} A_{s}(Z)+\frac{M_{o} T}{E I} B_{s}(Z) \\
& M=E I \frac{d^{2} u}{d z^{2}}=V_{o} T A_{m}(Z)+M_{o} B_{m}(Z) \\
& V=E I \frac{d^{3} u}{d z^{3}}=V_{o} A_{v}(Z)+\frac{M_{o}}{T} B_{v}(Z)
\end{aligned}
$$

The various functions of $A$ and $B$ are plotted in Appendix A (Figures B1 through B24) for constant, linear, and parabolic variations of $E_{z}$ with depth $(n=0,1$, and 2, respectively, in Equation 96).

\section{Pile Head Stiffness Coefficients for Lateral Loading}

Pile head stiffness coefficients for lateral loading are obtained by inverting Equations 100 and 101 with $Z=0$ as shown in the following matrix equation

$$
\left\{\begin{array}{c}
V_{o} \\
M_{o}
\end{array}\right\}=\frac{E I}{T^{3}\left(A_{u o} B_{s o}-A_{s o} B_{u o}\right)}\left[\begin{array}{cc}
B_{s o} & -T B_{u o} \\
-T A_{s o} & T^{2} A_{u o}
\end{array}\right]\left\{\begin{array}{c}
u_{o} \\
\rho_{o}
\end{array}\right\}
$$

where

$$
\begin{aligned}
& A_{u o}=A_{u}(Z=0) \\
& B_{u o}=B_{u}(Z=0) \\
& A_{s o}=A_{s}(Z=0) \\
& B_{s o}=B_{s}(Z=0)
\end{aligned}
$$

The coefficients $A_{u o}, B_{u o}, A_{s o}$, and $B_{s o}$ are shown for various relative pile lengths $Z_{\max }$ in Appendix B (Figures B25 through B28). The following items should be noted: (a) $A_{s o}=B_{u o}$; (b) piles with $Z_{\max }<2$ may be treated as rigid (see page 76); and (c) The $A$ and $B$ coefficients remain constant for $Z_{\max } \geq 4$. 
As noted on page 59, piles with $Z_{\max } \geq 4$ may be treated as inflexible. In this case the lateral displacement at any depth may be expressed in terms of the pile head displacements as

$$
u=u_{o}+\rho_{o} z
$$

and the soil resistance at that point is

$$
p=K z^{n} u=K z^{n}\left(u_{o}+\rho_{o} z\right)
$$

From an equilibrium analysis of the rigid pile, the head shear and moment are given in terms of the head displacements by

$$
\left\{\begin{array}{c}
M_{o} \\
V_{o}
\end{array}\right\}=K L^{n+1}\left[\begin{array}{cc}
\frac{1}{n+1} & \frac{L}{n+2} \\
\frac{L}{n+2} & \frac{L^{2}}{n+3}
\end{array}\right]\left\{\begin{array}{l}
u_{o} \\
\rho_{o}
\end{array}\right\}
$$

\section{Evaluation of Linear Lateral Soil Resistance}

In order to apply the linearized solutions described in the preceding paragraphs, the variation and magnitude of the lateral soil resistance stiffness must be evaluated. Terzaghi (1955) provides estimates of clay soil stiffness constant with depth $(n=0)$ and sand soil stiffness varying linearly with depth $(n=1)$ as shown in Tables 9 and 10. (Note: Terzaghi states that the soil stiffness values are for a " 1 foot wide pile" and in order to apply these values to piles of different widths the stiffness for the 1-ft-wide pile must be divided by the actual width of the pile. In order to utilize the resulting "horizontal subgrade modulus" in the linearized analysis, Terzaghi's modulus must be multiplied by the width of the pile in contact with the soil (see Hetenyi 1941). Consequently the moduli given by Terzaghi may be used without alteration as the value of $K$ in the linearized equations.)

Because the laterally loaded pile-soil system is highly nonlinear, particularly under large loads, immutable pile head stiffness coefficients do not exist. Although the soil stiffness moduli given in Tables 9 and 10 can be used to evaluate explicit coefficients, these values must be interpreted as only first approximations. Higher approximations may be obtained by combining the nondimensional solutions with the nonlinear $p$ - $u$ curves discussed earlier (Reese, Cooley, and Radhakrishnan 1984, "Executive Summary....") as outlined in the following steps. 
a. Evaluate $p-u$ curves for the appropriate soil profile. These curves should be closely spaced in the top 10 to 20 pile diameters.

b. Estimate a variation and lateral stiffness (i.e., $K$ and $n$ in Equation 97) for the soil profile using Terzaghi's soil moduli. (Reese, Cooley, and Radhakrishnan (1983) suggest that a value of $T$ (Equation 98) be assumed; Terzaghi's moduli provide a means for this assumption.)

$c$. Evaluate the deflections at the locations of the $p$ - $u$ curves in step $a$ using the appropriate nondimensional curves for head loads in the working range.

$d$. Determine the slope of a secant line from the $p-u$ curve for the deflection calculated for each location. This establishes the soil modulus $E_{z}$ at each $p$ - $u$ curve location and allows $E_{z}$ to be plotted versus depth $z$.

e. Revise the variation and lateral soil stiffness (i.e., new $K$ and $n$ in Equation 97) to best approximate the curve of $E_{z}$ versus $z$ in step $d$.

$f$. Repeat steps $c, d$, and $e$ until convergence is achieved.

g. Use the final values of $K$ and $n$ to calculate the pile head stiffness coefficients in Equations 107 and 110. 


\section{Algorithm for Analysis of Torsionally Loaded Single Piles}

Three-dimensional analysis of a single pile requires a relationship between the resistance of the soil and the torsional displacement of the pile. There has been only limited investigation (O'Neill 1964, Poulos 1975, Scott 1981, Stoll 1972) of this torque-twist relation because its effect is small compared to the axial and lateral effects. Until more detailed data are available, the following simplistic relationship should be used.

It is assumed that the soil is a radially linearly elastic, homogenous medium, that the pile is prismatic and linearly elastic, and that the resistance of the soil at any point is a function only of the torsional displacement of the pile-soil interface at that point. Under these assumptions the soil in any plane perpendicular to the axis of the pile is in a state of plane, pure shear. The theory of elasticity solution for this case yields

$$
\tau=\tau_{o}\left(\frac{R}{r}\right)^{2}
$$

and

$$
v=\frac{\tau_{o} R^{2}}{2 G_{s} r^{3}}
$$

where

$$
\begin{aligned}
& \tau=\text { shear stress at a radial distance } r \text { from the centerline of the pile } \\
& \tau_{o}=\text { shear stress at the pile-soil interface } \\
& R=\text { radius of the pile }
\end{aligned}
$$


$V=$ displacement perpendicular to the radial direction at $r$

$G_{s}=$ shear modulus of the soil

If there is no slippage between the pile and soil at the interface, the tangential displacement of a point on the interface is

$$
v=R \theta
$$

where $\theta$ is the rotation of the pile. And, finally, the required relation is

$$
\frac{\tau_{o}}{\theta}=2 G_{s}
$$

The linear relationship between surface shear and pile rotation represented by Equation 113 is assumed to terminate when the surface shear $\tau_{o}$ reaches a limit of

$$
\tau_{o u}=k_{o} \sigma_{v} \tan \delta
$$

for sands, or

$$
\tau_{o u}=\alpha s_{u}
$$

for clays, where

$$
\begin{aligned}
& \begin{array}{l}
\tau_{o u}=\text { ultimate surface shear resisting rotation of the pile about its longitudinal } \\
\text { axis }
\end{array} \\
& k_{o}=\text { at-rest pressure coefficient } \\
& \delta=\text { angle of pile-soil interface friction for sand } \\
& \sigma_{o}=\text { vertical effective stress } \\
& \begin{aligned}
\alpha= & \text { an adhesion factor which may be obtained from Figure } 12 \\
s_{u}= & \text { shear strength of clay. The resistance to rotation remains constant at } \tau_{o u} \\
& \text { for additional rotational displacement as shown in Figure } 39
\end{aligned}
\end{aligned}
$$

\section{Elastic Analysis}

So long as the surface shear is less than $\tau_{o u}$, the entire pile-soil system is linearly elastic. The governing differential equation for torsional response of the linear pile-soil system is 


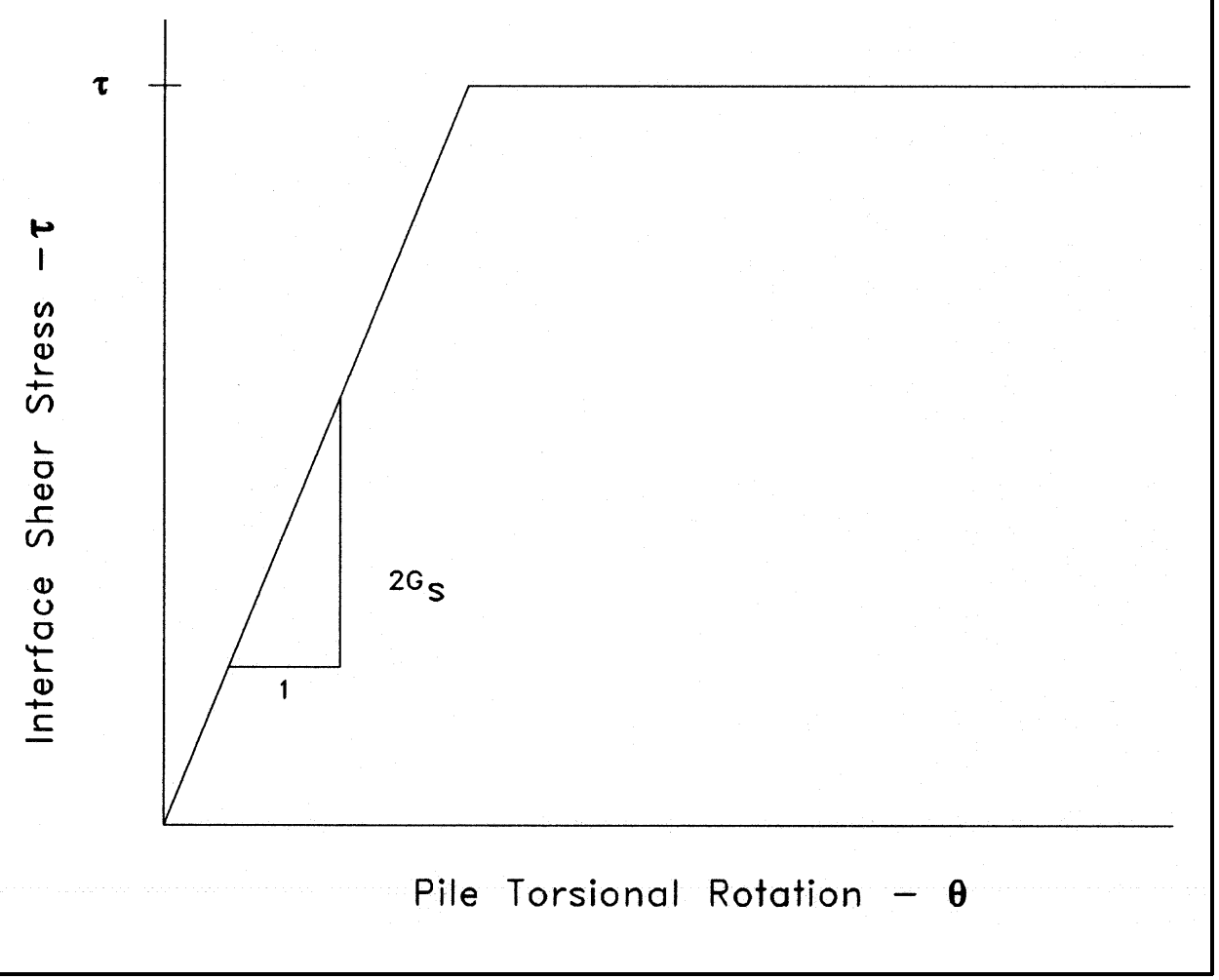

Figure 39. Proposed torsional shear - rotation curve

$$
G J \frac{d^{2} \theta}{d z^{2}}-4 \pi R^{2} G_{s}(z) \theta=o
$$

where

$$
\begin{aligned}
G= & \text { shear modulus of the pile material } \\
J= & \text { torsional area property of the pile cross section (polar moment of inertia } \\
& \quad \text { for a circular section) }
\end{aligned}
$$

Because Equation 116 is identical in form to the differential equation for an axially loaded pile, pile head torque-twist stiffness may be obtained from the equations and procedures appearing on pages A3-A6 of Appendix A by performing the following substitutions:

a. In Equations A4 and A5 (in Appendix A), define $T_{z}=\left(G J / 4 \pi R^{2} G_{s}\right)^{1 / 2}$ for $G_{s}$ constant with depth.

b. In Equations $\mathrm{A} 7$ and $\mathrm{A} 11$, replace $E A$ with $G J$; replace $w_{\mathrm{o}}$ with $\theta_{o}$ (the twist angle at the pile head); and, replace $P_{o}$ with $M_{o}$ (the torsional moment at the pile head). 
c. In Equation A16, replace $E A$ with $G J$; replace $w(z)$ with $O(z)$; and, replace $P_{o}$ with $M_{o}$.

d. In Equation A18, replace $E A$ with $G J$; and, define $K_{f}$ such that $G_{s}(z)=$ $K_{f} z^{n}$ for $G_{s}$ varying with depth.

(Note: Scott (1981) indicates that the torsional resistance to twist at the pile tip may be included as was done for tip reaction for the axially loaded pile. However, in most situations the tip resistance against twist will be negligible.) 


\section{$5 \quad$ Pile Head Stiffness Matrix}

\section{Three-Dimensional System}

Figure 40 illustrates the coordinate system, forces, and displacements at the pile head which must be considered in a three-dimensional analysis. The $\mathrm{x}$ - and $y$-axes are the principal axes of the pile cross section and the $\mathrm{z}$-axis is the longitudinal axis of the pile. Forces and displacements are assumed to have positive senses in the positive coordinate directions ("right-hand rule" for moments and rotations).

For a linearly elastic system, the forces and displacements are related by

$\left.\begin{array}{c}F_{x} \\ F_{y} \\ F_{z} \\ M_{x} \\ M_{z}\end{array}\right\}=\left[\begin{array}{cccccc}b_{11} & 0 & 0 & 0 & b_{15} & 0 \\ & b_{22} & 0 & b_{24} & 0 & 0 \\ & & b_{33} & 0 & 0 & 0 \\ & & & b_{44} & 0 & 0 \\ \text { Symmetric } & & & b_{55} & 0 \\ w \\ \phi \\ \rho \\ \rho \\ \theta\end{array}\right.$

The $b$ coefficient matrix array is the pile head stiffness matrix and the individual elements $b_{i j}$ are obtained from Equations A21, 107, and 108. 


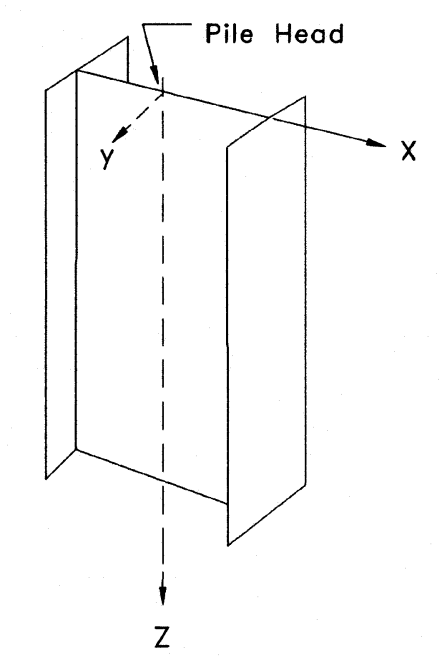

a. Coordinate Axes

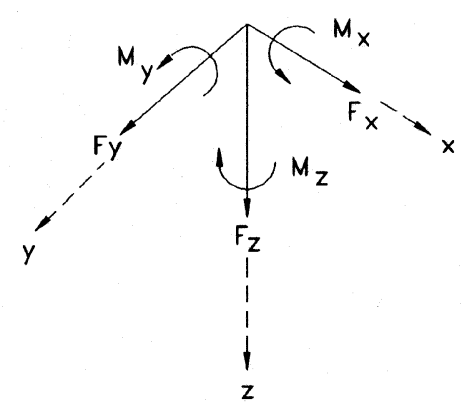

b. Pile Head Forces

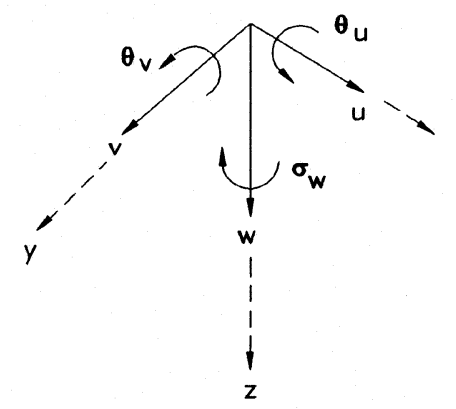

c. Pile Head Displacements and Rotations

Figure 40. Notation for pile head effects

$$
\begin{aligned}
& b_{11}=\frac{E I_{y}}{T_{x z}}\left(\frac{1}{A_{u o}-\frac{B_{u o}}{B_{s o}} A_{s o}}\right) \\
& b_{15}=\frac{E I_{y}}{T_{x z}}\left(\frac{1}{A_{s o}-\frac{B_{s o}}{B_{u o}} A_{u o}}\right) \\
& b_{33}=\frac{E A}{T_{z} a_{o}} \\
& b_{66}=\frac{G J}{T_{z} a_{o}}
\end{aligned}
$$


where

$$
\begin{aligned}
E & =\text { modulus of elasticity of pile material } \\
I_{y} & =\text { moment of inertia of pile cross section about y-axis } \\
T_{x z} & =\text { length parameter for lateral loading in the } x-z \text { plane }
\end{aligned}
$$

Equation 98 coefficients $A_{u o}, A_{s o}, B_{u o}$, and $B_{s o}$ are obtained from Figures B25 through B28 with $Z_{\max }=L / T_{x z}$; terms appearing in Equation 122 are defined in Chapter 2; and, terms in Equation 123 are defined in Chapter 4. The remaining elements of the pile head stiffness matrix, $b_{22}, b_{24}, b_{55}$, and $b_{44}$, are evaluated for bending in the $y-z$ plane.

\section{Pile Head Fixity}

If the pile head is attached to the supported structure so that the displacements of the pile head and the point of attachment on the structure undergo identical displacements, the stiffness matrix as shown in Equation 118 may be included as a part of the overall system stiffness without alteration. In most installations, the pile head and the supported structure will experience the same translational displacements $(u, v, w)$. However, the method of connection may permit relative rotation between the structure and the pile. To illustrate the effect of relative rotation of the pile and structure, the two-dimensional system shown in Figure 38 is used. The relationship between the head forces and displacements is

$$
\begin{aligned}
& u_{o}=\frac{V_{o} T^{3}}{E I} A_{u o}+\frac{M_{o} T^{2}}{E I} B_{u o} \\
& \rho_{o}=\frac{V_{o} T^{2}}{E I} A_{s o}+\frac{M_{o} T}{E I} B_{s o}
\end{aligned}
$$

The attendant inverse relationship, considering only the terms associated with lateral loading and the notation of Equation 119,

$$
\left\{\begin{array}{l}
v_{o} \\
M_{o}
\end{array}\right\}=\left[\begin{array}{ll}
b_{11} & b_{15} \\
b_{51} & b_{55}
\end{array}\right]\left\{\begin{array}{l}
u_{o} \\
\rho_{o}
\end{array}\right\}
$$




\section{Pinned-Head Pile}

If the pile-to-structure connection is such that no moment is transmitted through the connection, then $M_{o}$ will be zero. For a unit lateral translation, $u_{o}=1$, Equations 123,124 , and 125 yield

$$
1=\frac{V_{o} T^{3}}{E I} A_{v o}
$$

or

$$
b_{11}^{\prime}=\frac{E I}{T^{3}} \frac{1}{A_{u o}}
$$

and, the resulting rotation of the pile head,

$$
\rho_{o}^{\prime}=\frac{1}{T} \frac{A_{s o}}{A_{u o}}
$$

with $b_{15}^{\prime}=b_{51}=b_{55}=0$. (The prime superscript denotes the pinned head condition.)

\section{Partial Fixity at Pile Head}

Frequently the pile-structure connection permits a limited relative rotation before moment resistance at the pile head is developed. To simulate the partial fixity, it is assumed that moment resistance develops at a reduced rate proportional to the degree of fixity $f(o \leq f \leq 1)$. To evaluate the stiffness elements $b_{11}$ and $b_{51}$ for partial fixity, a unit value of $u_{o}$ is imposed at the pile head and the rotation is allowed to increase to $(1-f) \rho_{o}^{\prime}$. Similarly, to evaluate $b_{15}$ and $b_{55}$, $u_{o}=0$ and $\rho_{o}=f \rho_{o}^{\prime}$ are imposed. The resulting stiffness elements are

$$
\begin{aligned}
& b_{11}^{\prime \prime}=\frac{E I}{T^{3}} \frac{1}{A_{u o}}\left(1+\frac{f}{\frac{A_{u o}}{A_{s o}} \frac{B_{s o}}{B_{u o}}-1}\right) \\
& b_{51}^{\prime \prime}=b_{15}^{\prime \prime}=\frac{E I}{T^{2}} \frac{f}{B_{u o}-\frac{A_{u o}}{A_{s o}} B_{u o}} \\
& b_{55}^{\prime \prime}=\frac{E I}{T} \frac{f}{B_{s o}-\frac{A_{s o}}{A_{u o}} B_{u o}}
\end{aligned}
$$




\section{Free-Standing Pile Segment}

A portion of the pile may extend above the ground surface as illustrated in Figure 41 for bending in the $x-z$ plane. Although the free-standing segment may be considered as a part of the structure supported by the pile, it may be advantageous to combine the free-standing and embedded segments to express the relationship between forces and displacements at the pile head, point o in Figure 41, and eliminate consideration of the effects at the ground surface.

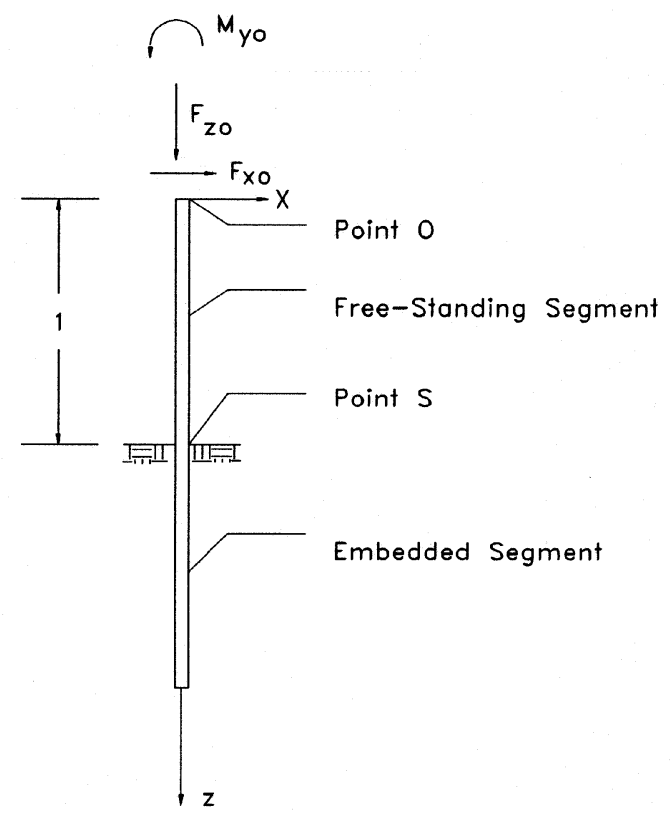

a. Pile With Free-Standing Segment

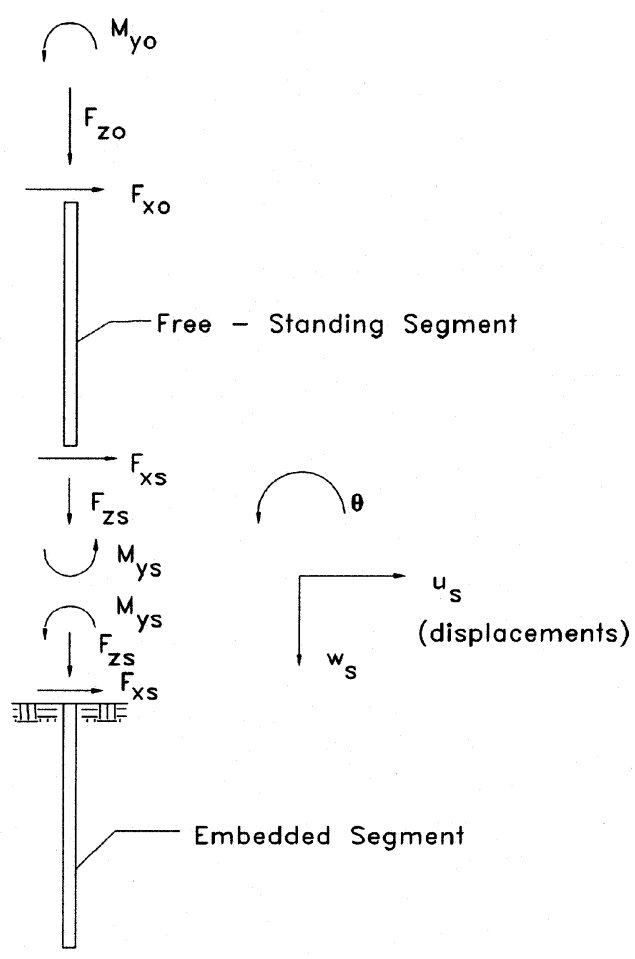

b. Free Body Diagram

Figure 41. Linearly elastic pile/soil system with free-standing segment

The free-standing segment is not subjected to the effects of surrounding soil; hence, the relationship between end forces and end displacements for the freestanding portion is required. Using conventional beam-column element theory for the two-dimensional system in Figure 41, the free-standing segment's STIFFNESS matrix can be written as: 


$$
\left\{\begin{array}{l}
F_{x o} \\
M_{y o} \\
F_{z o} \\
F_{x s} \\
M_{Y s} \\
F_{z s}
\end{array}\right\}=\frac{E}{1}\left[\begin{array}{cccccc}
\frac{I_{y}}{1^{2}}(3+9 f) & \frac{6 I_{y}}{1} f & 0 & -\frac{I_{y}}{1^{2}}(3+9 f) & \frac{3 I_{y}}{1}(1+f) & 0 \\
& 4 I_{y} f & 0 & \frac{6 I_{y}}{1} f & 2 I_{y} f & 0 \\
\text { Symmetric } & A & 0 & 0 & -A \\
& & & \frac{I_{y}}{1^{2}}(3+9 f) & -\frac{3 I_{y}}{1}(1+f) & 0 \\
w_{o} \\
u_{s} \\
\rho_{s} \\
w_{s} .
\end{array}\right.
$$

where $E, A, I_{\mathrm{y}}$, and $l$ are the modulus of elasticity, cross-sectional area, moment of inertia and length, respectively, of the free-standing segment, and $f$ is the degree of fixity between the pile head and structure at point $o$. For convenience, the matrices in Equation 132 are partitioned as indicated by the dashed lines and this equation may be written symbolically as

$$
\left\{\begin{array}{c}
F_{o}^{\sim} \\
F_{s}^{\sim}
\end{array}\right\}=\left[\begin{array}{cc}
b_{o o}^{\sim} & b_{o s}^{\sim} \\
b_{s o}^{\sim} & b_{s s}^{\sim}
\end{array}\right]\left\{\begin{array}{l}
U_{o}^{\sim} \\
U_{s}^{\sim}
\end{array}\right\}
$$

Similarly, the relationship between forces and displacements at point $s$ (Figure 41) may be written as (see Equation 118)

$$
\left\{\begin{array}{l}
F_{x s} \\
M_{y s} \\
F_{z s}
\end{array}\right\}=\left[\begin{array}{ccc}
b_{11} & b_{15} & 0 \\
b_{51} & b_{55} & 0 \\
0 & 0 & b_{33}
\end{array}\right]\left\{\begin{array}{l}
u_{s} \\
\rho_{s} \\
w_{s}
\end{array}\right\}
$$

or

$$
F_{s}^{\sim}=b_{s}^{\sim} U_{s}^{\sim}
$$


Because there are no external forces at point $s$, Equations 133 and 135 may be combined to obtain

$$
\begin{aligned}
& F_{o}^{\sim}=\tilde{b_{o o}^{\sim}} U_{o}^{\sim}+b_{o s}^{\sim} U_{s}^{\sim} \\
& \widetilde{F}_{s}=0=b_{s o}^{\sim} U_{o}^{\sim}+\left(\tilde{b}_{s s}^{\sim}+b_{s}^{\sim}\right) U_{s}^{\sim}
\end{aligned}
$$

From Equation 137

$$
U_{s}^{\sim}=-\left(\tilde{b_{s s}}+b_{s}^{\sim}\right)^{-1} b_{s o}^{\sim} U_{o}^{\sim}
$$

And substitution of Equation 138 into Equation 136 yields

$$
F_{o}^{\sim}=\left[b_{o o}^{\sim}-b_{o s}\left(b_{s s}^{\sim}+b_{s}^{\sim}\right)^{-1} b_{s o}^{\sim}\right] U_{o}^{\sim}=[B \sim] U_{o}^{\sim}
$$

where

$$
[B \sim]=\left[\begin{array}{ccc}
b_{11}^{\prime \prime \prime} & b_{15}^{\prime \prime \prime} & 0 \\
b_{51}^{\prime \prime \prime} & b_{55}^{\prime \prime \prime} & 0 \\
0 & 0 & b_{33}^{\prime \prime \prime}
\end{array}\right]
$$

is the pile head stiffness matrix for bending in the $x z$-plane. A similar operation is required for bending in the $y z$-plane. The torsion stiffness coefficient is given by

$$
b_{66}^{\prime \prime \prime}=\left(\frac{1}{b_{66}}+\frac{1}{G J}\right)^{-1}
$$

where $b_{66}$ is the torsional coefficient for the embedded segment from Chapter 4, and $G$ and $J$ are shear modulus and torsional area moment of inertia, respectively, for the free-standing segment.

\section{Alternatives for Evaluating Pile Head Stiffnesses}

The most reliable means of evaluating the pile stiffness is from field tests of prototype piles. Although the coefficients relating lateral head loads and 
displacements may be evaluated from lateral load tests, such tests are not routinely performed.

For complex soil conditions and/or nonprismatic piles which are not readily approximated by one of the procedures for linearly elastic systems discussed previously, the pile head stiffness matrix may be obtained with the aid of computer programs such as CBEAMC, CAXPILE, or COM624. 


\section{Analysis of Pile Groups}

Although isolated single piles may be encountered in some applications, it is more common that a structure foundation will consist of several closely spaced piles (many building codes require a minimum of three piles in a group). The structure/pile/soil system is highly indeterminate and nonlinear. Historically, design methods have been based on numerous simplifying assumptions that render the analytical effort tractable for hand computations. The advent of the computer has allowed solutions to be obtained in which many of the simplifications of the classical design methods are no longer necessary. Synopses of some of the classical methods and more complete descriptions of the computer-based techniques are presented below.

\section{Classical Methods for Pile Group Analysis}

All of the classical methods assume that the pile cap (or super-structure) is rigid and that all loads are resisted only by axial forces in the piles. These methods attempt to allocate the superstructure loads to individual piles through the equations of static equilibrium. No direct attempt is made to determine the deformations of the system.

\section{Moment-of-Inertia (Simplified Elastic Center) Method}

A complete description of the Elastic Center method is given by Andersen (1956). For the simplified procedure presented here, it is assumed, in addition to a rigid cap, that only vertical loads are applied to the cap, that all piles are vertical, that all piles have the same axial stiffness (EA/L), and that the magnitudes of the axial loads in the piles vary linearly with distance from the centroid of the pile group. The axial load at the head of the $i^{\text {th }}$ pile is given by

$$
P_{o, i}=\frac{V}{n} \pm \frac{M_{y} x_{i}}{I_{x}} \pm \frac{M_{x} y_{i}}{I_{y}}
$$


where

$$
\begin{aligned}
V= & \text { resultant vertical load on the cap } \\
n= & \text { number of piles in the group } \\
I_{x}, I_{y}= & \text { moments of inertia about } x \text { - and } y \text {-axes, respectively, through the } \\
& \text { centroid of the piles which are treated as point (unit) areas } \\
M_{x}, M_{y}= & \begin{array}{l}
\text { moments of the vertical loads on the cap about the } x \text { - and } y \text {-axes, } \\
\text { respectively }
\end{array}
\end{aligned}
$$

\section{Culmann's Method}

The method attributed to Culmann (see Terzaghi (1943)) requires three nonparallel subgroups of piles in the foundation. The piles within each subgroup are assumed to be parallel and are assumed to have the same head load. Each subgroup is replaced by a single pile at the centroid of the subgroup. A graphical procedure is used to resolve the superstructure load applied to the rigid cap to each subgroup.

\section{“Analytical” Method}

Teng (1962) describes a simplified procedure for including the effects of horizontal loads as well as battered piles. The vertical component of the axial force in each pile due to the resultant vertical load and moments of the superstructure on the rigid cap is calculated according to the moment of inertia method. The total axial pile load and its horizontal component may be calculated from the vertical component. Teng suggests that an adequate design has been attained if the applied horizontal foundation load does not exceed the sum of the horizontal components of axial pile forces by more than $1,000 \mathrm{lb} /$ pile.

\section{Stiffness Analysis of Pile Foundations}

The classical methods described in the previous paragraphs essentially neglect the capability of the piles to resist lateral loads and do not provide a means of evaluating the stresses induced in the pile by bending and shear at the pile head. The classical methods may underestimate the strength of the foundation or may lead to an unconservative design depending on the manner in which the pile head is attached to the structure. Hrennikoff (1950) and Saul (1968) developed a direct stiffness approach to the analysis of two- and three-dimensional pile groups in which the interaction of the piles with the surrounding soil as well as compatibility of pile head and pile cap displacements is included. In this procedure, the relationship between the pile head forces and the displacements of the point of attachment to the rigid pile cap is assumed to be linear. 
The two coordinate systems necessary for the direct stiffness analysis are shown in Figures 42 and 43 along with the forces and displacements on the pile cap and pile head. Relationships between the global and local axes are shown in Figure 44.

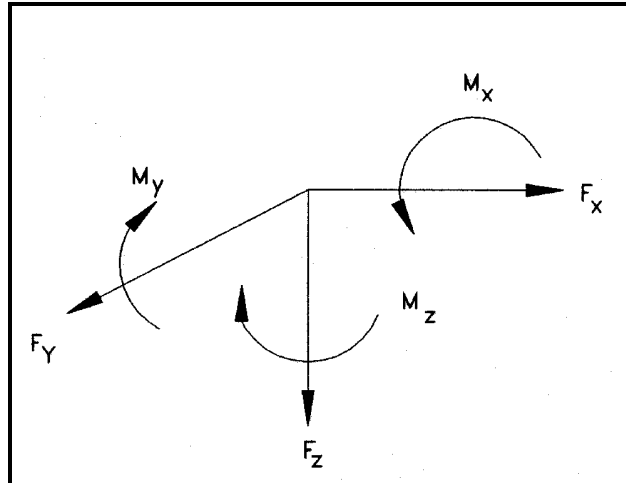

a. Pile Cap Loads

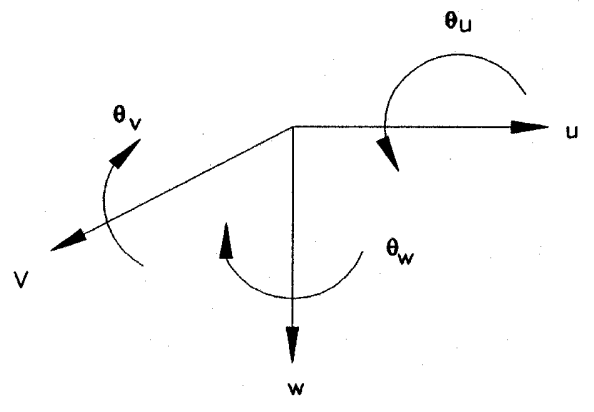

b. Pile Cap Displacements

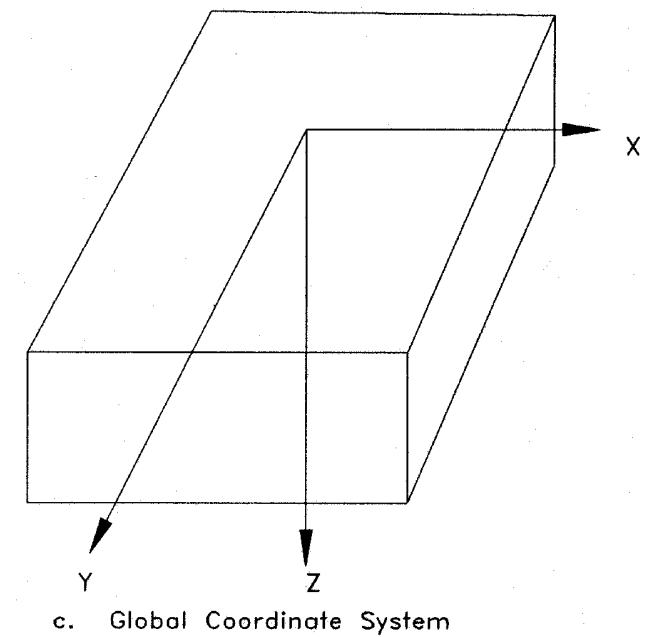

Figure 42. Pile cap loads, displacements, and coordinates

The pile head displacements in the local coordinate system for a pile are expressed in terms of the pile cap displacements by the transformation

$$
\{u\}_{i}=[A]_{i}[G]_{i}\{U\}
$$

where $\{u\}_{i}=\left\{u_{i} v_{i} w_{i} \phi_{i} \rho_{i} \theta_{i}\right\}^{T}=$ pile head displacements in the local coordinate system for the $i^{\text {th }}$ pile; $[A]_{i},[G]_{i}=$ geometric transformation matrices given by (see Figure 44 for definitions of symbols) 


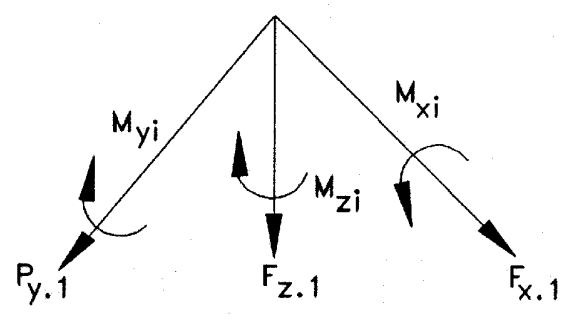

a. Pile head Forces

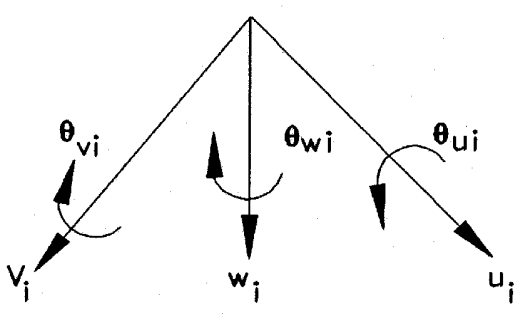

b. Pile Head Displacements

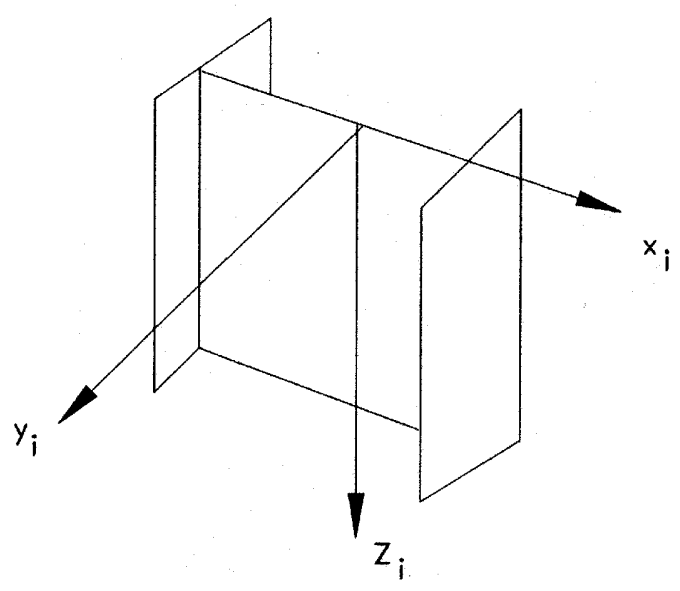

c. Local Coordinate System

Figure 43. Head forces, displacements, and coordinates for $\mathrm{i}_{\mathrm{TH}}$ pile

$[A]_{i}=\left[\begin{array}{cccccc}\left(\cos \beta_{i} \cos \alpha_{i}\right) & \left(\cos \beta_{i} \sin \alpha_{i}\right) & -\sin \beta_{i} & 0 & 0 & 0 \\ -\sin \alpha_{i} & \cos \alpha_{i} & 0 & 0 & 0 & 0 \\ \left(\sin \beta_{i} \cos \alpha_{i}\right) & \left(\sin \beta_{i} \cos \alpha_{i}\right) & \cos \beta_{i} & 0 & 0 & 0 \\ 0 & 0 & 0 & \left(\cos \beta_{i} \cos \alpha_{i}\right) & \left(\cos \alpha_{i} \sin \alpha_{i}\right) & -\sin \beta_{i} \\ 0 & 0 & 0 & -\sin \alpha_{i} & \cos \alpha_{i} & 0 \\ 0 & 0 & 0 & \left(\sin \beta_{i} \cos \alpha_{i}\right) & \left(\sin \beta_{i} \sin \alpha_{i}\right) & \left.\cos \beta_{i}\right)\end{array}\right]$




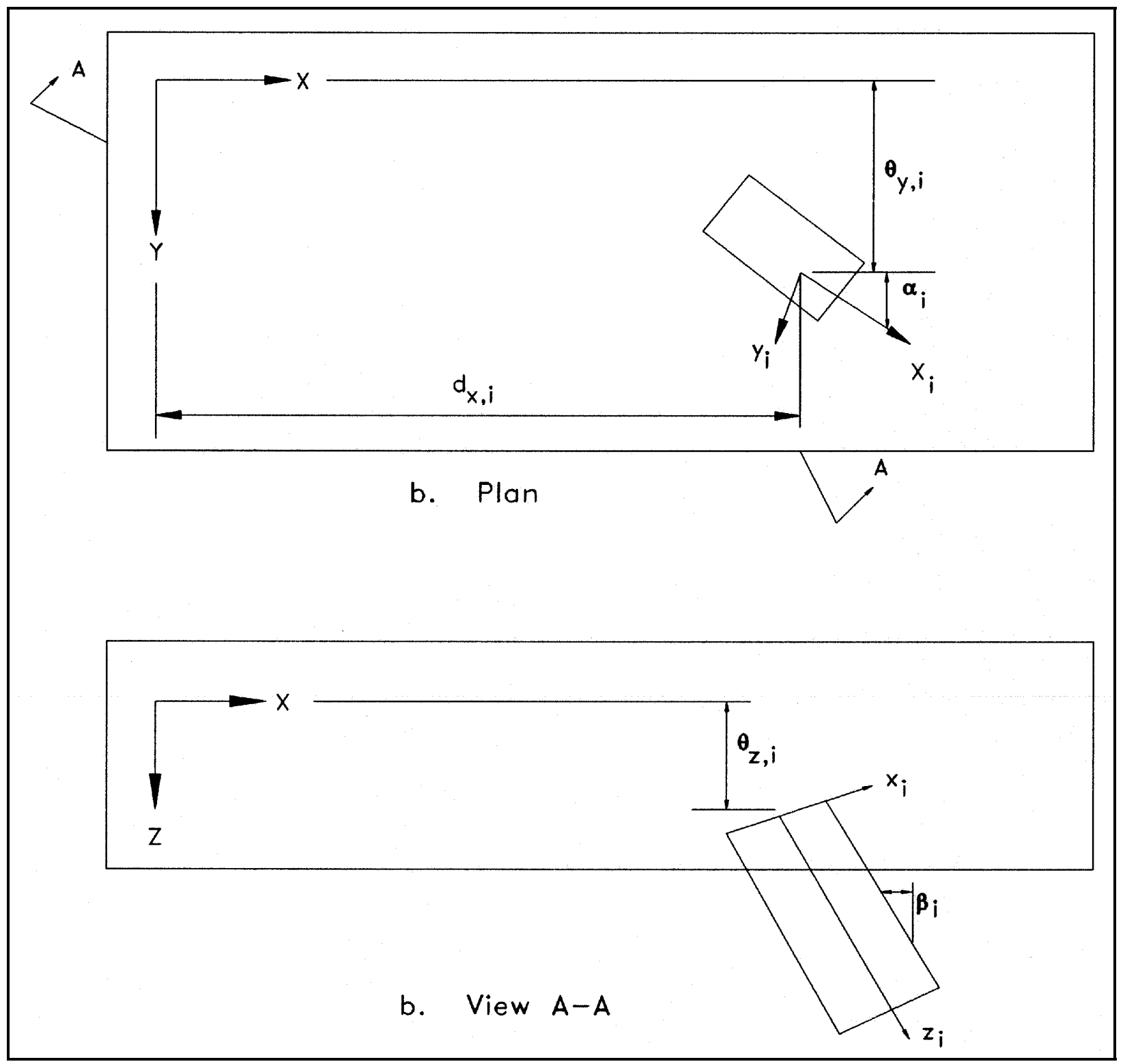

Figure 44. Relationship between global and local coordinates

$$
[G]_{i}=\left[\begin{array}{cccccc}
1 & 0 & 0 & d_{z, i} & -d_{y, i} & \\
0 & 1 & 0 & -d_{z, i} & 0 & d_{x, i} \\
0 & 0 & 1 & d_{y, i} & -d_{x, i} & 0 \\
0 & 0 & 0 & 1 & 0 & 0 \\
0 & 0 & 0 & 1 & 0 & \\
0 & 0 & 0 & 0 & 0 & 1
\end{array}\right]
$$


and $\{U\}=\left\{U_{G} V_{G} W_{G} \phi_{G} \rho_{G} \theta_{G}\right\}^{T}=$ pile cap displacements in the global coordinate directions. by

The relationship between pile cap forces and pile cap displacements is given

$$
\{F\}=\left\{\sum_{i=1}^{n}[G]_{i}^{T}[A]_{i}^{T}[b]_{i}[A]_{i}[G]_{i}\right\}\{U\}
$$

where $\{F\}=\left\{F_{x} F_{y} F_{z} M_{x} M_{y} M_{z}\right\}^{T}=$ superstructure loads on pile cap in global coordinate directions; $\mathrm{n}=$ number of piles in the group; and, $[b]_{\mathrm{i}}=$ pile head stiffness matrix for the local coordinate system described in Chapter 5.

$$
(C)_{i}=\left\{\begin{array}{cccccc}
1 & 0 & 0 & 0 & 0 & 0 \\
0 & 1 & 0 & 0 & 0 & 0 \\
0 & 0 & 1 & 0 & 0 & 0 \\
0 & -u_{3} & u_{2} & 1 & 0 & 0 \\
u_{3} & 0 & -u_{1} & 0 & 1 & 0 \\
-u_{2} & u_{1} & 0 & 0 & 0 & 1
\end{array}\right\}
$$

After Equation 146 has been solved for the pile cap displacements, the head displacements and head forces in the local coordinate system for each pile are obtained from Equations 143 and 118, respectively. This method of analysis has been incorporated into the CASE computer program CPGA (Hartman et al. 1984).

The pile-soil-pile interaction (PSPI) method is identical to Saul's method in its treatment of geometric and structural analysis aspects of the pile group problem. However, its treatment of soil reactions against piles is more comprehensive and rigorous. The method was first formalized by O'Neill, Ghazzaly and Ha (1977) for the analysis of pile clusters in offshore drilling platforms. The PSPI algorithm PILGP2R automates the process of computing pile-head stiffness constants $b_{11}-b_{66}$ and $b_{15}, b_{24}$, and $b_{42}$ by first developing nonlinear relationships between axial pile-head load and axial displacement, pile-head torque and twist, lateral pile-head load and displacement with zero rotation, pile-head moment and rotation with zero displacement, and the cross-coupling relationship between rotation and lateral load and between displacement and moment. Sets of lateral relationships are developed for each of two orthogonal directions to accommodate nonisotorepic piles, such as H-piles. Nonlinear subroutines similar to those described in Chapters 2 and 3 are used to develop the axial and lateral relationships, respectively. Hence, the user inputs become unit load transfer curves. Torsional stiffness of individual piles is generally of minor significance in large groups of piles. For that reason special computations of torsional stiffnesses are not made, and the torsional stiffness is assumed to be equal to a constant value of $(G J)_{\text {pile }} / 2 L$ throughout the computations. The piles remain linearly elastic. 
Similarly,

$$
\left(U^{\prime}\right)_{i}=(c)_{i}^{T}(\Delta)
$$

where $(\Delta)$ is the vector of global deflections at the origin. By using this transformation, each pile stiffness is moved to the origin of the pile cap. By using Equations 93, 94, and 95, a single-pile force-deflection relationship can be expressed as

$$
\begin{aligned}
& (q)_{i}=(c)_{i}(a)_{i}(a)_{i}^{T}(c)_{i}^{T}(\Delta) \\
& (Q)=\sum_{i=1}^{n}(q)_{i}
\end{aligned}
$$

where

$(Q)=$ resultant external loads applied at origin of pile foundation

$n=$ total number of piles in the foundation

This leads to the expression

$$
(Q)=\sum_{i=1}^{n}(c)_{i}(a)_{i}(b)_{i}(a)_{i}^{T}(c)_{i}^{T}(\Delta)
$$

An iterative solution is used to determine the deformation vector for the rigid pile cap. Initial $b$-factors are taken as the initial tangents to the various relationships described in the previous paragraph. The three-dimensional load vector is then applied, the cap deformation vector is computed, and the pile-head deformation vectors are computed. From these deformations pile-head reactions are computed from the present b-values. A check is then made of the compatibility of the reactions and deformations at each pile head using the predetermined nonlinear relationships. If compatibility in the reaction and deformation values is noted, new b-values are computed as secants to the axial and lateral pile head load-deformation relationships at the computed values of deformation, and the process is repeated as necessary until tolerance between the computed deformations and deformations on the predetermined relationships at the computed value of pile-head reaction is achieved at every pile.

Since individual, predetermined nonlinear relationships are used to represent the relationships between the various lateral deformation modes in two orthogonal directions, the solution that is thus obtained involves, in effect, superposition of nonlinear functions, which is not theoretically correct, and which may produce errors of practical magnitude as the pile-head behavior becomes highly nonlinear. However, where nonlinearity is relatively small, as would typically occur in the services load range, the errors are not significant. 


\section{Axial and lateral behavior algorithm used}

Pile-soil-pile interaction is then included as indicated in Figure 45. Once the pile-head deformation is known from the preceding solution, the axial and lateral behavior algorithms are used to compute the soil reaction (axial or lateral) at every node along every pile. (In practice, only selected nodes need to be used at this stage of the calculations.) Lateral reactions are computed in two local orthogonal directions. The lumped reactions against the soil on any generic Pile $\mathrm{J}$ at generic Node $\mathrm{j}$ are then transformed into a vector of orthogonal reactions in the local coordinate system $(X, Y, Z)$ shown in Figure 45 . The additional displacements in the local $X, Y, Z$ directions produced by these reactions on any other pile 1 in the system, denoted $d_{\text {ace }}(k=X, Y$, or $Z)$ in Figure 45, are then computed by using Mindlin's equations for displacements in the interior of a semi-infinite halfspace. If a rigid layer (e.g., rock) exists, the deflections computed using halfspace theory are corrected as indicated on Figure 45.

$$
\begin{aligned}
& d_{Z 11}^{J_{j}}=\frac{Q_{Z J j}}{16 \pi G(1-v)} \frac{3-4 v}{R_{1}}+\left[\frac{8(1-v)^{2}-(3-4 v)}{R_{2}}+\frac{(Z-C)^{2}}{R_{1}^{3}}\right. \\
& \left.+\frac{(3-4 v)(Z+C)^{2}-2 C Z}{R_{2}^{3}}+\frac{6 C Z(Z+C)^{2}}{R_{2}^{5}}\right] \\
& +\frac{Q_{X j i}\left(X_{j}^{i}\right)+Q_{Y J j}\left(Y_{j}^{i}\right)}{16 \pi G(1-v)}\left[\frac{Z-C}{R_{1}^{3}}+\frac{(3-4 v)(Z-C)}{R_{2}^{3}}\right. \\
& \left.-\frac{6 C Z(Z+C)}{R_{2}^{5}}+\frac{4(1-v)(1-2 v)}{R_{2}\left(R_{2}+Z+C\right)}\right] \\
& d_{X 11}^{J j}=\frac{Q_{X J j}}{16 \pi G(1-v)}\left\{\frac{3-4 v}{R_{1}}+\frac{1}{R_{2}}+\frac{\left(X_{j}^{i}\right)^{2}}{R_{1}^{3}}+\frac{(3-4 v)\left(X_{j}^{i}\right)^{2}}{R_{2}^{3}}\right. \\
& \left.+\frac{2_{C Z}}{R_{2}^{3}}\left[1-\frac{3\left(X_{j}^{i}\right)^{2}}{R_{2}^{2}}\right]\right\}+\frac{Q_{X J j}\left(X_{j}^{i}\right)\left(X_{j}^{i}\right)}{16 \pi G(1-v)}\left[\frac{1}{R_{1}^{3}}\right. \\
& \left.+\frac{(3-4 v)}{R_{2}^{3}}-6 \frac{C Z}{R_{2}^{5}}-\frac{4(1-v)(1-2 v)}{R_{2}\left(R_{2}+Z+C\right)^{2}}\right]
\end{aligned}
$$




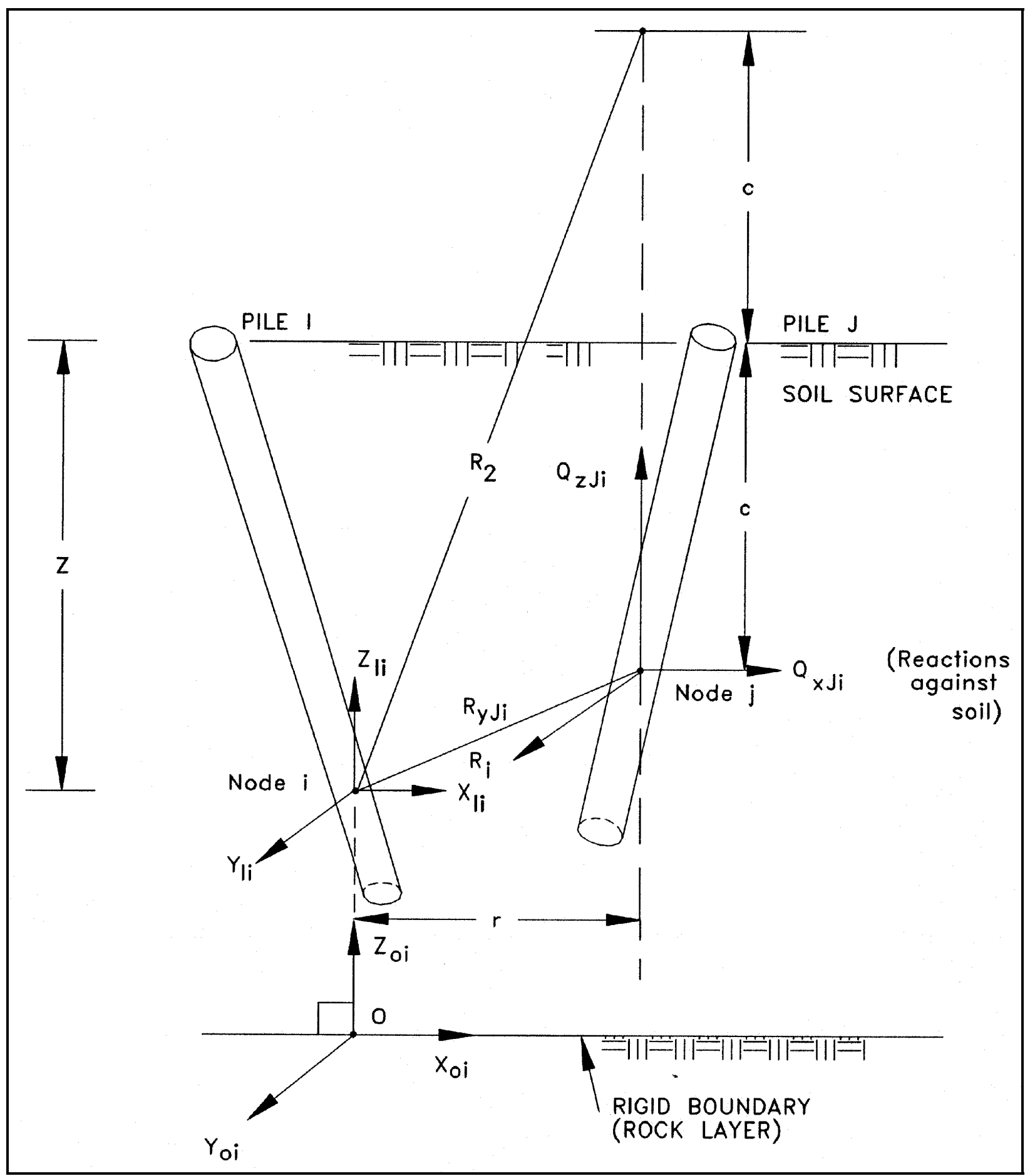

Figure 45. Geometric definitions for computation of added displacement 


$$
\begin{aligned}
d_{Y 11}^{J j} & =\frac{Q_{X J j}}{16 \pi G(1-v)}\left\{\frac{3-4 v}{R_{1}}+\frac{1}{R_{2}}+\frac{\left(Y_{j}^{i}\right)^{2}}{R_{1}^{3}}+\frac{(3-4 v)\left(Y_{j}^{i}\right)^{2}}{R_{2}^{3}}\right. \\
& \left.+\frac{2_{C Z}}{R_{2}^{3}}\left[1-\frac{3\left(Y_{j}^{i}\right)^{2}}{R_{2}^{2}}\right]\right\}+\frac{Q_{X J j}\left(X_{j}^{i}\right)\left(X_{j}^{i}\right)}{16 \pi G(1-v)}\left[\frac{1}{R_{1}^{3}}\right. \\
& \left.+\frac{(3-4 v)}{R_{2}^{3}}-6 \frac{C Z}{R_{2}^{5}}-\frac{4(1-v)(1-2 v)}{R_{2}\left(R_{2}+Z+C\right)^{2}}\right]
\end{aligned}
$$

It is therefore necessary for the analyst to prescribe values of Young's modulus and Poisson's ratio for the soil, which can vary linearly from the soil surface to the top of the rigid surface, and depth to the rigid surface. As with the elastic methods for axial response calculations, these moduli should generally conform to values obtained at low magnitudes of strain (O'Neill 1983).

The additional displacements at Node i, Pile I, due to reactions at all nodes on all piles other than Pile I, are then calculated and summed, and the resulting added deformations at Node i, Pile I due to PSPI are transformed back into the normal pile coordinate system. These displacements are then compared with the displacements computed initially, without considering PSPI. Adjustments are made to the unit load transfer curves ( $f-w, Q-w p-u$ in two orthogonal directions) to force the unit load transfer curves to pass through the soil displacement value defined by the sum of the initial displacement $\delta$ and the additional displacement $\delta^{\prime}$ in the appropriate direction at the value of soil reaction computed initially. Specifically, the entire curve is "stretched" by multiplying all displacement values on the original curve input by the analyst by $\left(\delta^{\prime}+\delta\right) / \delta$. This process is illustrated in Figure 46. It is evident that in geometrically complex groups every unit load transfer curve on every pile will be modified in a different manner. It is also evident that this procedure does not reduce the maximum unit load transfer that can occur at any node in either the axial or lateral direction; thus, it does not reduce the "capacity efficiency" of the group.

The solution for pile-cap deformations is then repeated using the modified unit load transfer curves, which produce, in general, different $b$ matrices for each pile in the system during this pass through the solution. The regeneration of the load-deformation relationships for this second pass for every pile in the system is the source of the high computational effort required for this method compared with Saul's method and which makes it generally impractical for the design office. Once the new, compatible pile head loads and deformations have been determined, the cap deformation vector is defined, and the axial and lateral algorithms are entered with pile-head deformations as boundary conditions to compute moments, shears and axial thrusts along the piles, if desired. If greater accuracy is desired, the correction process can be repeated; however, one set of 


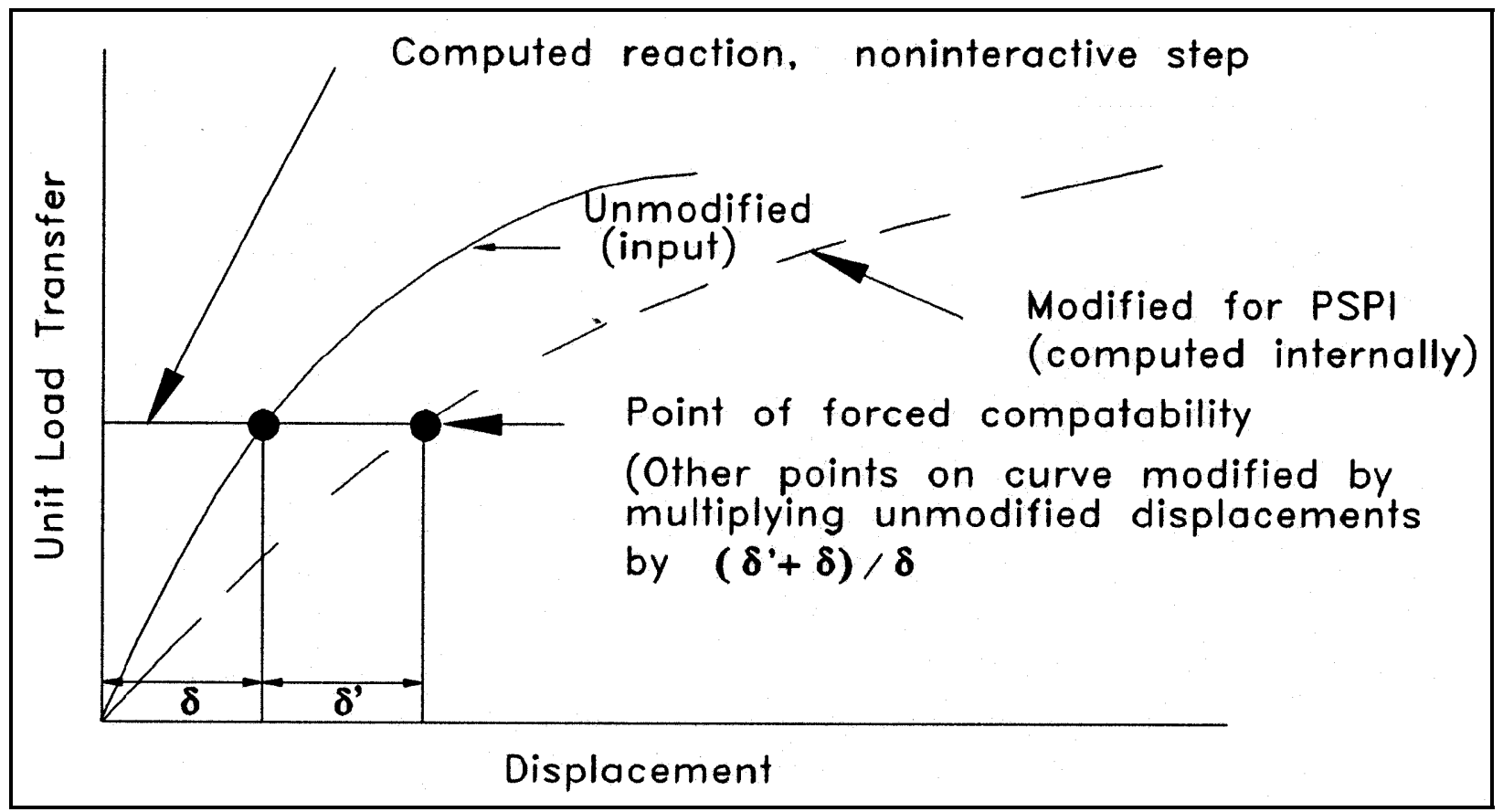

Figure 46. Modification of unit load transfer relationship for group effects at Node i, Pile I

corrections of the unit-load transfer curves appears appropriate for most problems.

\section{Flexible pile cap analysis}

The pile analysis methods described above assume that the pile cap, or structure base slab, is rigid in comparison to the stiffness of the piles. For many structures, such as U-frame lock monoliths, this is not a valid assumption, and the flexibility of the base slab should be considered. Currently there are no special-purpose programs to perform this type analysis, so the use of large general-purpose programs like SAP or STRUDL that can represent a flexible pile-cap foundation and piles must be used. The pile element used in the rigid base method has been added to several versions of the SAP and STRUDL programs. Flexible base analyses have already been performed for pile-founded structures designed by the Corps of Engineers. A more detailed report on flexible base analysis will be furnished at some future date.

\section{Nonlinear analysis}

One of the assumptions made in the rigid base analysis method is that a pile can be represented by a set of linear stiffnesses. The actual behavior of the pilesoil system may be highly nonlinear. Some existing programs are capable of nonlinear analysis of a structure that is supported by only a few piles. One such 
program which may be able to economically analyze a large number of piles under a foundation using a nonlinear model is PILGP2R. However, for large structures supported by as many as 200 piles, nonlinear analysis is not currently practical. The results of the two types of analyses are very close. In O'Neil and Tsao (1984) it was found that, while nonlinearity was an insignificant effect, a rational procedure must be applied to adjusting the subgrade reaction to be able to account for PSPI in typical Corps' structures. 


\section{References}

Andersen, P. (1956). "Substructure analysis and design," Ronald Press, New York.

Aschenbrenner, T. B., and Olson, R. E. (1984). "Prediction of settlement of single piles in clay." Analysis and design of pile foundations. American Society of Civil Engineers, J. R. Meyer, ed.

Briaud, J. L., and Tucker, L. (1984). "Piles in sand: A method including residual stresses." Journal of Geotechnical Engineering, Proceedings Paper 19262, American Society of Civil Engineers, Vol 110(11).

Cox, W. R., Reese, L.C., and Grubbs, B. R. (1974). "Field testing of laterally loaded piles in sand." Proceedings, Offshore Technology Conference, Paper No. 2079, Houston, TX.

Coyle, H. M., and Castello, R. R. (1981). "New design correlations for piles in sand," Journal of the Geotechnical Engineering Division, Proceedings Paper 16379, American Society of Civil Engineers, Vol 107(GT7).

Coyle, H. M., and Reese, L. C. (1966). "Load transfer for axially loaded piles in clay," Journal Soil Mechanics and Foundations Division, Proceedings Paper 4702, American Society of Civil Engineers, Vol 93(SM6).

Coyle, H. M., and Salaiman, I. H. (1967). "Skin friction for steel piles in sand," Journal Soil Mechanics and Foundations Division, Proceedings Paper 5590, American Society of Civil Engineers, Vol 93(SM6).

Dawkins, W. P. (1980). “Computer Program CBEAMC: Analysis of beamcolumns with nonlinear supports," U.S. Army Engineer Waterways Experiment Station, Vicksburg, MS.

(1982). "Pile head stiffness matrix on complete analysis of 2-D and 3-D vertical piles," U.S. Army Engineer Waterways Experiment Station, Vicksburg, MS. 
Dawkins, W. P. (1984). "Users guide: Computer program for soil-structure interaction analysis of axially loaded piles (CAXPILE)," Instruction Report K-84-4, U.S. Army Engineer Waterways Experiment Station, Vicksburg, MS.

Girijavallabhan, C. Y. (1969). "Buckling loads of nonuniform columns," Journal of the Structural Division, Paper No. 6908, American Society of Civil Engineers, Vol 95(ST11).

Hartman, J. P., Jaeger, J. J., Jobst, J. J., and Martin, D. K. (1989). “User's guide: Pile group analysis (CPGA) computer program," Technical Report ITL-89-3, U.S. Army Engineer Waterways Experiment Station, Vicksburg, MS.

Hetenyi, M. (1946). Beams on elastic foundation. The University of Michigan Press, Ann Arbor.

Heydinger, A. G. (1984). "Recommendations: Load-transfer criteria for piles in clay,” Technical Report ITL-87-1, U.S. Army Engineer Waterways Experiment Station, Vicksburg, MS. . (1986). "Analysis of axial pile-soil interaction in clay," International Journal for Numerical and Analytical Methods in Geomechanics 10(4), 367-381.

Hrennikoff, A. (1950). "Analysis of pile foundations with batter piles," Transactions, American Society of Civil Engineers Vol 115, 351-383.

Kraft, L. M., Ray, R. P., and Kagawa, T. (1981). "Theoretical t-z curves," Journal Geotechnical Engineering Division, Proceedings Paper 16653, American Society of Civil Engineers, Vol 107(GT11).

Matlock, H. (1970). "Correlations for design of laterally loaded piles in soft clay," Preprints, Second Annual Offshore Technology Conference, Paper No. 1204, Vol 1, 577-588.

Matlock, H., and Reese, L. C. (1962). "Generalized solutions for laterally loaded piles," Transactions, American Society of Civil Engineers, Paper No. 3170, Vol 127, Part 1, 1220-1248.

Mosher, R. L. (1984). "Load transfer criteria for numerical analysis of axially loaded piles in sand; Part 1: Load transfer criteria," Technical Report K-84-1, U.S. Army Engineer Waterways Experiment Station, Vicksburg, MS.

Murchison, J. M., and O'Neill, M. W. (1984). "Evaluation of p-y relationships in cohesionless soils," Analysis and design of pile foundations, American Society of Civil Engineers, J. R. Meyer, ed., 174-191. 
O'Neill, M.W. (1964). "Determination of the pile-head torque-twist relationship for a circular pile embedded in a clay soil," M.S. thesis, University of Texas, Austin.

O’Neill, M. W. (1983). "Group action in offshore piles." Proceedings, Geotechnical Practice in Offshore Engineering, American Society of Civil Engineers, 2-64.

O’Neill, M. W., and Gazioglu, S. M. (1984). "An evaluation of p-y relationships in clays," American Petroleum Institute, University of Houston.

O’Neill, M. W., and Tsai, C. N. (1984). “An investigation of soil nonlinearity and pile-soil-pile interaction in pile group analysis," Research Report No. UHUC 84-9, Department of Civil Engineering, University of Houston, prepared for U.S. Army Engineer Waterways Experiment Station, Vicksburg, MS.

O'Neill, M. W., Ghazzaly, O. I., and Ha, H. B. (1977). "Analysis of threedimensional pile groups with nonlinear soil response and pile-soil-pile interaction," Paper No. 2838, Proceedings, Ninth Offshore Technology Conference, Houston, TX.

Poulos, H. G. (1975). "Torsional response of profiles," Proceedings, American Society of Civil Engineers, GTIO.

. (1983). "Cyclic axial pile response - alternative analyses," Proceedings, Specialty Conference on Geotechnical Practice in Offshore Engineering, American Society of Civil Engineers, S. G. Wright, ed., 403-21.

Poulas, H. G., and Davis, E. H. (1980). Pile foundation analysis and design. John Wiley and Sons, New York, 13-15, 52-66, 71-83.

Randolph, M. F., and Wroth, C. P. (1978). "Analysis of deformation of vertically loaded piles," Journal Geotechnical Engineering Division, American Society of Civil Engineers, Proceedings Paper 14262,Vol 104(GT12).

Reese, L. C., and Matlock, H. (1956). "Non-dimensional solutions for laterally loaded piles with soil modulus assumed proportional to depth," Proceedings, Eighth Texas Conference on Soil Mechanics and Foundation Engineering, Special Publication No. 29, Bureau of Engineering Research, The University of Texas at Austin.

Reese, L. C., and Sullivan, W. R. (1980). "Documentation of Computer Program COM624; Parts I and II, Analysis of Stresses and Deflections for Laterally-Loaded Piles Including Generation of p-y Curves," Geotechnical Engineering Software SG80-1, Geotechnical Engineering Center, Bureau of Engineering Research, University of Texas at Austin. 
Reese, L. C., and Welch, R. C. (1975). "Lateral loading of deep founcations in stiff clay," Journal, Geotechnical Engineering Division, American Society of Civil Engineering 101(GT7), 633-649.

Reese, L. C., Cooley, L. A., and Radhakrishnan, N. (1984). "Laterally loaded piles and computer program COM624G," Technical Report K-84-2, U.S. Army Engineer Division, Lower Mississippi Valley, Vicksburg, MS.

Reese, L. C., Cox, W. R., and Koop, F. D. (1974). "Analysis of laterally loaded piles in sand." Proceedings, Fifth Annual Offshore Technology Conference, Paper No. OTC 2080, Houston, TX.

. (1975). "Field testing and analysis of laterally loaded piles in stiff clay." Proceedings, Seventh Offshore Technology Conference, Paper No. OTFC 2312. Houston, TX.

Saul, W. E. (1968). "Static and dynamic analysis of pile foundations," Journal Structural Division, American Society of Civil Engineers, Proceedings Paper 5936,Vol 94(ST5).

Scott, R. F. (1981). Foundation analysis. Prentice-Hall, Englewood Cliffs, NJ.

Seed, H. B., and Reese, L. C. (1957). "The action of soft clay along friction piles," Transactions, American Society of Civil Engineers, Vol 122.

Semple, R. M., and Rigden, W. J. (1984). "Shaft capacity of driven pile in clay," Analysis and design of pile foundations, American Society of Civil Engineers, J. R. Meyer, ed., 59-79.

Skempton, A. W. (1951). "The Bearing Capacity of Clays." Proceedings, Building Research Congress, Vol I, Part IIV, 180-189.

Stoll, U. W. (1972). "Torque shear test of cylindrical friction piles." Civil Engineering, American Society of Civil Engineers, Vol 42, 63-65.

Sullivan, W. R. (1977). Development and evaluation of a unified method for the analysis of laterally loaded piles in clay, M. S. thesis, Graduate School of the University of Texas at Austin.

Sullivan, W. R., Reese, L. C., and Fenske, C. W. (1979). "Unified method for analysis of laterally loaded piles in clay." Proceedings, Numerical Methods in Offshore Piling, Institution of Civil Engineers, London, 107-118.

Teng, W. C. (1962). Foundation design. Prentice-Hall, Inc.

Terzaghi, K. (1943). Theoretical soil mechanics. John Wiley and Sons, Inc., New York. 
Terzaghi, K. (1955). "Evaluation of coefficients of subgrade reaction," Geotechnique, Vol 5.

U.S. Army Corps of Engineers. (1994). "Design of Pile Foundations," Engineer Manual 1110-2-2906, Washington, DC.

Vesic, A. S. (1977). "Design of pile foundations," NCHRP Synthesis of Highway Practice No. 42, Transportation Research Board, Washington, DC.

Vijayvergiya, V. N. (1977). "Load-movement characteristics of piles," Proceedings, Ports 77, American Society of Civil Engineers, Vol II, 269-286.

Yazdanbod, A., O'Neill, M. W., and Aurora, R. P. (1984). "Phenomenological study of model piles in sand," Geotechnical Testing Journal, American Society for Testing and Materials 7(3), 135-144. 


\section{Bibliography}

Alizadeh, M., and Davisson, M. T. (1970). "Lateral load tests on piles-Arkansas River Project," Journal Soil Mechanics and Foundations Division, Proceedings Paper 7510, American Society of Civil Engineers, Proceedings Paper 7510, Vol 96 (SM5), 1583-1604.

Bogard, D., and Matlock, H. (1980). "Simplified calculations of p-y curves for laterally loaded piles in sand," (unpublished report), The Earth Technology Corporation, Inc., Houston, TX.

. (1981). "Computer Program AXPILE: Soil-structure interaction analysis of axially loaded piles," U.S. Army Engineer Waterways Experiment Station, Vicksburg, MS.

Department of the Army. "User guide: Computer program for analysis of pile groups - CPGA," in preparation, CASE Task Group on Pile Foundations, Headquarters, U.S Army Corps of Engineers, Washington, DC.

Department of the Army. (1983). "Basic pile group behavior," Technical Report K-83-1, CASE Task Group on Pile Foundations, Headquarters, U.S. Army Corps of Engineers, Washington, DC.

Meyer, B., and Reese, L. C. (1979). "Analysis of single piles under lateral load ing," Research Report No. 244-1, Center for Transportation Research, The University of Texas at Austin.

O'Neill, M. W., and Tsai, C-N. (1984). "An investigation of soil nonlinearity and pile-soil-pile interaction in pile group analysis," Report No. UHCE 84-9, Department of Civil Engineering, University of Houston, University Park, TX.

Puech, A., Boulton, M., and Meimon, Y. (1982). “Tension piles: Field data and numerical modeling," Proceedings, Second International Conference on Numerical Methods in Offshore Piling, I.C.E. and The University of Texas, April, 293-312. 


\section{Appendix A}

\section{Linear Approximations for Load Deformation of Axial Piles}

\section{Linear Elastic Analyses}

For a linearly elastic representation of the pile-soil system, the governing differential equation is

$$
E A \frac{d^{2} w}{d_{z}^{2}}-E_{z}(z) w=0
$$

where $E_{z}(z)$ is the stiffness of the axial load-transfer mechanism. A typical $f$-w curve is shown in Figure A1. At any displacement $w$ the nonlinear $f$ - $w$ curve may be replaced by a linear secant $k_{f}(\mathrm{z})$. The total stiffness of the load-transfer mechanism appearing in Equation A1 is given by

$$
E_{z}(z)=2 R k_{f}(z)
$$

\section{Soil Stiffness Constant with Depth}

Even though Equation A1 is representative of a linearly elastic system, a closed-form solution is possible only if the side friction stiffness is constant with depth. While this condition is not encountered in most soil-pile systems, the solution for constant stiffness serves to indicate characteristics of the system behavior.

For $E_{z}$ constant with depth, the solution of Equation A1 may be written as 


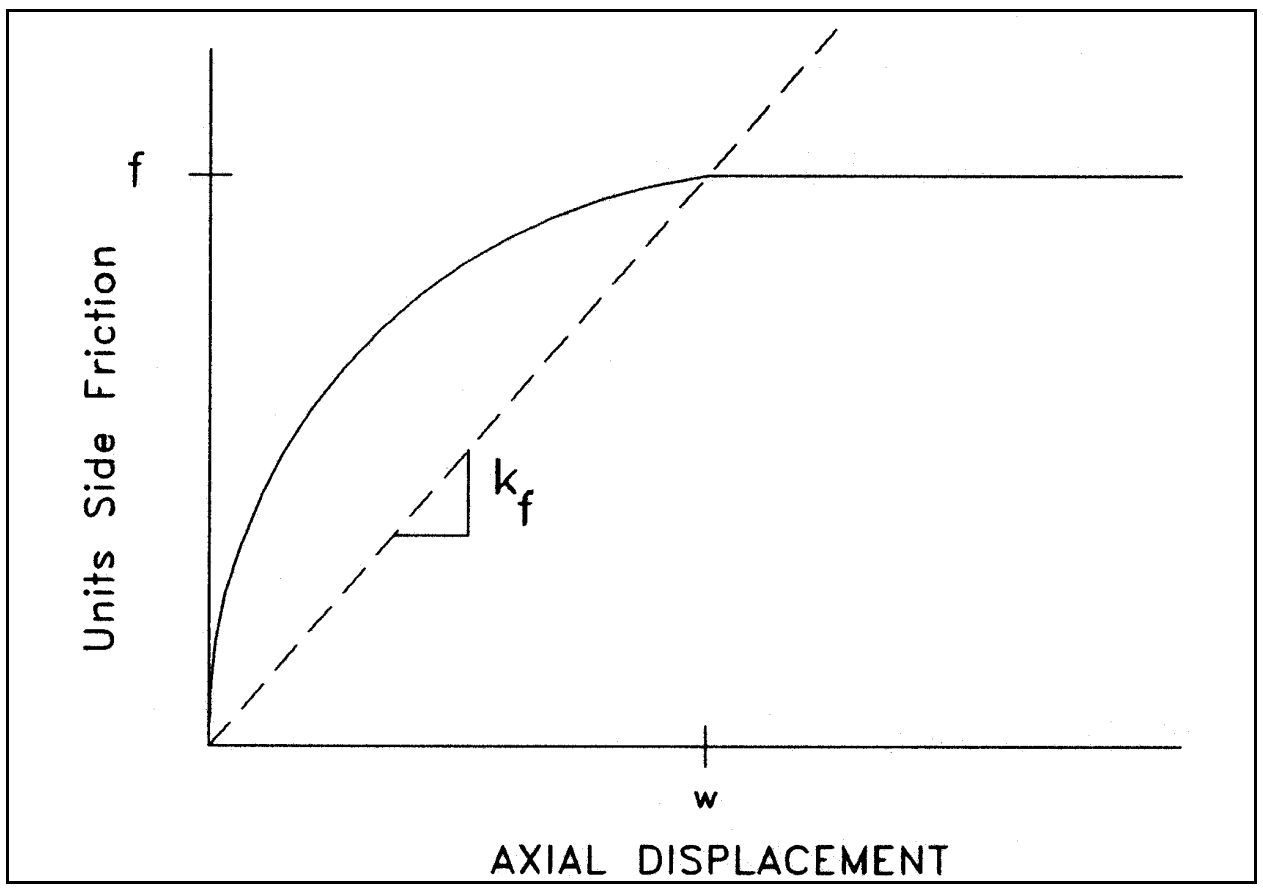

Figure A1. Typical $f-w$ curve

$$
w=\frac{P_{o} T_{z}}{E A}\left(C 1 \cos h \frac{z}{T_{z}}-\sin h \frac{z}{T_{z}}\right)
$$

where

$P_{o}=$ axial compressive force at pile head

$$
T_{\mathrm{z}}=\mathrm{EA} / \mathrm{E}
$$

$C 1=$ constant to be determined from conditions at the pile tip $(z=L)$

At the pile tip, three alternative conditions are presented:

a. Tip reaction equals zero: At $z=L, Q=0$, hence

$$
C 1=\frac{\cos h L / T_{z}}{\sin h L / T_{z}}=\frac{\cos h Z_{\max }}{\sin h Z_{\max }}
$$

b. Tip displacement equals zero: At $z=L, w=0$, hence

$$
C 1=\frac{\sin h Z_{\max }}{\cos h Z_{\max }}
$$


c. Tip elastically restrained: At $z=L, Q=K_{t} w_{t}$, hence

$$
C 1=\frac{\cos h Z_{\text {max }}+r \sin h Z_{\text {max }}}{\sin h Z_{\text {max }}+r \cos h Z_{\text {max }}}
$$

where

$$
\begin{aligned}
r & =K_{t} / E_{z} T_{z} \\
K_{t} & =\text { stiffness of elastic resistance at pile tip } \\
Z_{\max } & =L / T_{z}
\end{aligned}
$$

\section{Pile Head Axial Stiffness}

Of particular interest is the relationship between the pile head force $P_{\mathrm{o}}$ and axial displacement $w_{o}$. For convenience, this is defined by

$$
a_{o}=\frac{E A}{T_{z}} \frac{w_{o}}{P_{o}}
$$

where

a. Pile tip free

$$
a_{o}=\frac{\cos h Z_{\max }}{\sin h Z_{\max }}
$$

b. $\quad$ Pile tip fixed

$$
a_{o}=\frac{\sin h Z_{\max }}{\cos h Z_{\max }}
$$

c. Pile tip elastically restrained

$$
a_{o}=\frac{\cos h Z_{\max }+\sin h Z_{\max }}{\sin h Z_{\max }+r \cos h Z_{\max }}
$$

$a_{o}$ is plotted for various values of $Z_{\max }$ in Figure A2. It is observed that for values of $Z_{\max }$ greater than 2, conditions at the tip have a negligible effect on the pile head force-displacement relationship. As will be discussed later, the pile head axial force-displacement relationship forms a part of the elastic pile head stiffness matrix used in the analysis of pile groups. The axial pile head stiffness coefficient is given by 


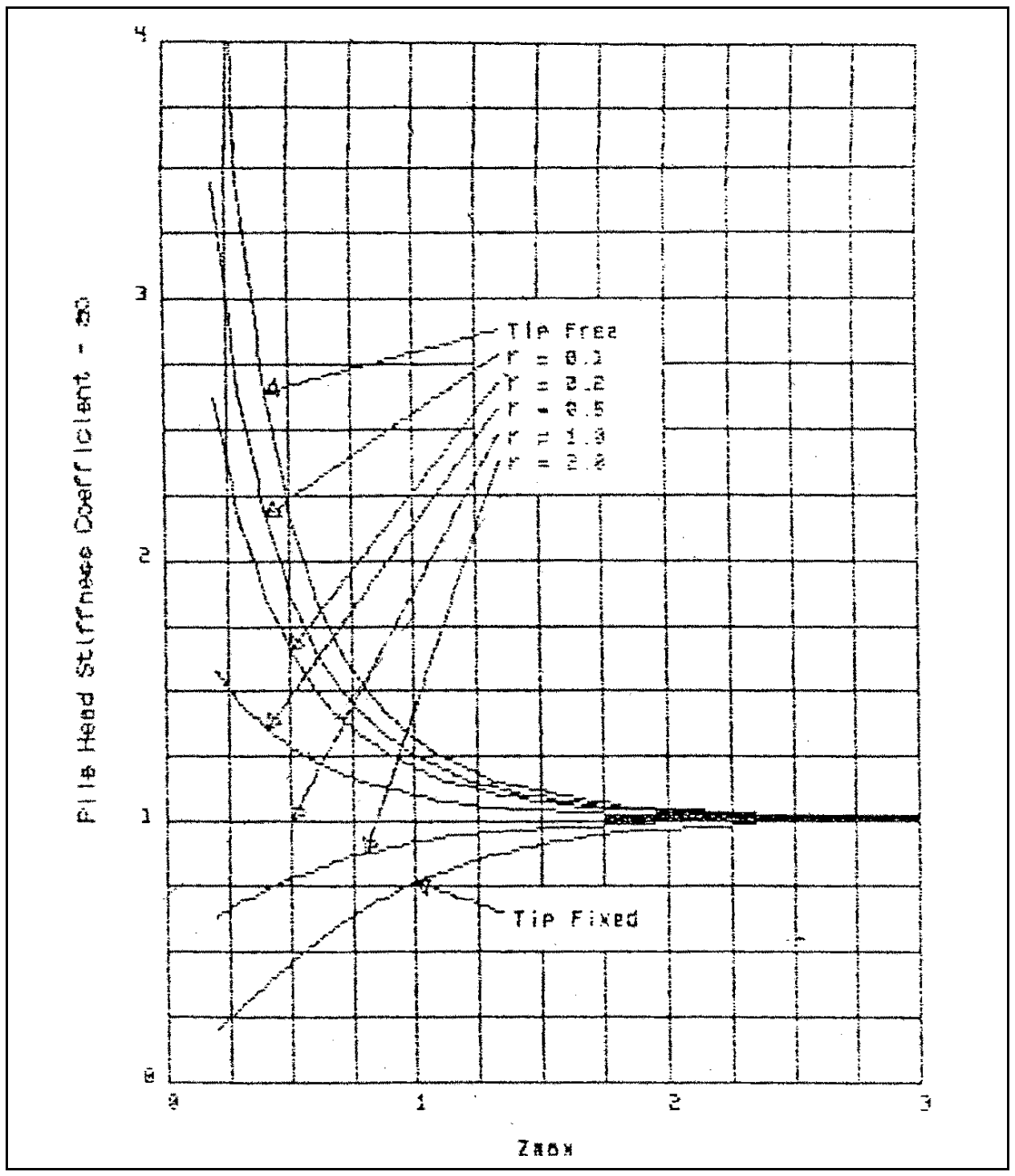

Figure A2. Axial stiffness coefficient for constant soil stiffness

$$
\frac{P_{o}}{w_{o}}=\frac{E A}{T_{z}} \frac{1}{a_{o}}
$$

\section{Nondimensional Analysis for Variable Soil Stiffness}

As discussed earlier, the stiffness of the side friction displacement relationship increases with depth. For axial head loads in the working load range (e.g., one-half of the ultimate load), it has been found that the equivalent elastic 
side friction increases approximately linearly with depth for normally consolidated clays and as the square root of the depth in homogeneous sands. In general, these variations may be expressed as

$$
E_{z}(z)=K_{o}+K_{f} z^{n}
$$

where

$$
\begin{aligned}
K_{o}= & \text { elastic stiffness of the side friction effect at the ground surface } \\
K_{f}= & \text { elastic stiffness coefficient of the side friction effect in units of force per } \\
& \text { unit length of pile per unit deflection } \\
n= & 1 \text { for a linear variation with depth } \\
n= & 1 / 2 \text { for variation as the square root of depth }
\end{aligned}
$$

Because the stiffness of the side friction effect is a function of the strength of the soil, $K_{o}$ will be zero for sands. Some adhesion of clay soil may occur at the ground surface and $K$ for clays may not be zero. However, it is likely that installation effects will minimize adhesion near the ground surface and a conservative estimate is obtained for $K_{o}=0$. For the general variation with $K_{o}=$ 0 , the governing differential equation is

$$
E A \frac{d^{2} w}{d z^{2}}-K f z^{n} w=o
$$

Closed form solutions of Equation A13 do not exist. However, nondimensional solutions may be obtained with relatively simple numerical techniques as described below.

Following the procedures described by Matlock and Reese (1962), the following nondimensional parameters are defined.

$$
\begin{aligned}
& Z=\frac{Z}{T_{z}} \\
& Z_{\text {max }}=\frac{L}{T_{z}} \\
& a(Z)=\frac{E A w(z)}{P_{o} T_{z}} \\
& r=\frac{K_{t}}{K_{f}\left(T_{z}\right)^{n+1}}
\end{aligned}
$$




$$
T_{z}^{(n+20)}=\frac{E A}{K_{f}}
$$

Substitution of the nondimensional parameters into the governing differential equation yields

$$
\frac{d^{2} a(Z)}{d Z^{2}}-Z^{n} a(Z)=0
$$

Equation A19 may be solved for $a(Z)$ by any numerical technique (e.g., finite differences). From the solution of Equation A19, the relationship between pile head force and head displacement is obtained as $a(Z=0)$, whence

$$
a_{o}=\frac{E A w_{o}}{P_{o} T_{z}}
$$

and the pile head axial stiffness is

$$
\frac{P_{o}}{w_{o}}=\frac{E A}{T_{z}} \frac{1}{a_{o}}
$$

Values of the stiffness parameter are plotted in Figure A3 for a linear variation of side friction stiffness with depth and in Figure 25 for side friction stiffness varying as the square root of depth. These figures indicate that the tip reaction stiffness has negligible effect for values of $Z_{\max }$ greater than 2 .

\section{Evaluation of Side Friction Stiffness for Piles in Sand}

\section{Method ESSF1}

Mosher (1984) suggested a secant stiffness computed using an axial displacement of $0.1 \mathrm{in}$. from his expression for the $f$ - $w$ curve. The resulting estimate of elastic stiffness for side friction is

$$
E_{z}=\frac{k_{f} f_{\max } C}{144\left(f_{\max }+0.1 k_{f}\right)}
$$




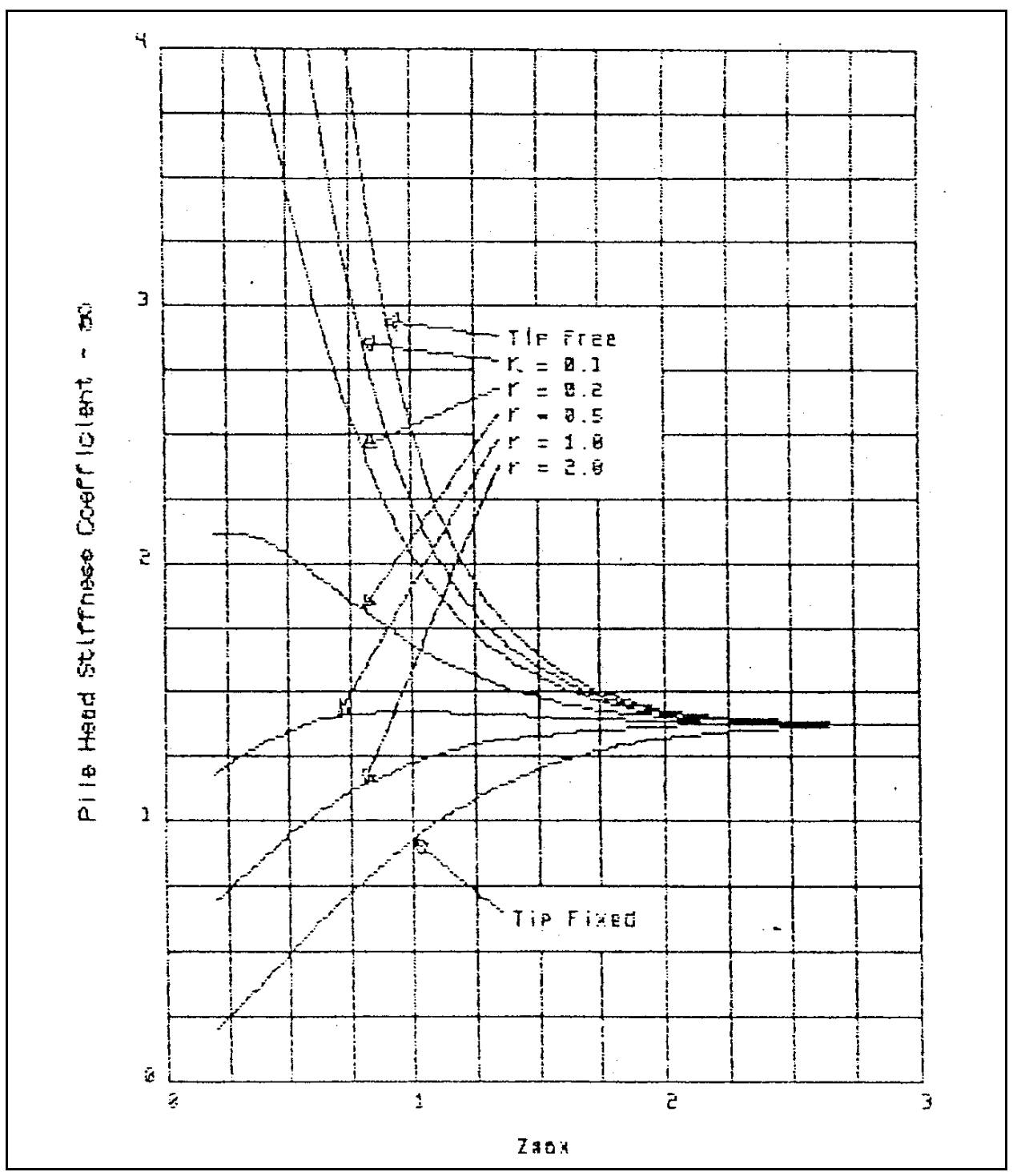

Figure A3. Axial stiffness coefficient for soil stiffness varying linearly with depth where

$$
\begin{aligned}
k_{f} & =\text { initial slope of the } f-w \text { curve given in Table } 1 \text { in psf } \\
f_{\max } & =\text { ultimate side friction given in Figure } 4 \text { converted to units of psf } \\
C & =2 \\
R & =\text { circumference of the pile }
\end{aligned}
$$

The resulting units of $E_{z}$ are in psi. 


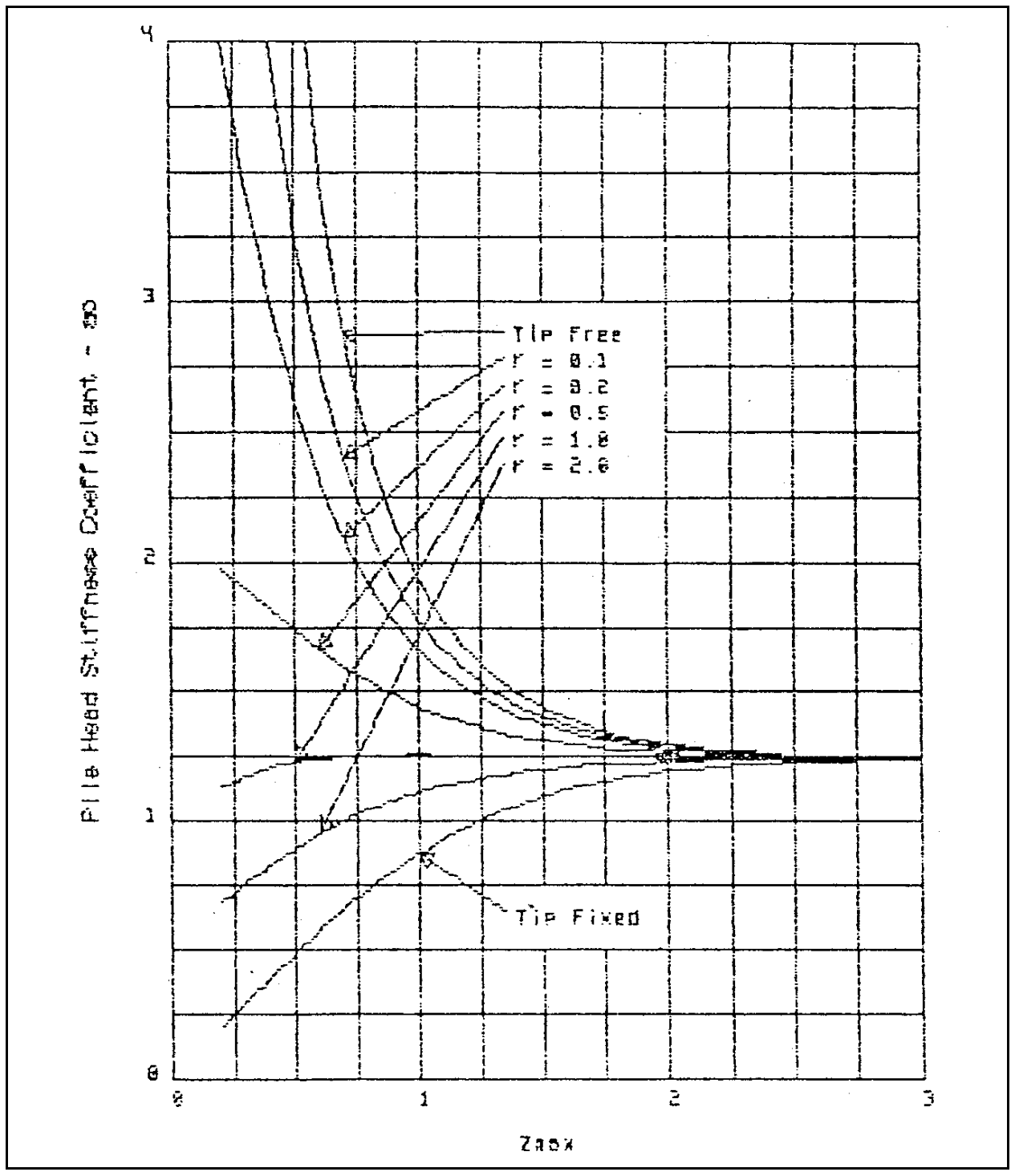

Figure A4. Axial stiffness coefficient for soil stiffness varying as square root of depth

The expression for $E_{z}$ in Equation A22 includes an implicit variation with depth embodied in the curves for $f_{\max }$ as a function of relative depth (see Figure 4 in the main text). An examination of these curves suggests that the variation of $E_{z}$ approximates a curve proportional to the square root of depth. To utilize the side friction stiffness for this procedure, the actual variation of $E_{z}$ could be fitted to a curve which varies as the square root of depth (e.g. by least squares fit). 


\section{Method ESSF2}

The procedure of Kraft, Ray, and Cagawa (1981) for $f$ - $w$ curves for sand may be used to approximate elastic conditions through the use of the initial slope of the $f-w$ curve. From Equation 6 in the main text, the initial slope of the $f-w$ curve yields:

a. For a homogeneous medium, a constant side friction stiffness equal to

$$
E_{z}(z)=\frac{G_{t} C}{R \ln \frac{2 L(1-v)}{R}}
$$

$b$. For a medium in which shear modulus varies from zero at the ground surface to $G_{t}$ at the pile tip, a linearly varying side friction stiffness equal to

$$
E_{z}(z)=\frac{G_{t} C}{R \ln \frac{2 L(1-v)}{R}} \frac{z}{L}
$$

c. For a soil affected by pile installation, the shear modulus $G$ or $G_{t}$ appearing in Equations A23 and A24 should be replaced by an effective modulus as given in Equation 10 or 11 in the main text.

\section{Evaluation of Side Friction Stiffness for Piles in Clay}

\section{Method ECSF1}

Kraft, Ray, and Kagawa (1981) suggest that the same procedures used for sand may be used for piles in clay with the shear moduli appearing in Equations A23 and A24 being modified to account for magnitude and time of loading, as shown in Table A1.

\section{Method ECSF2}

Heydinger (1984) suggests using a secant to the $f$-w curve evaluated at a relative displacement $w / 2 R=0.005$. From Equation 22 in the main text, 


\begin{tabular}{||l|l|}
\hline $\begin{array}{l}\text { Table A1 } \\
\text { Adjustment in G for Various Loading Conditions (Adjustment } \\
\text { factor = G (operational/G (in situ)) }\end{array}$ \\
\hline \hline Condition & Adjustment Factor \\
\hline \hline & \multicolumn{1}{|c|}{ Immediately After Driving } \\
\hline \hline Small load & 0.85 \\
\hline Large load (> working load) & 0.54 \\
\hline \hline & After Setup \\
\hline \hline Small load & 1.04 \\
\hline Large load $\left(f=0.4 s_{u}\right)$ & 0.96 \\
\hline Large load $\left(f=s_{u}\right)$ & 0.73 \\
\hline
\end{tabular}

$$
E_{z}=\frac{E_{f} C / 2 R}{1+\left(0.005 \frac{E_{f}}{f_{\max }}\right)^{m^{1 / m}}}
$$

where $E_{f}$ and $m$ are given by Equations 23 and 24 in the main text, respectively. The variation of $E_{2}$ along the pile depends on the distribution of soil modulus of elasticity used in the evaluation of $E_{f}$ from Equation 23.

\section{Method ECSF2}

The elasto-plastic representation of side friction due to Aschenbrener and Olson (1984) yields

$$
E_{z}=\frac{s_{u} C}{0.1(\text { in. })}
$$

where for consistent units $S_{u}$ should be expressed in psi and $C$ in inches producing $E_{z}$ in psi.

\section{Evaluation of Tip Reaction Stiffness}

\section{General}

As shown previously, the tip reaction only has a significant effect on the pile head stiffness coefficient for piles having $Z_{\max }$ less than 2 . If the value of $Z_{\max }$ resulting from any of the assessments of side friction described above is less than 2 , the tip reaction stiffness may be omitted. 
In the discussions for evaluating the tip reaction stiffness that follow, stiffness is proportional to the effective area at the tip $A_{\mathrm{t}}$ bearing on the soil. For closed end or solid piles the effective tip area may reasonably be taken as the cross section area of the pile. For H-piles or open-ended pipe piles the tip area may be as little as the area of material in the cross section to an area equal to that bounded by the exterior of the section (see Figure 5 in the main text). When the radius of the tip reaction area is required to evaluate tip stiffness, an effective radius is obtained from

$$
R_{t}=\sqrt{A_{t} / \pi}
$$

The tip reaction stiffness may be obtained from any of the procedures described previously for developing $q$ - $w$ curves by evaluating a secant stiffness for a tip displacement representative of working load conditions. Typically in the Corps of Engineers, failure at the tip is considered to occur at a tip displacement of $0.25 \mathrm{in}$. Unless stated otherwise, working load conditions are assumed to occur at one-tenth of the displacement corresponding to failure (i.e., 0.025 in.).

\section{Evaluation of Tip Reaction Stiffness for Piles in Sand}

\section{Method EST1}

The theory of elasticity solution for a rigid punch has been used by Kraft, Ray, and Kagawa (1981) (see also Randolph and Wroth 1978) to estimate the tip reaction stiffness as

$$
K_{t}=\frac{4 R_{t} G}{I_{t}(1-v)}
$$

where the shear modulus $G$ should be taken as an average in situ value between $6 R_{t}$ above the pile tip to $6 R_{t}$ below the tip. The factor $I_{t}$ in Equation A28 is an influence factor ranging from 0.5 to 0.78 .

\section{Method EST2}

Mosher (1984) and Vijayvergiya (1977) express the tip reaction $q$ - $w$ curve as a power function (see pages 24-26). Mosher recommends for working load approximations a secant tip reaction stiffness corresponding to a tip displacement of 0.025 in. The corresponding tip stiffnesses are:

a. For loose sand: $K_{t}=12.6 A_{t} q_{\max }$

b. For medium sand: $K_{t}=18.6 A_{t} q_{\max }$ 
c. For dense sand: $K_{t}=22.5 A_{t} q_{\max }$

where $q_{\max }$ is the ultimate unit tip reaction from Figure 17. For consistent units in Equations A29 through A31, $q_{\max }$ must be in pounds per square inch, and $A_{t}$ must be in square inches, which yields $K_{t}$ in pounds per inch.

\section{Method EST3}

A secant stiffness obtained from the work of Briaud and Tucker (1984), which considers the effects of residual stresses due to installation for a tip displacement 0.0.025 in., is

$$
K_{t}=\frac{k_{q} q_{\max } A_{t}}{q_{\max }+0.025 k_{q}}
$$

and

$$
k_{q}=467.1 N^{0.0065}
$$

where $N$ is the average uncorrected standard penetration count in blows per foot from a distance of $8 R_{t}$ above the pile tip to $8 R_{t}$ below the tip. The units of $k_{q}$ in Equation A33 are tsf/in. The required units of other terms in Equation A32 are $q_{\max }$ in tons per square foot and $A_{t}$ in square feet, which yields $K_{t}$ in tons per inch.

\section{Evaluation of Tip Reaction Stiffness for Piles in Clay}

\section{Method ECT1}

The bilinear tip reaction curve used by Aschenbrener and Olson (1984) produces

$$
K_{t}=\frac{9 s_{u} A_{t}}{0.02 R_{t}}
$$

where $s_{u}$ is the average undrained shear strength of the clay from $6 R_{t}$ above the pile tip to $6 R_{t}$ below the tip.

\section{Method ECT2}

The tip stiffness developed by Kraft, Ray, and Kagawa (1981) described on page A11 may be used for piles in clay. 


\section{Method ECT3}

Skempton (1951) observed the similarity of the load-displacement behavior of a plate load test and the laboratory stress-strain curve for soft clays. It was concluded that a linear approximation of the load displacement relationship up to half of the ultimate load could be related to the strain at 50 percent of the unconfined compression strength indicated by the laboratory stress-strain curve. The observation has been used to obtain an estimate of the pile tip reaction stiffness as

$$
K_{t}=\frac{q_{u} A_{t}}{5 \epsilon_{50} R_{t}}
$$

where

$q_{u}=$ unconfined compression strength of the clay at the pile tip

$A_{t}=$ effective tip area

$\epsilon_{50}=$ strain at 50 percent of ultimate strength from a laboratory stress-strain curve

$R_{t}=$ effective radius of the tip area

Typical values of $\epsilon_{50}$ are 0.02 for a very soft clay, 0.01 for a soft clay, and 0.005 for a stiff clay. 


\section{Appendix B Nondimensional Coefficients for Laterally Loaded Piles}

Basic Equations

$$
\begin{aligned}
& E_{z}=k z^{n} \\
& T^{n+4}=\frac{E I}{k} \\
& E I \frac{d^{4} u(z)}{d z^{4}}+k z^{n} u(z)=0 \\
& Z=\frac{z}{T} \\
& Z_{\max }=\frac{L}{T} \\
& u(Z)=\frac{V_{o} T^{3}}{E I} A_{u}(Z)+\frac{M_{o} T^{2}}{E I} B_{u}(Z) \\
& M(Z)=V_{o} T A_{m}(Z)+M_{o} B_{m}(Z) \\
& \frac{d u}{d z}=\frac{V_{o} T^{2}}{E I} A_{s}(Z)+\frac{M_{o} T}{E I} B_{s}(Z)
\end{aligned}
$$




\begin{tabular}{|c|c|c|c|c|c|c|c|c|c|}
\hline \multicolumn{10}{|c|}{$\begin{array}{l}\text { Table B1 } \\
\text { Nondimensional Coefficients for Laterally Loaded Pile for Soil Modulus Constant with } \\
\text { Depth (Head Shear } V_{0}=1 \text {, Head Moment } M_{o}=0 \text { ) }\end{array}$} \\
\hline \multirow[b]{2}{*}{$z$} & \multicolumn{3}{|c|}{$Z_{\max }=2$} & \multicolumn{3}{|c|}{$Z_{\max }=3$} & \multicolumn{3}{|c|}{$Z_{\max }=4$} \\
\hline & $\boldsymbol{A}_{u}$ & $\boldsymbol{A}_{s}$ & $\boldsymbol{A}_{m}$ & $\underline{\boldsymbol{A}_{u}}$ & $A_{s}$ & $\boldsymbol{A}_{m}$ & $\boldsymbol{A}_{u}$ & $\boldsymbol{A}_{s}$ & $\boldsymbol{A}_{m}$ \\
\hline 0.00 & 2.118 & -1.741 & 0.000 & 1.597 & -1.116 & 0.000 & 1.474 & -1.032 & 0.000 \\
\hline 0.10 & 1.944 & -1.736 & 0.092 & 1.486 & -1.111 & 0.094 & 1.371 & -1.027 & 0.095 \\
\hline 0.20 & 1.771 & -1.723 & 0.164 & 1.375 & -1.097 & 0.174 & 1.248 & -1.009 & 0.192 \\
\hline 0.30 & 1.600 & -1.704 & 0.219 & 1.266 & -1.076 & 0.240 & 1.168 & -0.992 & 0.247 \\
\hline 0.40 & 1.430 & -1.680 & 0.257 & 1.160 & -1.050 & 0.293 & 1.051 & -0.958 & 0.315 \\
\hline 0.50 & 1.264 & -1.653 & 0.282 & 1.057 & -1.018 & 0.335 & 0.976 & -0.931 & 0.351 \\
\hline 0.60 & 1.100 & -1.624 & 0.294 & 0.956 & -0.983 & 0.366 & 0.867 & -0.886 & 0.395 \\
\hline 0.70 & 0.939 & -1.594 & 0.294 & 0.860 & -0.945 & 0.388 & 0.797 & -0.854 & 0.417 \\
\hline 0.80 & 0.781 & -1.565 & 0.286 & 0.767 & -0.906 & 0.401 & 0.698 & -0.802 & 0.441 \\
\hline 0.90 & 0.626 & -1.537 & 0.269 & 0.679 & -0.865 & 0.406 & 0.635 & -0.767 & 0.451 \\
\hline 1.00 & 0.474 & -1.512 & 0.246 & 0.594 & -0.825 & 0.405 & 0.546 & -0.712 & 0.458 \\
\hline 1.10 & 0.324 & -1.488 & 0.219 & 0.514 & -0.784 & 0.397 & 0.491 & -0.675 & 0.459 \\
\hline 1.20 & 0.176 & -1.468 & 0.188 & 0.437 & -0.745 & 0.385 & 0.413 & -0.620 & 0.454 \\
\hline 1.30 & 0.030 & -1.451 & 0.156 & 0.365 & -0.708 & 0.368 & 0.365 & -0.584 & 0.447 \\
\hline 1.40 & -0.114 & -1.437 & 0.123 & 0.296 & -0.672 & 0.347 & 0.298 & -0.532 & 0.433 \\
\hline 1.50 & -0.258 & -1.426 & 0.091 & 0.230 & -0.638 & 0.324 & 0.257 & -0.497 & 0.421 \\
\hline 1.60 & -0.400 & -1.418 & 0.062 & 0.168 & -0.607 & 0.298 & 0.200 & -0.448 & 0.400 \\
\hline 1.70 & -0.541 & -1.413 & 0.037 & 0.109 & -0.579 & 0.270 & 0.165 & -0.417 & 0.385 \\
\hline 1.80 & -0.683 & -1.411 & 0.017 & 0.052 & -0.553 & 0.241 & 0.118 & -0.372 & 0.359 \\
\hline 1.90 & -0.824 & -1.410 & 0.005 & -0.002 & -0.531 & 0.212 & 0.089 & -0.344 & 0.341 \\
\hline 2.00 & -0.965 & -1.410 & 0.000 & -0.054 & -0.511 & 0.183 & 0.051 & -0.305 & 0.314 \\
\hline 2.10 & & & & -0.104 & -0.494 & 0.154 & 0.027 & -0.280 & 0.295 \\
\hline 2.20 & & & & -0.153 & -0.480 & 0.127 & -0.004 & -0.247 & 0.266 \\
\hline 2.30 & & & & -0.200 & -0.469 & 0.101 & -0.023 & -0.226 & 0.247 \\
\hline 2.40 & & & & -0.247 & -0.460 & 0.077 & -0.049 & -0.198 & 0.218 \\
\hline 2.50 & & & & -0.292 & -0.453 & 0.055 & -0.064 & -0.182 & 0.200 \\
\hline 2.60 & & & & -0.337 & -0.449 & 0.037 & -0.084 & -0.159 & 0.173 \\
\hline 2.70 & & & & -0.382 & -0.446 & 0.021 & -0.097 & -0.146 & 0.155 \\
\hline
\end{tabular}




\begin{tabular}{|c|c|c|c|c|c|c|c|c|c|}
\hline \multicolumn{10}{|c|}{ Table B1 (Concluded) } \\
\hline \multirow[b]{2}{*}{$z$} & \multicolumn{3}{|c|}{$Z_{\max }=2$} & \multicolumn{3}{|c|}{$Z_{\max }=3$} & \multicolumn{3}{|c|}{$Z_{\max }=4$} \\
\hline & $\underline{\boldsymbol{A}_{u}}$ & $A_{s}$ & $\boldsymbol{A}_{m}$ & $\boldsymbol{A}_{u}$ & $\boldsymbol{A}_{s}$ & $\boldsymbol{A}_{m}$ & $\boldsymbol{A}_{u}$ & $A_{s}$ & $\boldsymbol{A}_{m}$ \\
\hline 2.80 & & & & -0.426 & -0.444 & 0.010 & -0.113 & -0.129 & 0.130 \\
\hline 2.90 & & & & -0.471 & -0.444 & 0.003 & -0.123 & -0.119 & 0.115 \\
\hline 3.00 & & & & -0.515 & -0.443 & 0.000 & -0.136 & -0.107 & 0.093 \\
\hline 3.10 & & & & & & & -0.145 & -0.100 & 0.079 \\
\hline 3.20 & & & & & & & -0.156 & -0.091 & 0.060 \\
\hline 3.30 & & & & & & & -0.163 & -0.087 & 0.049 \\
\hline 3.40 & & & & & & & -0.173 & -0.082 & 0.034 \\
\hline 3.50 & & & & & & & -0.180 & -0.080 & 0.026 \\
\hline 3.60 & & & & & & & -0.189 & -0.077 & 0.015 \\
\hline 3.70 & & & & & & & -0.195 & -0.076 & 0.010 \\
\hline 3.80 & & & & & & & -0.205 & -0.076 & 0.004 \\
\hline 3.90 & & & & & & & -0.211 & -0.075 & 0.001 \\
\hline 4.00 & & & & & & & -0.218 & -0.075 & 0.000 \\
\hline
\end{tabular}




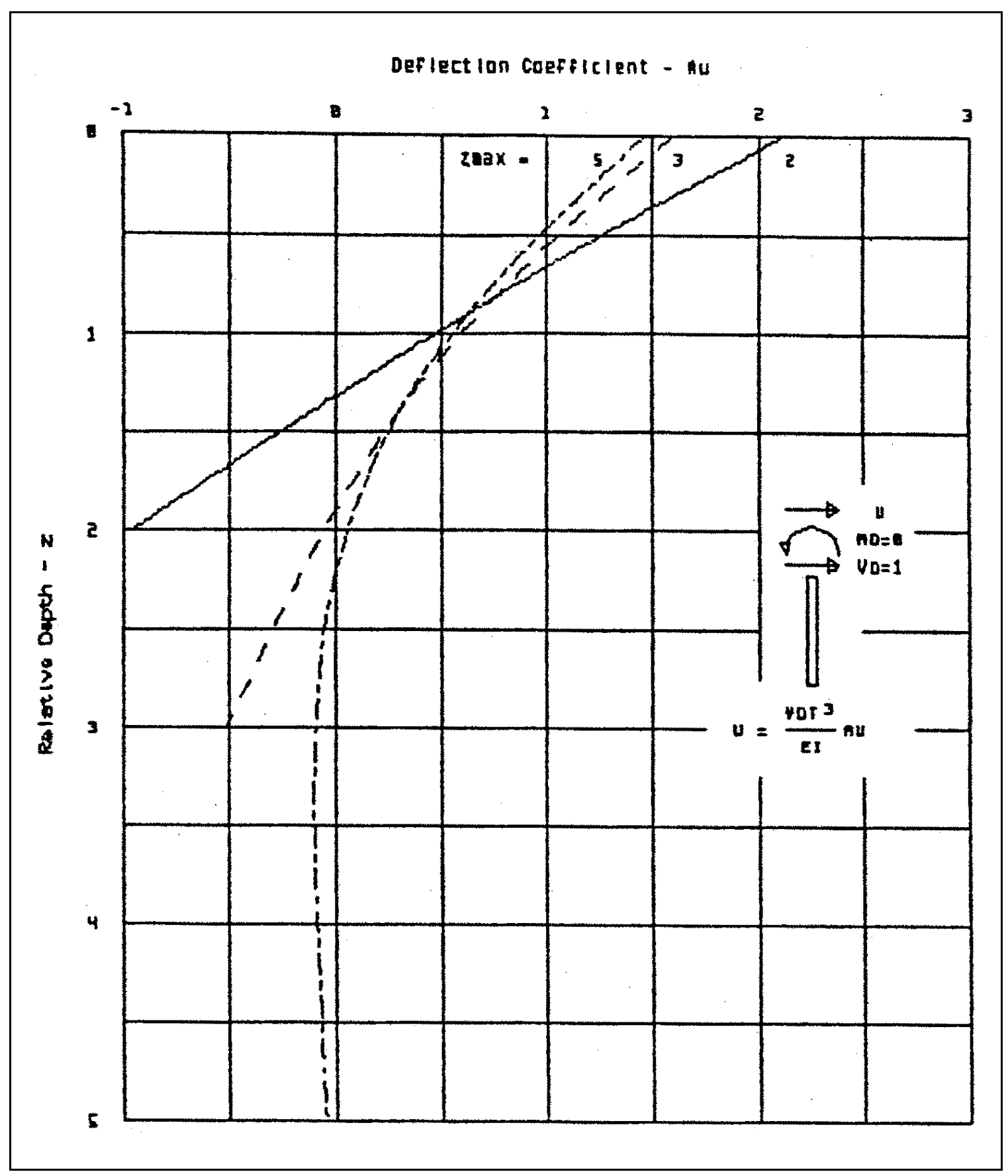

Figure B1. Deflection coefficient for unit head shear for soil stiffness constant with depth 


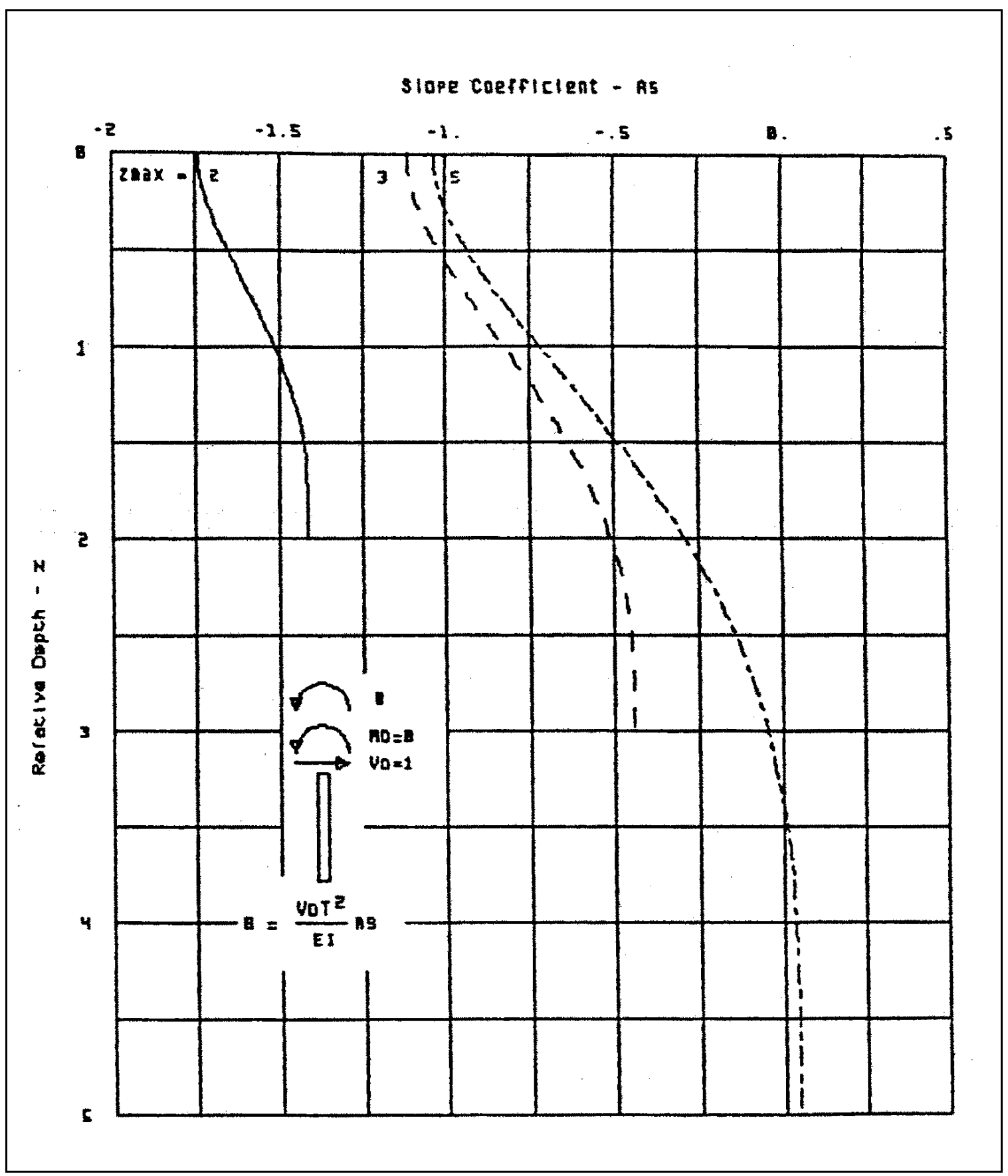

Figure B2. Slope coefficient for unit head shear for soil stiffness constant with depth 


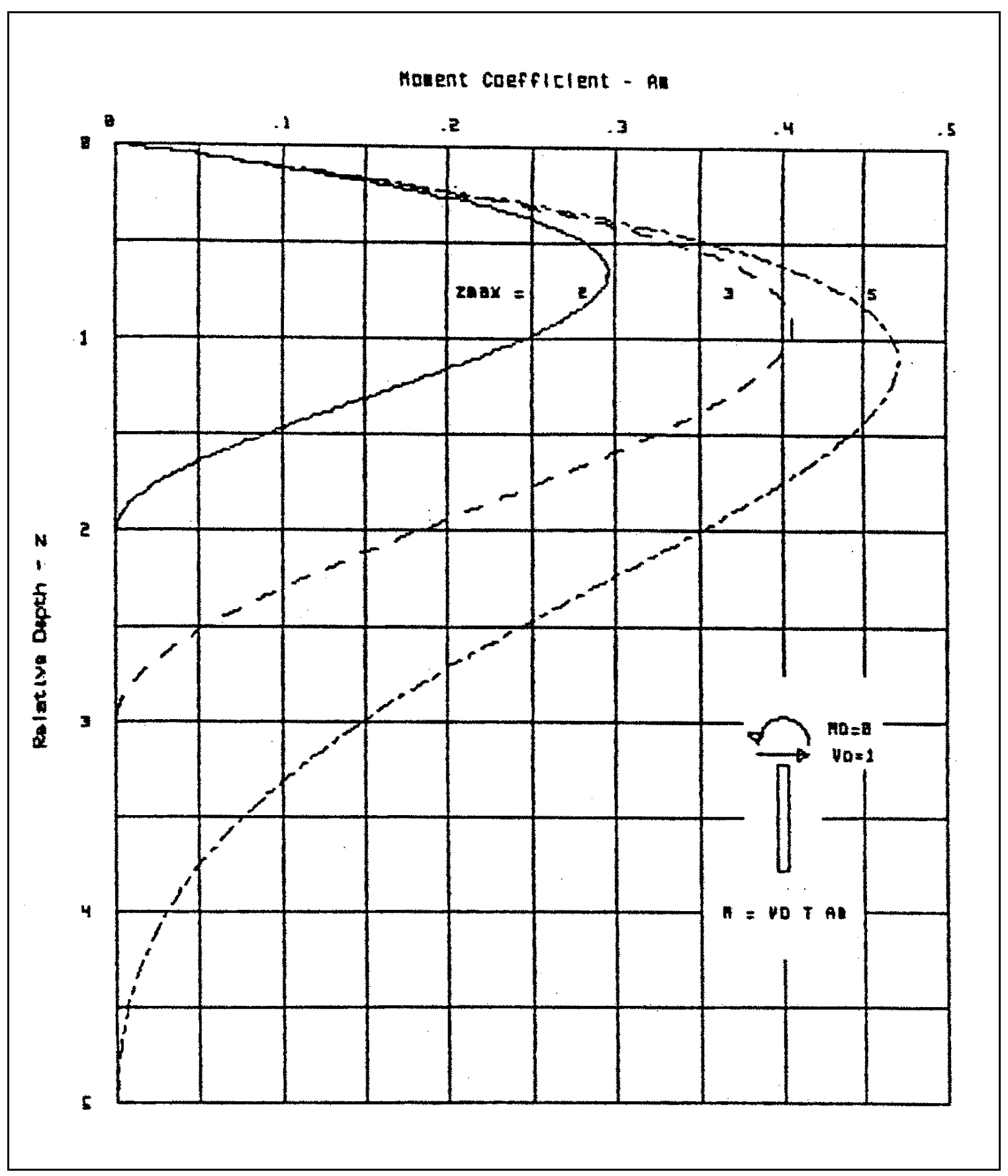

Figure B3. Bending moment coefficient for unit head shear for soil stiffness constant with depth 


\begin{tabular}{|c|c|c|c|c|c|c|c|c|c|}
\hline \multicolumn{10}{|c|}{\begin{tabular}{|l|} 
Table B2 \\
Nondimensional Coefficients for Laterally Loaded Pile for Soil Modulus Constant with \\
Depth (Head Shear $V_{0}=0$, Head Moment $M_{o}=1$ ) \\
\end{tabular}} \\
\hline \multirow[b]{2}{*}{$\underline{z}$} & \multicolumn{3}{|c|}{$Z_{\max }=2$} & \multicolumn{3}{|c|}{$Z_{\max }=3$} & \multicolumn{3}{|c|}{$Z_{\max }=4$} \\
\hline & $B_{u}$ & $\boldsymbol{B}_{s}$ & $\boldsymbol{B}_{m}$ & $B_{u}$ & $B_{s}$ & $B_{m}$ & $B_{u}$ & $B_{s}$ & $B_{m}$ \\
\hline 0.00 & -1.741 & 2.261 & -1.000 & -1.116 & 1.500 & -1.000 & -1.032 & 1.441 & -1.000 \\
\hline 0.10 & -1.519 & 2.161 & -0.993 & -0.971 & 1.400 & -0.996 & -0.893 & 1.341 & \begin{tabular}{|l}
-0.997 \\
\end{tabular} \\
\hline 0.20 & -1.308 & 2.063 & -0.972 & -0.836 & 1.301 & -0.983 & -0.739 & 1.222 & \begin{tabular}{|l}
-0.982 \\
\end{tabular} \\
\hline 0.30 & -1.107 & 1.967 & \begin{tabular}{|l|} 
\\
\end{tabular} & -0.710 & 1.204 & -0.961 & -0.645 & 1.144 & -0.966 \\
\hline 0.40 & -0.915 & 1.876 & -0.891 & -0.595 & 1.109 & -0.932 & -0.514 & 1.030 & -0.934 \\
\hline 0.50 & -0.731 & 1.789 & -0.836 & -0.489 & 1.017 & \begin{tabular}{|l|l} 
& -0.897
\end{tabular} & -0.435 & 0.956 & -0.909 \\
\hline 0.60 & -0.557 & 1.709 & -0.773 & -0.391 & 0.930 & -0.858 & -0.327 & 0.850 & -0.865 \\
\hline 0.70 & -0.389 & 1.635 & -0.705 & -0.303 & 0.846 & -0.814 & -0.261 & 0.782 & -0.834 \\
\hline 0.80 & -0.229 & 1.568 & -0.633 & -0.222 & 0.767 & -0.767 & -0.173 & 0.685 & -0.784 \\
\hline 0.90 & -0.076 & 1.508 & -0.559 & -0.149 & 0.693 & -0.719 & -0.121 & 0.623 & -0.749 \\
\hline 1.00 & 0.072 & 1.456 & -0.484 & -0.083 & 0.623 & -0.668 & -0.052 & 0.537 & -0.695 \\
\hline 1.10 & 0.216 & 1.412 & -0.410 & -0.024 & 0.559 & -0.617 & -0.011 & 0.483 & -0.658 \\
\hline 1.20 & 0.355 & 1.374 & -0.338 & 0.029 & 0.500 & -0.565 & 0.042 & 0.407 & -0.604 \\
\hline 1.30 & 0.491 & 1.344 & -0.269 & 0.076 & 0.446 & -0.514 & 0.073 & 0.360 & -0.568 \\
\hline 1.40 & 0.624 & 1.320 & -0.205 & 0.118 & 0.397 & -0.464 & 0.112 & 0.295 & -0.515 \\
\hline 1.50 & 0.755 & 1.303 & -0.148 & 0.156 & 0.353 & -0.415 & 0.134 & 0.255 & -0.480 \\
\hline 1.60 & 0.885 & 1.290 & \begin{tabular}{|l}
-0.098 \\
\end{tabular} & 0.189 & 0.314 & -0.367 & 0.162 & 0.201 & -0.430 \\
\hline 1.70 & 1.013 & 1.283 & -0.057 & 0.218 & 0.280 & -0.321 & 0.176 & 0.168 & -0.397 \\
\hline 1.80 & 1.141 & 1.279 & -0.026 & 0.245 & 0.250 & -0.277 & 0.194 & 0.123 & -0.351 \\
\hline 1.90 & 1.269 & 1.277 & -0.007 & 0.269 & 0.224 & -0.236 & 0.202 & 0.096 & \begin{tabular}{|l}
-0.322 \\
\end{tabular} \\
\hline 2.00 & 1.397 & 1.277 & 0.000 & 0.290 & 0.202 & \begin{tabular}{|l}
-0.198 \\
\end{tabular} & 0.212 & 0.060 & -0.280 \\
\hline 2.10 & & & & 0.309 & 0.184 & -0.162 & 0.216 & 0.038 & -0.254 \\
\hline 2.20 & & & & 0.327 & 0.170 & -0.130 & 0.218 & 0.010 & -0.218 \\
\hline 2.30 & & & & 0.343 & 0.158 & -0.100 & 0.219 & -0.006 & -0.196 \\
\hline 2.40 & & & & 0.359 & 0.150 & -0.075 & 0.216 & -0.028 & \begin{tabular}{|l|}
-0.164 \\
\end{tabular} \\
\hline 2.50 & & & & 0.373 & 0.143 & -0.052 & 0.214 & -0.040 & -0.145 \\
\hline 2.60 & & & & 0.387 & 0.139 & -0.034 & 0.208 & -0.056 & -0.119 \\
\hline 2.70 & & & & 0.401 & 0.136 & \begin{tabular}{|l}
-0.019 \\
\end{tabular} & 0.203 & -0.065 & -0.104 \\
\hline
\end{tabular}




\begin{tabular}{|c|c|c|c|c|c|c|c|c|c|}
\hline \multicolumn{10}{|c|}{ Table B2 (Concluded) } \\
\hline \multirow[b]{2}{*}{$z$} & \multicolumn{3}{|c|}{$Z_{\max }=2$} & \multicolumn{3}{|c|}{$Z_{\max }=3$} & \multicolumn{3}{|c|}{$Z_{\max }=4$} \\
\hline & $\boldsymbol{B}_{u}$ & $B_{s}$ & $B_{m}$ & $\boldsymbol{B}_{u}$ & $B_{s}$ & $B_{m}$ & $\boldsymbol{B}_{u}$ & $B_{s}$ & $B_{m}$ \\
\hline 2.80 & & & & 0.415 & 0.135 & -0.009 & 0.195 & -0.076 & -0.083 \\
\hline 2.90 & & & & 0.428 & 0.134 & -0.002 & 0.188 & -0.082 & -0.070 \\
\hline 3.00 & & & & 0.442 & 0.134 & 0.000 & 0.178 & -0.090 & -0.054 \\
\hline 3.10 & & & & & & & 0.170 & -0.094 & -0.044 \\
\hline 3.20 & & & & & & & 0.159 & -0.098 & -0.032 \\
\hline 3.30 & & & & & & & 0.151 & -0.101 & -0.025 \\
\hline 3.40 & & & & & & & 0.139 & -0.103 & -0.017 \\
\hline 3.50 & & & & & & & 0.130 & -0.104 & -0.012 \\
\hline 3.60 & & & & & & & 0.118 & -0.105 & -0.007 \\
\hline 3.70 & & & & & & & 0.109 & -0.106 & -0.004 \\
\hline 3.80 & & & & & & & 0.097 & -0.106 & -0.001 \\
\hline 3.90 & & & & & & & 0.088 & -0.106 & -0.000 \\
\hline 4.00 & & & & & & & 0.078 & -0.106 & 0.000 \\
\hline
\end{tabular}




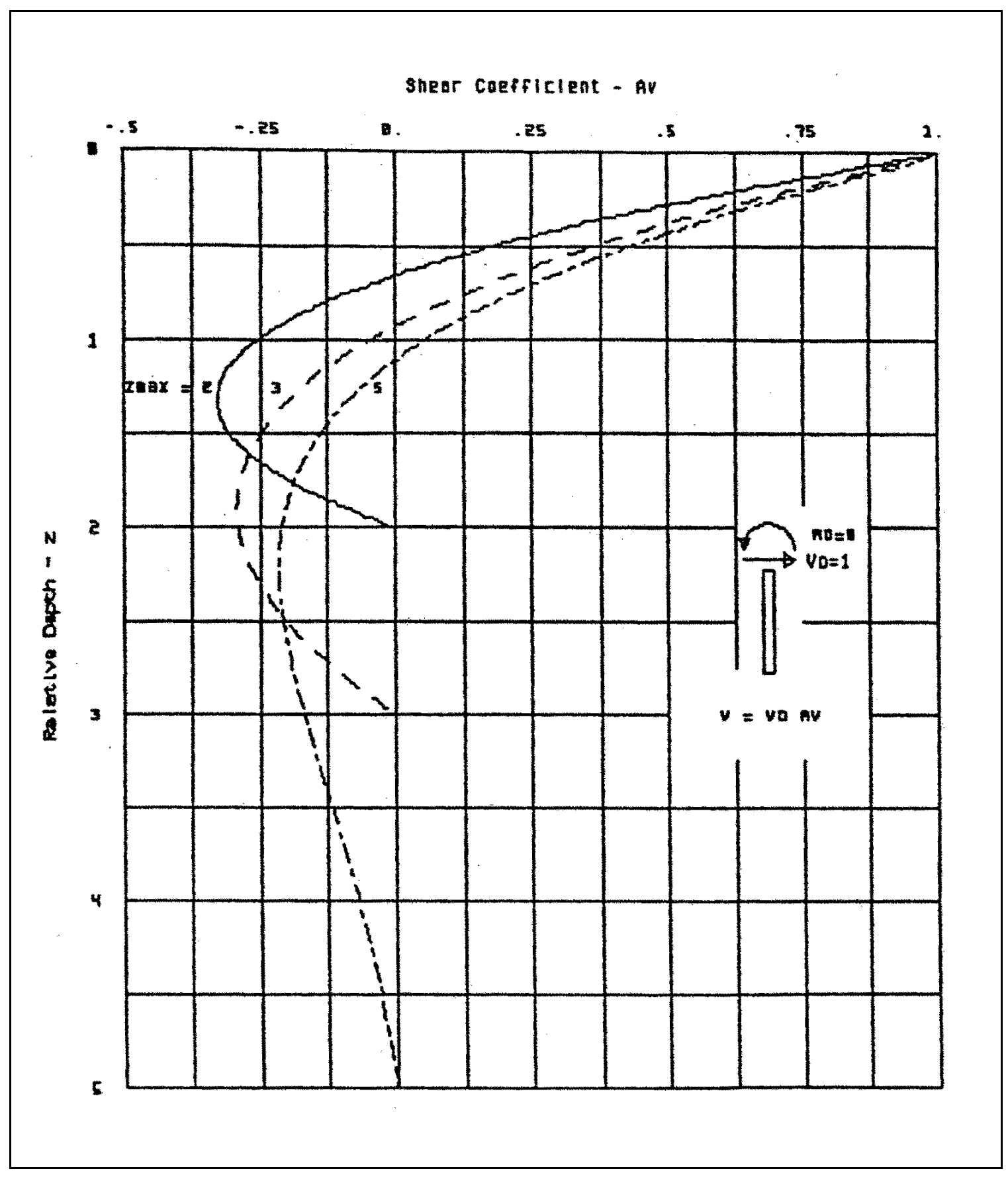

Figure B4. Shear coefficient for unit head shear for soil stiffness constant with depth 


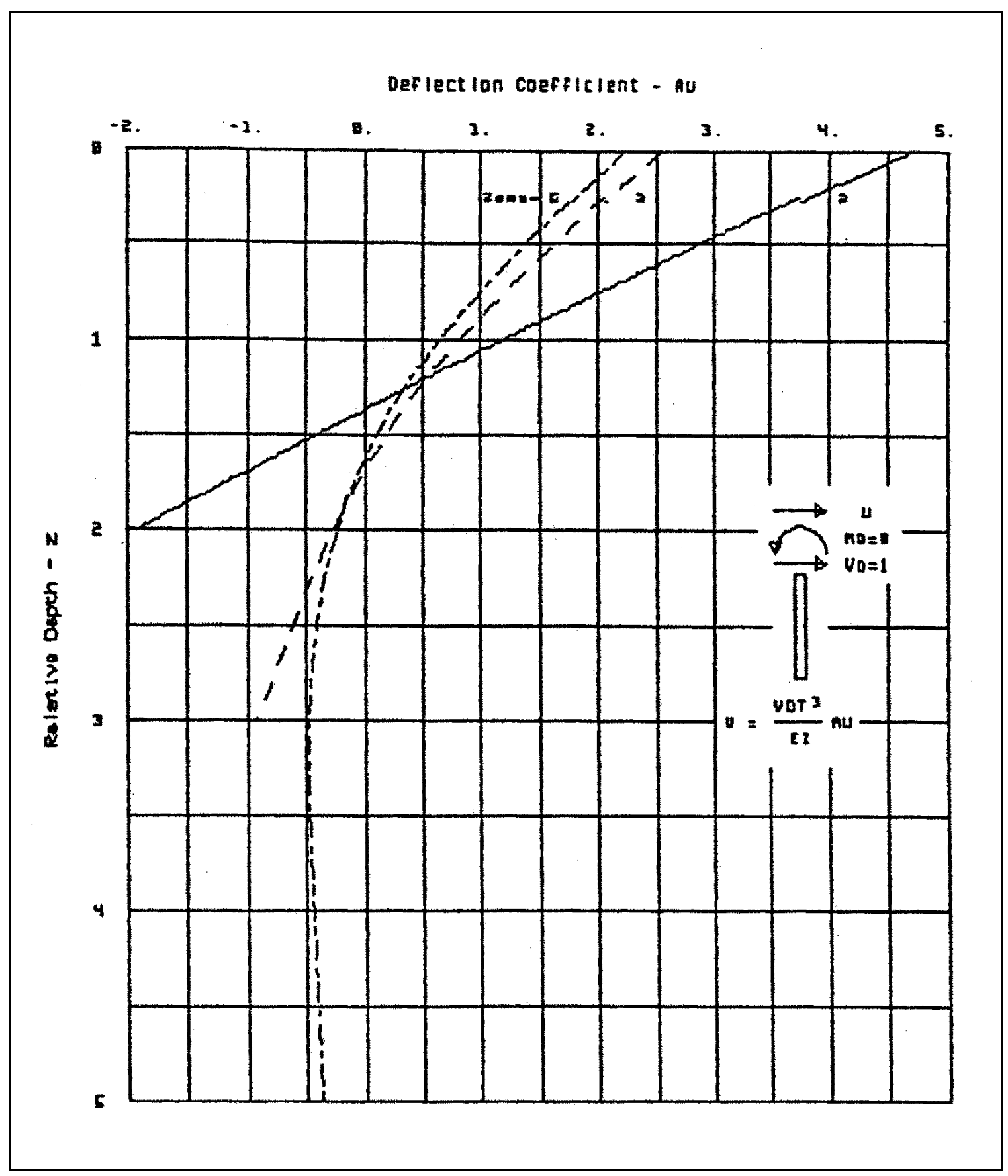

Figure B5. Deflection coefficient for unit head shear for soil stiffness varying linearly with depth 


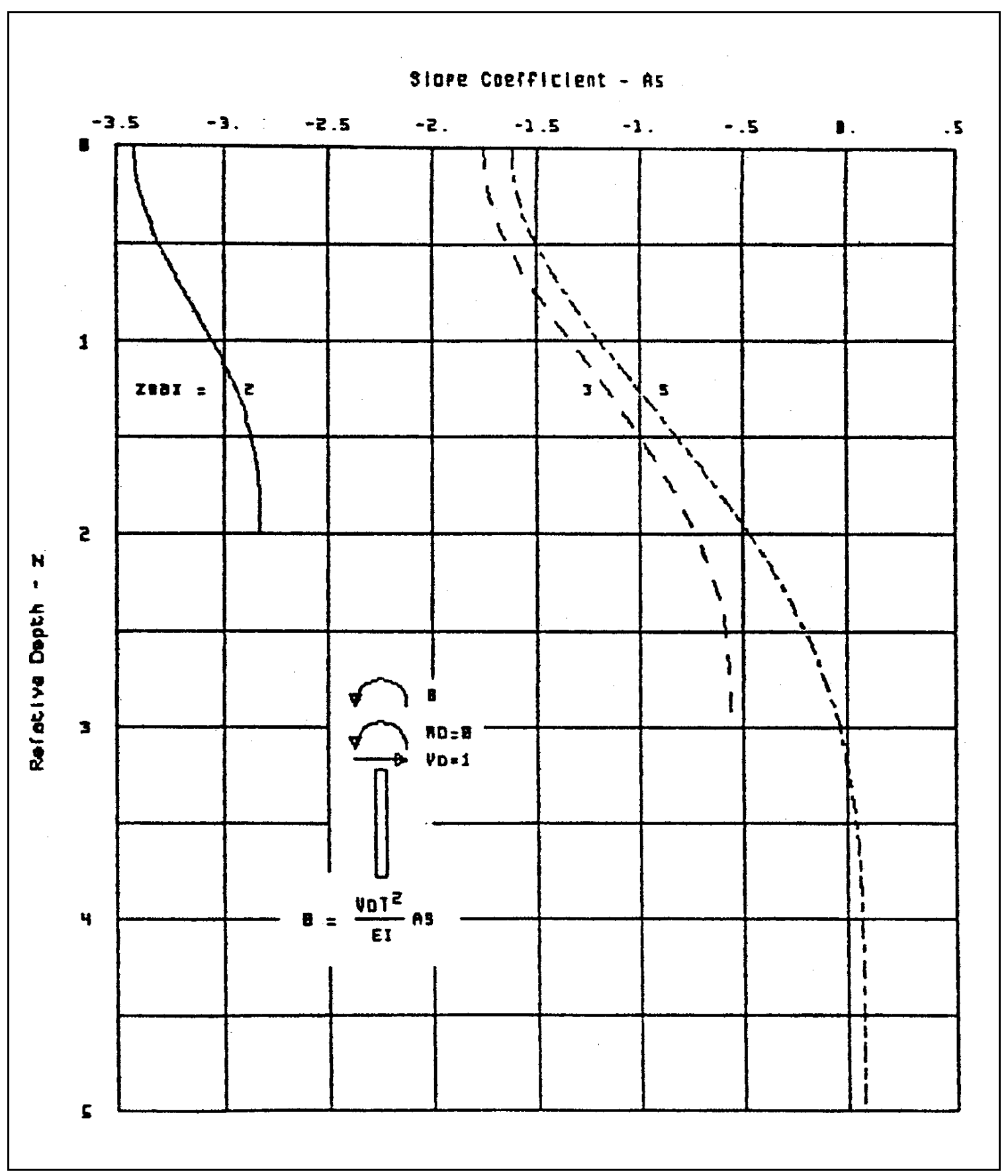

Figure B6. Slope coefficient for unit head shear for soil stiffness varying linearly with depth 


\begin{tabular}{|c|c|c|c|c|c|c|c|c|c|}
\hline \multicolumn{10}{|c|}{$\begin{array}{l}\text { Table B3 } \\
\text { Nondimensional Coefficients for Laterally Loaded Pile for Soil Modulus Varying } \\
\text { Linearly with Depth (Head Shear } V_{0}=1 \text {, Head Moment } M_{o}=0 \text { ) }\end{array}$} \\
\hline \multirow[b]{2}{*}{$\underline{z}$} & \multicolumn{3}{|c|}{$Z_{\max }=2$} & \multicolumn{3}{|c|}{$Z_{\max }=3$} & \multicolumn{3}{|c|}{$Z_{\max }=4$} \\
\hline & $\underline{\boldsymbol{A}_{u}}$ & $\underline{A_{s}}$ & $\underline{\boldsymbol{A}_{m}}$ & $\boldsymbol{A}_{u}$ & $\boldsymbol{A}_{s}$ & $\underline{\boldsymbol{A}_{m}}$ & $\boldsymbol{A}_{u}$ & $\underline{A_{s}}$ & $\boldsymbol{A}_{m}$ \\
\hline 0.00 & 4.738 & -3.418 & 0.000 & 2.727 & -1.758 & 0.000 & 2.442 & -1.622 & 0.000 \\
\hline 0.10 & 4.396 & -3.413 & 0.099 & 2.552 & -1.753 & 0.100 & 2.280 & -1.616 & 0.100 \\
\hline 0.20 & 4.055 & -3.399 & 0.194 & 2.377 & -1.738 & 0.197 & 2.087 & -1.597 & \begin{tabular}{|l|}
0.216 \\
\end{tabular} \\
\hline 0.30 & 3.717 & -3.375 & 0.281 & 2.204 & -1.714 & 0.289 & 1.960 & -1.577 & 0.290 \\
\hline 0.40 & 3.381 & -3.343 & 0.357 & 2.034 & -1.680 & 0.375 & 1.773 & -1.536 & \begin{tabular}{|l|}
0.394 \\
\end{tabular} \\
\hline 0.50 & 3.048 & -3.304 & 0.419 & 1.868 & -1.639 & 0.452 & 1.651 & -1.502 & 0.458 \\
\hline 0.60 & 2.720 & -3.259 & 0.466 & 1.707 & -1.590 & 0.521 & 1.474 & -1.442 & 0.543 \\
\hline 0.70 & 2.396 & -3.211 & 0.497 & 1.551 & -1.535 & 0.579 & 1.361 & -1.396 & 0.592 \\
\hline 0.80 & 2.078 & -3.161 & 0.511 & 1.400 & -1.475 & 0.626 & 1.198 & -1.321 & 0.655 \\
\hline 0.90 & 1.764 & -3.109 & 0.509 & 1.256 & -1.410 & 0.662 & 1.094 & -1.268 & 0.689 \\
\hline 1.00 & 1.456 & -3.059 & 0.490 & 1.118 & -1.343 & 0.687 & 0.947 & -1.182 & \begin{tabular}{|l|}
0.729 \\
\end{tabular} \\
\hline 1.10 & 1.152 & -3.012 & 0.458 & 0.987 & -1.273 & 0.701 & 0.855 & -1.123 & 0.747 \\
\hline 1.20 & 0.853 & -2.968 & 0.412 & 0.863 & -1.203 & 0.703 & 0.725 & -1.032 & \begin{tabular}{|l|l|} 
& 0.764 \\
\end{tabular} \\
\hline 1.30 & 0.559 & -2.930 & 0.357 & 0.747 & -1.133 & 0.696 & 0.645 & -0.971 & 0.768 \\
\hline 1.40 & 0.267 & -2.897 & 0.294 & 0.637 & -1.064 & 0.679 & 0.534 & -0.879 & 0.764 \\
\hline 1.50 & -0.021 & -2.871 & 0.227 & 0.534 & -0.998 & 0.653 & 0.466 & -0.818 & 0.755 \\
\hline 1.60 & -0.307 & -2.852 & 0.161 & 0.437 & -0.934 & 0.618 & 0.374 & -0.729 & 0.733 \\
\hline 1.70 & -0.592 & -2.839 & 0.100 & 0.347 & -0.874 & 0.577 & 0.318 & -0.671 & 0.714 \\
\hline 1.80 & -0.875 & -2.831 & 0.049 & 0.262 & -0.819 & 0.530 & 0.242 & -0.587 & 0.679 \\
\hline 1.90 & -1.158 & -2.828 & 0.013 & 0.183 & -0.768 & 0.479 & 0.197 & -0.534 & 0.652 \\
\hline 2.00 & -1.441 & -2.828 & 0.000 & 0.108 & -0.723 & 0.423 & 0.138 & -0.459 & 0.607 \\
\hline 2.10 & & & & 0.038 & -0.684 & 0.366 & 0.103 & -0.411 & 0.574 \\
\hline 2.20 & & & & -0.029 & -0.650 & 0.308 & 0.058 & -0.346 & 0.523 \\
\hline 2.30 & & & & -0.092 & -0.622 & 0.250 & 0.032 & -0.305 & \begin{tabular}{|l|l|} 
& 0.488 \\
\end{tabular} \\
\hline 2.40 & & & & -0.153 & -0.600 & 0.195 & -0.002 & -0.250 & 0.435 \\
\hline 2.50 & & & & -0.212 & -0.583 & 0.143 & -0.020 & -0.216 & 0.399 \\
\hline 2.60 & & & & -0.270 & -0.571 & 0.097 & -0.043 & -0.172 & 0.346 \\
\hline 2.70 & & & & -0.327 & -0.563 & 0.057 & -0.056 & -0.145 & 0.312 \\
\hline
\end{tabular}




\begin{tabular}{|c|c|c|c|c|c|c|c|c|c|}
\hline \multicolumn{10}{|c|}{ Table B3 (Concluded) } \\
\hline \multirow[b]{2}{*}{$z$} & \multicolumn{3}{|c|}{$Z_{\max }=2$} & \multicolumn{3}{|c|}{$Z_{\max }=3$} & \multicolumn{3}{|c|}{$Z_{\max }=4$} \\
\hline & $\underline{\boldsymbol{A}_{u}}$ & $A_{s}$ & $\boldsymbol{A}_{m}$ & $\underline{\boldsymbol{A}_{u}}$ & $\boldsymbol{A}_{s}$ & $\boldsymbol{A}_{m}$ & $\boldsymbol{A}_{u}$ & $A_{s}$ & $\boldsymbol{A}_{m}$ \\
\hline 2.80 & & & & -0.383 & -0.559 & 0.027 & -0.071 & -0.111 & 0.262 \\
\hline 2.90 & & & & -0.439 & -0.558 & 0.007 & -0.079 & -0.091 & 0.231 \\
\hline 3.00 & & & & -0.494 & -0.557 & 0.000 & -0.089 & -0.066 & 0.186 \\
\hline 3.10 & & & & & & & -0.093 & -0.052 & 0.159 \\
\hline 3.20 & & & & & & & -0.099 & -0.036 & 0.121 \\
\hline 3.30 & & & & & & & -0.101 & -0.027 & 0.098 \\
\hline 3.40 & & & & & & & -0.104 & -0.017 & 0.069 \\
\hline 3.50 & & & & & & & -0.105 & -0.012 & 0.051 \\
\hline 3.60 & & & & & & & -0.106 & -0.007 & 0.030 \\
\hline 3.70 & & & & & & & -0.106 & -0.005 & 0.019 \\
\hline 3.80 & & & & & & & -0.107 & -0.004 & 0.007 \\
\hline 3.90 & & & & & & & -0.107 & -0.003 & 0.002 \\
\hline 4.00 & & & & & & & -0.108 & -0.003 & 0.000 \\
\hline
\end{tabular}




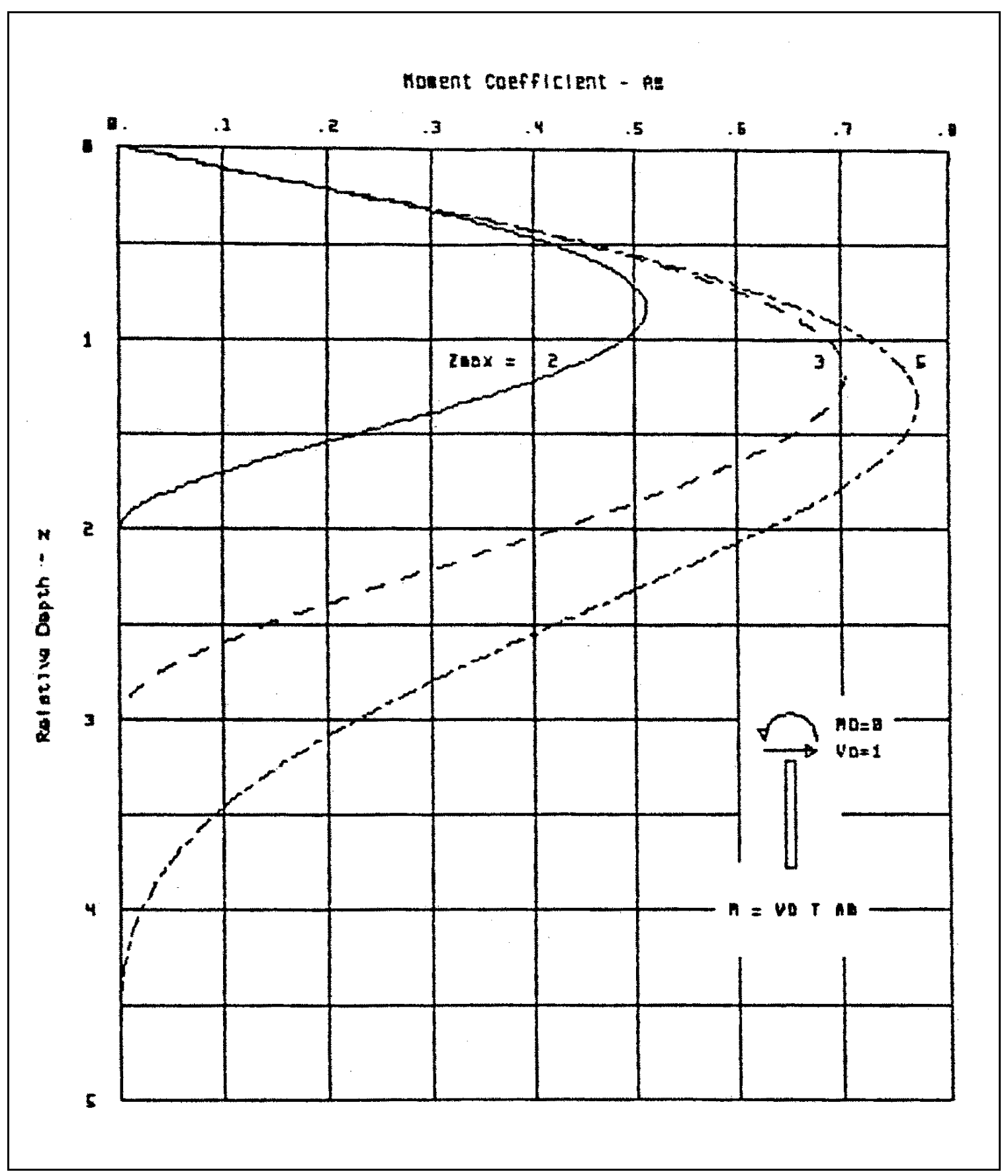

Figure B7. Bending moment coefficient for unit head shear for soil stiffness varying linearly with depth 


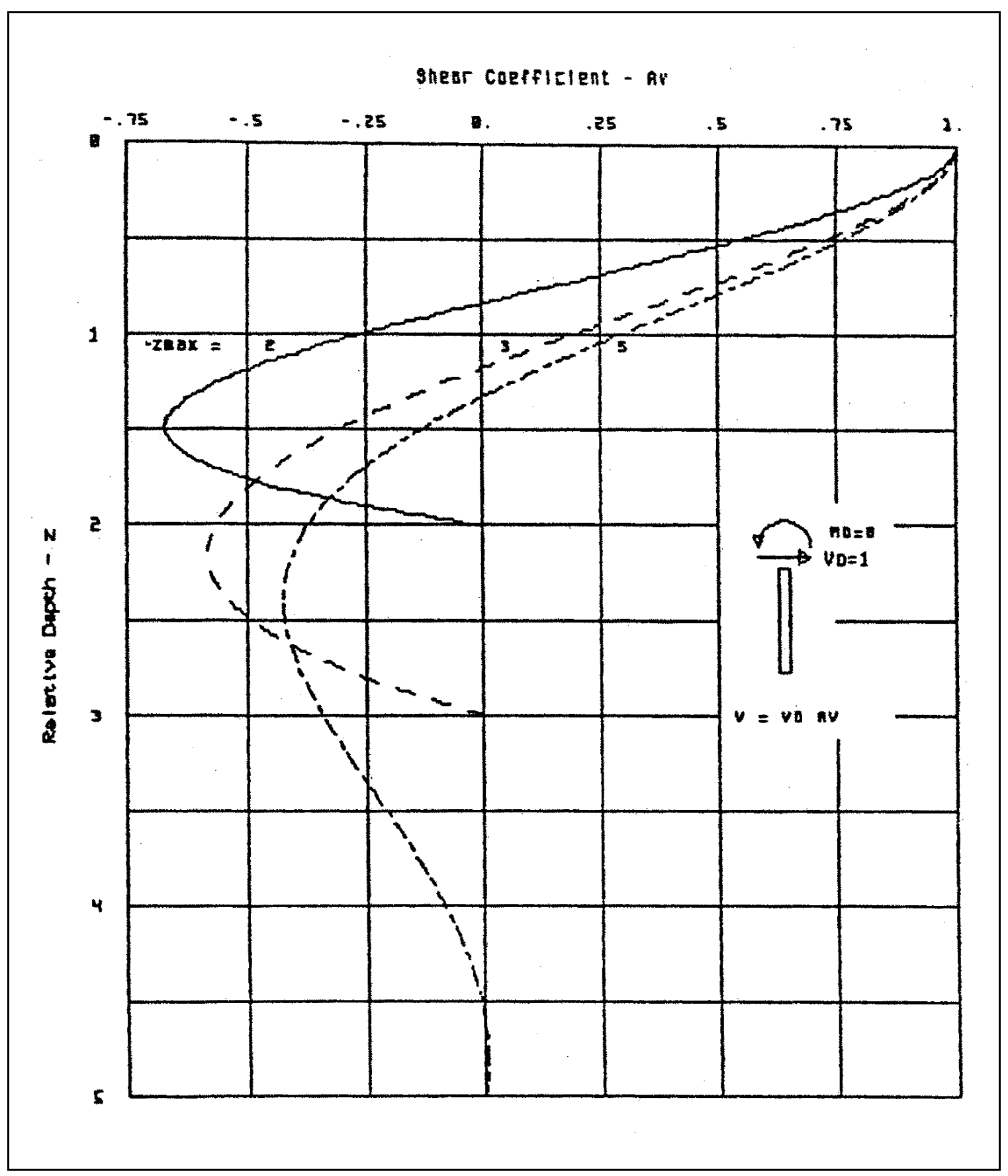

Figure B8. Shear coefficient for unit head shear for soil stiffness varying linearly with depth 


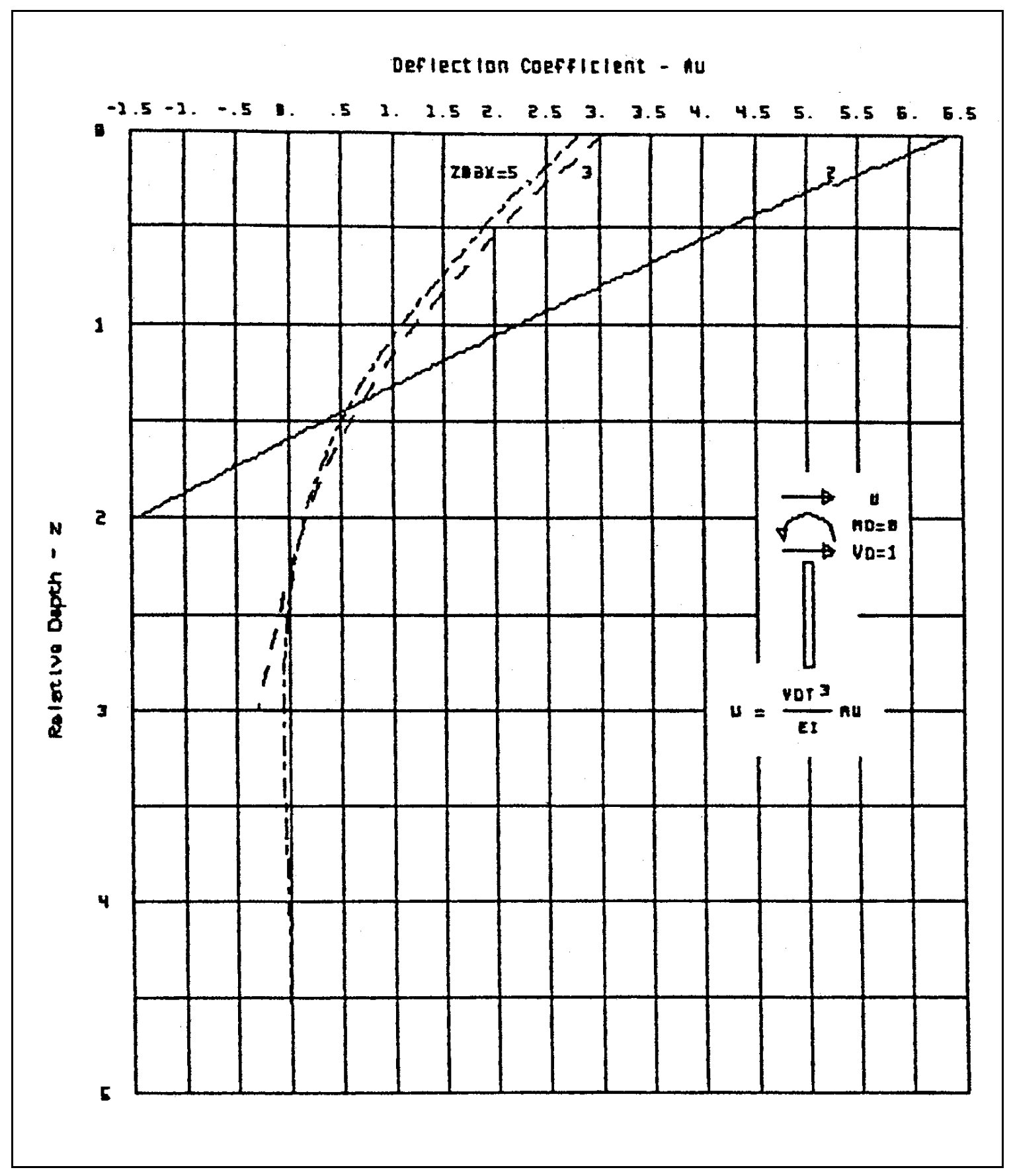

Figure B9. Deflection coefficient for unit head shear for soil stiffness varying linearly with depth 


\begin{tabular}{|c|c|c|c|c|c|c|c|c|c|}
\hline \multicolumn{10}{|c|}{$\begin{array}{l}\text { Table B4 } \\
\text { Nondimensional Coefficients for Laterally Loaded Pile for Soil Modulus Varying } \\
\text { Linearly with Depth (Head Shear } V_{o}=0 \text {, Head Moment } M_{o}=1 \text { ) }\end{array}$} \\
\hline \multirow[b]{2}{*}{$\underline{z}$} & \multicolumn{3}{|c|}{$Z_{\max }=2$} & \multicolumn{3}{|c|}{$Z_{\max }=3$} & \multicolumn{3}{|c|}{$Z_{\max }=4$} \\
\hline & $\boldsymbol{B}_{u}$ & $B_{s}$ & $\boldsymbol{B}_{m}$ & $B_{u}$ & $B_{s}$ & $\boldsymbol{B}_{m}$ & $B_{u}$ & $B_{s}$ & $\boldsymbol{B}_{m}$ \\
\hline 0.00 & -3.418 & 3.213 & -1.000 & -1.758 & 1.819 & -1.000 & -1.622 & 1.751 & -1.000 \\
\hline 0.10 & -3.102 & 3.113 & -0.999 & -1.581 & 1.719 & -1.000 & -1.452 & 1.651 & -1.000 \\
\hline 0.20 & -2.796 & 3.013 & -0.996 & -1.414 & 1.619 & -0.998 & -1.261 & 1.531 & -0.997 \\
\hline 0.30 & -2.499 & 2.914 & -0.987 & -1.257 & 1.519 & -0.993 & -1.141 & 1.452 & -0.994 \\
\hline 0.40 & -2.213 & 2.816 & -0.970 & -1.110 & 1.420 & -0.985 & -0.974 & 1.333 & -0.984 \\
\hline 0.50 & -1.936 & 2.720 & -0.945 & -0.973 & 1.322 & -0.972 & -0.871 & 1.254 & -0.975 \\
\hline 0.60 & -1.668 & 2.628 & -0.910 & -0.846 & 1.226 & -0.955 & -0.727 & 1.139 & -0.955 \\
\hline 0.70 & -1.410 & 2.539 & -0.865 & -0.728 & 1.132 & \begin{tabular}{|l}
-0.932 \\
\end{tabular} & \begin{tabular}{|l|}
-0.639 \\
\end{tabular} & 1.063 & -0.938 \\
\hline 0.80 & -1.161 & 2.455 & -0.810 & -0.619 & 1.040 & -0.904 & -0.518 & 0.952 & -0.908 \\
\hline 0.90 & -0.919 & 2.377 & -0.746 & -0.520 & 0.951 & \begin{tabular}{|l|}
-0.871 \\
\end{tabular} & -0.445 & 0.880 & -0.884 \\
\hline 1.00 & -0.685 & 2.306 & -0.674 & -0.429 & 0.866 & -0.834 & -0.346 & 0.777 & -0.844 \\
\hline 1.10 & -0.458 & 2.243 & -0.594 & -0.347 & 0.784 & -0.792 & -0.286 & 0.710 & -0.814 \\
\hline 1.20 & -0.236 & 2.187 & -0.510 & -0.272 & 0.707 & -0.747 & -0.207 & 0.615 & -0.766 \\
\hline 1.30 & -0.020 & 2.141 & -0.423 & -0.205 & 0.635 & -0.698 & -0.160 & 0.555 & -0.732 \\
\hline 1.40 & 0.192 & 2.103 & -0.336 & -0.145 & 0.568 & \begin{tabular}{|l|}
-0.647 \\
\end{tabular} & \begin{tabular}{|l}
-0.099 \\
\end{tabular} & 0.471 & -0.678 \\
\hline 1.50 & 0.401 & 2.073 & -0.252 & -0.091 & 0.506 & -0.593 & -0.063 & 0.418 & -0.641 \\
\hline 1.60 & 0.607 & 2.052 & -0.173 & -0.044 & 0.449 & -0.538 & -0.017 & 0.345 & -0.584 \\
\hline 1.70 & 0.812 & 2.038 & -0.105 & -0.001 & 0.398 & -0.483 & 0.008 & 0.299 & -0.546 \\
\hline 1.80 & 1.015 & 2.031 & -0.050 & 0.036 & 0.353 & -0.427 & 0.040 & 0.237 & -0.490 \\
\hline 1.90 & 1.218 & 2.028 & -0.013 & 0.070 & 0.313 & -0.373 & 0.058 & 0.199 & -0.452 \\
\hline 2.00 & 1.421 & 2.027 & 0.000 & 0.099 & 0.278 & -0.319 & 0.079 & 0.148 & -0.398 \\
\hline 2.10 & & & & 0.125 & 0.249 & -0.267 & 0.089 & 0.118 & -0.363 \\
\hline 2.20 & & & & 0.149 & 0.225 & -0.219 & 0.101 & 0.078 & -0.312 \\
\hline 2.30 & & & & 0.170 & 0.205 & -0.173 & 0.106 & 0.054 & -0.280 \\
\hline 2.40 & & & & 0.190 & 0.190 & -0.131 & 0.111 & 0.023 & -0.236 \\
\hline 2.50 & & & & 0.209 & 0.179 & -0.094 & 0.112 & 0.005 & -0.208 \\
\hline 2.60 & & & & 0.226 & 0.171 & -0.062 & 0.111 & -0.017 & -0.170 \\
\hline 2.70 & & & & 0.243 & 0.166 & -0.036 & 0.109 & -0.030 & -0.146 \\
\hline
\end{tabular}




\begin{tabular}{|c|c|c|c|c|c|c|c|c|c|}
\hline \multicolumn{10}{|c|}{ Table B4 (Concluded) } \\
\hline \multirow[b]{2}{*}{$z$} & \multicolumn{3}{|c|}{$Z_{\max }=2$} & \multicolumn{3}{|c|}{$Z_{\max }=3$} & \multicolumn{3}{|c|}{$Z_{\max }=4$} \\
\hline & $\boldsymbol{B}_{u}$ & $B_{s}$ & $B_{m}$ & $\boldsymbol{B}_{u}$ & $B_{s}$ & $B_{m}$ & $\boldsymbol{B}_{u}$ & $B_{s}$ & $B_{m}$ \\
\hline 2.80 & & & & 0.259 & 0.163 & -0.017 & 0.105 & -0.046 & -0.115 \\
\hline 2.90 & & & & 0.276 & 0.162 & -0.004 & 0.101 & -0.054 & -0.097 \\
\hline 3.00 & & & & 0.292 & 0.162 & 0.000 & 0.093 & -0.064 & -0.072 \\
\hline 3.10 & & & & & & & 0.088 & -0.069 & -0.059 \\
\hline 3.20 & & & & & & & 0.079 & -0.075 & -0.041 \\
\hline 3.30 & & & & & & & 0.073 & -0.078 & -0.031 \\
\hline 3.40 & & & & & & & 0.064 & -0.081 & -0.020 \\
\hline 3.50 & & & & & & & 0.057 & -0.083 & -0.014 \\
\hline 3.60 & & & & & & & 0.047 & -0.084 & -0.007 \\
\hline 3.70 & & & & & & & 0.040 & -0.084 & -0.004 \\
\hline 3.80 & & & & & & & 0.030 & -0.085 & -0.001 \\
\hline 3.90 & & & & & & & 0.023 & -0.085 & -0.000 \\
\hline 4.00 & & & & & & & 0.015 & -0.085 & -0.000 \\
\hline
\end{tabular}




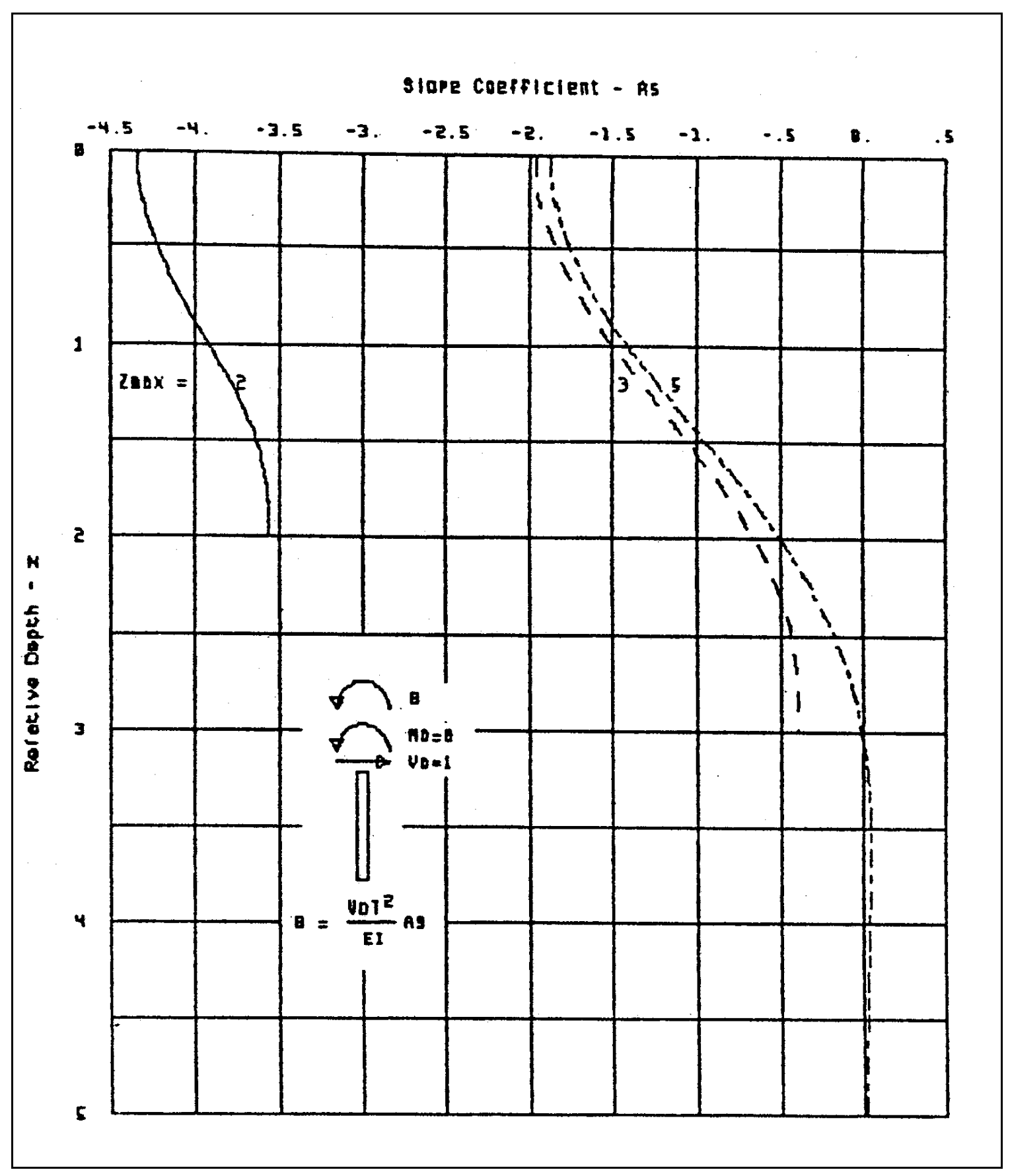

Figure B10. Slope coefficient for unit head shear for soil stiffness varying parabolically with depth 


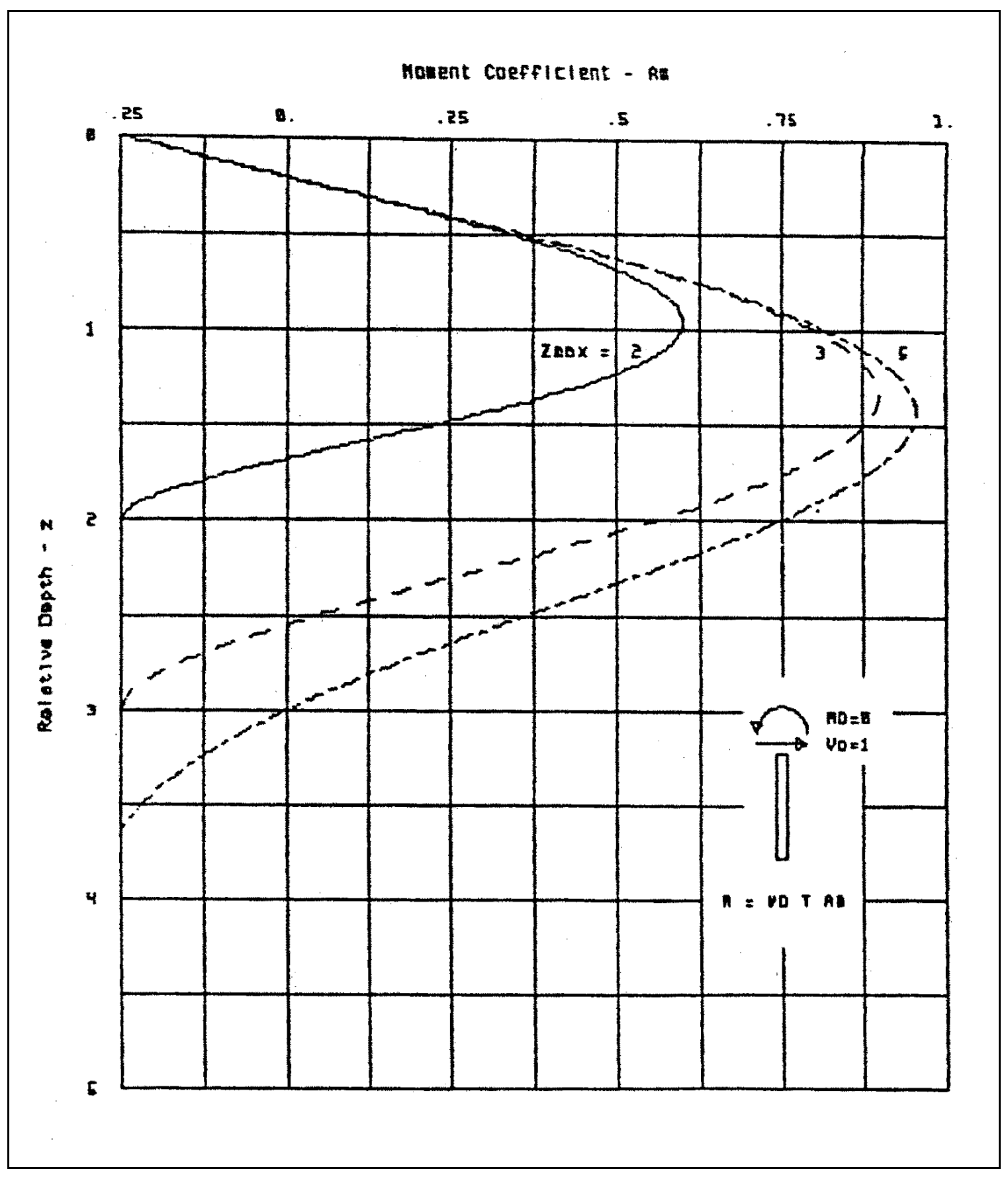

Figure B11. Bending moment coefficient for unit head shear for soil stiffness varying parabolically with depth 


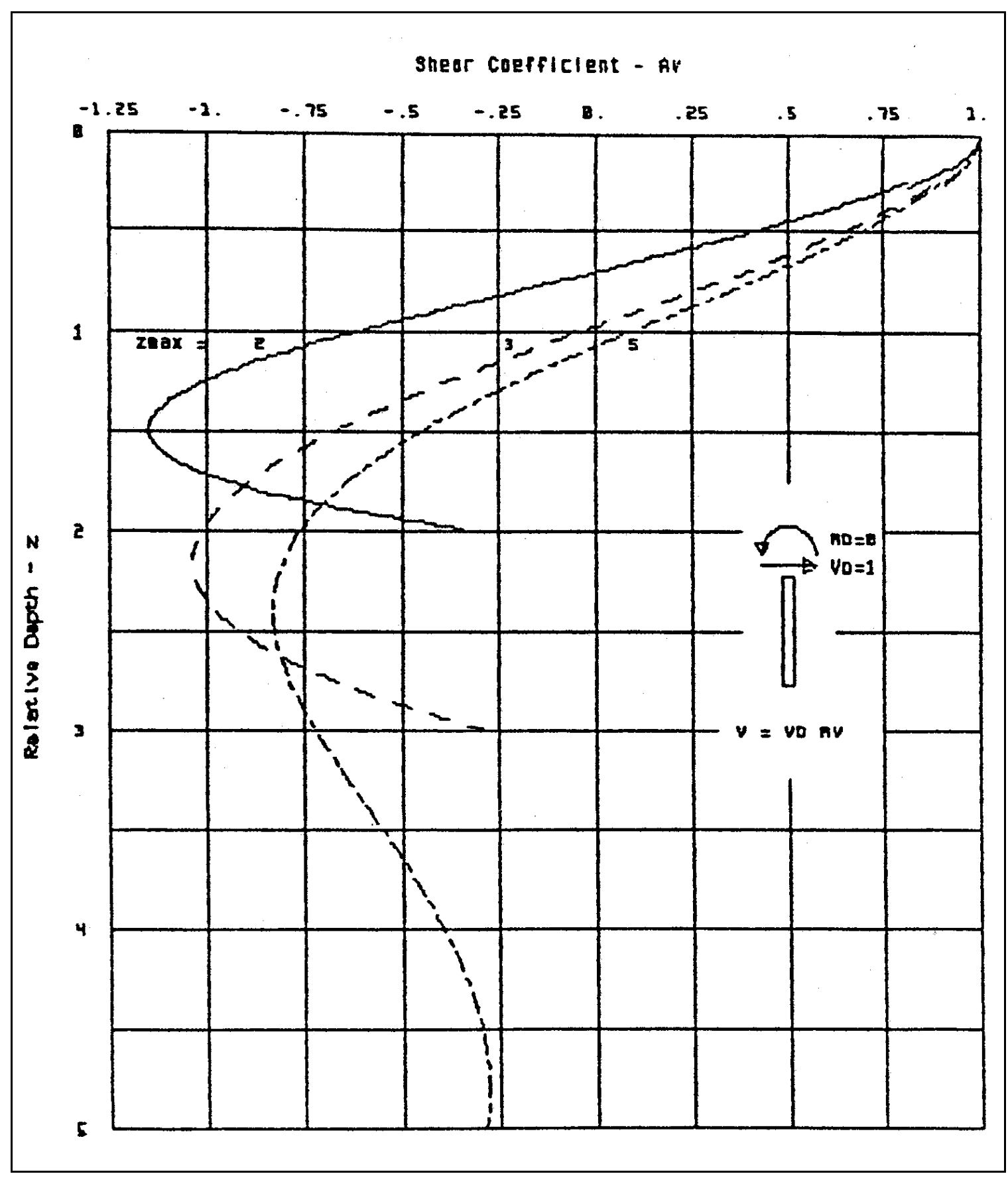

Figure B12. Shear coefficient for unit head shear for soil stiffness varying parabolically with depth 


\begin{tabular}{|c|c|c|c|c|c|c|c|c|c|}
\hline \multicolumn{10}{|c|}{$\begin{array}{l}\text { Table B5 } \\
\text { Nondimensional Coefficients for Laterally Loaded Pile for Soil Modulus Varying } \\
\text { Parabolically with Depth (Head Shear } V_{0}=1 \text {, Head Moment } M_{0}=0 \text { ) }\end{array}$} \\
\hline \multirow[b]{2}{*}{$z$} & \multicolumn{3}{|c|}{$Z_{\max }=2$} & \multicolumn{3}{|c|}{$Z_{\max }=3$} & \multicolumn{3}{|c|}{$Z_{\max }=4$} \\
\hline & $\boldsymbol{A}_{u}$ & $A_{s}$ & $\boldsymbol{A}_{m}$ & $\boldsymbol{A}_{u}$ & $\boldsymbol{A}_{s}$ & $\boldsymbol{A}_{m}$ & $\boldsymbol{A}_{u}$ & $A_{s}$ & $\boldsymbol{A}_{m}$ \\
\hline 0.00 & 6.418 & -4.348 & 0.000 & 3.039 & -1.970 & 0.000 & 2.820 & -1.884 & 0.000 \\
\hline 0.10 & 5.983 & -4.343 & 0.100 & 2.842 & -1.965 & 0.100 & 2.631 & -1.879 & 0.100 \\
\hline 0.20 & 5.550 & -4.328 & 0.199 & 2.647 & -1.950 & 0.200 & 2.407 & -1.859 & 0.219 \\
\hline 0.30 & 5.118 & -4.303 & 0.296 & 2.453 & -1.925 & 0.298 & 2.259 & -1.839 & 0.298 \\
\hline 0.40 & 4.689 & -4.269 & 0.389 & 2.262 & -1.890 & 0.395 & 2.041 & -1.796 & 0.414 \\
\hline 0.50 & 4.265 & -4.225 & 0.473 & 2.075 & -1.846 & 0.487 & 1.898 & -1.760 & 0.488 \\
\hline 0.60 & 3.845 & -4.174 & 0.548 & 1.893 & -1.793 & 0.575 & 1.691 & -1.695 & 0.594 \\
\hline 0.70 & 3.430 & -4.116 & 0.608 & 1.717 & -1.732 & 0.655 & 1.557 & -1.645 & 0.659 \\
\hline 0.80 & 3.022 & -4.053 & 0.651 & 1.547 & -1.662 & 0.728 & 1.365 & -1.560 & 0.748 \\
\hline 0.90 & 2.619 & -3.987 & 0.676 & 1.384 & -1.586 & 0.790 & 1.243 & -1.498 & 0.800 \\
\hline 1.00 & 2.224 & -3.919 & 0.679 & 1.230 & -1.505 & 0.841 & 1.069 & -1.398 & 0.865 \\
\hline 1.10 & 1.836 & -3.852 & 0.660 & 1.083 & -1.418 & 0.880 & 0.960 & -1.328 & 0.900 \\
\hline 1.20 & 1.454 & -3.788 & 0.619 & 0.946 & -1.329 & 0.906 & 0.807 & -1.217 & 0.938 \\
\hline 1.30 & 1.078 & -3.729 & 0.557 & 0.818 & -1.238 & 0.918 & 0.712 & -1.141 & 0.955 \\
\hline 1.40 & 0.708 & -3.677 & 0.477 & 0.699 & -1.146 & 0.917 & 0.582 & -1.026 & 0.964 \\
\hline 1.50 & 0.342 & -3.634 & 0.383 & 0.588 & -1.055 & 0.902 & 0.503 & -0.949 & 0.961 \\
\hline 1.60 & -0.019 & -3.601 & 0.282 & 0.488 & -0.966 & 0.873 & 0.396 & -0.835 & 0.943 \\
\hline 1.70 & -0.378 & -3.578 & 0.181 & 0.395 & -0.881 & 0.832 & 0.333 & -0.760 & 0.923 \\
\hline 1.80 & -0.735 & -3.564 & 0.091 & 0.311 & -0.800 & 0.780 & 0.248 & -0.652 & 0.881 \\
\hline 1.90 & -1.091 & -3.559 & 0.026 & 0.235 & -0.725 & 0.718 & 0.199 & -0.582 & 0.847 \\
\hline 2.00 & -1.447 & -3.558 & 0.000 & 0.166 & -0.657 & 0.647 & 0.135 & -0.484 & 0.786 \\
\hline 2.10 & & & & 0.103 & -0.596 & 0.570 & 0.099 & -0.423 & 0.742 \\
\hline 2.20 & & & & 0.047 & -0.543 & 0.488 & 0.053 & -0.338 & 0.670 \\
\hline 2.30 & & & & -0.005 & -0.498 & 0.404 & 0.028 & -0.287 & 0.619 \\
\hline 2.40 & & & & -0.053 & -0.462 & 0.320 & -0.002 & -0.217 & 0.542 \\
\hline 2.50 & & & & -0.098 & -0.434 & 0.239 & -0.018 & -0.176 & 0.491 \\
\hline 2.60 & & & & -0.140 & -0.414 & 0.164 & -0.036 & -0.121 & 0.416 \\
\hline 2.70 & & & & -0.181 & -0.401 & 0.099 & -0.044 & -0.090 & 0.367 \\
\hline
\end{tabular}




\begin{tabular}{|c|c|c|c|c|c|c|c|c|c|}
\hline \multicolumn{10}{|c|}{ Table B5 (Concluded) } \\
\hline \multirow[b]{2}{*}{$\underline{z}$} & \multicolumn{3}{|c|}{$Z_{\max }=2$} & \multicolumn{3}{|c|}{$Z_{\max }=3$} & \multicolumn{3}{|c|}{$Z_{\max }=4$} \\
\hline & $\boldsymbol{A}_{u}$ & $\boldsymbol{A}_{s}$ & $\boldsymbol{A}_{m}$ & $\boldsymbol{A}_{u}$ & $A_{s}$ & $\boldsymbol{A}_{m}$ & $\boldsymbol{A}_{u}$ & $\boldsymbol{A}_{s}$ & $\boldsymbol{A}_{m}$ \\
\hline 2.80 & & & & -0.221 & -0.394 & 0.047 & -0.052 & -0.050 & 0.298 \\
\hline 2.90 & & & & -0.260 & -0.391 & 0.013 & -0.055 & -0.028 & 0.256 \\
\hline 3.00 & & & & -0.299 & -0.390 & 0.000 & -0.057 & -0.001 & 0.198 \\
\hline 3.10 & & & & & & & -0.057 & 0.013 & 0.163 \\
\hline 3.20 & & & & & & & -0.054 & 0.030 & 0.117 \\
\hline 3.30 & & & & & & & -0.051 & 0.038 & 0.091 \\
\hline 3.40 & & & & & & & -0.046 & 0.047 & 0.059 \\
\hline 3.50 & & & & & & & -0.042 & 0.051 & 0.042 \\
\hline 3.60 & & & & & & & -0.036 & 0.055 & 0.023 \\
\hline 3.70 & & & & & & & -0.031 & 0.057 & 0.013 \\
\hline 3.80 & & & & & & & -0.024 & 0.058 & 0.004 \\
\hline 3.90 & & & & & & & -0.020 & 0.058 & 0.001 \\
\hline 4.00 & & & & & & & -0.014 & 0.058 & 0.000 \\
\hline
\end{tabular}




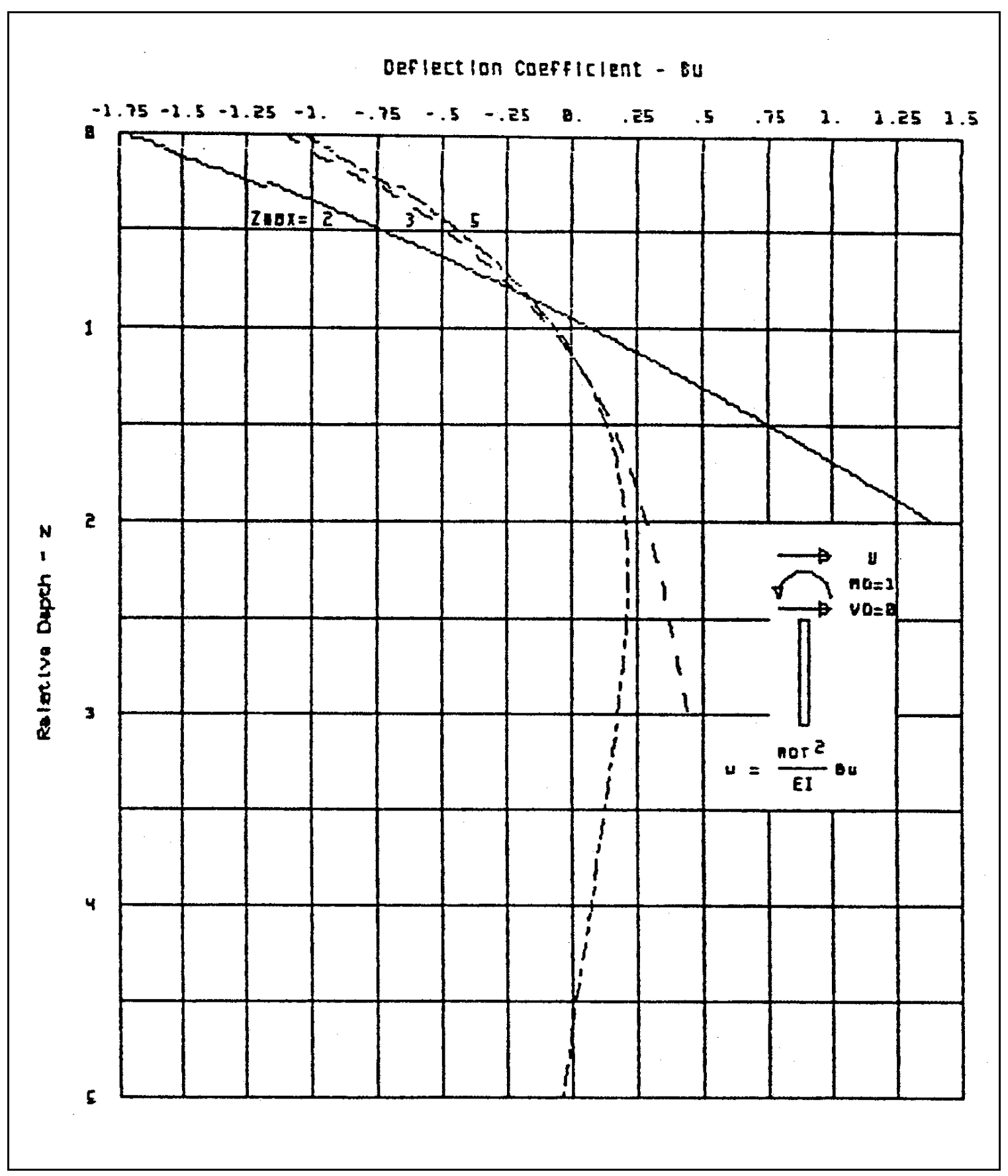

Figure B13. Deflection coefficient for unit head moment for soil stiffness constant with depth 


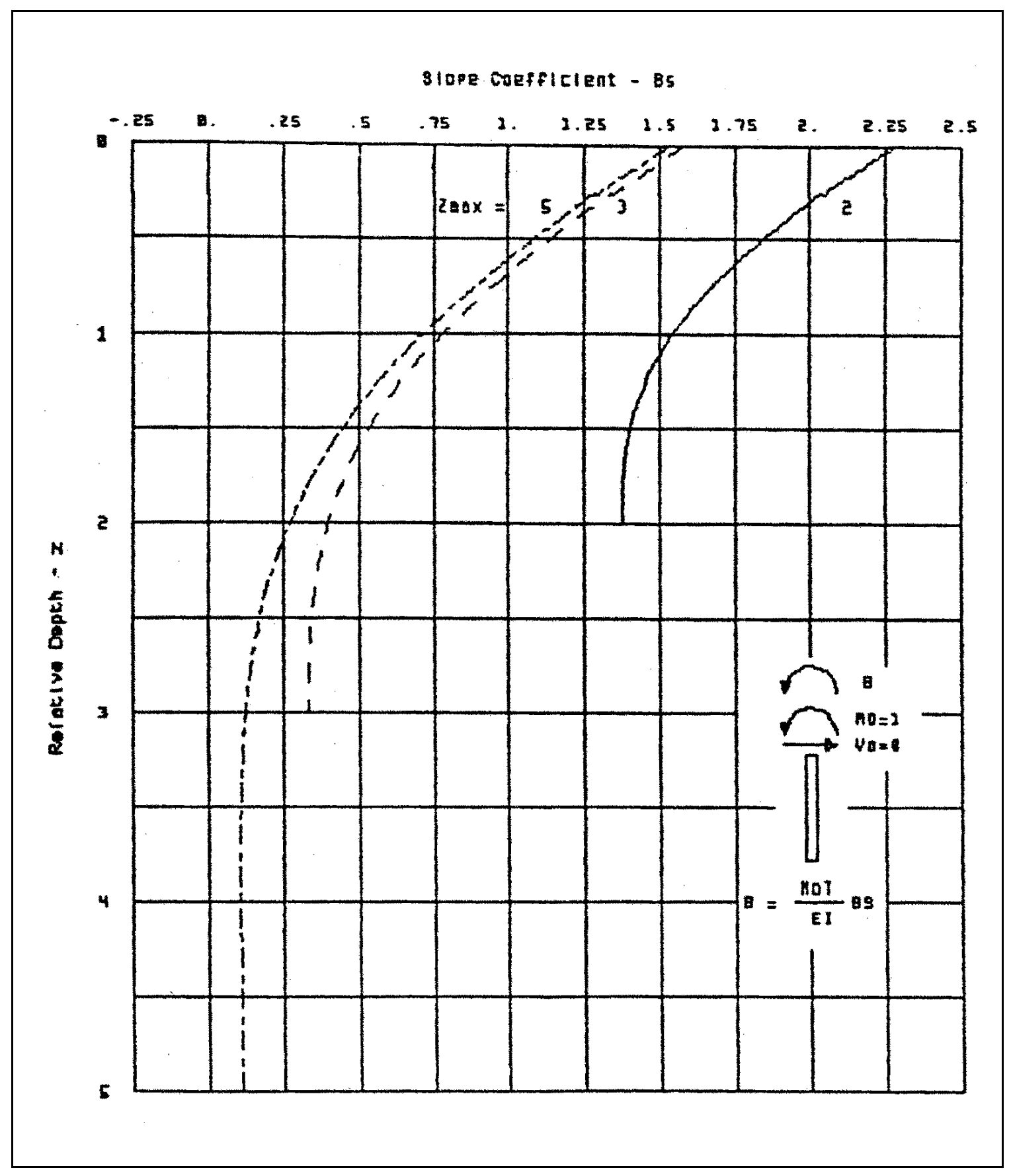

Figure B14. Slope coefficient for unit head moment for soil stiffness constant with depth 


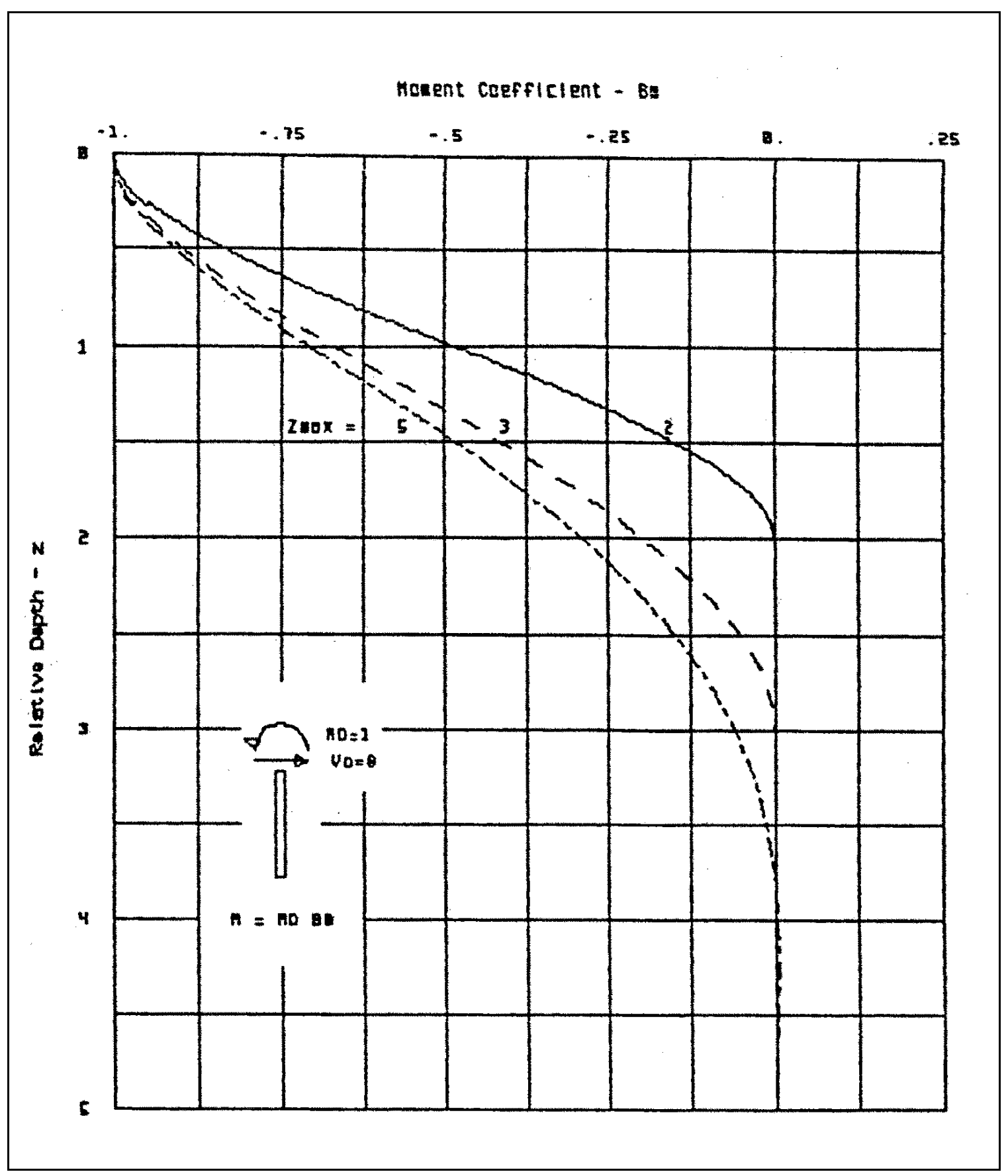

Figure B15. Bending moment coefficient for unit head moment for soil stiffness constant with depth 


\begin{tabular}{|c|c|c|c|c|c|c|c|c|c|}
\hline \multicolumn{10}{|c|}{$\begin{array}{l}\text { Table B6 } \\
\text { Nondimensional Coefficients for Laterally Loaded Pile for Soil Modulus Varying } \\
\text { Parabolically with Depth (Head Shear } V_{0}=0 \text {, Head Moment } M_{0}=1 \text { ) }\end{array}$} \\
\hline \multirow[b]{2}{*}{$z$} & \multicolumn{3}{|c|}{$Z_{\max }=2$} & \multicolumn{3}{|c|}{$Z_{\max }=3$} & \multicolumn{3}{|c|}{$Z_{\max }=4$} \\
\hline & $B_{u}$ & $B_{s}$ & $\boldsymbol{B}_{m}$ & $B_{u}$ & $B_{s}$ & $B_{m}$ & $B_{u}$ & $B_{s}$ & $\boldsymbol{B}_{m}$ \\
\hline 0.00 & -4.348 & 3.624 & -1.000 & -1.970 & 1.925 & -1.000 & -1.884 & 1.888 & -1.000 \\
\hline 0.10 & -3.990 & 3.524 & -1.000 & -1.783 & 1.825 & -1.000 & -1.700 & 1.788 & -1.000 \\
\hline 0.20 & -3.643 & 3.424 & -0.999 & -1.605 & 1.725 & -1.000 & -1.493 & 1.668 & -1.000 \\
\hline 0.30 & -3.306 & 3.324 & -0.998 & -1.438 & 1.625 & -0.999 & -1.362 & 1.589 & -0.999 \\
\hline 0.40 & -2.978 & 3.224 & -0.993 & -1.280 & 1.525 & -0.997 & -1.179 & 1.469 & -0.996 \\
\hline 0.50 & -2.661 & 3.125 & -0.983 & -1.133 & 1.425 & -0.992 & -1.065 & 1.389 & -0.993 \\
\hline 0.60 & -2.353 & 3.028 & -0.966 & -0.995 & 1.326 & -0.985 & -0.905 & 1.271 & -0.984 \\
\hline 0.70 & -2.055 & 2.932 & -0.942 & -0.867 & 1.228 & -0.975 & -0.807 & 1.192 & -0.976 \\
\hline 0.80 & -1.767 & 2.840 & -0.907 & -0.749 & 1.132 & -0.960 & 0.670 & 1.076 & -0.959 \\
\hline 0.90 & -1.487 & 2.751 & -0.860 & -0.641 & 1.037 & -0.940 & -0.587 & 1.000 & -0.944 \\
\hline 1.00 & -1.216 & 2.668 & -0.802 & -0.542 & 0.944 & -0.915 & -0.474 & 0.888 & -0.916 \\
\hline 1.10 & -0.953 & 2.591 & -0.732 & -0.452 & 0.854 & -0.885 & -0.406 & 0.816 & -0.893 \\
\hline 1.20 & -0.698 & 2.522 & -0.650 & -0.371 & 0.767 & -0.850 & -0.315 & 0.711 & -0.853 \\
\hline 1.30 & -0.449 & 2.462 & -0.559 & -0.299 & 0.684 & -0.808 & -0.260 & 0.644 & -0.822 \\
\hline 1.40 & -0.205 & 2.411 & -0.460 & -0.234 & 0.605 & -0.762 & -0.189 & 0.548 & -0.771 \\
\hline 1.50 & 0.034 & 2.370 & -0.356 & -0.177 & 0.532 & -0.712 & -0.147 & 0.488 & -0.734 \\
\hline 1.60 & 0.269 & 2.339 & -0.254 & -0.128 & 0.463 & -0.657 & -0.094 & 0.404 & -0.675 \\
\hline 1.70 & 0.502 & 2.319 & -0.159 & -0.085 & 0.400 & -0.599 & -0.064 & 0.351 & -0.633 \\
\hline 1.80 & 0.733 & 2.307 & -0.078 & -0.047 & 0.343 & -0.539 & -0.026 & 0.279 & -0.569 \\
\hline 1.90 & 0.964 & 2.302 & -0.022 & -0.016 & 0.293 & -0.477 & -0.006 & 0.235 & -0.525 \\
\hline 2.00 & 1.194 & 2.302 & 0.000 & 0.011 & 0.248 & -0.415 & 0.019 & 0.176 & -0.459 \\
\hline 2.10 & & & & 0.034 & 0.210 & -0.353 & 0.032 & 0.141 & -0.416 \\
\hline 2.20 & & & & 0.053 & 0.177 & -0.292 & 0.046 & 0.095 & -0.353 \\
\hline 2.30 & & & & 0.070 & 0.151 & -0.235 & 0.052 & 0.069 & -0.312 \\
\hline 2.40 & & & & 0.084 & 0.130 & -0.180 & 0.058 & 0.035 & -0.255 \\
\hline 2.50 & & & & 0.096 & 0.115 & -0.131 & 0.060 & 0.016 & -0.219 \\
\hline 2.60 & & & & 0.107 & 0.104 & -0.088 & 0.061 & -0.008 & -0.171 \\
\hline 2.70 & & & & 0.117 & 0.097 & -0.052 & 0.060 & -0.020 & -0.142 \\
\hline
\end{tabular}




\begin{tabular}{|c|c|c|c|c|c|c|c|c|c|}
\hline \multicolumn{10}{|c|}{ Table B6 (Concluded) } \\
\hline \multirow[b]{2}{*}{$z$} & \multicolumn{3}{|c|}{$Z_{\max }=2$} & \multicolumn{3}{|c|}{$Z_{\max }=3$} & \multicolumn{3}{|c|}{$Z_{\max }=4$} \\
\hline & $\boldsymbol{B}_{u}$ & $B_{s}$ & $B_{m}$ & $\boldsymbol{B}_{u}$ & $B_{s}$ & $B$ & $B$ & $B_{s}$ & $B_{m}$ \\
\hline 2.80 & & & & 0.126 & 0.093 & -0.024 & 0.056 & -0.035 & -0.103 \\
\hline 2.90 & & & & 0.136 & 0.092 & -0.006 & 0.053 & -0.042 & -0.081 \\
\hline 3.00 & & & & 0.145 & 0.092 & 0.000 & 0.048 & -0.050 & -0.053 \\
\hline 3.10 & & & & & & & 0.043 & -0.054 & -0.038 \\
\hline 3.20 & & & & & & & 0.037 & -0.057 & -0.021 \\
\hline 3.30 & & & & & & & 0.032 & -0.059 & -0.012 \\
\hline 3.40 & & & & & & & 0.025 & -0.060 & -0.003 \\
\hline 3.50 & & & & & & & 0.020 & -0.060 & 0.000 \\
\hline 3.60 & & & & & & & 0.013 & -0.060 & 0.002 \\
\hline 3.70 & & & & & & & 0.008 & -0.059 & 0.003 \\
\hline 3.80 & & & & & & & 0.001 & -0.059 & 0.002 \\
\hline 3.90 & & & & & & & -0.004 & -0.059 & 0.001 \\
\hline 4.00 & & & & & & & -0.009 & -0.059 & 0.000 \\
\hline
\end{tabular}




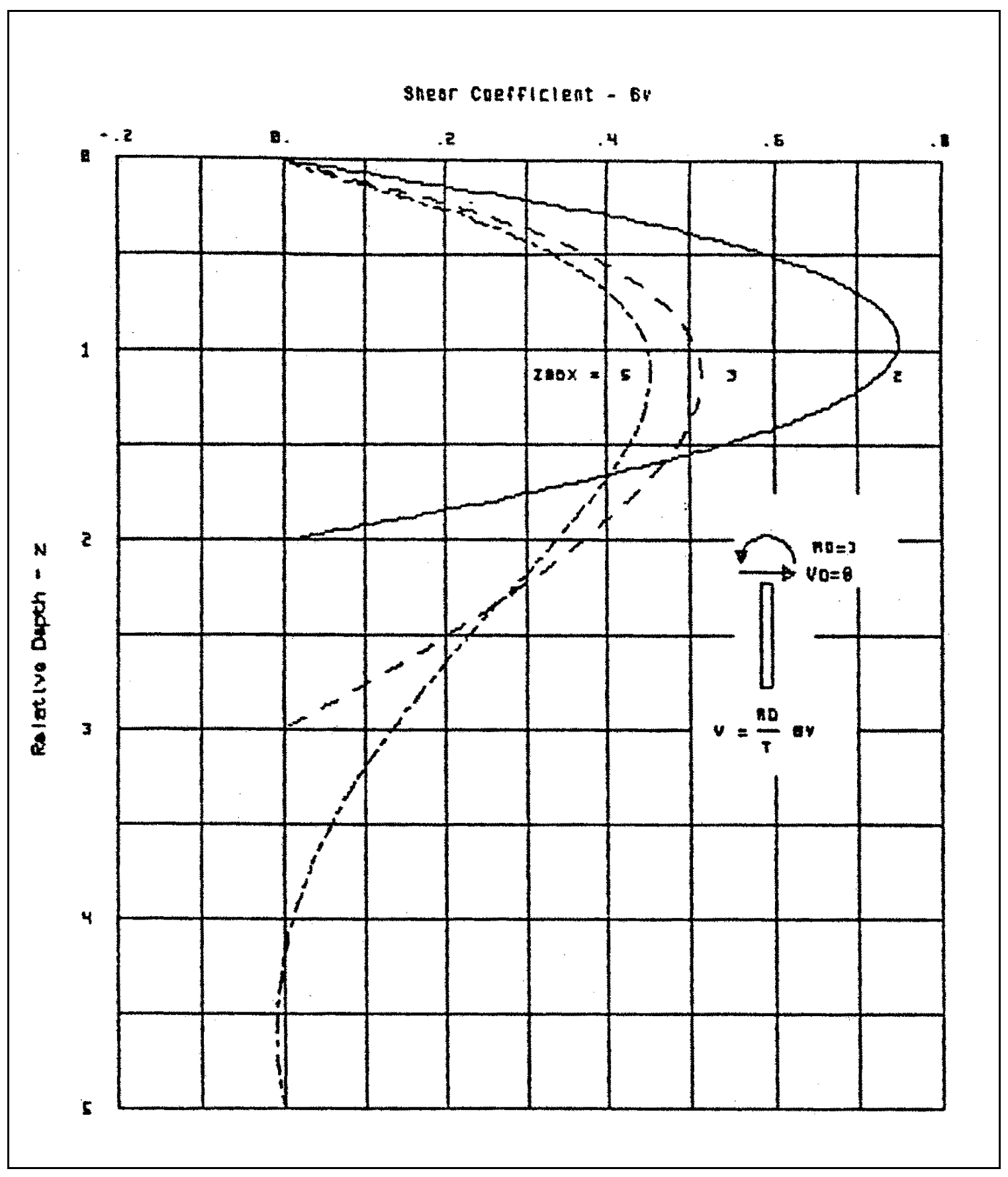

Figure B16. Shear coefficient for unit head moment for soil stiffness constant with depth 


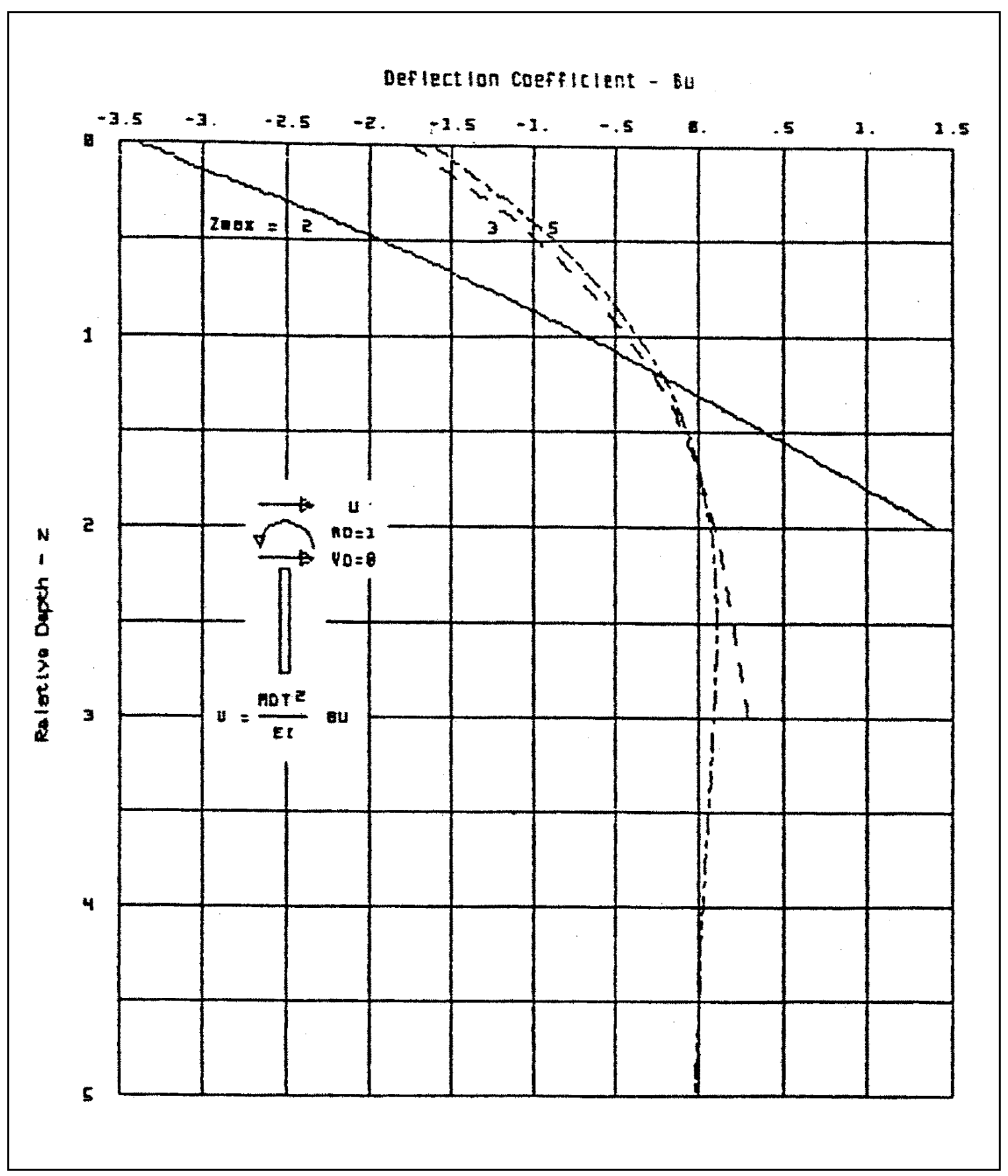

Figure B17. Deflection coefficient for unit head moment for soil stiffness constant with depth 


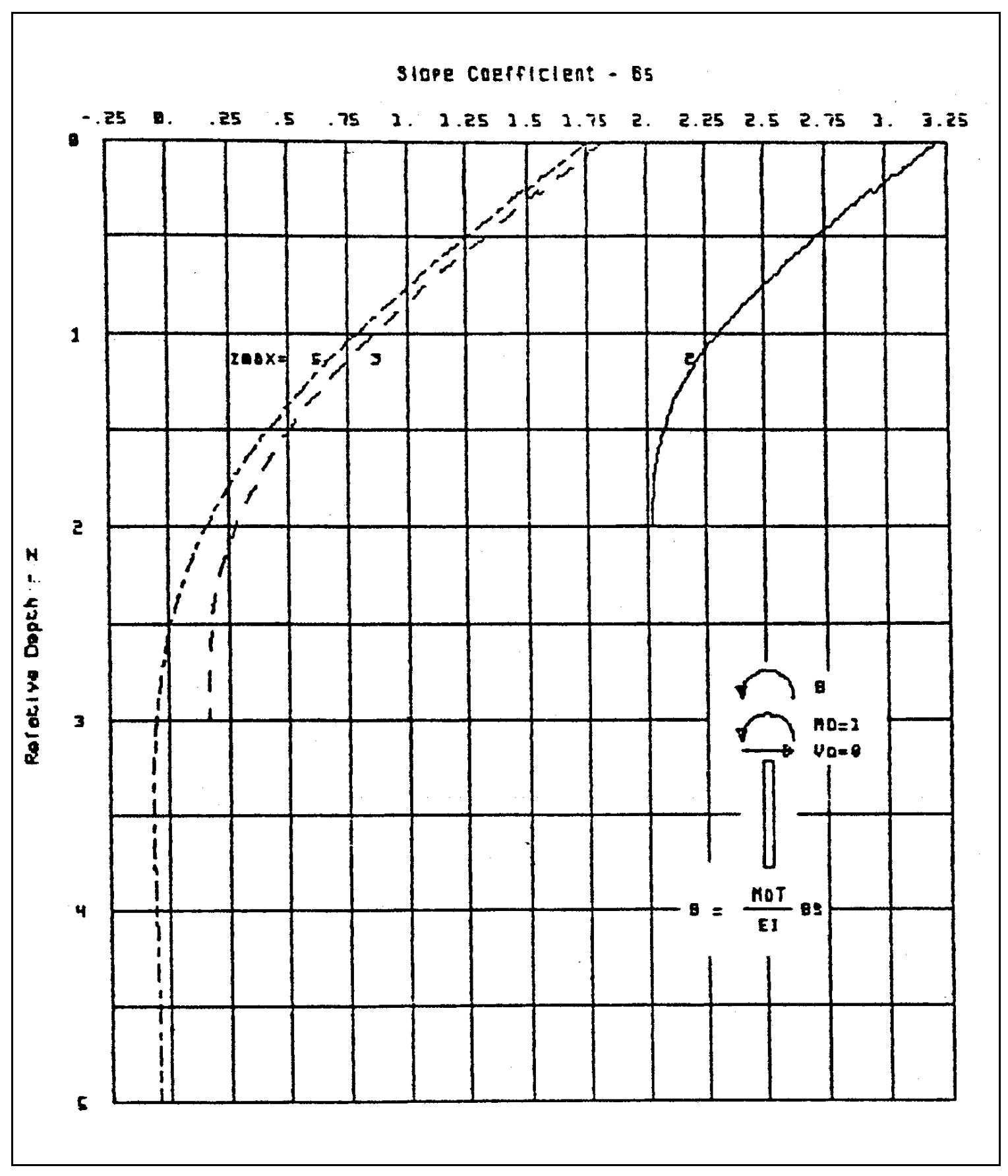

Figure B18. Slope coefficient for unit head moment for soil stiffness constant with depth 


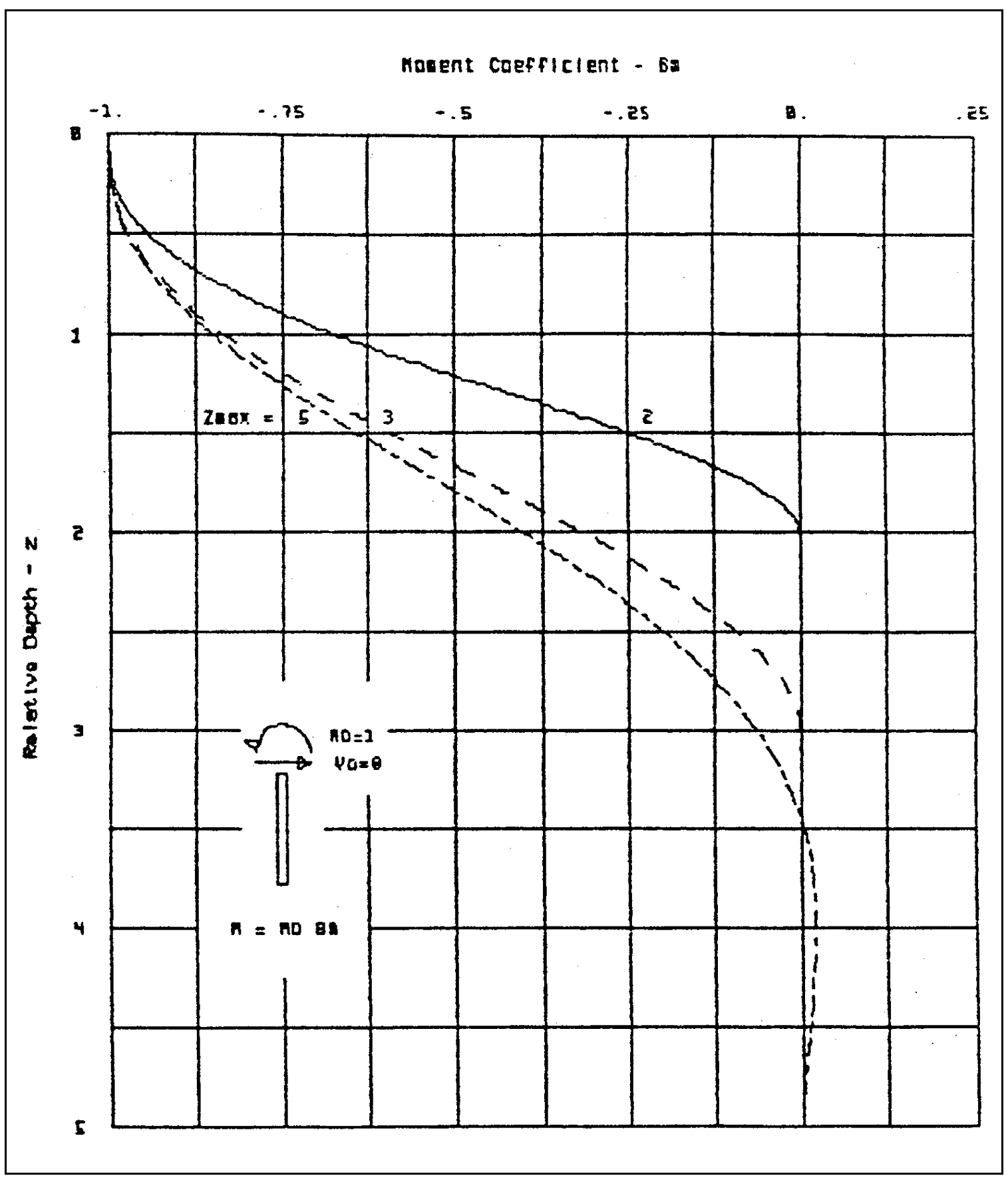

Figure B19. Bending moment coefficient for unit head moment for soil stiffness varying linearly with depth 


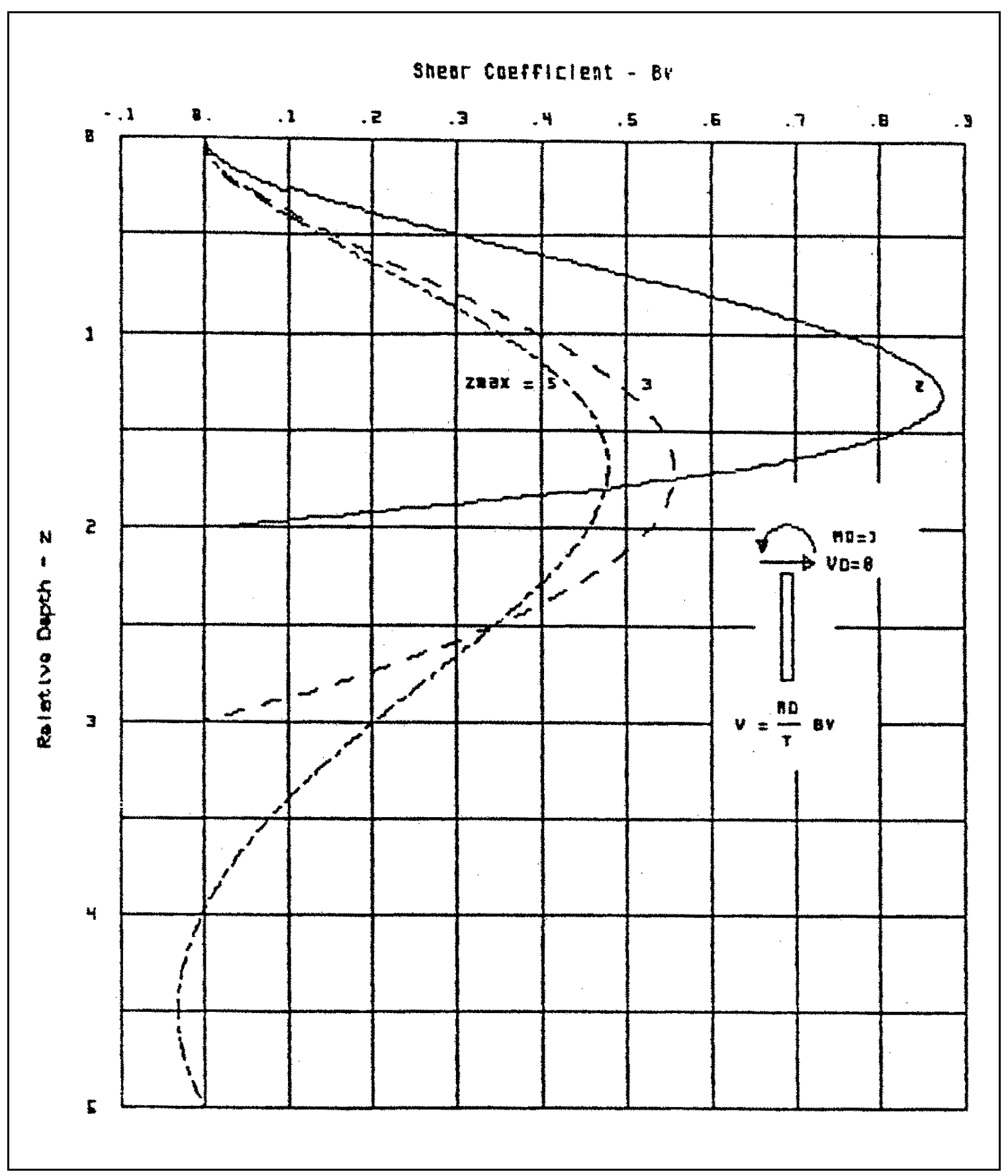

Figure B20. Shear coefficient for unit head moment for soil stiffness varying linearly with depth 


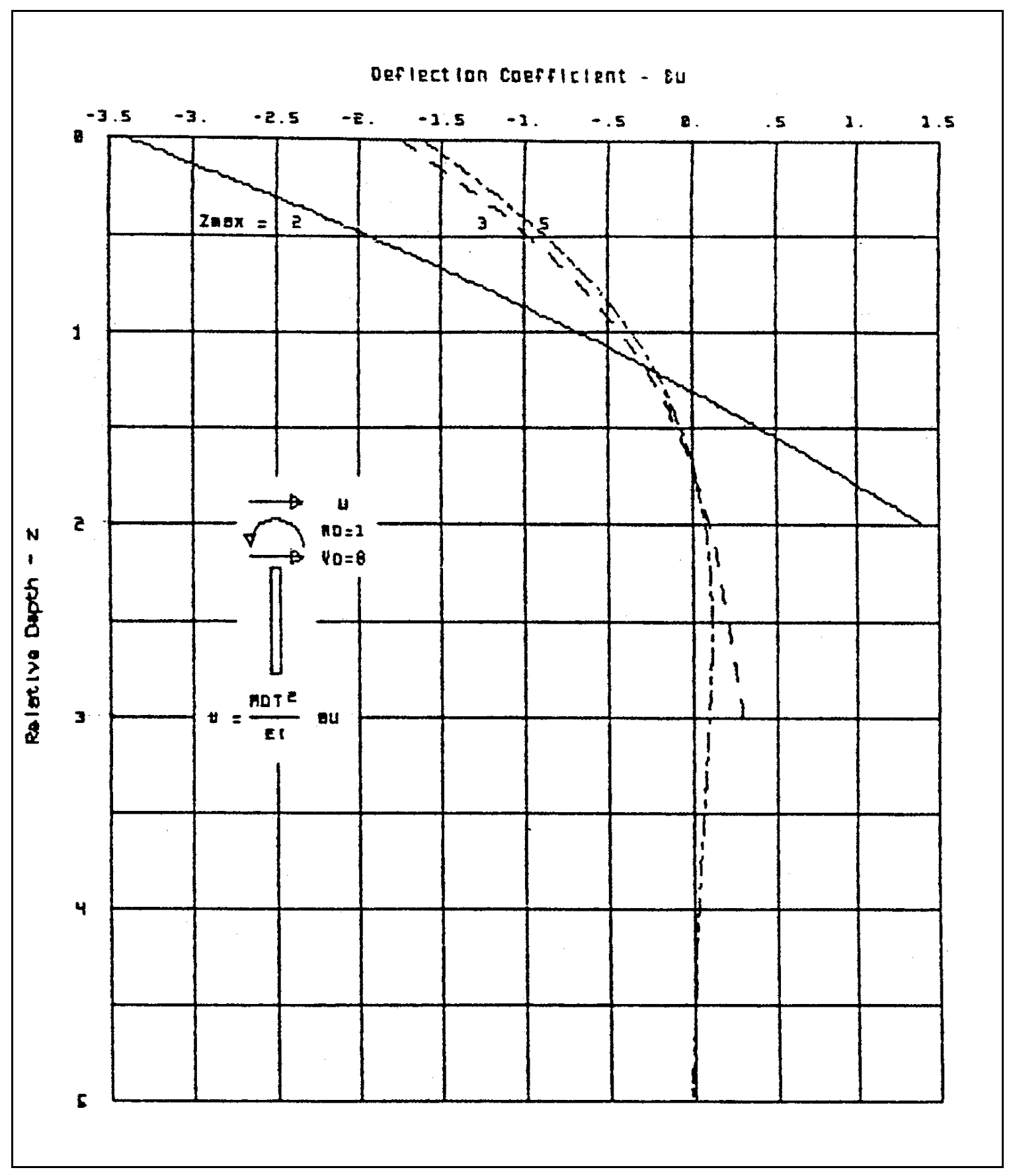

Figure B21. Deflection coefficient for unit head moment for soil stiffness varying parabolically with depth 


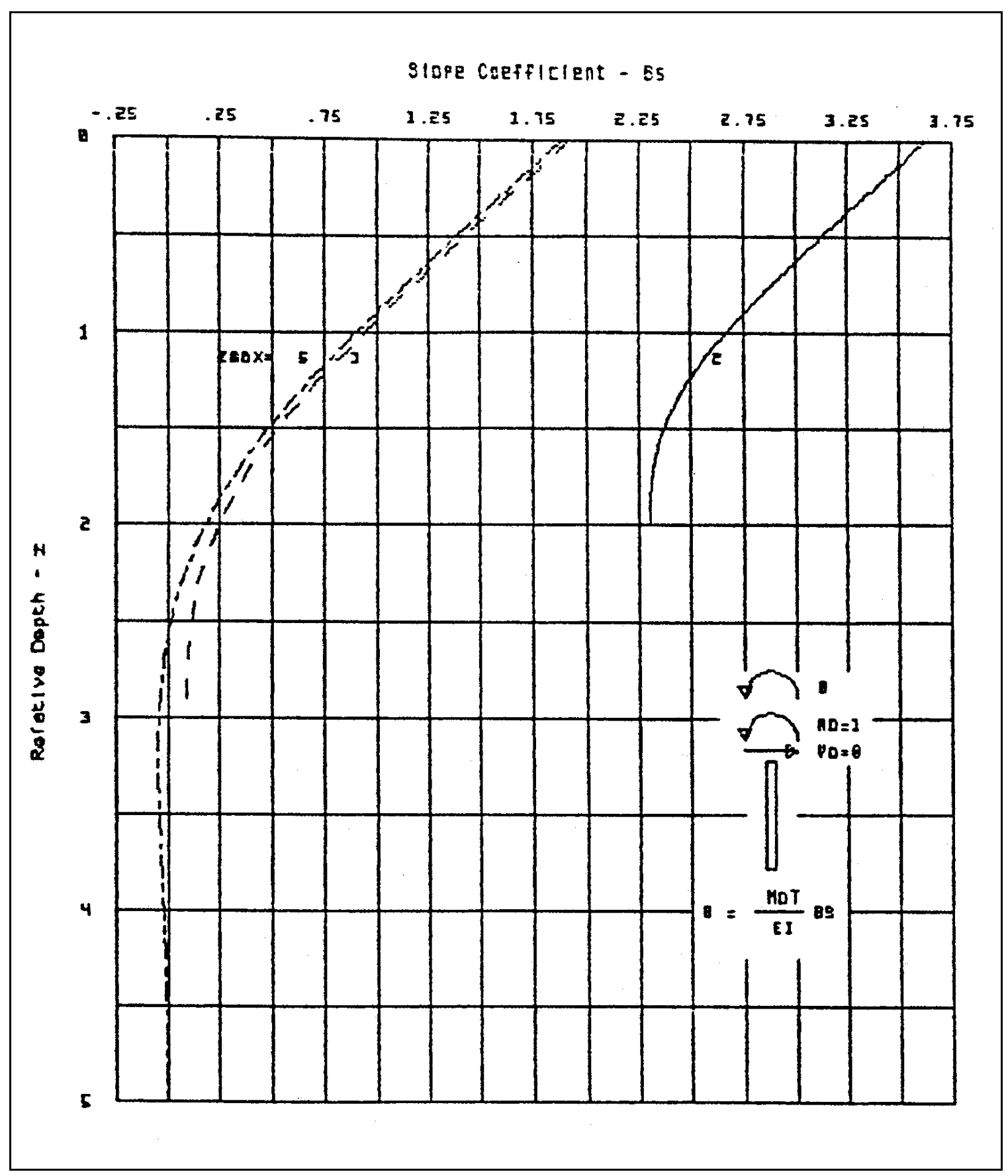

Figure B22. Slope coefficient for unit head moment for soil stiffness varying parabolically with depth 


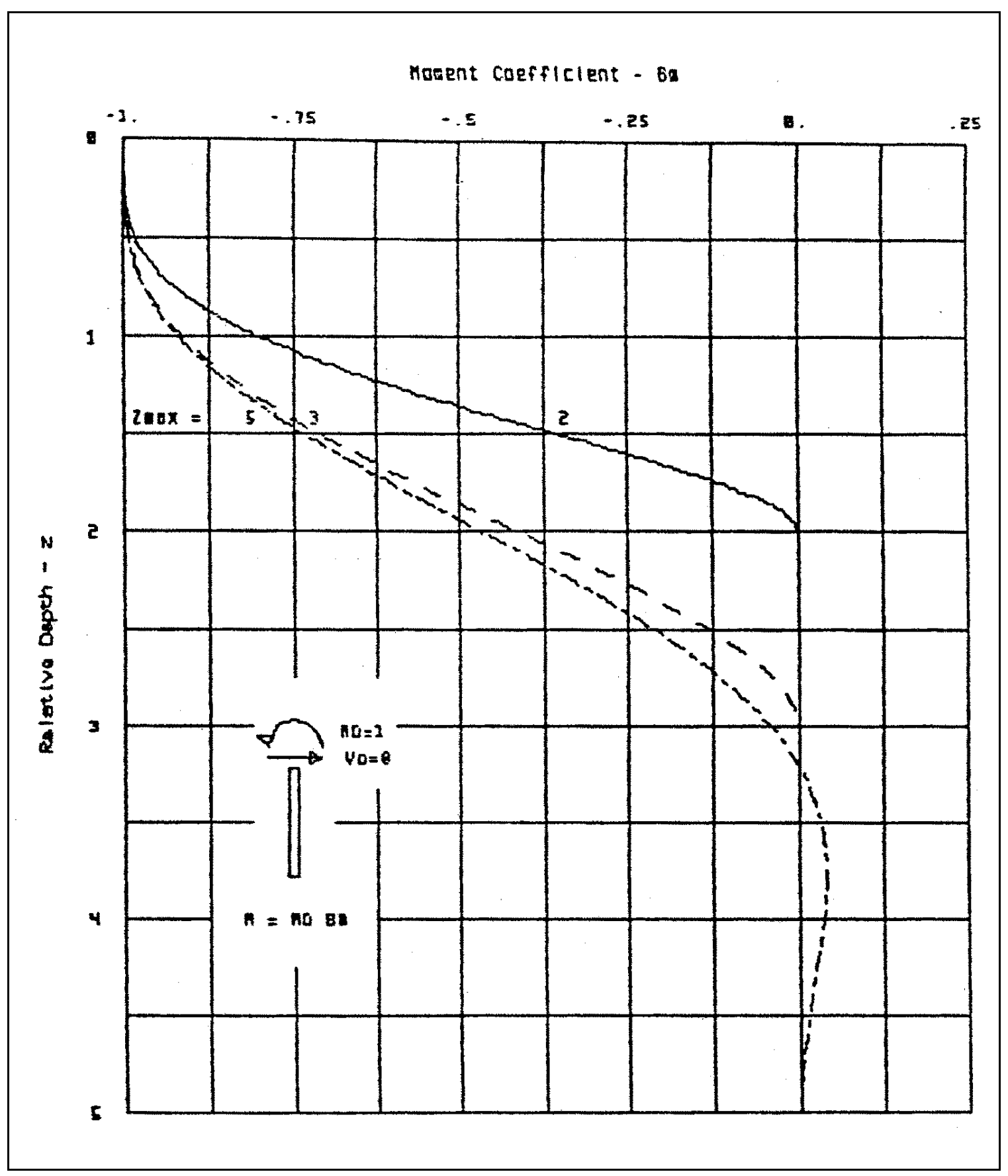

Figure B23. Bending moment coefficient for unit head moment for soil stiffness varying parabolically with depth 


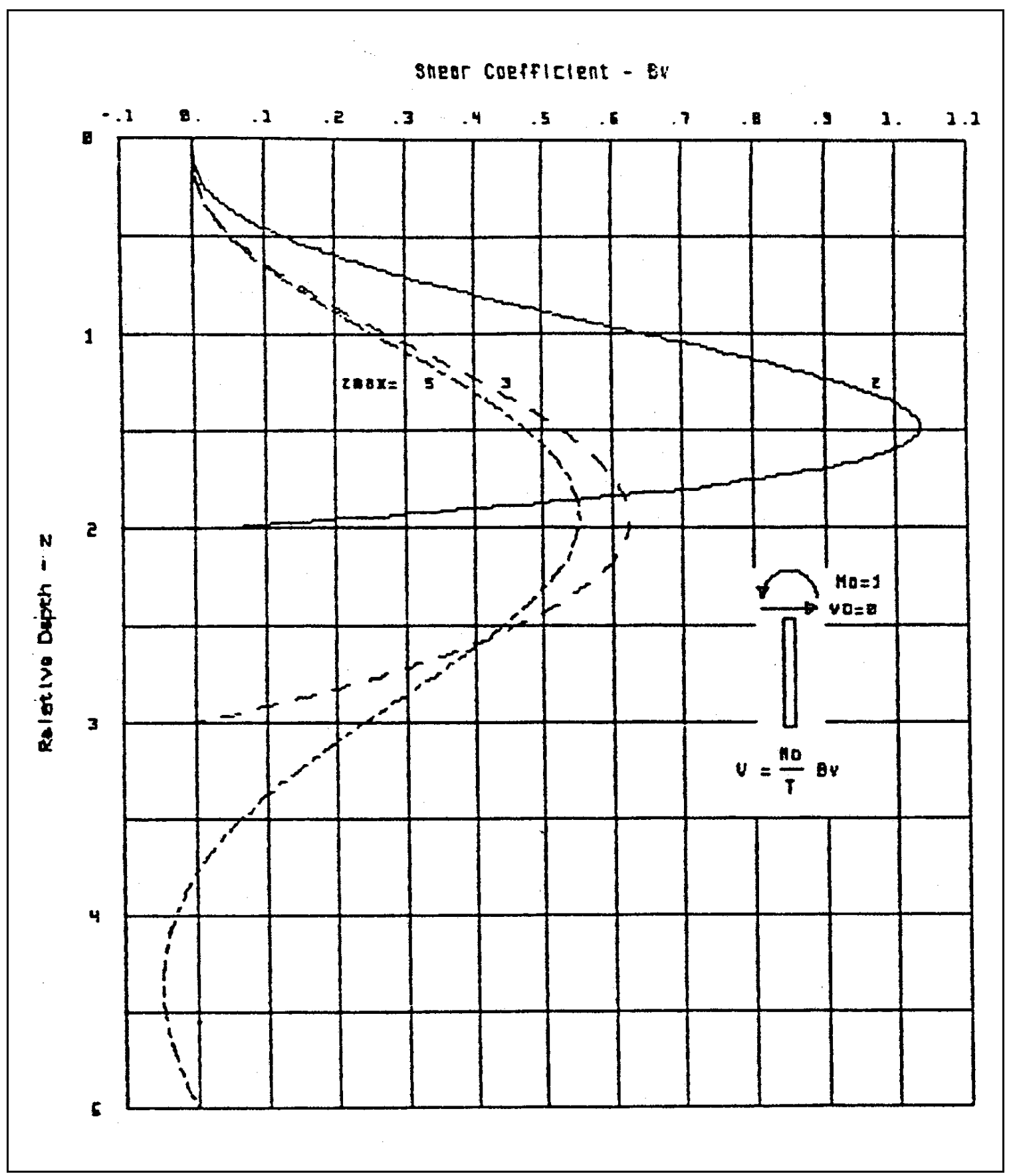

Figure B24. Shear coefficient for unit head moment for soil stiffness varying parabolically with depth 


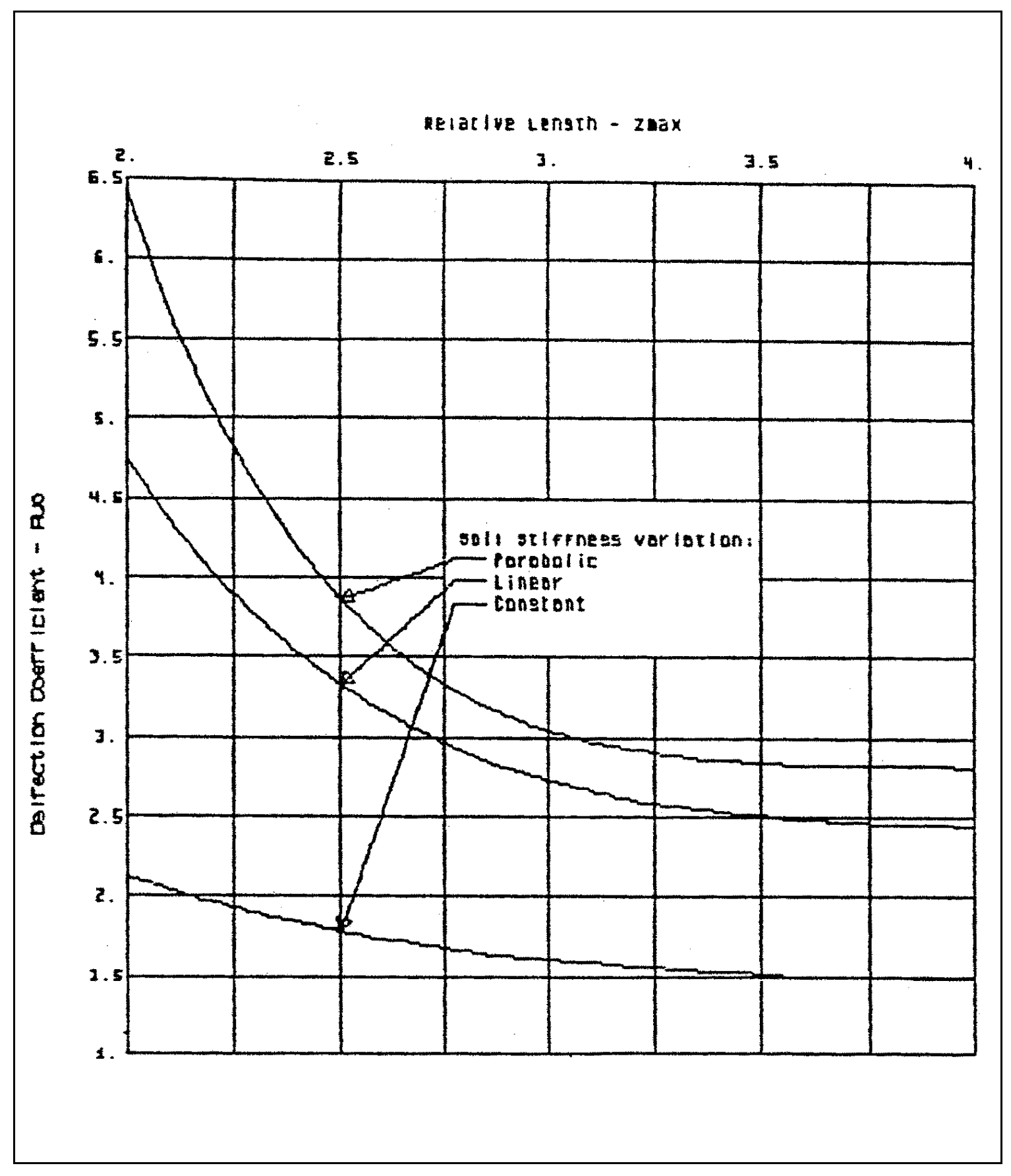

Figure B25. Pile head deflection coefficients for unit head shear 


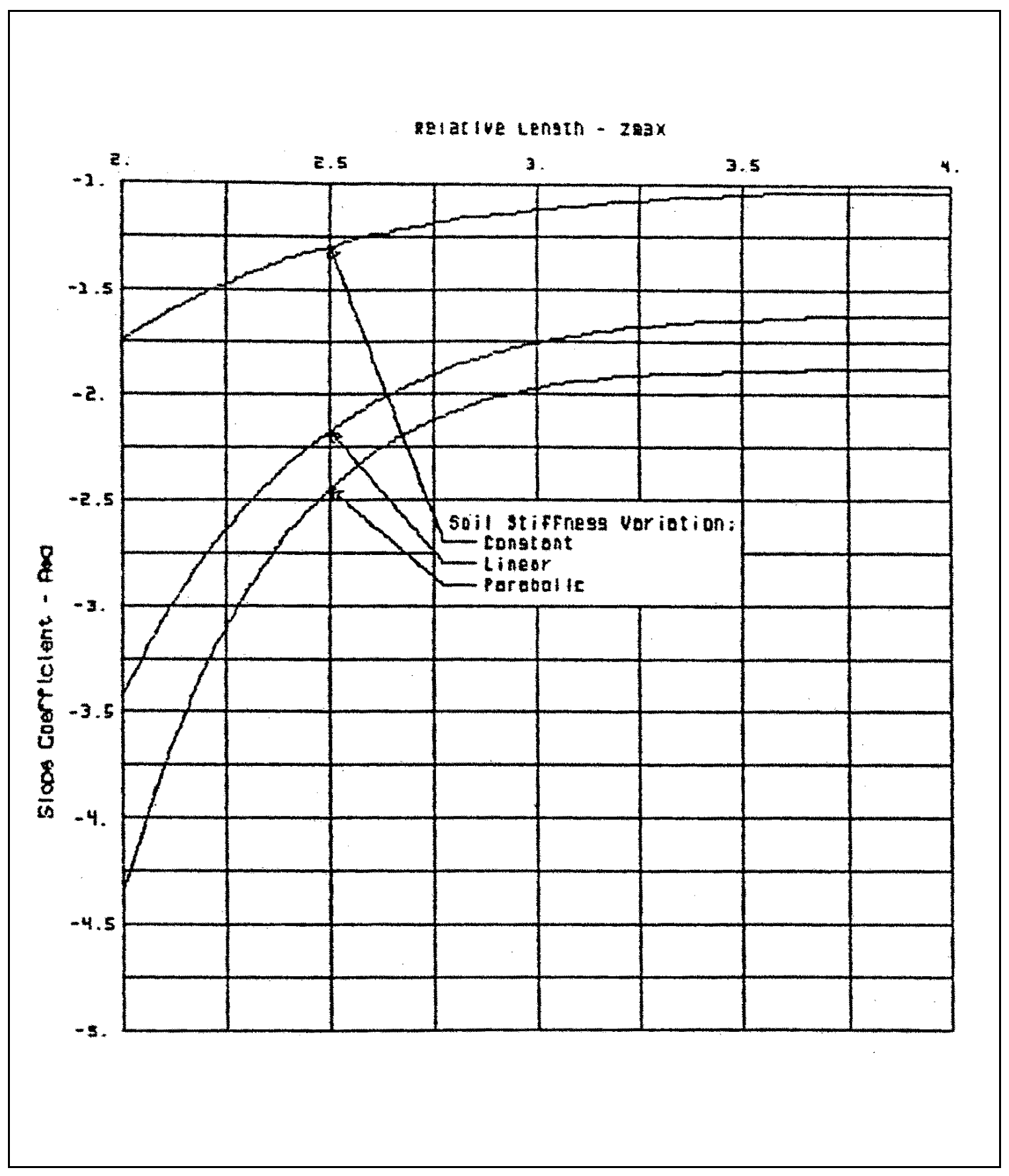

Figure B26. Pile head slope coefficients for unit head shear 


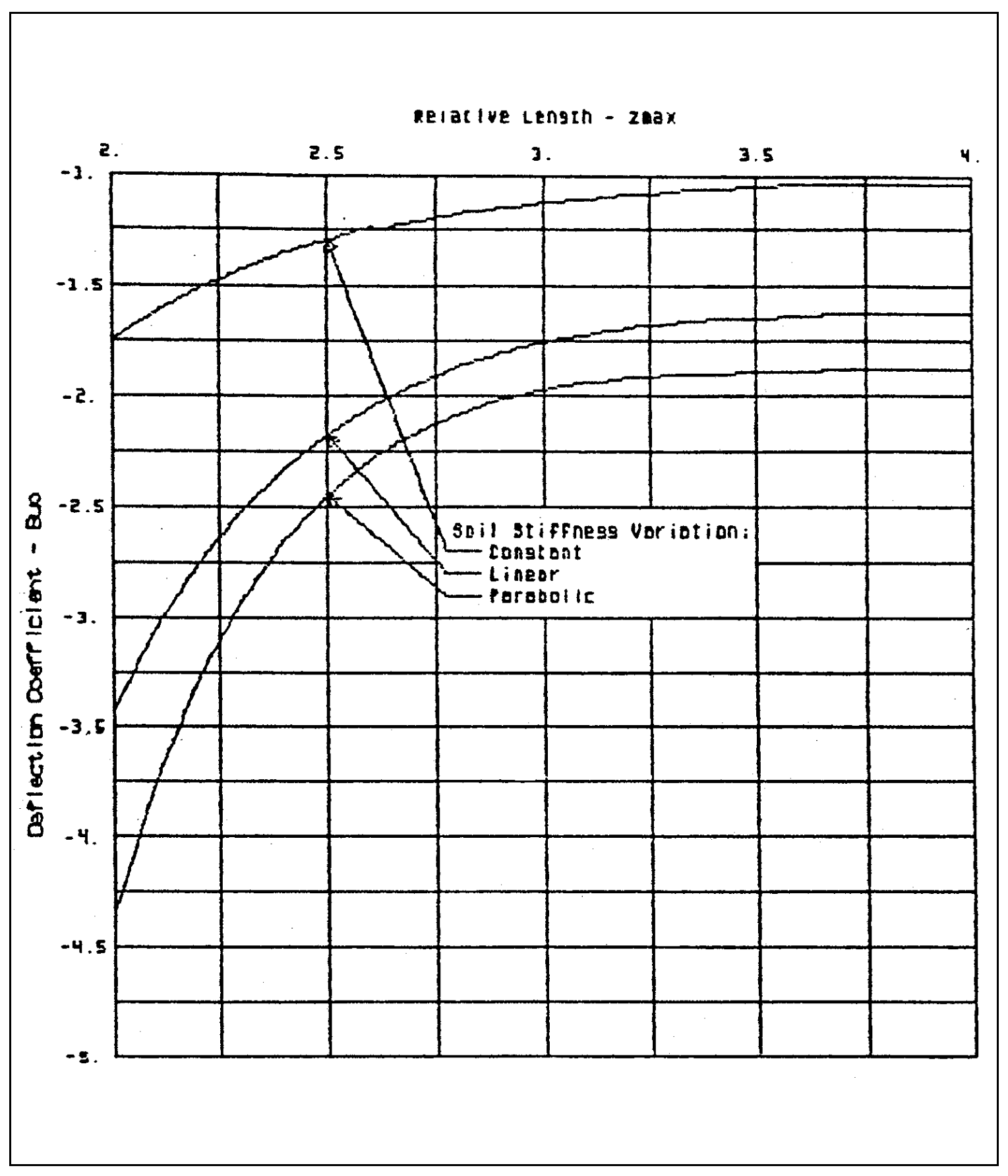

Figure B27. Pile head deflection coefficients for unit head moment 


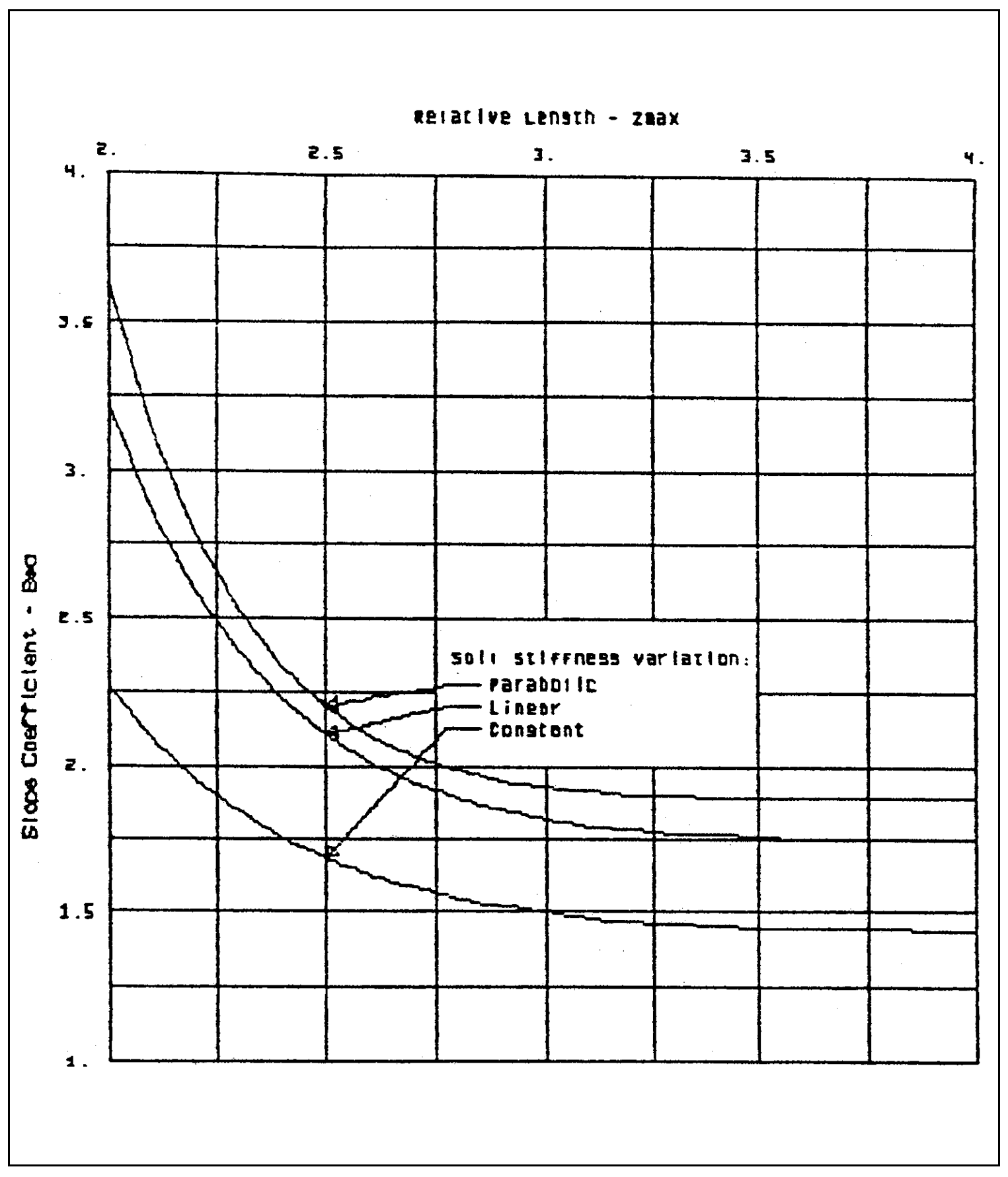

Figure B28. Pile head slope coefficients for unit head moment 


\section{REPORTS PUBLISHED UNDER THE COMPUTER-AIDED STRUCTURAL ENGINEERING (CASE) PROJECT}

Title

Date

Technical Report K-78-1

List of Computer Programs for Computer-Aided Structural Engineering

Feb 1978

Instruction Report 0-79-2

User's Guide: Computer Program with Interactive Graphics for Analysis of Plane Frame Structures (CFRAME)

Technical Report K-80-1

Survey of Bridge-Oriented Design Software

Mar 1979

Jan 1980

Evaluation of Computer Programs for the Design/Analysis of Highway and Railway Bridges

Instruction Report K-80-1

User's Guide: Computer Program for Design/Review of Curvi-linear Conduits/Culveris (CURCON)

Instruction Report K-80-3

A Three-Dimensional Finite Element Data Edit Program

A Three-Dimensional Stability Analysis/Design Program (3DSAD)

Report 1: General Geometry Module

Report 3: General Analysis Module (CGAM)

Report 4: Special-Purpose Modules for Dams (CDAMS)

Instruction Report K-80-6

Instruction Report K-80-7

Technical Report K-80-4

Technical Report K-80-5

Instruction Report K-81-2

Instruction Report K-81-3

Instruction Report K-81-4

Instruction Report K-81-6

Instruction Report K-81-7

Instruction Report K-81-9

Technical Report K-81-2
Basic User's Guide: Computer Program for Design and Analysis of Inverted-T Retaining Walls and Floodwalls (TWDA)

User's Reference Manual: Computer Program for Design and Analysis of Inverted-T Retaining Walls and Floodwalls (TWDA)

Documentation of Finite Element Analyses Report 1: Longview Outlet Works Conduit

Report 2: Anchored Wall Monolith, Bay Springs Lock

Basic Pile Group Behavior

User's Guide: Computer Program for Design and Analysis of Sheet Pile Walls by Classical Methods (CSHTWAL)

Report 1: Computational Processes

Report 2: Interactive Graphics Options

Validation Report: Computer Program for Design and Analysis of Inverted-T Retaining Walls and Floodwalls (TWDA)

User's Guide: Computer Program for Design and Analysis of Cast-inPlace Tunnel Linings (NEWTUN)

User's Guide: Computer Program for Optimum Nonlinear Dynamic Design of Reinforced Concrete Slabs Under Blast Loading (CBARCS)

User's Guide: Computer Program for Design or Investigation of Orthogonal Culverts (CORTCUL)

User's Guide: Computer Program for Three-Dimensional Analysis of Building Systems (CTABS80)

Theoretical Basis for CTABS80: A Computer Program for Three-Dimensional Analysis of Building Systems
Mar 1980

Jan 1980

Feb 1980

Jun 1980

Jun 1982

Aug 1983

Dec 1980

Dec 1980

Dec 1980

Dec 1980

Dec 1980

Feb 1981

Mar 1981

Feb 1981

Mar 1981

Mar 1981

Mar 1981

Aug 1981

Sep 1981

(Continued) 


\section{REPORTS PUBLISHED UNDER THE COMPUTER-AIDED STRUCTURAL ENGINEERING (CASE) PROJECT}

\begin{tabular}{|c|c|c|}
\hline & Title & Date \\
\hline Instruction Report K-82-6 & $\begin{array}{l}\text { User's Guide: Computer Program for Analysis of Beam-Column } \\
\text { Structures with Nonlinear Supports (CBEAMC) }\end{array}$ & Jun 1982 \\
\hline Instruction Report K-82-7 & $\begin{array}{l}\text { User's Guide: Computer Program for Bearing Capacity Analysis of } \\
\text { Shallow Foundations (CBEAR) }\end{array}$ & Jun 1982 \\
\hline Instruction Report K-83-1 & $\begin{array}{l}\text { User's Guide: Computer Program with Interactive Graphics for } \\
\text { Analysis of Plane Frame Structures (CFRAME) }\end{array}$ & Jan 1983 \\
\hline Instruction Report K-83-2 & $\begin{array}{l}\text { User's Guide: Computer Program for Generation of Engineering } \\
\text { Geometry (SKETCH) }\end{array}$ & Jun 1983 \\
\hline Instruction Report K-83-5 & $\begin{array}{l}\text { User's Guide: Computer Program to Calculate Shear, Moment, and } \\
\text { Thrust (CSMT) from Stress Results of a Two-Dimensional Finite } \\
\text { Element Analysis }\end{array}$ & Jul 1983 \\
\hline Technical Report K-83-1 & Basic Pile Group Behavior & Sep 1983 \\
\hline Technical Report K-83-3 & $\begin{array}{l}\text { Reference Manual: Computer Graphics Program for Generation of } \\
\text { Engineering Geometry (SKETCH) }\end{array}$ & Sep 1983 \\
\hline Technical Report K-83-4 & Case Study of Six Major General-Purpose Finite Element Programs & Oct 1983 \\
\hline Instruction Report K-84-2 & $\begin{array}{l}\text { User's Guide: Computer Program for Optimum Dynamic Design of } \\
\text { Nonlinear Metal Plates Under Blast Loading (CSDOOR) }\end{array}$ & Jan 1984 \\
\hline Instruction Report K-84-7 & $\begin{array}{l}\text { User's Guide: Computer Program for Determining Induced Stresses } \\
\text { and Consolidation Settlements (CSETT) }\end{array}$ & Aug 1984 \\
\hline Instruction Report K-84-8 & $\begin{array}{l}\text { Seepage Analysis of Confined Flow Problems by the Method of } \\
\text { Fragments (CFRAG) }\end{array}$ & Sep 1984 \\
\hline Instruction Report K-84-11 & $\begin{array}{l}\text { User's Guide for Computer Program CGFAG, Concrete General } \\
\text { Flexure Analysis with Graphics }\end{array}$ & Sep 1984 \\
\hline Technical Report K-84-3 & Computer-Aided Drafting and Design for Corps Structural Engineers & Oct 1984 \\
\hline Technical Report ATC-86-5 & $\begin{array}{l}\text { Decision Logic Table Formulation of } \mathrm{ACI} 318-77 \text {, Building Code } \\
\text { Requirements for Reinforced Concrete for Automated Constraint } \\
\text { Processing, Volumes I and } 11\end{array}$ & Jun 1986 \\
\hline Technical Report ITL-87-2 & $\begin{array}{l}\text { A Case Committee Study of Finite Element Analysis of Concrete Flat } \\
\text { Slabs }\end{array}$ & Jan 1987 \\
\hline $\begin{array}{l}\text { Instruction Report ITL-87-2 } \\
\text { (Revised) }\end{array}$ & $\begin{array}{l}\text { User's Guide for Concrete Strength Investigation and Design } \\
\text { (CASTR) in Accordance with ACl 318-89 }\end{array}$ & Mar 1992 \\
\hline Instruction Report ITL-87-1 & $\begin{array}{l}\text { User's Guide: Computer Program for Two-Dimensional Analysis of } \\
\text { U-Frame Structures (CUFRAM) }\end{array}$ & Apr 1987 \\
\hline Instruction Report ITL-87-2 & $\begin{array}{l}\text { User's Guide: For Concrete Strength Investigation and Design } \\
\text { (CASTR) in Accordance with ACI 318-83 }\end{array}$ & May 1987 \\
\hline Technical Report ITL-87-6 & $\begin{array}{l}\text { Finite-Element Method Package for Solving Steady-State Seepage } \\
\text { Problems }\end{array}$ & May 1987 \\
\hline
\end{tabular}

(Continued) 


\title{
REPORTS PUBLISHED UNDER THE COMPUTER-AIDED STRUCTURAL ENGINEERING (CASE) PROJECT
}

\author{
Title \\ Instruction Report ITL-87-3 \\ User's Guide: A Three-Dimensional Stability Analysis/Design Program \\ (3DSAD) Module \\ Report 1: Revision 1: General Geometry \\ Report 2: General Loads Module \\ Report 6: Free-Body Module \\ Instruction Report ITL-87-4 \\ User's Guide: 2-D Frame Analysis Link Program (LINK2D) \\ Technical Report ITL-87-4 \\ Finite Element Studies of a Horizontally Framed Miter Gate \\ Report 1: Initial and Refined Finite Element Models (Phases A, \\ $\mathrm{B}$, and $\mathrm{C})$, Volumes I and 11 \\ Report 2: Simplified Frame Model (Phase D) \\ Report 3: Alternate Configuration Miter Gate Finite Element \\ Studies-Open Section \\ Report 4: Alternate Configuration Miter Gate Finite Element \\ Studies-Closed Sections \\ Report 5: Alternate Configuration Miter Gate Finite Element \\ Studies-Additional Closed Sections \\ Report 6: Elastic Buckling of Girders in Horizontally Framed \\ Miter Gates \\ Report 7: Application and Summary \\ Instruction Report GL-87-1 User's Guide: UTEXAS2 Slope-Stability Package; Volume 1, User's \\ Manual \\ Instruction Report ITL-87-5 \\ Sliding Stability of Concrete Structures (CSLIDE) \\ Instruction Report ITL-87-6 \\ Criteria Specifications for and Validation of a Computer Program for \\ the Design or Investigation of Horizontally Framed Miter Gates \\ (CMITER) \\ Technical Report ITL-87-8 \\ Procedure for Static Analysis of Gravity Dams Using the Finite \\ Element Method - Phase la \\ Instruction Report ITL-88-1 \\ User's Guide: Computer Program for Analysis of Planar Grid \\ Structures (CGRID) \\ Technical Report ITL-88-1 \\ Development of Design Formulas for Ribbed Mat Foundations on \\ Expansive Soils \\ Technical Report ITL-88-2 \\ User's Guide: Pile Group Graphics Display (CPGG) Postprocessor to \\ CPGA Program \\ Instruction Report ITL-88-2 \\ User's Guide for Design and Investigation of Horizontally Framed \\ Miter Gates (CMITER) \\ Instruction Report ITL-88-4 \\ User's Guide for Revised Computer Program to Calculate Shear, \\ Moment, and Thrust (CSMT) \\ Instruction Report GL-87-1 User's Guide: UTEXAS2 Slope-Stability Package; Volume 11, \\ Theory \\ Technical Report ITL-89-3 User's Guide: Pile Group Analysis (CPGA) Computer Group
}

Date

Jun 1987

Jun 1987

Sep 1989

Sep 1989

Jun 1987

Aug 1987

Aug 1987

Oct 1987

Dec 1987

Jan 1988

Feb 1988

Apr 1988

Apr 1988

Jun 1988

Sep 1988

Feb 1989

Jul 1989

(Continued) 


\section{REPORTS PUBLISHED UNDER THE COMPUTER-AIDED STRUCTURAL ENGINEERING (CASE) PROJECT}

Title

Date

Technical Report ITL-89-4

Technical Report ITL-89-5

Technical Report ITL-89-6

Contract Report ITL-89-1

Instruction Report ITL-90-1

Instruction Report ITL-90-2

Instruction Report ITL-90-3

Instruction Report ITL-90-6

Technical Report ITL-91-3

Instruction Report ITL-91-1

Technical Report ITL-92-2

Technical Report ITL-92-4

Instruction Report ITL-92-3

Instruction Report ITL-92-4

Instruction Report ITL-92-5
CBASIN-Structural Design of Saint Anthony Falls Stilling Basins According to Corps of Engineers Criteria for Hydraulic Structures; Computer Program X0098

CCHAN-Structural Design of Rectangular Channels According to Corps of Engineers Criteria for Hydraulic Structures; Computer Program X0097

The Response-Spectrum Dynamic Analysis of Gravity Dams Using the Finite Element Method; Phase 11

State of the Art on Expert Systems Applications in Design, Construction, and Maintenance of Structures

User's Guide: Computer Program for Design and Analysis of Sheet Pile Walls by Classical Methods (CWALSHT)

User's Guide: Pile Group-Concrete Pile Analysis Program (CPGC) Preprocessor to CPGA Program

Aug 1989

Aug 1989

Aug 1989

Sep 1989

Feb 1990

Jun 1990

Investigation and Design of U-Frame Structures Using Program CUFRBC

Volume A: Program Criteria and Documentation

Volume B: User's Guide for Basins

Volume C: User's Guide for Channels

User's Guide: Computer Program for Two-Dimensional Analysis of U-Frame or W-Frame Structures (CWFRAM)

Application of Finite Element, Grid Generation, and Scientific Visualization Techniques to 2-D and 3-D Seepage and Groundwater Modeling

User's Guide: Computer Program for Design and Analysis of SheetPile Walls by Classical Methods (CWALSHT) Including Rowe's Moment Reduction

Finite Element Modeling of Welded Thick Plates for Bonneville Navigation Lock

May 1990

May 1990

May 1990

Sep 1990

Sep 1990

Introduction to the Computation of Response Spectrum for Earthquake Loading

Concept Design Example, Computer-Aided Structural Modeling (CASM)

Report 1: Scheme A

Report 2: Scheme B

Report 3: Scheme C

Oct 1991

May 1992

Jun 1992

User's Guide: Computer-Aided Structural Modeling (CASM) Version 3.00

Tutorial Guide: Computer-Aided Structural Modeling (CASM) Version 3.00

(Continued) 


\section{REPORTS PUBLISHED UNDER THE COMPUTER-AIDED STRUCTURAL ENGINEERING (CASE) PROJECT}

\begin{tabular}{|c|c|c|}
\hline & Title & Date \\
\hline Contract Report ITL-92-1 & Optimization of Steel Pile Foundations Using Optimality Criteria & Jun 1992 \\
\hline Technical Report ITL-92-7 & Refined Stress Analysis of Melvin Price Locks and Dam & Sep 1992 \\
\hline Contract Report ITL-92-2 & $\begin{array}{l}\text { Knowledge-Based Expert System for Selection and Design of } \\
\text { Retaining Structures }\end{array}$ & Sep 1992 \\
\hline Contract Report ITL-92-3 & $\begin{array}{l}\text { Evaluation of Thermal and Incremental Construction Effects for } \\
\text { Monoliths AL-3 and AL-5 of the Melvin Price Locks and Dam }\end{array}$ & Sep 1992 \\
\hline Instruction Report GL-87-1 & $\begin{array}{l}\text { User's Guide: UTEXAS3 Slope-Stability Package; Volume IV, User's } \\
\text { Manual }\end{array}$ & Nov 1992 \\
\hline Technical Report ITL-92-11 & The Seismic Design of Waterfront Retaining Structures & Nov 1992 \\
\hline Technical Report ITL-92-12 & 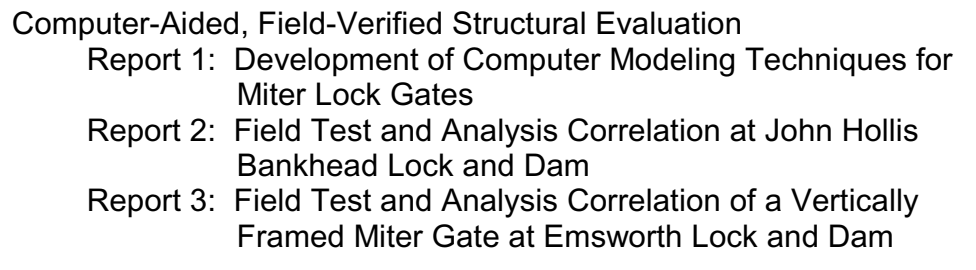 & $\begin{array}{l}\text { Nov } 1992 \\
\text { Dec } 1992 \\
\text { Dec } 1993\end{array}$ \\
\hline Instruction Report GL-87-1 & $\begin{array}{l}\text { Users Guide: UTEXAS3 Slope-Stability Package; Volume III, } \\
\text { Example Problems }\end{array}$ & Dec 1992 \\
\hline Technical Report ITL-93-1 & Theoretical Manual for Analysis of Arch Dams & Jul 1993 \\
\hline Technical Report ITL-93-2 & $\begin{array}{l}\text { Steel Structures for Civil Works, General Considerations for Design } \\
\text { and Rehabilitation }\end{array}$ & Aug 1993 \\
\hline Technical Report ITL-93-3 & $\begin{array}{l}\text { Soil-Structure Interaction Study of Red River Lock and Dam No. } 1 \\
\text { Subjected to Sediment Loading }\end{array}$ & Sep 1993 \\
\hline Instruction Report ITL-93-3 & User's Manual-ADAP, Graphics-Based Dam Analysis Program & Aug 1993 \\
\hline Instruction Report ITL-93-4 & Load and Resistance Factor Design for Steel Miter Gates & Oct 1993 \\
\hline Technical Report ITL-94-2 & $\begin{array}{l}\text { User's Guide for the Incremental Construction, Soil-Structure } \\
\text { Interaction Program SOILSTRUCT with Far-Field Boundary } \\
\text { Elements }\end{array}$ & Mar 1994 \\
\hline Instruction Report ITL-94-1 & $\begin{array}{l}\text { Tutorial Guide: Computer-Aided Structural Modeling (CASM); } \\
\text { Version } 5.00\end{array}$ & Apr 1994 \\
\hline Instruction Report ITL-94-2 & $\begin{array}{l}\text { User's Guide: Computer-Aided Structural Modeling (CASM); } \\
\text { Version } 5.00\end{array}$ & Apr 1994 \\
\hline Technical Report ITL-94-4 & $\begin{array}{l}\text { Dynamics of Intake Towers and Other MDOF Structures Under } \\
\text { Earthquake Loads: A Computer-Aided Approach }\end{array}$ & Jul 1994 \\
\hline Technical Report ITL-94-5 & $\begin{array}{l}\text { Procedure for Static Analysis of Gravity Dams Including Foundation } \\
\text { Effects Using the Finite Element Method - Phase } 1 \mathrm{~B}\end{array}$ & Jul 1994 \\
\hline
\end{tabular}

(Continued) 


\title{
REPORTS PUBLISHED UNDER THE COMPUTER-AIDED STRUCTURAL ENGINEERING (CASE) PROJECT
}

\author{
Title \\ Date \\ Instruction Report ITL-94-5 \\ User's Guide: Computer Program for Winkler Soil-Structure \\ Interaction Analysis of Sheet-Pile Walls (CWALSSI) \\ Nov 1994 \\ Instruction Report ITL-94-6 \\ User's Guide: Computer Program for Analysis of Beam-Column \\ Nov 1994 \\ Structures with Nonlinear Supports (CBEAMC) \\ Instruction Report ITL-94-7 \\ User's Guide to CTWALL - A Microcomputer Program for the \\ Analysis of Retaining and Flood Walls \\ Dec 1994 \\ Contract Report ITL-95-1 \\ Comparison of Barge Impact Experimental and Finite Element Results \\ Jun 1995 \\ for the Lower Miter Gate of Lock and Dam 26 \\ Technical Report ITL-95-5 \\ Soil-Structure Interaction Parameters for Structured/Cemented Silts \\ Aug 1995 \\ Instruction Report ITL-95-1 \\ User's Guide: Computer Program for the Design and Investigation of \\ Horizontally Framed Miter Gates Using the Load and Resistance Factor \\ Criteria (CMITER-LRFD) \\ Technical Report ITL-95-8 \\ Constitutive Modeling of Concrete for Massive Concrete Structures, A \\ Simplified Overview \\ Aug 1995 \\ Instruction Report ITL-96-1 \\ Use's Guide: Computer Program for Two-Dimensional Dynamic Analysis \\ of U-Frame or W-Frame Structures (CDWFRM) \\ Instruction Report ITL-96-2 \\ Computer-Aided Structural Modeling (CASM), Version 6.00 \\ Report 1: Tutorial Guide \\ Report 2: User's Guide \\ Report 3: Scheme A \\ Report 4: Scheme B \\ Report 5: Scheme C \\ Technical Report ITL-96-8 \\ Hyperbolic Stress-Strain Parameters for Structured/Cemented Silts \\ Aug 1996 \\ Instruction Report ITL-96-3 \\ User's Guide: Computer Program for the Design and Investigation of \\ Horizontally Framed Miter Gates Using the Load and Resistance \\ Factor Criteria (CMITERW-LRFD) Windows Version \\ Instruction Report ITL-97-1 User's Guide: Computer Aided Inspection Forms for Hydraulic Steel \\ Structures (CAIF-HSS), Windows Version \\ Sep 1995 \\ Jun 1996 \\ Jun 1996 \\ User's Guide: Arch Dam Stress Analysis System (ADSAS) \\ Sep 1996 \\ Instruction Report ITL-97-2 \\ User's Guide for the Three-Dimensional Stability Analysis/Design \\ (3DSAD) Program \\ Instruction Report ITL-98-1 \\ Sep 1996 \\ Technical Report ITL-98-4 \\ Investigation of At-Rest Soil Pressures due to Irregular Sloping Soil \\ Surfaces and CSOILP User's Guide \\ Aug 1996 \\ Sep 1998 \\ Sep 1998 \\ Technical Report ITL-98-5 The Shear Ring Method and the Program Ring Wall \\ Sep 1998 \\ Technical Report ITL-98-6 \\ Reliability and Stability Assessment of Concrete Gravity Structures \\ (RCSLIDE): Theoretical Manual \\ Dec 1998
}

(Continued) 


\title{
REPORTS PUBLISHED UNDER THE COMPUTER-AIDED STRUCTURAL ENGINEERING (CASE) PROJECT
}

\author{
(Concluded) \\ Title \\ Page \\ Technical Report ITL-99-1 \\ Development of an Improved Numerical Model for Concrete-to-Soil \\ Interfaces in Soil-Structure Interaction Analyses \\ Report 1: Preliminary Study \\ Report 2: Final Study \\ Jan 1999 \\ Aug 2000 \\ Technical Report ITL-99-5 \\ River Replacement Analysis \\ Dec 1999 \\ ERDC/ITL TR-00-1 \\ Evaluation and Comparison of Stability Analysis and Uplift Criteria for \\ Jan 2000 \\ ERDC/ITL TR-00-2 \\ Concrete Gravity Dams by Three Federal Agencies \\ Reliability and Stability Assessment of Concrete Gravity Structures \\ (RCSLIDE): User's Guide \\ Jul 2000 \\ ERDC/ITL TR-00-5 \\ Theoretical Manual for Pile Foundations \\ Nov 2000
}




\section{REPORT DOCUMENTATION PAGE}

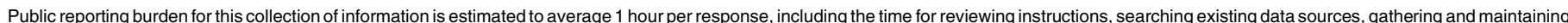

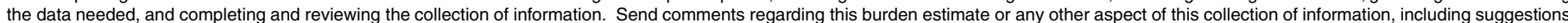

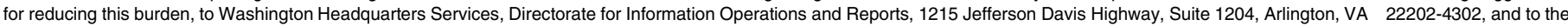
Office of Management and Budget, Paperwork Reduction Project (0704-0188), Washington, DC 20503.
1. AGENCY USE ONLY (Leave blank)
2. REPORT DATE
November 2000
3. REPORT TYPE AND DATES COVERED
Final report

\section{TITLE AND SUBTITLE}

Theoretical Manual for Pile Foundations

6. AUTHOR(S)

Reed L. Mosher, William P. Dawkins

\section{FUNDING NUMBERS}

\section{PERFORMING ORGANIZATION NAME(S) AND ADDRESS(ES)}

U.S. Army Engineer Research and Development Center, Information Technology Laboratory, 3909 Halls Ferry Road, Vicksburg, MS 39180-6199;

Oklahoma State University, Stillwater, OK 74074

9. SPONSORING/MONITORING AGENCY NAME(S) AND ADDRESS(ES)

U.S. Army Corps of Engineers

Washington, DC 20314-1000
8. PERFORMING ORGANIZATION REPORT NUMBER

ERDC/ITL TR-00-5

\section{SUPPLEMENTARY NOTES}

\section{2a. DISTRIBUTION/AVAILABILITY STATEMENT}

Approved for public release; distribution is unlimited. 12b. DISTRIBUTION CODE

\section{ABSTRACT (Maximum 200 words)}

This theoretical manual for pile foundations describes the background and research and the applied methodologies used in the analysis and design of pile foundations. This research was developed through the U.S. Army Engineer Research and Development Center by the Computer-Aided Structural Engineering (CASE) Project. Several of the procedures have been implemented in the CASE Committee computer programs CAXPILE, CPGA, and COM624. Theoretical development of these engineering procedures and discussions of the limitations of each method are presented.

14. SUBJECT TERMS

Axial piles

CASE

Group piles
Lateral piles

Pile foundations
15. NUMBER OF PAGES

157

16. PRICE CODE

\begin{tabular}{|l|l|l|l} 
17. SECURITY CLASSIFICATION & 18. $\begin{array}{l}\text { SECURITY CLASSIFICATION } \\
\text { OF REPORT } \\
\text { OF THIS PAGE } \\
\text { UNCLASSIFIED }\end{array}$ & $\begin{array}{l}\text { UNCLASSIFIED } \\
\text { SECURITY CLASSIFICATION } \\
\text { OF ABSTRACT }\end{array}$ \\
\hline
\end{tabular}

NSN 7540-01-280-5500
Standard Form 298 (Rev. 2-89)

Prescribed by ANSI Std. Z39-18 298-102 